\title{
BASES GENÉTICAS Y BIOLÓGICAS DEL SÍNDROME DE X FRÁGIL
}

\section{GENETIC AND BIOLOGICAL BASIS OF FRAGILE $X$ SYNDROME}

\author{
Ruth Maribel Forero Castro* \\ Edwin Javier Vergara Estupiñán** \\ Jefer Iván Moreno Granados***
}

Recepción 05/08/2011

\section{Resumen}

Después del síndrome de Down, el síndrome de $X$ frágil es la causa más frecuente de retardo mental. Su distribución geográfica es universal y afecta a diferentes grupos raciales. Esta anomalía genética presenta un patrón de herencia ligado a $X$, dominante, con penetrancia incompleta y anticipación, por lo que revela una segregación nomendeliana. En 1969, Lubs fue el primero en relacionar el retardo mental con la existencia de un sitio frágil, actualmente reconocido en el brazo largo del cromosoma $X$ en la banda Xq27.3 denominada FRAXA. El gen involucrado en el síndrome de $X$ frágil es el FMR 1, el cual fue identificado en 1991 y su defecto fue atribuido a una expansión del trinucleótido repetitivo CGG, localizado en el primer exón del gen. En la población normal, las repeticiones CGG varían entre un rango de 6 a 54, en individuos portadores entre 43 a 200 repeticiones (premutación), mientras que en afectados la expansión de la secuencia CGG tiene más de 200 repeticiones (mutación completa) y está asociada con la metilación e inactivación del gen. El clonaje del gen FMR 1 condujo a la caracterización de su producto de expresión: la proteína FMRP, involucrada en el metabolismo del 
RNA y en la función ribosomal. Cuando la región promotora está hipermetilada, se frena la producción del ARN mensajero (ARNm) del gen FMR 1 y, porende, la producción de la proteína, causando retardo mental, macroorquidismo y otros rasgos físicos y comportamentales característicos del síndrome de $X$ frágil. El diagnóstico del síndrome de $X$ frágil se puede hacer a nivel clínico, citogenético, molecular e inmunohistoquímico, implicando el hallazgo de la fragilidad, la determinación de individuos normales, portadores y afectados, el grado de metilación del gen FMR 1 y la expresión de la proteína FMRP. Aunque este síndrome no tiene cura, el tratamiento en la última década ha sido un foco de interés no solo para los genetistas y médicos generales sino también para otros profesionales, tales como pediatras, psicólogos, trabajadores sociales, logopedas y educadores. El presente artículo tiene como objetivo informar sobre las bases genéticas y biológicas del síndrome de $X$ frágil, y la ruta diagnóstica que debe tenerse en cuenta en el seguimiento de los pacientes y familias afectadas.

Palabras clave: Síndrome de $X$ frágil, FMR 1, FMRP, retardo mental, premutación, mutación completa.

\section{Abstract}

Following the Down syndrome, Fragile $X$ Syndrome is the most common cause of mental retardation. Its geographical distribution is universal and affects different racial groups. This genetic anomaly shows a pattern of inheritance linked to $X$, dominant, with incomplete penetrance and anticipation, so it reveals a non-Mendelian segregation. In 1969, Lubs was the first to link mental retardation with the existence of a fragile site, currently recognised by the long arm of the $X$ chromosome in band Xq27.3 called FRAXA. The gene involved in Fragile $X$ Syndrome is the FMR 1, which was identified in 1991 and its defect was attributed to an expansion of repetitive trinucleotide CGG, located in the first exon of the gene. In the normal population, the CGG repetitions vary from a range of 6 to 54, in carriers between 43 to 200 repetitions (Premutation) while in affected individuals the expansion of the sequence CGG has more than 200 repetitions (Full Mutation) and associated with methylation and gene inactivation. The cloning of the FMR 1 gene led to the characterization of its 
expression product: FMRP protein, involved in RNA metabolism and ribosomal function. When the promoter region is hypermethylated, it reduces the production of messenger RNA (mRNA) of FMR-1 gene and, thus, the production of the protein, causing mental retardation, macroorquidism and other physical and behavioral traits which are characteristic of Fragile $X$ Syndrome. The diagnosis of Fragile $X$ Syndrome can be made at clinical, cytogenetic, molecular and immunohistochemical level, involving the discovery of the fragility, the determination of normal individuals, carriers and affected persons, the degree of methylation of the FMR-1 gene and expression of FMRP protein. Although this syndrome has no cure, treatment in the last decade has been a source of interest not only for geneticists and general practitioners, but also for other professionals, such as paediatricians, psychologists, social workers, speech therapists and educators. This article aims to report on the biological and genetic bases of the Fragile $X$ Syndrome, and the diagnostic route to be taken into account in the follow-up of patients and families affected.

Keywords: Fragile $X$ Syndrome, FMR 1, FMRP, mental retardation, premutation, full mutation.

\section{Introducción}

En 1943, un cuarto de siglo antes de la identificación del X frágil, Martín y Bell ya habían descrito rasgos fenotípicos de un trastorno genético con retardo metal ligado al sexo, en una familia con hombres y mujeres afectados, por lo cual al fenotipo del síndrome de $X$ frágil se le atribuye el nombre de estos dos autores [1]. Veintiséis años después, en 1969, Lubs -mediante estudios citogenéticos- fue el primero en relacionar el retraso mental con la existencia de un marcador cromosómico en leucocitos de algunos hombres con retardo mental [2]. Sutherland, en 1977, identificó el medio de cultivo carente de ácido fólico y timidina como un factor esencial para la inducción del sitio frágil en las bandas Xq27 y Xq28 [3]. En 1983, la presencia del sitio frágil fue reportada en la banda Xq27.2 por Brookwell y Turner, mientras que Harrison y colaboradores en 1983, con la ayuda del microscopio electrónico scanning (SEM), sugirieron su localización en la banda Xq27.3. Krawczun, en 1985, confirmó esta localización con preparaciones de bandeo $\mathrm{G}$ de alta resolución [4]. 
Simultáneamente a estos hallazgos, muchos autores reportaron diversos rasgos físicos y de comportamiento que permitieron caracterizar clínicamente el síndrome de $X$ frágil. Los más característicos son cara alargada y estrecha, frente prominente, orejas grandes y salientes, nariz de base ancha, mentón puntiagudo, dentición tardía, macroorquidismo, retardo en la expresión del habla, del lenguaje, problemas de comportamiento, rasgos autísticos, hipertelorismo, afecciones cardiacas y alteraciones en el tejido conectivo [5].

Actualmente no hay cura para el síndrome de $X$ frágil. No obstante, muchas entidades ofrecen tratamientos multidisciplinarios que reducen los efectos nocivos del síndrome y benefician el desarrollo familiar y social durante toda la vida del paciente [6]. En dichos tratamientos participan padres, médicos, genetistas, psicólogos, pedagogos, logopedas, terapeutas ocupacionales, educadores especiales y otros profesionales, quienes trabajan coordinadamente para tratar a estos pacientes de manera individualizada, teniendo en cuenta sus necesidades particulares [7].

El presente artículo de revisión tiene como objetivo informar sobre las bases genéticas y biológicas del síndrome de $X$ frágil (OMIM +309550), y la ruta diagnóstica que debe tenerse en cuenta en el seguimiento de los pacientes y familias afectadas.

\section{Gen FMR 1}

El diagnóstico clínico y citogenético fue la única herramienta ofrecida para la identificación del síndrome de $X$ frágil, hasta la primavera de 1991, cuando Verkerk y colaboradores [9], y Fu y colaboradores [10] clonaron el gen FMR 1 (retraso mental ligado al sitio frágil 1) ubicado en el locus FRAXA (Frágil X A) del cromosoma $X$, en la región Xq27.3. Eichler et al., en 1993 [11] establecieron la estructura del gen de $38 \mathrm{~kb}$, constituida por 17 exones y 16 intrones. Tiene una longitud de $9.9 \mathrm{~kb}$ entre el primer y último exón y una gran amplitud de 1.9 kb en la región 3' no traducida (UTR) [11].

El primer exón es relativamente largo $(318 \mathrm{pb})$ con respecto a otros genes y es muy rico en GC, lo que sugiere su intervención en el control postranscripcional [2]. Posee un triplete repetitivo CGG 
polimórfico que se encuentra en la región inicial 5', llamada SANT (secuencia anterior no traducida), ubicada antes del codón de iniciación de la traducción. Por esta razón, la mayoría del primer exón no se traduce y solo aporta 17 aminoácidos a la proteína madura [12], [13].

\section{Proteína FMRP}

El gen FMR 1 codifica para un ARNm de $4.4 \mathrm{~kb}$, a partir del cual se traduce la proteína FMRP (proteína ligada con retardo mental del sitio frágil 1), expresada predominantemente en el citoplasma. Los estudios de expresión sobre la proteína FMRP han puesto de manifiesto que existen 24 isoformas diferentes que varían en estructura, localización y función celular, determinadas por la maduración alternativa del ARNm en varios tejidos humanos entre los exones 12, 14 y 15 [13]. Las isoformas oscilan entre 67 y $90 \mathrm{KDa}$. Una de las más expresadas es la de $69 \mathrm{KDa}$, constituida por 614 aminoácidos [14].

Se ha observado que la proteína coprecipita con la subunidad $60 \mathrm{~S}$ de los ribosomas libres y pegados al retículo endoplasmático, lo que sugiere una intervención en la función ribosomal y transporte de ciertas proteínas [15]. También se ha postulado una interacción de la proteína FMRP con los ARN mensajeros en el núcleo, seguido por la exportación hacia el citoplasma como parte de las partículas mRNP que se asocian con los ribosomas [15].

La proteína FMRP se expresa en numerosos tejidos y más abundantemente en cerebro y testículos. En estadios tempranos del desarrollo embrionario, la transcripción es ubicua, mientras que en fetos de 20 semanas la expresión es más intensa en cerebros, ojos, hígado, músculo esquelético, médula espinal y pulmones, manteniéndose la expresión en el adulto, sobre todo en cerebro, linfocitos y gónadas [2], [16].

\section{Defecto molecular asociado con el síndrome de $X$ frágil}

Verkerk et al. [9] y Fu et al. [10], asociaron el defecto molecular del síndrome con una expansión del trinucleótido repetitivo CGG 
que atraviesa la región promotora y el primer exón del gen. Los individuos normales usualmente contienen más o menos 30 repeticiones CGG intercaladas con 0-3 secuencias AGG, encontradas aproximadamente cada 10 repeticiones CGG. Esta secuencia es polimórfica con respecto al número de repeticiones (entre un rango de 6-54 repeticiones) y el número y posición de secuencias AGG interpuestas [17]. Normalmente la región repetitiva es transmitida de manera estable de generación en generación, demostrando un patrón de herencia mendeliana normal [17].

Existen dos formas de manifestarse la mutación dentro de las repeticiones CGG: la premutación y la mutación completa [18]. La premutación muestra una expansión de la secuencia CGG en un rango entre 43 a 200 repeticiones. Aunque no causa inactivación del gen y por ende un fenotipo anormal, los individuos (tanto hombres como mujeres) que contienen este número de repeticiones son portadores normales, pues no exhiben rasgos clínicos; sin embargo, la región es inestable con tendencia a expandirse en cada generación [18].

La mutación completa presenta más de 200 repeticiones del triplete CGG y está asociada con la manifestación del síndrome de $X$ frágil, debido a que las citosinas de la secuencia repetitiva CGG son hipermetiladas, lo que lleva a la inactivación del gen FMR 1 y, por ende, a la no producción de la proteína FMRP [12]. Esta amplificación de tripletes se transmite inestablemente aumentando el número de copias por generaciones y dando lugar a ordenamientos más largos de manera casi unidireccional (Figura 1) [19]

En los individuos con síndrome de $X$ frágil, se presentan dos clases de mosaicismos, distinguidos sobre el tamaño de la secuencia CGG y el patrón de metilación:

- Mosaicos por tamaño de la secuencia: son aquellos pacientes que portan en sus células una mezcla de premutación y mutación completa, esto implica que la mutación es heredada como premutación y se convierte en mutación completa en la embriogénesis temprana, en alguna de las células en crecimiento. Este mosaico ha sido observado entre un $20 \%$ a 40 $\%$ de pacientes masculinos y $10 \%$ de pacientes femeninos [20]. 
- Mosaicos por metilación: ocurre en casos raros cuando pacientes con la mutación completa presentan variaciones en la metilación, entre diversas células [4], [20].

El síndrome de $X$ frágil también se manifiesta cuando el gen FMR 1 presenta mutaciones clásicas que son mucho menos frecuentes que la expansión de repeticiones: tales como deleciones, sustituciones o duplicaciones que afectan en diferentes grados la funcionalidad o expresividad del gen [21]

Estos hallazgos permitieron abordar el estudio y diagnóstico de esta anomalía por técnicas de análisis molecular como PCR y Southern Blot, y determinar con mayor confiabilidad el diagnóstico de individuos portadores, puesto que aproximadamente el $50 \%$ de ellos manifiesta un fenotipo normal y no se observa a nivel citogenético el $X$ frágil, ni siquiera en el $1 \%$ de las metafases estudiadas [22].

\section{Mecanismo mutacional del síndrome de $X$ frágil}

La razón por la cual el sexo del individuo afectado influye en el fenotipo del síndrome de $X$ frágil es que, en las mujeres afectadas (que generalmente son heterocigotas para la mutación FRAXA), la variabilidad de la expresión de los síntomas se origina por el proceso de lionización que ocurre en uno de los cromosomas X. Si el cromosoma que lleva el gen normal fuera siempre el lionizado en todas las células, la mujer expresaría el fenotipo del síndrome en igual grado que el hombre; como esto no ocurre, sino que hay un "mosaicismo" en la lionización de los cromosomas X, se observa dicha variabilidad de los síntomas [23].

Se ha notado que la proporción de cromosomas $X$ no lionizados con el gen FMR 1 normal (llamada "índice de inactivación") respecto del $\mathrm{X}$ con mutación completa, es directamente proporcional a la levedad de los síntomas en mujeres heterocigotas para esta mutación completa, lo cual es muestra del efecto "protector" de la lionización [24].

El mecanismo de inactivación del gen FMR 1 aún no tiene una explicación concreta, pero una de las más fundamentadas se sustenta en el bloqueo de la interacción entre factores de transcripción y la 
región promotora del gen. Esto se debe a la hipermetilación de las citosinas, distribuidas en la región repetitiva CGG y en la isla CpG de la zona promotora, por lo cual se impide su interacción con factores de transcripción y así mismo la expresión de gen FMR 1 [25].

Se identificaron cuatro interacciones DNA/proteína en genes transcripcionalmente activos de individuos normales, y estuvieron ausentes para genes inactivos de individuos afectados, puesto que muchas de las citosinas metiladas están ubicadas en estos sitios de unión y por consiguiente se imposibilita la interacción [26].

Las repeticiones CGG son normalmente intercaladas con dos tripletes AGG que previenen la expansión patológica de esta región. A medida que el número de repeticiones se excede del límite normal, se va aumentando la inestabilidad de la secuencia, puesto que los tripletes se distribuyen ininterrumpidamente dando pie, probablemente, a un deslizamiento de la ADN polimerasa más allá del límite de la secuencia molde o a otros tipos de errores en los procesos de replicación, intercambio genético y reparación del DNA [27].

La inestabilidad intergeneracional de la premutación es dependiente del sexo del progenitor transmisor y del tamaño de la repetición [19]. Existen muchos estudios que sostienen que la amplificación ocurre por vía materna, puesto que en las hijas esta región recibe una impronta génica durante la ovogénesis, la cual facilita la amplificación mayor de los tripletes en sus hijos durante la etapa embrionaria temprana (entre el día 5 y el día 20 postfertilización). Por lo anterior, solo las mujeres con premutación tienen el riesgo de procrear hijos (hombres o mujeres) afectados con mutación completa [17]. La probabilidad de que ocurra esta conversión depende de la longitud del alelo premutado en la madre, así, es menos del $20 \%$ cuando las repeticiones CGG son menores de 70 copias, pero es más del $80 \%$ para premutaciones mayores de 80 repeticiones CGG [28].

La premutación siempre precede la aparición de la mutación completa. Todas las madres de niños afectados portan la mutación completa o la premutación. En ningún caso se ha observado conversión directa del número de copias normal a la mutación completa [28]. 
En el rango de 43 a 55 repeticiones CGG, existe un sobrelapamiento entre alelos normales y premutados, que interpone la secuencia a un límite de estabilidad (alelo normal) e inestabilidad (alelo premutado), el cual puede heredarse de la misma manera por muchas generaciones o aumentar lentamente su tamaño a través de las generaciones [29].

Según Azis, el mecanismo mutacional del síndrome de $X$ frágil, reúne una serie de aspectos que en conjunto hacen que su herencia se desajuste de los patrones mendelianos usuales [30]:

Tiene un patrón de herencia ligado a X dominante con penetrancia incompleta, que incluye a hombres transmisores normales (NTMs) que portan y transmiten la permutación a sus hijas, sin manifestar el síndrome de $\mathrm{X}$ frágil. Las hijas de estos hombres transmisores son normales y portadoras obligadas, sin embargo, en ellas ocurre una impronta génica que promueve la amplificación de la secuencia CGG en sus hijos y por lo tanto, los nietos de los hombres transmisores normales tienen un riesgo alto de sufrir el síndrome de $X$ frágil [30]. Como se mencionó anteriormente, el riesgo que tienen estas mujeres portadoras de tener un hijo afectado por el síndrome de $X$ frágil, es directamente proporcional al tamaño de su secuencia CGG premutada. Este primer aspecto se conoce como la paradoja de Sherman, la cual se ilustra en los árboles genealógicos de las familias afectadas por este síndrome (Figura 2) [31], [32].

Este síndrome exhibe el fenómeno de anticipación que consiste en que la manifestación de la mutación completa se incrementa en las generaciones sucesivas, aumentando de igual manera su frecuencia de aparición y la severidad del fenotipo. Por esta razón se afirma que la anticipación o grado de expresión de la mutación, aumenta la penetrancia a medida que transcurren las generaciones y tiene su explicación en el aumento de la secuencia repetitiva CGG en las mujeres portadoras. Por lo anterior, las madres y las hijas de hombres transmisores normales tienen diferentes etapas de progresión de la mutación (Figura 2) [31], [32].

Por otra parte, la mutación del gen FMR 1 tiene penetrancia incompleta (característica de genes dominantes) puesto que no siempre se observa el efecto del fenotipo cuando el gen está alterado, 
solamente se manifiesta el síndrome de $X$ frágil cuando la mutación excede el límite de las 200 repeticiones del triplete CGG y no en los individuos permutados [33].

Debido a que la mutación por expansión evoluciona a lo largo de una etapa premutacional hasta la mutación completa, que manifiesta el fenotipo, las madres de hombres afectados siempre son portadoras y en ningún caso el síndrome surge por una mutación de novo desarrollada en el ovocito materno [19], [34].

\section{Diagnóstico clínico del síndrome de $\mathrm{X}$ frágil}

El síndrome de $X$ frágil reúne características clínicas que son muy variables y no siempre se encuentran todas en un mismo individuo, incluso a nivel intrafamiliar su fenotipo no siempre se manifiesta de la misma forma (Tabla 1). De igual manera, el sexo del individuo afectado influye en el fenotipo del síndrome de $X$ frágil, pues el coeficiente intelectual en la mayor parte de los varones se sitúa entre 35 y 45 , mientras que en las mujeres el coeficiente intelectual está menos afectado (60-80) y los signos somáticos son más leves [31], [35].

Se han descrito también dos fenotipos distintos al más frecuente, que se pueden encontrar en el síndrome de $X$ frágil, uno de ellos es muy parecido al síndrome de Prader-Willi, que cursa con obesidad extrema, cara redondeada, estatura baja, pies y manos cortos con dedos gordos e hiperpigmentación difusa. El otro fenotipo cursa con talla alta al nacer, circunferencia craneal grande, crecimiento inusual y gigantismo con anomalías faciales menores [31], [35]. (Tabla 1).

\section{Pruebas diagnósticas para el estudio del síndrome de X frágil}

El diagnóstico para el síndrome de $X$ frágil se realiza a nivel clínico, citogenético, molecular e inmunohistoquímico. Desde 1993 se han desarrollado pruebas diagnósticas de hibridización in situ, e inmunohistoquímicas para detectar la presencia o ausencia de la proteína FMRP en linfocitos, teniendo en cuenta que existen 24 formas alternativas de esta proteína que varían en tamaño desde 67 y $90 \mathrm{KDa}[2]$. 
También se han desarrollado pruebas moleculares encaminadas a establecer el nivel de metilación, el cual está estrechamente relacionado con el grado de severidad del síndrome. Estas pruebas son realizadas porque se han observado hombres y mujeres con síndrome de $\mathrm{X}$ frágil en mosaico para la mutación completa y la premutación, al igual que diferentes grados de metilación en individuos con mutación completa [36].

Diagnóstico citogenético: este síndrome está asociado con un marcador cromosómico identificado como un sitio frágil localizado en el brazo largo del cromosoma X en la banda Xq27.3, el cual se torna visible en un microscopio de luz como un "gap" o espacio sin colorear [37].

Para que se exprese este sitio frágil, es necesario cultivar las células (linfocitos) en medios pobres en ácido fólico y timidina (como el TC199), a un pH elevado y suplementado solo con un $5 \%$ de suero fetal bovino (SFB). Para la expresión de un sitio frágil se requieren 96 horas de cultivo, puesto que las células deben someterse a uno o más periodos de síntesis de ADN en condiciones de baja oferta de desoxitimidintrifosfato (dTTP) [37].

Recientemente se han implementado nuevas técnicas confirmatorias de microscopía (microscopio electrónico de transmisión y microscopio de fluorescencia), que permiten localizar en el cromosoma $X$ fragilidades poco visibles en el microscopio de luz convencional e incluso identificar las primeras etapas de formación del sitio frágil. Esta identificación ultraestructural del sitio frágil Xq27.3 se lleva a cabo teniendo en cuenta las diferencias en la densidad de luz sobre la región cromosómica, de tal manera que aquellas zonas con alta densidad de luz evidencian la existencia o surgimiento de un sitio frágil puesto que tienen un nivel de condensación disminuido [38].

Las pruebas citogenéticas no son confiables para detectar individuos con mutación completa o premutación, ya que reportan un porcentaje discreto de la fragilidad, pues en pacientes afectados se descubre solamente con una proporción del 10 al $40 \%$ de las células en división, mientras que en los portadores es probable evidenciarla en proporciones mucho más bajas e incluso no apreciarse. Por esta razón, este tipo de pruebas requiere estudios moleculares para 
confirmarse el diagnóstico y determinar la presencia de portadores y el nivel de amplificación de la secuencia CGG [39].

Diagnóstico molecular: a nivel molecular se emplean dos pruebas diagnósticas que son complementarias: el Southern Blot y el PCR, que permiten identificar los portadores que fueron citogenéticamente negativos [40].

Por Southern Blot, el número de copias CGG puede estimarse usando enzimas de restricción, tales como Hind III, Bgl II, EcoRI que cortan en sitios de la zona FRAXA. Cada uno de ellos tiene un patrón específico en el tamaño de los fragmentos [41]. El análisis del gen FMR 1 por Southern Blot tiene en cuenta el tamaño de los fragmentos y el sexo de los individuos analizados. Por ejemplo, haciendo una digestión con la enzima de restricción Hind III del DNA de individuos normales, portadores y afectados, extraída de linfocitos de sangre periférica, se obtiene un patrón de migración de fragmentos que permite identificar su condición genética [42] (Figura 3).

La técnica de Southern Blot también es empleada para detectar el nivel de metilación de la isla CpG. Esto es posible haciendo una doble digestión e incluyendo una enzima de restricción (como Eagl) sensible a la metilación que no corta el ADN si se encuentra metilado [43].

Al detectar el nivel de metilación de la isla CpG por la técnica de Southern Blot, es posible identificar casos esporádicos de hombres con mutación completa pero con un grado de metilación incompleta (mosaico por metilación), en el cual ciertas células metilan el gen FMR 1 mientras que otras no, así los genes que son metilados pueden ser distinguidos por tamaño de aquellos que no lo están. Esta determinación es importante puesto que en algunos casos el grado de metilación puede influir en la severidad de los síntomas del síndrome, específicamente si la metilación está presente en menos del $10 \%$ de las células probadas de hombres con la mutación completa, el deterioro mental es menor comparado con aquellos que son afectados con metilación generalizada [43], [44].

Por Southern Blot solo se identifican premutaciones grandes, el diagnóstico se complementa con la técnica del PCR (reacción 
en cadena de la polimerasa) que establece exactamente el número de repeticiones CGG en secuencias normales y en premutaciones pequeñas (hasta 150 repeticiones), puesto que se dificulta la amplificación en ordenamientos largos con mutación completa, ya que los productos de PCR forman estructuras se cund a rias y heterodúplex que dan como resultado patrones de migración anormales [45].

Para determinar el número de repeticiones de la secuencia CGG por PCR, se emplea un marcador de peso molecular que al compararse con productos amplificados puede dar una estimación del tamaño del fragmento (Figura 4) [45]. Así mismo, en una familia afectada puede estudiarse el modo de segregación de la secuencia CGG y de esta manera determinar la presencia o ausencia de individuos portadores [2], [45].

Diagnóstico inmunohistoquímico: esta prueba con anticuerpo busca detectar la presencia de la proteína FMRP en linfocitos normales y su ausencia en linfocitos de individuos afectados por el síndrome de $X$ frágil. El análisis toma como referencia la proporción de células que producen la proteína FMRP, permitiendo distinguir entre hombres afectados (expresión de la proteína en menos del $30 \%$ de células) e individuos normales ( $>40 \%$ de las células). Esta prueba no detecta proteínas disfuncionales ni diferencia entre personas con alelos normales y personas con alelos premutados [46].

El diagnóstico prenatal comprende pruebas moleculares a partir de muestras de líquido amniótico, vellosidades criónicas, sangre y tejido fetal. Las pruebas inmunohistoquímicas también se han usado con muestras de vellosidades coriónicas de 12.5 semanas de gestación y células de líquido amniótico no cultivadas [47].

Las pruebas inmunohistoquímicas en vellosidades coriónicas también requieren pruebas moleculares anexas, por las diferencias de metilación que se presentan entre las vellosidades coriónicas y el tejido fetal hacia la semana once de gestación. Sin embargo, cuando se detecta por Southern Blot una premutación en una muestra de vellosidades coriónicas debe confirmarse este hallazgo en muestras de líquido amniótico o sangre de cordón umbilical, para determinar la estabilidad de la premutación durante la vida fetal. También se ha 
encontrado que en algunos diagnósticos las muestras de vellosidades coriónicas tempranas (menos de 12 semanas de gestación) no se revela metilación de un gen que presente mutación completa, mientras que en tejido fetal ya es evidente la hipermentilación [48].

\section{Conclusiones}

A partir de la observación realizada por Martin y Bill en 1943 sobre el síndrome de $X$ frágil, como una anomalía familiar con retardo mental ligado al cromosoma $\mathrm{X}$, comenzaron a desarrollarse innumerables trabajos encaminados a mejorar su diagnóstico clínico y molecular.

Las bases biológicas no mendelianas del fenómeno poco usual de los hombres transmisores normales (NTMs), anticipación, penetrancia incompleta y la paradoja de Sherman, han llegado a aclararse después de la clonación del gen FMR 1 identificando las repeticiones CGG del extremo 5' y su inestabilidad intergeneracional.

Aún no es claro cuándo y cómo exactamente ocurre el proceso de expansión del trinucleótido CGG y de qué manera este mecanismo mutacional tiene un comportamiento dinámico a nivel intergeneracional. Igualmente, pese a que teóricamente sea claro que la mutación completa es la responsable del silenciamiento del gen, los hallazgos en individuos mosaicos por metilación en pruebas de diagnóstico prenatal sobre vellosidades coriónicas, hacen pensar que no es la causa suficiente para la metilación del promotor.

Para que haya confiabilidad en el diagnóstico pre o postnatal del síndrome de $X$ frágil, es importante hacer en complementariedad pruebas citogenéticas, moleculares e inmunohistoquímicas, en que cada una de ellas arroje resultados particulares sobre la fragilidad, presencia de individuos normales, portadores o afectados, metilación o expresión de la proteína FMRP.

Debido a que el cuadro clínico del síndrome de $X$ frágil se asocia primordialmente con el sistema nervioso central, muchas investigaciones actualmente se concentran en comprender el mecanismo de disfunción neuronal ocasionado por la ausencia de la proteína FMRP, sin embargo estos estudios dependen a su vez 


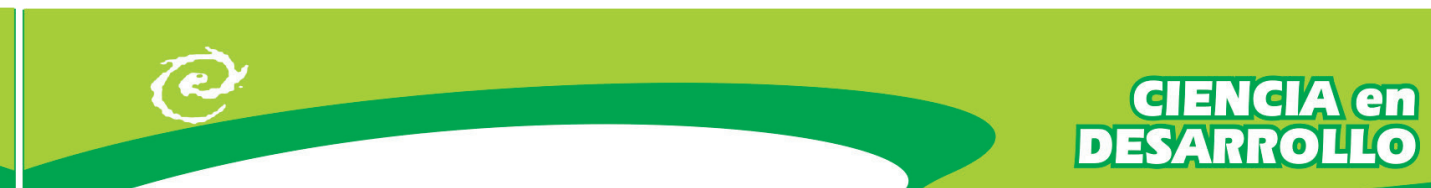

del entendimiento de su funcionalidad en las células, lo cual aún permanece sin resolver.

Las nuevas alternativas para el tratamiento del síndrome de $X$ frágil se están enfocando hacia terapia génica (estudiando el gen FMR 1 para determinar la posibilidad de insertar un gen normal dentro del ADN de individuos afectados), terapia de reemplazo de la proteína (por suplemento de la proteína desde un origen externo, sin embargo debe considerarse que la proteína debe restaurarse en las células en un mínimo del $50 \%$ para que se pueda llevar a cabo una función cognitiva normal) y farmacoterapia (probando diferentes medicamentos que contrarresten los síntomas manifestados).

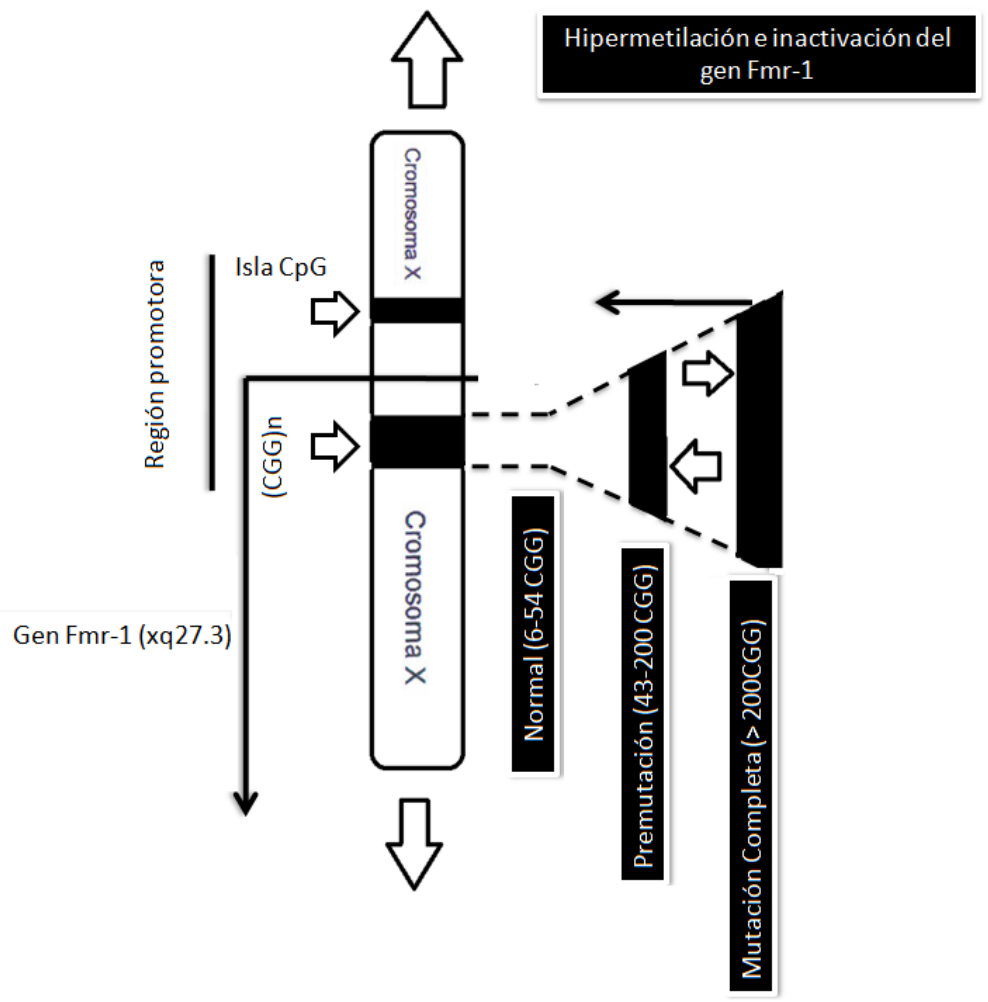

Figura 1. Esquema de la zona de tripletes inestables del gen FMR 1. Se pueden observar la isla $\mathrm{CpG}$ (que se hipermetila, inactivando el gen, en los pacientes con mutaciones por expansión superior a 200 tripletes CGG) y la zona de repeticiones de tripletes CGGn (ADN repetitivo que sufre de expansiones en las familias afectadas por el síndrome X frágil, basado en Otero [31], y Sullivan et al., [33]. 


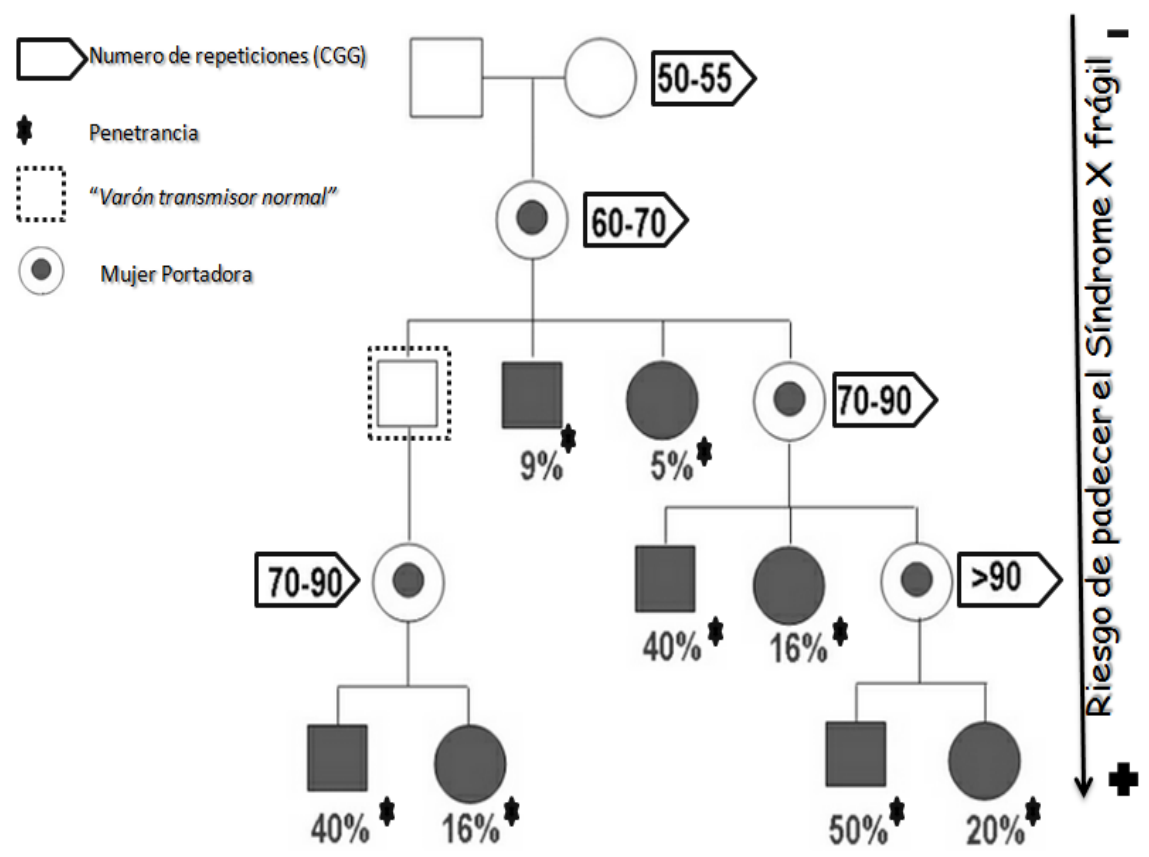

Figura 2. La paradoja de Sherman: un pedigrí hipotético donde se parte de una mujer sana con $50-55$ repeticiones que sufre una pequeña expansión a premutación en su hija (60-70 repeticiones). Así, el $9 \%$ de los hijos varones sufrirá expansión completa, mientras que esto sucede solo en el $5 \%$ de las hijas. Ahora, el riesgo de tener hijos enfermos es mayor, ya que una premutación de 70-90 tiene mayor riesgo de sufrir expansión completa. Vemos que en este caso el $40 \%$ de los hijos varones y el $16 \%$ de las hijas, sufrirán la enfermedad. Si la repetición sigue expandiéndose dentro del rango de premutación (por encima de 90 repeticiones), ahora el riesgo de expansión completa es todavía mayor (50 \% para hijos y $20 \%$ para hijas). En la rama izquierda del árbol se observa también un hecho interesante: la presencia de un "varón transmisor sano" que reciben un alelo con premutación y lo transmite a su descendencia. El varón ha recibido de su madre un cromosoma $X$ con 70-90 repeticiones y transmite su cromosoma $X$ a sus hijas sin sufrir ninguna expansión, por lo que ninguno de sus hijos puede padecer la enfermedad. Sus hijas, en cambio, sí pueden sufrir expansiones completas al transmitirlo, siendo el riesgo de que esto suceda dependiente del tamaño de la repetición. Basado en Otero et al., [31], Richards et al., [32] y Sullivan et al., [33]. 

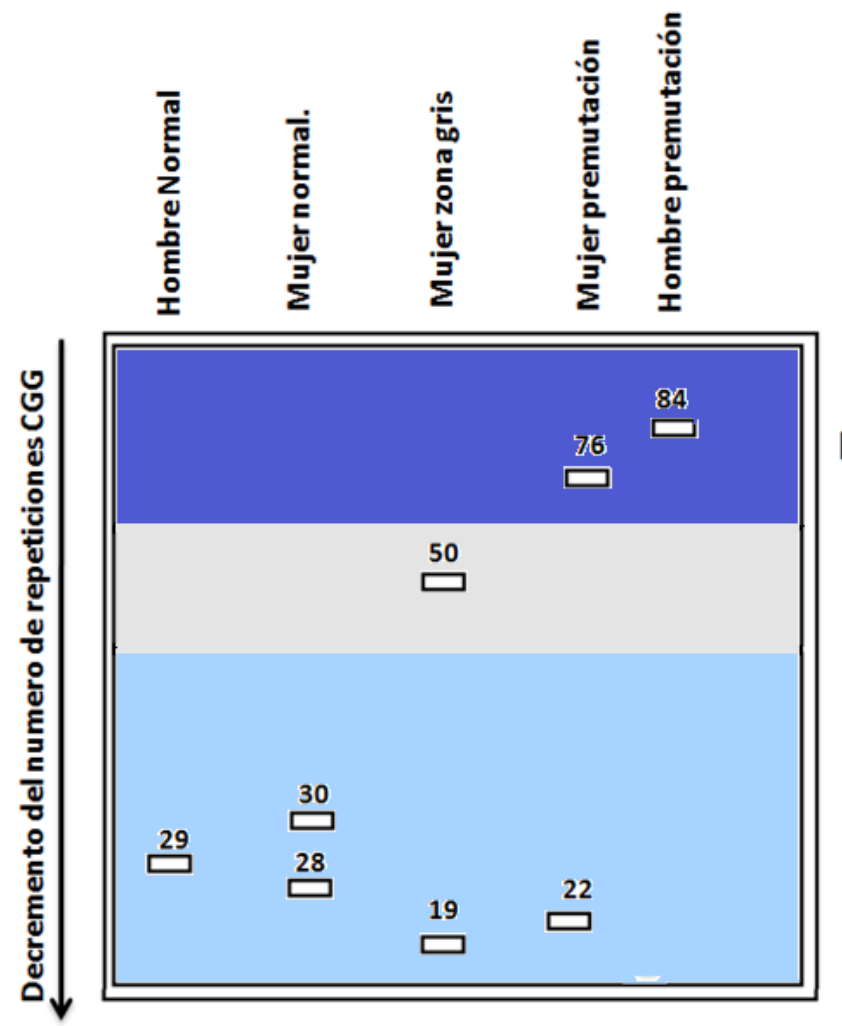

Premutación

Zona gris

Normal

Figura 4. Análisis de X-frágil por PCR. Se muestra el número de repeticiones y ubicación de las bandas en un hombre normal (29 repeticiones), mujer normal (30 y 28 repeticiones en sus dos cromosomas $X$ respectivos), mujer con alelos intermediarios (50 repeticiones zona gris y 19 repeticiones-alelo normal), mujer con premutación (84 repeticiones-premlitación y 22 repeticiones alelo normal), hombre con premutación (78 repeticiones), hombre con mutación completa (no muestra ninguna banda) que debe ser confirmado por análisis de Southern Blot. Tomado y modificado de Willemsen [45]. 
Tabla 1. Rasgos clínicos característicos del síndrome de $\mathrm{X}$ frágil

\begin{tabular}{|c|}
\hline FACIALES \\
\hline $\begin{array}{c}\text { Cara alargada asimétrica } \\
\text { Labios finos } \\
\text { Mandíbula prominente } \\
\text { Facies acromegaloides en adultos } \\
\text { Frente amplia } \\
\text { Orejas grandes y prominentes de implantación baja } \\
\text { Estrabismo }\end{array}$ \\
\hline NEUROLÓGICAS \\
\hline $\begin{array}{c}\text { Retraso mental } \\
\text { Comportamiento hiperactivo en la infancia } \\
\text { Falta de concentración } \\
\text { Problemas de aprendizaje } \\
\text { Alteración del lenguaje } \\
\text { Habla reiterativa característica } \\
\text { Rasgos autistas con falta de interacción social } \\
\text { Convulsión y epilepsia } \\
\text { Agresividad } \\
\text { Contacto ocular escaso } \\
\text { Onicofagia temprana }\end{array}$ \\
\hline CEREBRALES \\
\hline $\begin{array}{c}\text { Disminución del vemis cerebral superior } \\
\text { Aumento del tamaño del cuarto ventrículo } \\
\text { Aumento del tamaño del núcleo audado } \\
\text { Atrofia frontal y parietal mediana } \\
\text { Disminución del volumen del girus temporal superior, con la edad } \\
\text { Aumento del volumen del hipocampo }\end{array}$ \\
\hline GENITALES \\
\hline $\begin{array}{l}\text { Macroorquidismo postpuveral en varones } \\
\text { Disfunción ovárica en mujeres } \\
\text { Menopausia en mujeres portadoras }\end{array}$ \\
\hline
\end{tabular}

\begin{tabular}{|c|}
\hline CABEZA \\
\hline Macrocefalia \\
Dolicocefalia \\
\hline BOCA \\
\hline Dentición irregular \\
Paladar hendido \\
\hline
\end{tabular}




\begin{tabular}{|c|}
\hline PIEL \\
\hline $\begin{array}{c}\text { Hiperpigmentación periorbital y escrotal } \\
\text { Excesivamente suave y lisa en las manos }\end{array}$ \\
\hline ESQUELÉTICAS \\
Escoliosis \\
Pies planos y/o zambos \\
OíDO \\
\hline Otitis media en la primera infancia \\
Problemas auditivos de la otitis media \\
\hline ARTICULARES \\
\hline Inestabilidad articular \\
\hline Hiperlaxitud articular en las manos \\
\hline MUSCULARES \\
\hline Hipotonía en la infancia \\
\hline CARDÍACAS \\
\hline Prolapso de la válvula mitral \\
Dilatación de la aorta ascendente \\
Soplo cardíaco \\
\hline BIOQUÍmICA \\
\hline Aumento de la hemoglobina corpuscular \\
Disminución del AMPC en células de cultivo \\
\hline
\end{tabular}

\section{Referencias}

[1] J. Artigas, C. Brun-Gasca \& E. Gabau, "Aspectos médicos y neuropsicológicos del síndrome X frágil", Rev Neurol Clin, vol. 2, pp. 4254, 2001.

[2] H. A. Lubs, "A marker X chromosome", Am J Hum Genet, vol. 21, pp. 231244, 1969.

[3] L. Glóver \& N.E. Guillén, "Síndrome X frágil", Rev Neurol, nº 42 (Supl. 1), pp. S51-S54. 2006.

[4] G. Y. Wen, E. C. Jenkins., E. M. Goldberg, M. Genovese, W. T. Brown \& H. Wtsniewski, "Ultrastructure of the Fragile X Chromosome", New Observations on the Fragile Sites, Am. J. of Med Genet, vol. 83, pp. 331333, 1999.

[5] A. Maddalena, C. S. Richards, M. J. McGinnis, A. Brothman, R. J. Desnick, R. E. Grier et al., "Technical standards and guidelines for fragile X: The first of a series of disease specific supplements to the standards and guidelines for clinical genetics laboratories of the American College of Medical Genetics", Quality Assurance Subcommittee of the Laboratory Practice Committee, Genet Med, vol. 3, pp. 200-205, 2001. 
[6] S. Jacquemont, R. J. Hagerman, M. A. Leehey, D. A. Hall, R. A. Levine et al., "Penetrance of the fragile $\mathrm{X}$-associated tremor-ataxia syndrome in a premutation carrier population", JAMA, vol. 29, n4, pp. 460-469, 2004.

[7] F. L. Raymond, "X linked mental retardation: a clinical guide", J Med Genet; vol. 43, pp. 193-200, 2006.

[8] K. A. Verker, M. Pieretti, I. S. Sutcliffe et al., "Identification of a gene (FMR 1) containing a CGG repeat coincident with a breakpoint cluster region exhibiting length variation in fragile $X$ syndrome", Cell, vol. 65, pp. 905-914, 1991.

[9] A. J. Verkerk, M. H. Pieretti, M. Sutcliffe, J. S. Fu, Y-H. Kuho, D. P. A. Pizzuti et al., "Identification of a gene (FMR-1) containing a CGG repeat coincident with a breakpoint cluster region exhibiting length variation in fragile X syndrome", Cell, vol. 65, pp. 905-914, 1991.

[10] Y.H. Fu, D. P. Kuhl, A. Pizzuti, A. Pieretti, M. Sutcliffe, J. S. Richards et al., "Variation of the CGG repeat at the fragile $X$ site results in genetic instability: Resolution of the Sherman paradox", Cell, vol. 67, pp. 10471058, 1991.

[11] E. E. Eichler, J. Holden, B. W. Popovich, A. L. Reiss, K. Snow, S.N. Thibodeau et al., "Length of uninterrupted CGG repeats determines instability in the FMR-1 gene", Nat Genet, vol. 8, pp. 88-94, 1994.

[12] Z. Li, Y. Zhang, L. Ku, K. D. Wilkinson, S. T. Warren \& Y. Feng, "The fragile $X$ mental retardation protein inhibits translation via interacting with mRNA", Nucleic Acids Res., vol. 29, pp. 2276-2283, 2001.

[13] B. Laggerbauer, D. Ostareck, M. Keidel \& E. M. Ostareck-Lederer, "Evidence that fragile $\mathrm{X}$ mental retardation protein is a negative regulator of translation", Hum. Mol. Genet., vol.10, pp. 329-338, 2001.

[14] F. Giliberto, I. Szijan \& V. Ferreiro, "Fragile-X mental retardation: molecular diagnosis in Argentine patients", Journal of Biochemistry and Molecular Biology, vol. 39, n. 6, pp. 766-773, Nov. 2006.

[15] S. Jacquemont, R. J. Hagerman, M. A. Leehey, D. A. Hall, R. A.Levine et al., "Penetrance of the fragile $X$-associated tremor-ataxia syndrome in a premutation carrier population", JAMA, vol. 291, n4, pp. 460-469, 2004.

[16] R. Pesso, M. Berkenstadt, H. Cuckle, E. Gak, L. Peleg, M. Frydman et al., "Screening for fragile $\mathrm{X}$ syndrome in women of reproductive age", Prenat Diagn, vol. 20, pp. 611-614, 2000.

[17] W. T. Brown, "The molecular biology of the fragile X mutation", in Fragile $X$ syndrome: Diagnosis, treatment and research, 3rd Ed., R. J. Hagerman \& P. J. Hagerman, Eds. Baltimore: The Johns Hopkins University Press, 2002, pp. 110-135. 
[18] S.L. Sherman, R. Hagerman \& P. Hagerman, Fragile $X$ syndrome: diagnosis, treatment and intervention, 3rd Ed. Maryland: The Johns Hopkins University Press, 2002, pp. 136-168.

[19] M. Solari, Genética Humana. Buenos Aires: Panamericana, 1999.

[20] S. L. Nolin, W. T. Brown, A. Glicksman, G. E. Houck, A. D. Gargano, et al., "Expansion of the fragile X CGG repeat in females with premutations or intermediate alleles", Am J Hum Genet, vol. 72, pp. 454-464, 2003.

[21] F. Tassone, A. Beilina, C. Carosi, S. Albertosi, C. Bagni, I. Li \& K. Glover, "Elevated FMR 1 mRNA in premutation carriers is due to increased transcription", RNA, vol. 13, pp. 555-562, 2007.

[22] K. De Boulle, A. J. Verkerk, H. Reyniers et al., "A point mutation in the FMR-1 gene associated with fragile X mental retardation", Nat Genet, vol. 3, pp. 31-35, 1993.

[23] R. L. Bennett, K. A. Hart, E. O’Rourke, J. A. Barranger, J. Johnson, K.D. MacDermot et al., "Fabry disease in genetic counseling practice: Recommendations of the National Society of Genetic Counselors", J Genet Couns, vol. 1, n² 2, pp. 121-146, 2002.

[24] L. Bennetto, B. F. Pennington, D. Porter, A. K. Taylor \& R. J. Hagerman, "Profile of cognitive functioning in women with the fragile X mutation", Neuropsychology, vol. 5, pp. 290-9, 2001.

[25] B. Genc, H. Muller-Hartmann, M. Zeschinig, H. Deissler, B. Schimtz, F. Majewski, A. Gontard \& W. Doerfler, "Methylation mosaicism of 5'-(CGG) (n)-3' repeats in fragile X, premutation and normal individuals", Nucleic Acids Res., vol. 28, pp. 2141-2152, 2000.

[26] R. J. Hagerman, B. R. Leavitt, F. Farzin, S. Jacquemont, C. M. Greco, J. A. Brunberg et al., "Fragile-X-associated tremor/ataxia syndrome (FXTAS) in females with the FMR 1 premutation", Am J Hum Genet, vol. 64, pp. 1051-1056, 2004.

[27] J. Tarleton, A. Kenneson, A. K. Taylor, K. Crandall, R. Fletcher, R. Casey et al., "A single base alteration in the CGG repeat region of FMR 1: possible effect on gene expression and phenotype", J Med Genet., vol. 39, pp.196-200, 2002.

[28] D. N. Cooper, "Human gene mutation in pathology and evolution", J. inherit. metab. dis., vol. 25, pp. 157-182, 2002.

[29] B. B. De Vries, A. Wiegers, A. M. Smits, T. Mohkamsing, S. Duivenvoorde et al., "Mental status of females with an FMR-1 gene full mutation", Am J Hum Genet, vol. 58, pp. 1025-1032, 1996.

[30] M. Aziz, "Clinical features of boys with fragile $X$ permutations and intermediate alleles", Am J Med Genet, vol. 121B, n¹, pp. 119-127, 2003. 
[31] Y. Otero de Diego, A. Hmadcha, M. Carrasco \& E. Pintado, "Síndrome X Frágil y discapacidad mental hereditaria". Sevilla: Universidad de Sevilla, 1999.

[32] R. Richards \& G. Sutherland, "Fragile X syndrome. The molecular picture comes into focus", Elsevier Science Publishers, vol. 8, n 7, pp. 249-253, 1992.

[33] A. K. Sullivan, M. Marcus, M. P. Epstein, E. G. Allen, A. E. Anido, W. He et al., "Association of FMR 1 repeat size with ovarian dysfunction", Hum Reprod, vol. 20, pp. 402-412, 2005.

[34] C. E. Pearson, "Slipping while slipping? Trinucleotide repeat expansions in germ cells", Trends Mol Med., vol. 9, pp. 490-495, 2003.

[35] D. B. Bailey, "Newborn screening for fragile X syndrome", Ment Retard Dev Disabil Res Rev, vol. 10, pp. 3-10, 2004.

[36] S. Sherman, B. A. Pletcher \& D. A. Driscoll, "Fragile X syndrome: diagnostic and carrier testing", Genetics in Medicine, 2002.

[37] A. Cronister, R. J. Hagerman, M. Wittenberger \& K. Amiri, "Mental impairment in cytogenetically positive fragile X females", Am J Med Genet, vol. 38, pp. 503-504, 1991.

[38] C. S. Keysor \& M. M. Mazzocco, "A developmental approach to understanding fragile X syndrome in females", Microscopy Research and Technique, vol. 57, pp. 179-186, 2002.

[39] A. Murray, S. Youings, N. Dennis, L. Latsky, P. Linehan, N. McKechnie et al., "Population screening at the FRAXA and FRAXE loci: A molecular analysis of boys with learning difficulties and their mothers", HumMol Genet, vol. 5, pp. 727- 735, 1996.

[40] L. R. Shapiro, P. L. Wilmot, P. D. Murphy \& W. R. Breg, "Experience with multiple approaches to the prenatal diagnosis of the fragile $\mathrm{X}$ syndrome: Amniotic fluid, chorionic villi, fetal blood and molecular methods", Am J Med Genet, vol. 30, pp. 347-354, 1988.

[41] C. E. Pearson, K. N. Edamura \& J. D. Cleary, "Repeat instability: mechanisms of dynamic mutations", Nature Rev. Genet. vol. 6, pp. 729742, 2005.

[42] A. K. Sullivan, D. C. Crawford, E. H. Scott, M. L. Leslie \& S. L. Sherman, "Paternally transmitted FMR 1 alleles are less stable than maternally transmitted alleles in the common and intermediate size range", Am J Hum Genet, vol. 70, pp. 1532-1544, 2002.

[43] H. Toledano-Alhadef, L. Basel-Vanagaite, N. Magal, B. Davidov, S. Ehrlich, V. Drasinover et al., "Fragile-X carrier screening and the prevalence of 
premutation and full- mutation carriers in Israel", Am J Hum Genet, vol. 69, pp. 352-360, 2001.

[44] R. Willemsen, C. J. Bontekoe, L. A. Severijnen \& B. A. Oostra, "Timing of the absence of FMR 1 expression in full mutation chorionic villi", Hum Genet, vol. 110, nº 6, pp. 601-605, 2002.

[45] A. Trepanier, M. Ahrens, W. McKinnon, J. Peters, J. Stopfer, S. Campbell Grumet et al., "Genetic cancer risk assessment and counseling: Recommendations of the National Society of Genetic Counselors", J Genet Couns, vol. 13, pp. 83-114, 2004.

[46] H. Toledano-Alhadef, L. Basel-Vanagaite, N. Magal, B. Davidov, S. Ehrlich, V. Drasinover et al., "Fragile-X carrier screening and the prevalence of premutation and full-mutation carriers in Israel", Am J Hum Genet, vol. 69, pp. 352-360, 2001.

[47] American College of Medical Genetics. American College of Medical Genetics Policy Statement, "Fragile X syndrome: diagnostic and carrier testing", Am J Med Genet, vol. 53, pp. 380-381, 1994.

[48] V. P. Sybert, S. B. Cassidy \& J. E. Allanson, "Management of genetic syndromes". New York: Wiley-Liss, 2001, pp. 459-484. 


\section{ESTUDIO DE LA ACIDEZ DE ZEOLITAS EN LA REACCIÓN DE ISOMERIZACIÓN DEL $\alpha$-PINENO}

\section{STUDY OF ACIDITY OF ZEOLITES IN THE ISOMERIZATION REACTION INTHE $\alpha$-PINENE}

A. Pérez-Larios ${ }^{1 *}$ M. Ostroumov ${ }^{2 *}$ R. Gómez J. L. Rico

\section{Resumen}

A fin de favorecer la producción del canfeno, producto de la isomerización del $\alpha$-pineno, en este trabajo se prueban las zeolitas clinoptilolita, natural (disponible en nuestro país, específicamente en Michoacán), así como las zeolitas comerciales ZSM-5 y mordenita, como catalizadores para esta reacción, en un intervalo de 130 a 230 ${ }^{\circ} \mathrm{C}$. Se ha encontrado que el material natural con un tratamiento simple (dos lavados con agua desionizada), presenta buena conversión en la isomerización del $\alpha$-pineno y mayor selectividad hacia canfeno, en comparación con las zeolitas comerciales.

1 * Laboratorio de Catálisis, FIQ, UMSNH. Morelia, Mich., México ; Universidad Autónoma Metropolitana-Iztapalapa, Departamento de Química, México. Correo electrónico: mciqalex@gmail.com

$2^{* * * *}$ Laboratorio de Catálisis, FIQ, UMSNH. Morelia, Mich., México. 
Palabras clave: Canfeno, $\alpha$-pineno, zeolitas, catalizadores e isomerización.

\section{Abstract}

In order to encourage the camphene production, isomerization product of $\alpha$-pinene, in this study are tested the clinoptiolite zeolites, natural (available in our country, Mexico, specifically in Michoacan), as well as comercial zeolites ZSM-5, as a catalyst for this reaction, in the range of 130 to $230^{\circ} \mathrm{C}$. It was found that the natural material with a simple treatment (two washed with deionized water) shows good conversión in the isomerization of $\alpha$-pinene and higher selectivity towards camphene, compared with comercial zeolites.

Keywords: Camphene, $\alpha$-pinene, zeolites,catalysts and isomerization.

\section{Introducción}

El $\alpha$-pineno es uno de los terpenos más importantes en la naturaleza, usado como solvente y precursor para la producción de canfeno, el cual es un componente en la industria de las fragancias. Aunque algunos sólidos ácidos se han usado como catalizadores para esta reacción, como zeolitas [1-5], montmorilonita modificada [6], arcillas [7-9], MCM-41 funcionalizada [10] y zirconia sulfatada [11], que han sido probadas para la isomerización del $\alpha$-pineno, el desarrollo de nuevos catalizadores para esta reacción es todavía un tópico de investigación en muchos laboratorios. En este trabajo de investigación se prueban una zeolita clinoptilolita natural, así como zeolitas comerciales (ZSM-5 y mordenita), como catalizadores en la isomerización del $\alpha$-pineno, en un intervalo de 130 a $230{ }^{\circ} \mathrm{C}$.

\section{Experimentación Preparación y caracterización de catalizadores}

La zeolita clinoptilolita se trituró, se lavó con agua desionizada y posteriormente se secó a $120 \mathrm{C}$ durante $4 \mathrm{~h}$. Después del secado, el catalizador se calcinó a $350 \mathrm{C}$ durante $4 \mathrm{~h}$. El área de la zeolita 
natural ya calcinada fue de $27.3 \mathrm{~m}^{2} / \mathrm{g}$ y un tamaño de poro entre 18-45 A. La mordenita (Zeolyst, con relación molar $\mathrm{SiO}_{2} / \mathrm{Al}_{2} \mathrm{O}_{3}$ de 90 y área de $500 \mathrm{~m}^{2} / \mathrm{g}$ ) y la HZSM-5 (Zeolyst, con relación molar $\mathrm{SiO}_{2} /$ $\mathrm{Al}_{2} \mathrm{O}_{3}$ de 30 y área de $400 \mathrm{~m}^{2} / \mathrm{g}$ ) se calcinaron a $350 \mathrm{C}$ durante $4 \mathrm{~h}$, y después se procedió a formar pastillas sometiendo el polvo en una prensa. Las pastillas se trituraron suavemente para tener una porción de tamaño de partícula uniforme de 0.71-0.425 $\mathrm{mm}$ para todos los catalizadores. La caracterización de la acidez de los materiales se realizó en un espectrómetro de infrarrojo, FTIR Nicolet Nexus 470, equipado con una celda de vidrio que permitió seguir la adsorción de la piridina en función de la temperatura. Para esto, el polvo se secó previamente a $300 \mathrm{C}$ durante $1 \mathrm{~h}$, y después se impregnó de piridina. Se tomaron espectros desde $25 \mathrm{C}$ hasta los $300 \mathrm{C}$, haciendo lecturas cada $50 \mathrm{C}$.

\section{Reacción de isomerización del $\alpha$-pineno}

La reacción se llevó a cabo en un reactor por lotes de $100 \mathrm{ml}$, Parr, Multi Reactor System, agregando $0.5 \mathrm{~g}$ de catalizador en 50 $\mathrm{ml}$ de $\alpha$-pineno. La reacción transcurrió durante $2 \mathrm{~h}$, a $500 \mathrm{rpm}$, a presión atmosférica, y en ambiente de Argón. Las temperaturas de reacción probadas fueron $130,150,170,190,210,230^{\circ} \mathrm{C}$. Después de $2 \mathrm{~h}$ de reacción, el producto fue analizado en un cromatógrafo de gases, Agilent 6820, equipado con una columna capilar HP-FFAP de $25 \mathrm{~m}$ de largo y $0.32 \mathrm{~mm}$ de diámetro interno.

\section{Resultados y discusión}

La isomerización del $\alpha$-pineno procede por dos vías: una que es capaz de producir productos bi y tricíclicos tales como canfeno, $\beta$-pineno, tricicleno y bornileno, y la otra que da compuestos monocíclicos como dipenteno, terpinoleno, limoneno, $\alpha$-terpineno, $\gamma$-terpineno y para-cimeno. Los productos que pueden formarse en la primera etapa de isomerización de $\alpha$-pineno, a partir del intermediario, se muestran en la Figura 1 y son canfeno, tricicleno y $\Delta 3$-Careno. Por la transformación de limoneno se puede obtener $\alpha$ y $\gamma$-terpineno, $\alpha$ y $\beta$ felandreno. 


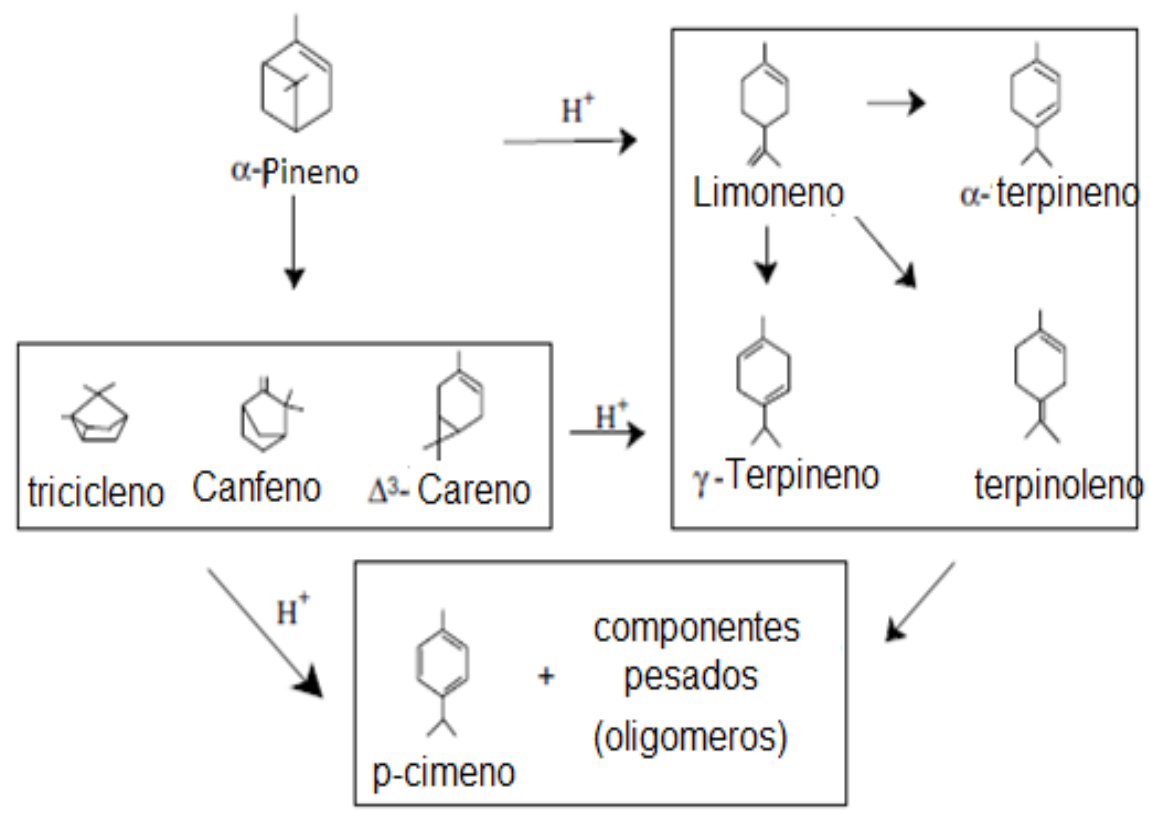

Figura 1. Esquema de transformación de $\alpha$-pineno.

En la Figura 2 se observa el mecánismo de reacción propuesto. Nos sugiere que los sitios ácidos Lewis tienen influencia en la reacción de isomerización en la obtención de canfeno, pues cuando se tienen ambos sitios ácidos - Lewis y Bronsted- se llega a producir Canfeno, $\Delta 3$ Careno y Tricicleno en diferentes proporciones. Estas proporciones dependen de la temperatura a la que se lleve la reacción, debido a que las zeolitas comerciales contienen ambos sitios. que no son tan estables y pueden tener influannis on in
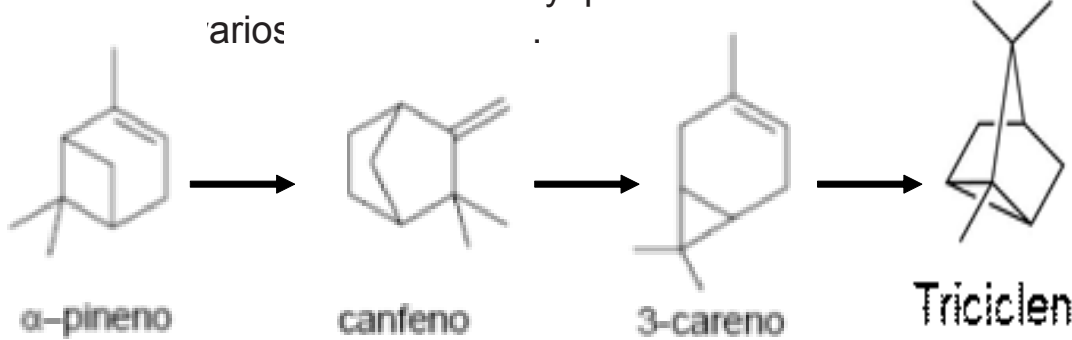

canfeno

Tricicleno 
Figura 2. Mecanismo de reacción en la isomerización del $\alpha$-pineno.

Fisisorción de $\mathbf{N}_{2}$

En la Tabla 1 se muestran los datos de fisisorción, los cuales pueden ser considerados en la clasificación convencional del tipo IV. Las curvas de histéresis son típicas de materiales porosos entre dos planos cristalinos, para la estructura de la zeolita natural clinoptilolita [14], [15]. En la Tabla 1 se presentan los resultados de área superficial específica utilizando el método BET, y la distribución de tamaño de poro con el método BJH. Las zeolitas comerciales presentan áreas superficiales de $490 \mathrm{~m}^{2} / \mathrm{g}$ y $387 \mathrm{~m}^{2} / \mathrm{g}$ para la Mordenita y ZSM-5, respectivamente, las cuales son acordes con la literatura [16]. La zeolita clinoptilolita exhibe la menor área superficial, de $25 \mathrm{~m}^{2} / \mathrm{g}$, debido a las impurezas formadas en ambientes naturales.

Tabla 1. Datos de fisisorción de los materiales usados.

\begin{tabular}{|c|c|c|}
\hline Zeolita & $\begin{array}{c}\text { Área Superficial } \\
\left(\mathbf{m}^{2} / \mathbf{g}\right)\end{array}$ & $\begin{array}{c}\text { Promedio del } \\
\text { tamaño de poro } \\
(\mathbf{A})\end{array}$ \\
\hline Clinoptilolita & 25 & 12 \\
\hline Mordenita & 490 & 48 \\
\hline ZSM-5 & 387 & 30 \\
\hline
\end{tabular}

\section{Adsorción de piridina por FT-IR}

Después de la adsorción de la piridina a temperatura ambiente, se tomaron las muestras y se observaron las bandas que se asocian con la quimisorción de la piridina a $1454 \mathrm{~cm}^{-1}, 1491 \mathrm{~cm}^{-1}$ y 1547 $\mathrm{cm}^{-1}$. De acuerdo con resultados reportados sobre la quimisorción de la piridina [6], [7], la banda en posición $1454 \mathrm{~cm}^{-1}$ se asigna a la piridina coordinada a los sitios Lewis, mientras que la banda en posición de $1491 \mathrm{~cm}^{-1}$ está conformada por bandas debido a sitios ácidos tipo Lewis y Brönsted; y, finalmente, la banda a $1547 \mathrm{~cm}^{-1}$ se asigna a iones piridinium adsorbidos en sitios ácidos tipo Brönsted. En la Figura 3, para la mordenita se observa la presencia de sitios ácidos Lewis y Brönsted, donde predominan los sitios ácidos Brönste con temperaturas de $250{ }^{\circ} \mathrm{C}$. La Figura 2 muestra que en la zeolita 
natural predomina la acidez moderada tipo Lewis, inferior a la que presentan las zeolitas comerciales, lo que sugiere que los sitios son estables para las reacciones de isomerización. No se ven cambios significativos con el aumento de la temperatura, solo una disminución pequeña de las bandas alrededor de 1450 y $1490 \mathrm{~cm}^{-1}$. La Figura 5 muestra el espectro para la zeolita ZSM-5, el cual indica que predomina la acidez tipo Brönsted.

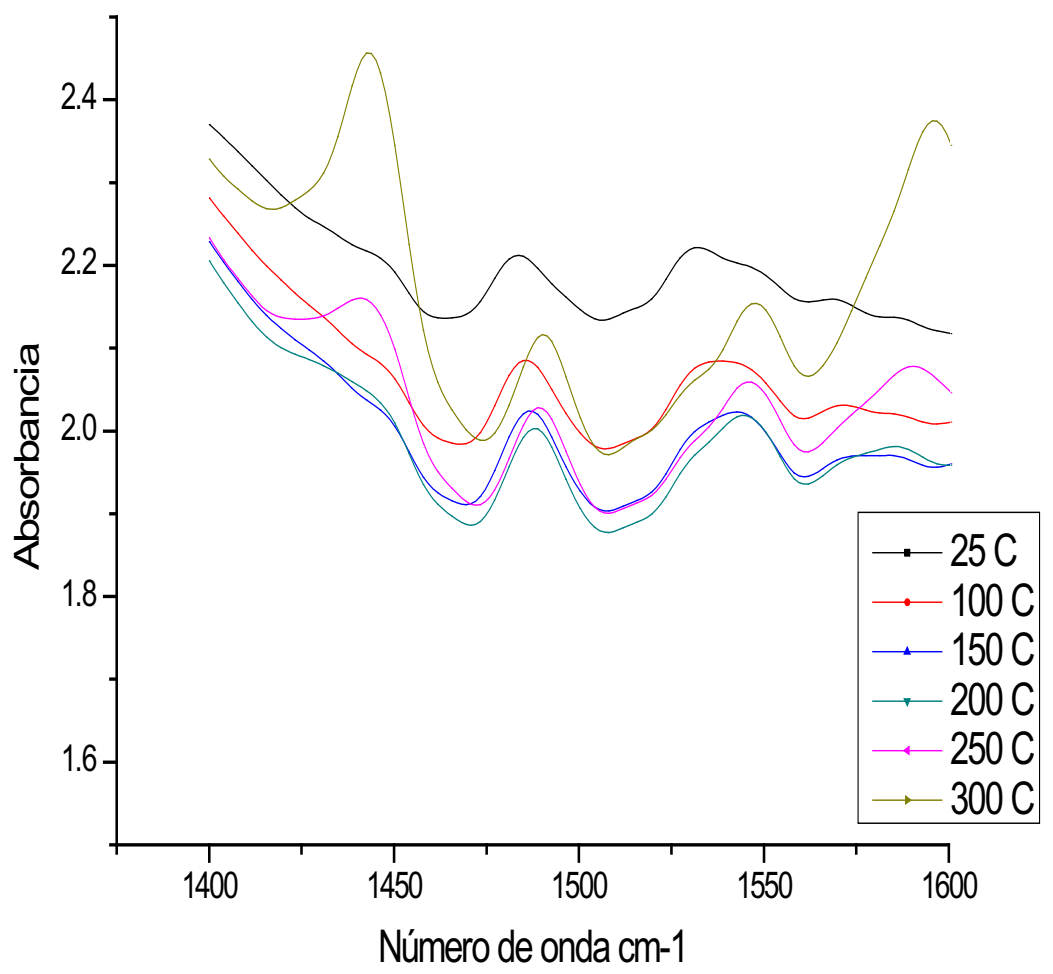

Figura 3. FT-IR de la zeolita mordenita 


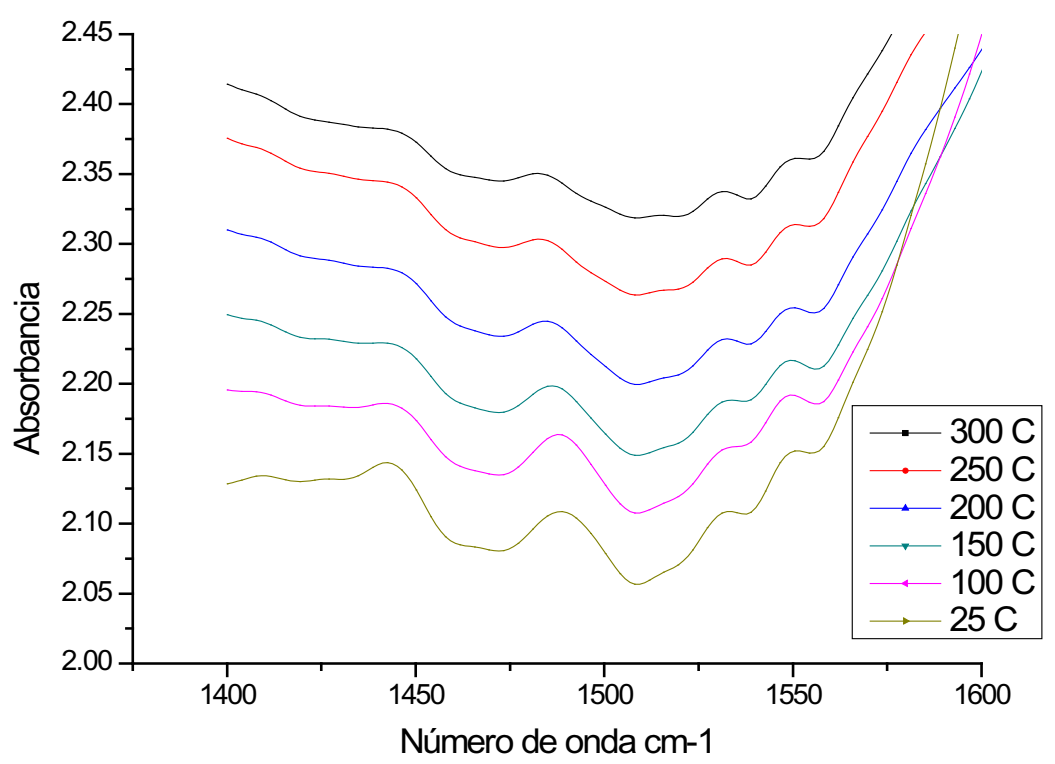

Figura 4. FT-IR de la zeolita natural clinoptilolita

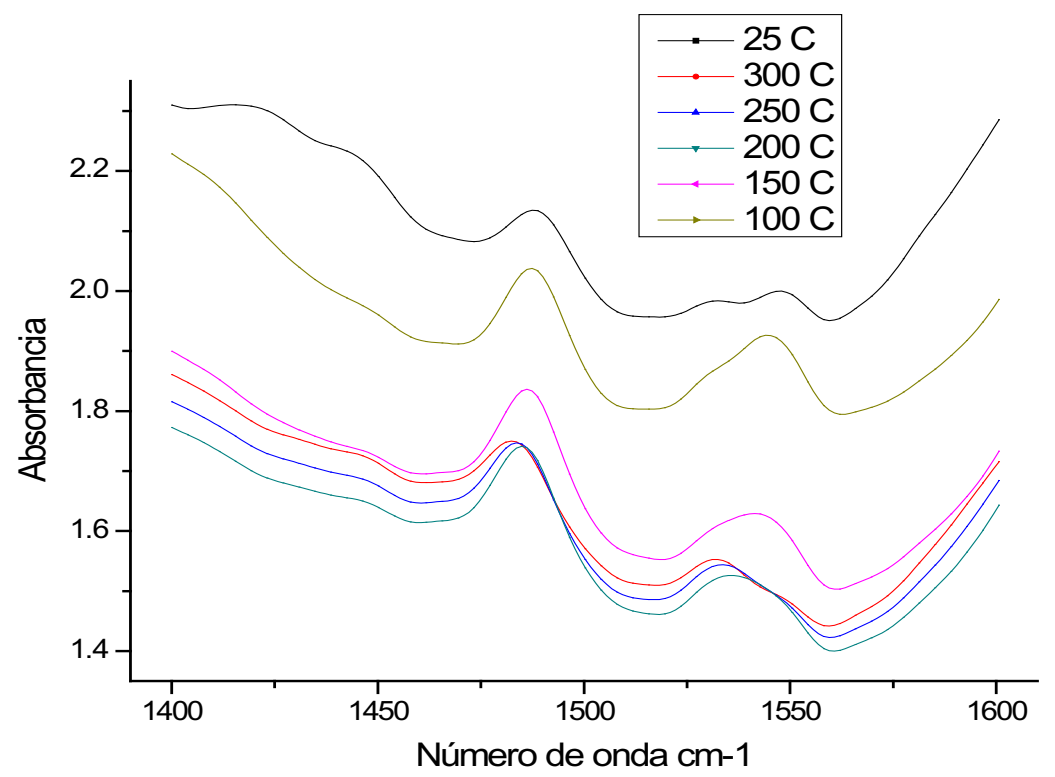


Figura 5. FT-IR de la zeolita ZSM-5

\section{Reacciones de isomerización}

La Figura 7 muestra la conversión de $\alpha$-pineno a las $2 \mathrm{~h}$ de reacción, en función de la temperatura. A temperaturas bajas, las zeolitas comerciales indican mayor conversión de $\alpha$-pineno que las naturales, pero a temperaturas mayores, los tres catalizadores presentan conversiones similares. Sin embargo es interesante observar la producción de Canfeno, Figura 8, y de los demás productos, agrupados como subproductos, en la Figura 9. Esta información se complementa con la Tabla 1. Podemos observar que la zeolita natural presenta para todas las temperaturas, excepto a $130^{\circ} \mathrm{C}$, una relación subproductos/Cafeno, S/C, más pequeña (por ejemplo, a 150 C, S/C es de 1.26) que las zeolitas comerciales, lo cual es interesante. Cabe también mencionar el hecho de que la zeolita natural es la de menos área superficial específica.

De acuerdo con Severino et al. [2], el canfeno y los productos bicíclicos se forman preferentemente sobre sitios ácidos tipo Lewis, debido a que estos son más débiles que los sitios ácidos tipo Brönsted. Nuestros resultados sobre la zeolita natural clinoptilolita para la producción del canfeno soportan esta idea. En otro estudio, López et al, [1], reportan que a $120{ }^{\circ} \mathrm{C}$ se tiene una selectividad mayor del $36 \%$ hacia Canfeno, usando una zeolita mordenita.

Por otra parte, estas reacciones nos sugieren que los sitios ácidos de Lewis tienen influencia sobre la obtención de Canfeno, y que la consecución de subproductos para la zeolita natural se debió posiblemente a la estabilidad de los sitios ácidos Lewis, Figura 4, no así para los otros dos catalizadores utilizados en esta reacción, ya que los subproductos logrados para estas reacciones van encaminados con la mezcla de los sitios ácidos Lewis y Brönsted. Lo que nos indica que cuando hay combinación de sitios ácidos, las reacciones no se ven favorecidas hacia un tipo de producto buscado en la industria de las fragancias [13]. 

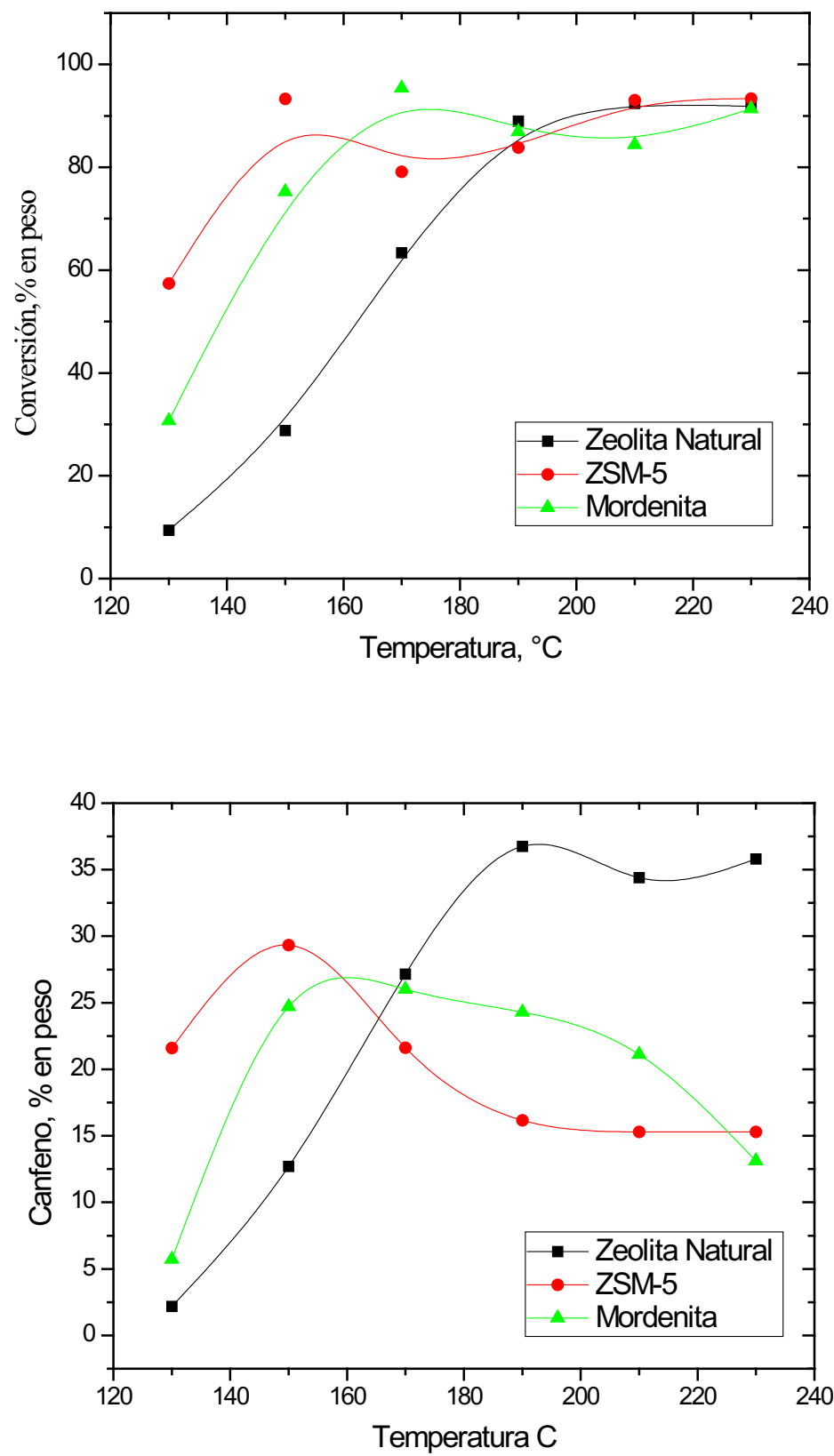

Figura 6. Efecto de la temperatura en la conversión de $\alpha$-pineno. 


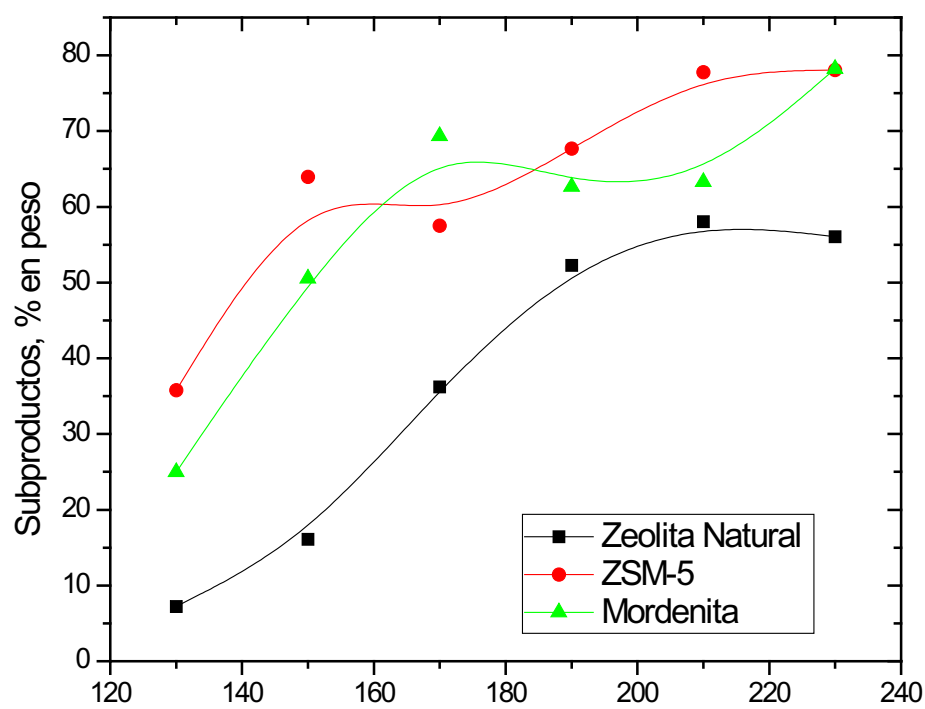

Figura 7. Efecto de la temperatura en la producción de canfeno.

Figura 8. Efecto de la temperatura en la obtención de subproductos.

Tabla 1. Producción de Canfeno (C), subproductos (S) y la relación $\mathrm{S} / \mathrm{C}$, en por ciento en peso, a las $2 \mathrm{~h}$ de reacción.

\begin{tabular}{cccccccccc}
\hline \multirow{2}{*}{$\mathrm{T},{ }^{0} \mathrm{C}$} & \multicolumn{3}{c}{ Natural } & \multicolumn{3}{c}{ ZSM-5 } & \multicolumn{3}{c}{ Mordenita } \\
\cline { 2 - 10 } & $\mathrm{C}$ & $\mathrm{S}$ & $\mathrm{S} / \mathrm{C}$ & $\mathrm{C}$ & $\mathrm{S}$ & $\mathrm{S} / \mathrm{C}$ & $\mathrm{C}$ & $\mathrm{S}$ & $\mathrm{S} / \mathrm{C}$ \\
\hline 130 & 2.2 & 7.2 & 3.27 & 21.6 & 35.8 & 1.65 & 5.7 & 25.0 & 4.38 \\
150 & 12.7 & 16.1 & 1.26 & 29.3 & 64.0 & 2.18 & 24.7 & 50.5 & 2.04 \\
170 & 27.1 & 36.2 & 1.33 & 21.6 & 57.5 & 2.66 & 26.0 & 69.3 & 2.66 \\
190 & 36.7 & 52.2 & 1.42 & 16.2 & 67.7 & 4.18 & 24.3 & 62.6 & 2.57 \\
210 & 34.4 & 58.0 & 1.68 & 15.3 & 77.8 & 5.08 & 21.1 & 63.3 & 3.00 \\
230 & 35.8 & 56.0 & 1.56 & 15.3 & 78.1 & 5.10 & 13.1 & 78.2 & 5.97 \\
\hline
\end{tabular}

\section{Conclusiones}

Los resultados indican que los tres materiales estudiados tienen acidez capaz de realizar la isomerización del $\alpha$-pineno, y que la reacción se puede llevar a cabo en sitios ácidos Lewis y Brönsted. La zeolita natural clinoptilolita tiene una acidez baja, tipo Lewis, y requiere de temperaturas mayores para aumentar la conversión de $\alpha$-pineno, comparada con los otros catalizadores, sin embargo, produce menos subproducto con respecto a la ZSM-5 y mordenita. 
La zeolita natural muestra una conversión de $\alpha$-pineno de alrededor de $90 \%$ a 190 C, y una relación S/C de 1.42, mucho más pequeña que las zeolitas comerciales mordenita y ZSM-5, lo cual indica una mayor selectividad hacia el canfeno.

\section{Agradecimientos}

Agradecemos a Conacyt-Gobierno del Estado de Michoacán, México, por su apoyo mediante el proyecto $n^{\circ} 2005-01-022$, para la realización de este proyecto.

\section{Referencias}

[1] C.M. López, F.J. Machado, K. Rodríguez, B. Méndez, M. Hasegawa \& S. Pekerar, Appl Catal A, vol. 173, pp. 75, 1998.

[2] A. Severino, A. Esculcas, J. Rocha, J. Vital \& L.S. Lobo, App/ Catal A, vol. 142, pp. 255, 1996.

[3] A.D. Stefanis, G. Pérez \& A.A.G. Tomlinson, Appl Catal A, vol. 132, pp. 353, 1995.

[4] T. Yamamoto, T. Matsuyama, T. Tanaka, T. Funabaki \& S.J. Yoshida, J Mol Catal A, vol. 155, pp. 271, 2000.

[5] R. Rachwalik, Z. Olejniczak, J. Jiao, J. Huang, M. Hunger \& B. Sulikowski, J Catal, vol. 252, pp. 161, 2007.

[6] M. Yadav, C. Chudasama \& R. Jasra, J Mol Catal A, vol. 216, pp. 51, 2004.

[7] C. Volzone, O. Masini, N.A. Comeli, L.M. Grzona, E.N. Ponzi \& M.I. Ponzi, Appl Catal A, vol. 214, pp. 213, 2001.

[8] S. Kullaj \& B. Shkoncave, Nature, vol. 43, pp. 81,1989.

[9] M. Nazir, M. Ahmed \& F.M. Chaudhary, J Sci Ind Res, vol. 19, pp. 175, 1976.

[10] M. Román-Aguirre, Y.P. Gochi, A. Robau, L. de la Torre \& A. AguilarElguezabal, Appl Catal A, vol. 334, pp. 59, 2008.

[11] N.N.A. Comelli, E.N. Ponzi \& M.I. Ponzi, Chem Eng J, vol. 117, pp. 93, 2006. 
[12] F. Ebmeyer, J Mol Struc (Theochem), vol. 582, pp. 251, 2002.

[13] F. Tzompantzi, M. Valverde, A. Pérez, J.L. Rico, A. Mantilla \& R. Gómez, Topics in Catalysis, vol. 53, pp.1176-1178, 2010.

[14] C. Volzone, O. Masini, N. A. Comelli, L. M. Grzona, E. N. Ponzi \& M. I. Ponzi, Applied Catalysis A: General, vol. 214, pp. 213-218, 2001.

[15] M. T. Olguín, Instituto Nacional de Investigaciones Nucleares, 2009.

[16] K.S. W. Sing, D.H. Everett, R.A.W. Haul, L. Moscou, R.A. Pierotti, J. Rouquerol \& T. Siemieniewska, "Reporting physisoption data for gas/ solid systems with special reference to the determination of surface area and porosity", Pure \& Appli. Chem., vol. 57, pp. 603, 1985. 


\section{बाज्सबत्बलि \\ DEsAriorto}

Aca va el articulo 3 
बाENGIA ED

DESARBRLLL

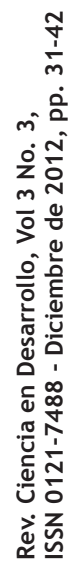

38 


\title{
ESTABLECIMIENTO DE UN PROTOCOLO DE PROPAGACIÓN DE PHYSALIS PERUVIANA L. A PARTIR DE YEMAS AXILARES ADULTAS
}

\author{
ESTABLISHMENT OF A PROTOCOL OF \\ PROPAGATION OF PHYSALIS PERUVIANA L. \\ FROM ADULT AXILLARY BUDS
}

Leidy Yanira Rache Cardenal ${ }^{1 *}$ José Constantino Pacheco Maldonado2**

\section{Resumen}

La uchuva tiene importancia ecológica, medicinal e industrial, $y$ posee un alto potencial comercial porque su fruto es apetecido en el mercado nacional e internacional. Dichas características han originado una alta demanda de frutos que no alcanza a ser suplida con la oferta actual. En este trabajo se estableció un protocolo para la propagación de uchuva utilizando MS como medio de cultivo, semillas de frutos maduros y yemas axilares de plantas adultas como explantes primarios. Después de la fase de establecimiento (30 días en MS sin reguladores y 60 días en $M S$ con $0.05 \mathrm{mg} \cdot \mathrm{L}^{-1} \mathrm{de}$ AIB más $0.1 \mathrm{mg} \cdot \mathrm{L}^{-1}$ de BA) se cuantificó $100 \%$ de germinación de semillas y yemas viables que reactivaron su actividad meristemática. La tasa de multiplicación de los segmentos nodales procedentes de plántulas cultivadas en MS con $0.05 \mathrm{mg} \cdot \mathrm{L}^{-1}$ de AIB fue de 4.5 , y la de explantes nodales procedentes de microtallos desarrollados a partir de yemas axilares cultivadas en MS con $0.05 \mathrm{mg} \cdot \mathrm{L}^{-1}$ de AIB más 0.1

\footnotetext{
1 *Ms.C. Biología. Docente - Universidad de Boyacá. e-mail: leidyrache@gmail.com ** Dr. Biología. Docente - Universidad Pedagógica y Tecnológica de Colombia, Tunja. 2 e-mail: jocpach@hotmail.com.
} 
$m g \cdot L^{-1}$ de $B A$, fue de 5.1. Durante el enraizamiento se cuantificó 100 $\%$ de microtallos enraizados en MS sin reguladores de crecimiento. Después del endurecimiento en invernadero, el $95 \%$ de las plántulas fue viable y reactivó su crecimiento.

Palabras clave: Uchuva, plantas adultas, semillas, yemas axilares, cultivo in vitro.

\section{Abstract}

Cape gooseberry has ecological, medicinal and industrial importance, and possesses a high commercial potential because its fruit is very well-accepted in both national and international market. These characteristics have caused a high demand for fruit, which does not reach to be supplied with the current bid. In this research a protocol for cape gooseberry micro propagation was established, using $M S$ as a culture medium, seeds from ripe fruits and axillary buds from mature plants as primary explants. After the establishment phase (30 days in MS without regulators and 60 days in MS with IBA $0.05 \mathrm{mg} \cdot \mathrm{L}^{-1}$ plus BA $\left.0.1 \mathrm{mg} \cdot \mathrm{L}^{-1}\right) 100 \%$ of germinated seeds and viable buds that reactivated their meristematic activity were quantified. The multiplication rate of the nodal segments coming from plantlets cultivated in MS supplemented with IBA $0.05 \mathrm{mg} \cdot \mathrm{L}^{-1}$, was 4.5 , and the multiplication rate of the nodal explants coming from developed shoots from axillary buds cultivated in MS supplemented with IBA $0.05 \mathrm{mg} \cdot \mathrm{L}^{-1}$, plus $B A 0.1 \mathrm{mg} \cdot \mathrm{L}^{-1}$ was 5.1. During rooting phase was quantified $100 \%$ of micro shoots rooted in MS without growth regulators. After hardening in greenhouse, $95 \%$ of seedlings was viable and reactivated their growth.

Keywords: Cape gooseberry, mature plants, seeds, axillary buds, in vitro culture.

\section{Introducción}

La uchuva (Physalis peruviana L.) es una Solanácea [1] de gran importancia ecológica. Por su crecimiento robusto y expansivo se utiliza como planta de cobertura para protección de terrenos contra la erosión [2]. Posee diversos usos agroindustriales [3], [4], también medicinales, 
gracias a las sustancias antioxidantes y anticancerígenas que contiene [5], y un gran potencial para consumo como fruta fresca. Sus frutos son fuente de provitamina $A, C$, algunas del complejo $B$, proteínas, carbohidratos [6], hierro y fósforo [7]. Con respecto al desarrollo de procesos biotecnológicos en esta especie, se han reportado estudios sobre inducción de procesos organogénicos [8], [9], embriogénesis y multiplicación [10], [5], germinación de semillas [11]; además, algunos trabajos relacionados con aplicación de radiación gamma [11], [12], [13] y estudios citogenéticos [14], [15], [16].

En Colombia, la uchuva presenta una gran demanda y se comercializa en mercados nacionales e internacionales; es muy apetecida por su sabor y características medicinales, aunque los estudios dedicados a la propagación de esta fruta son poco conocidos [17], [18]. Por otra parte, en los cultivos se observa variabilidad fenotípica pues la propagación se realiza principalmente por semilla [17]. Según Santana y Angarita [9], debido a que P. peruviana es una planta alógama, muestra gran variabilidad fenotípica en la población. Esta característica no es deseada, por tanto, lo ideal es obtener variedades comerciales de un hábito particular de crecimiento, calidad uniforme y alta productividad [17].

Una alternativa viable para obtener materiales homogéneos de cultivares con características particulares como las mencionadas anteriormente, es la propagación asexual de uchuva mediante esquejes [18], no obstante según Miranda [19] y López y otros [17], estas plántulas y las provenientes de cultivos in vitro presentan inconvenientes con la emisión de raíces adventicias, lo cual influye en el anclaje de las plantas en el sitio de cultivo definitivo. Se ha encontrado que la capacidad de enraizamiento depende de las características genéticas del material por propagar, edad del cultivo, suplemento exógeno de reguladores, variación de hormonas exógenas, efectos morfogenéticos, cofactores físicos, químicos y nutricionales [17].

Una segunda alternativa para obtener material homogéneo de cultivares con características deseables en la producción es la micropropagación, ya que esta técnica facilita la clonación de individuos adultos seleccionados [20], [9].

Con el fin de obtener materiales vegetativos comerciales de alta uniformidad y productividad, en esta investigación se pretendió 
desarrollar un protocolo de micropropagación, utilizando como explantes primarios yemas axilares tomadas de plantas adultas con características deseables, seleccionadas en un huerto comercial. El medio de cultivo, los reguladores de crecimiento y la concentración de reguladores utilizados para propagar estos explantes, se eligieron teniendo en cuenta los resultados obtenidos en los ensayos en los que se cultivaron yemas juveniles de plántulas procedentes de semilla sexual. Los tratamientos en los que se cultivaron yemas axilares tomadas de plantas adultas fueron los que produjeron mayor número de entrenudos y menor longitud del microtallo o de la plántula desarrollada.

\section{Materiales y métodos}

Este trabajo se efectuó en el Laboratorio de Cultivo de Tejidos Vegetales- BIOPLASMA- de la Escuela de Ciencias Biológicas, Universidad Pedagógica y Tecnológica de Colombia, (Tunja). A fin de facilitar y acelerar el desarrollo del protocolo de micropropagación de plantas adultas, los ensayos iniciales en cada una de las etapas del protocolo se hicieron utilizando yemas juveniles de plántulas procedentes de semilla sexual, porque a partir de estas se obtuvo de manera eficiente y rápida una proliferación elevada de microtallos necesarios para el establecimiento de los ensayos. Las observaciones realizadas y los resultados obtenidos sirvieron de base para los ensayos con yemas adultas.

\section{Etapa 0. Selección de plantas madre}

Las plantas adultas se localizaron en el municipio de Arcabuco, Boyacá, ubicado a $5^{\circ} 42^{\prime}$ y $20^{\prime \prime}$ de latitud norte y a $0^{\circ} 30^{\prime}$ y $35^{\prime \prime}$ de longitud en relación al meridiano de Bogotá y $73^{\circ} 26^{\prime}$ del oeste de Greenwich, a 2,739 m s.n.m. y temperatura media de $15^{\circ} \mathrm{C}$. Se seleccionaron plantas que presentaron alta producción y frutos de buen tamaño. De estas plantas se colectaron frutos maduros y estacas de 5-8 cm de longitud, al menos con dos yemas axilares cada uno, las cuales se mantuvieron húmedas durante su traslado al laboratorio.

\section{Etapa 1. Establecimiento in vitro de cultivos}

En todas las etapas se utilizó medio MS (Murashige y Skoog), [21]. El pH de todos los medios de cultivo se ajustó a 5.6 con $\mathrm{KOH}$ 
y/o $\mathrm{HCl}(0.5-1.0 \mathrm{~N})$ y los medios se esterilizaron en autoclave a 15 psi y $121{ }^{\circ} \mathrm{C}$ durante 20 minutos. Los cultivos se mantuvieron en cuarto de incubación a temperatura de $24 \pm 1^{\circ} \mathrm{C}$ con iluminación continua $\left(70-80 \mu \mathrm{mol} . \mathrm{m}^{2} / \mathrm{s}\right)$, suministrada por lámparas fluorescentes SILVANA, luz día de $75 \mathrm{~W}$.

A partir de semilla. Los frutos maduros se enjuagaron con agua más Tween $20(0.1 \mathrm{ml} / 100 \mathrm{ml})$. La pulpa de los frutos se colectó en un tamiz y las semillas se extrajeron con ayuda de una corriente de agua. Las semillas obtenidas se embebieron en agua durante doce horas y, posteriormente, se sometieron al siguiente proceso de asepsia superficial: un enjuague con agua destilada más Tween 20 $(0.1 \mathrm{ml} / 100 \mathrm{ml})(\mathrm{v} / \mathrm{v})$ durante cinco minutos en agitación constante; inmersión en etanol al 70 \% durante quince segundos; inmersión en hipoclorito de sodio $(\mathrm{NaOCl}, 0.058 \% \mathrm{v} / \mathrm{v})$ durante quince minutos $\mathrm{y}$, finalmente, tres enjuagues, de dos minutos cada uno, con agua destilada estéril. Las semillas asépticas se cultivaron durante veinte días en frascos de vidrio de $200 \mathrm{ml}$., con alícuotas de $15 \mathrm{ml}$. de medio sin reguladores de crecimiento, cinco semillas por frasco.

A partir de yemas axilares adultas. Las estacas de 5-8 cm. de longitud con yemas vegetativas cerradas, se dividieron en segmentos nodales y para la desinfestación superficial se aplicó el siguiente procedimiento: un enjuague con agua destilada más Tween 20 (0.1 ml./100 ml.) ( $/ \mathrm{v})$ durante cinco minutos en agitación constante; inmersión en etanol al 70 \% durante 30 segundos; inmersión en $\mathrm{NaOCl}(0.066 \% \mathrm{v} / \mathrm{V})$ durante quince o treinta minutos $y$, finalmente, tres enjuagues consecutivos con agua destilada estéril. Posteriormente, en cámara de flujo laminar, de las yemas de cada segmento nodal se eliminaron las hojas en desarrollo y se escindió el meristemo acompañado de dos primordios foliares. Los meristemos se cultivaron durante 90 días en frascos de vidrio de 7 $\mathrm{ml}$. que contenían alícuotas de $3 \mathrm{ml}$. de medio suplementado con $0.2 \mathrm{mg} \cdot \mathrm{L}^{-1}$ de $B A\left(\mathrm{~N}^{6}\right.$ - Benciladenina) y $0.05 \mathrm{mg} \cdot \mathrm{L}^{-1}$ de $A \mathrm{AlB}$ (Ácido 3-indolbutírico), un meristemo por frasco. En total se cultivaron treinta meristemos y el ensayo se repitió dos veces consecutivas.

Durante esta etapa se evaluó la efectividad de los procesos de asepsia superficial, el porcentaje de germinación de semillas y la reactivación in vitro de la actividad meristemática. 


\section{Etapa 2. Propagación}

A partir de plántulas. Después de treinta días de cultivo, a las plántulas desarrolladas a partir de semillas se les eliminó la raíz, se fragmentaron en segmentos nodales, y se cultivaron en frascos de vidrio de $250 \mathrm{ml}$., con alícuotas de $15 \mathrm{ml}$. de medio con diferentes concentraciones de reguladores (Tabla 1). Las concentraciones y los reguladores de crecimiento se eligieron de acuerdo con la información registrada por Chaves y otros [5] y Díaz y otros [16]. En cada tratamiento se cultivaron 25 segmentos nodales, cinco explantes por frasco. Los cultivos se mantuvieron en cuarto de incubación y se efectuaron dos ciclos de proliferación, de treinta días cada uno.

Tabla 1. Reguladores de crecimiento adicionados al medio de cultivo ensayado para proliferación de microtallos de uchuva, a través de segmentos nodales, procedentes de plántulas obtenidas de semillas germinadas.

\begin{tabular}{cc}
\hline \hline $\begin{array}{c}\text { REGULADORES DE } \\
\text { CRECIMIENTO }\end{array}$ & $\begin{array}{c}\text { CONCENTRACIÓN } \\
\left(\mathbf{m g} \cdot \mathbf{L}^{-1}\right)\end{array}$ \\
\hline BA & 0.2 \\
BA & 0.1 \\
AIB & 0.1 \\
AIB & 0.05 \\
BA + AIB & $0.1+0.05$ \\
\hline \hline
\end{tabular}

A partir de yemas axilares adultas. De manera semejante a las plántulas, los microtallos desarrollados a partir de meristemos se dividieron en segmentos nodales y se cultivaron en medio con $0.1 \mathrm{mg} \cdot \mathrm{L}^{-1}$ de $B A$ más $0.05 \mathrm{mg} \cdot \mathrm{L}^{-1}$ de AIB, tratamiento del ensayo anterior en el cual se obtuvieron entrenudos más cortos con mayor cantidad de yemas neoformadas. El primer ciclo de proliferación se inició con treinta segmentos nodales y los microtallos obtenidos se multiplicaron durante tres ciclos consecutivos, (treinta días cada ciclo). En esta etapa, al final de cada ciclo se evaluó: la longitud de microtallos desarrollados, número de yemas neoformadas y el efecto de la concentración de los reguladores sobre la tasa de multiplicación. La tasa de multiplicación se calculó aplicando la siguiente fórmula:

Tasa de multiplicación $=$ No. ápices + No. segmentos nodales No. segmentos nodales iniciales 


\section{Etapa 3. Enraizamiento}

Microtallos de 3 a $5 \mathrm{~cm}$. de longitud (procedentes de cultivos establecidos a partir de semilla y de yemas axilares adultas) se cultivaron durante veinte días en medio con 0.05 ; 0.1 y $2.5 \mathrm{mg} \cdot \mathrm{L}^{-1}$ de AIB y sin reguladores. En cada tratamiento se cultivaron treinta microtallos y cada tratamiento se repitió dos veces.

Al final de esta etapa se cuantificó el porcentaje de microtallos enraizados en cada tratamiento.

\section{Etapa 4. Endurecimiento}

Las plántulas obtenidas in vitro se removieron de los frascos, las raíces se enjuagaron con agua corriente y se transfirieron a un sustrato compuesto de tierra, arena y cascarilla, en proporción $3: 1: 2$, y se mantuvieron en invernadero (75-85 \% de humedad relativa, temperatura media diurna $18{ }^{\circ} \mathrm{C}$ y nocturna $12{ }^{\circ} \mathrm{C}$ ) con riego por nebulización doce segundos cada seis horas durante dos semanas; posteriormente, durante dos a tres semanas, se redujo gradualmente el riego (seis segundos cada 24 horas). El tipo de sustrato y las condiciones de endurecimiento se eligieron de acuerdo con ensayos previos realizados por el grupo de investigación, en los cuales se cuantificó un $92 \%$ de plántulas viables que reactivaron su crecimiento. En esta etapa se cuantificó el número de plántulas viables que reactivaron su crecimiento y desarrollo después de cinco semanas de aclimatación.

\section{Análisis estadístico}

El diseño fue totalmente aleatorizado, se hizo análisis de varianza (Anova) unifactorial, con un nivel de confiabilidad del $95 \%$. Para los factores que resultaron estadísticamente significativos se realizó la prueba Tukey de Diferencia Honestamente Significativa (DHS). Los datos fueron procesados con el paquete estadístico StatGraphic versión 4.0 . 


\section{Resultados y discusión}

\section{Etapa 1. Establecimiento in vitro de cultivos}

La aplicación de un proceso de asepsia superficial adecuado es crítico para mantener la viabilidad y facilitar la reactivación del crecimiento y desarrollo del explante. Mroginski y Roca, [22] indican que evitar la contaminación con microorganismos es un aspecto básico que se debe tener en cuenta para el éxito, tanto en el establecimiento de los cultivos, como en su posterior incubación y manipulación. Así mismo, Chaves y otros [5] establecen que la utilización de diferentes agentes germicidas es fundamental para reducir la contaminación de explantes durante el establecimiento in vitro.

A partir de semilla sexual. El proceso de asepsia superficial aplicado permitió obtener $100 \%$ de semillas asépticas. El medio de cultivo favoreció la viabilidad de las semillas y el desarrollo de plántulas, cuantificándose $100 \%$ de semillas germinadas. Estos resultados concuerdan con los obtenidos por Putalun y otros [23], y Contreras y Almeida [24], en medio libre de reguladores en estudios de germinación de semillas de Physalis minima L. y Physalis ixocarpa L., respectivamente. Sin embargo, contrastan con los resultados de Rodríguez [15], quien reporta altos porcentajes de germinación (80 $\%$ a $99 \%$, dependiendo del ecotipo) cultivando semillas en MS con 1 $m g \cdot L^{-1}$ de AIA más $1 \mathrm{mg} \cdot \mathrm{L}^{-1}$ de AIB, y con Torres y otros [10], quienes utilizaron $M S$ con $1 \mathrm{mg} \cdot \mathrm{L}^{-1}$ de AIA, para inducir altos porcentajes de germinación. Los altos porcentajes de germinación que presentan las semillas de esta especie indican, según Rodríguez [15], una alta eficiencia biológica de la especie, una buena polinización y ausencia de baja fertilidad por hibridación o introgresión genética y, según Chaves y otros [5], un alto poder germinativo de la especie.

Durante el periodo de germinación se observó en las semillas de uchuva emergencia de radícula después de catorce días de cultivo y desarrollo de plántulas con tres a cuatro entrenudos después de 25 a 30 días de cultivo en medio MS sin reguladores de crecimiento; datos similares fueron registrados por Rodríguez [15], quien observó inicio del proceso de germinación después de ocho días de cultivo, aunque en medio MS con AIA y AIB. Esto indica que el tiempo y el porcentaje 
de germinación de las semillas de uchuva están relacionados con la presencia de reguladores de crecimiento en el medio de cultivo, evidenciándose un efecto positivo del AIA y AIB en la inducción e inicio de la germinación, pero un efecto negativo en el porcentaje de germinación. Sin embargo, se debe tener en cuenta, según Matilla [25], que las características de la semilla, como el tamaño, el contenido de los sustratos hidratables, permeabilidad de la cubierta seminal y toma de $\mathrm{CO}_{2}$, entre otros, juegan un papel importante en la duración de las fases de germinación de las semillas.

A partir de yemas axilares adultas. Cuando los explantes primarios proceden de plantas adultas, el establecimiento de cultivos y la proliferación in vitro de microtallos son etapas difíciles de realizar, debido principalmente al alto grado de contaminación exógena y endógena que presentan los explantes [26] y la escasa reactividad in vitro de los tejidos tomados de plantas adultas de campo [27]. En este trabajo, para desinfectar los segmentos nodales tomados de plantas adultas de campo, la inmersión en $\mathrm{NaOCl}$ al $0.066 \%$ $(\mathrm{V} / \mathrm{v})$ durante treinta minutos fue más efectiva $(73 \%$ de explantes asépticos) que la misma inmersión durante quince minutos (37\% de explantes asépticos). En los cultivos se observó que la reactivación del crecimiento de los explantes asépticos es un proceso lento que requiere entre sesenta y noventa días de cultivo, con subcultivos a medio fresco cada treinta días (Figuras $1 A$ y $B$ ).

\section{Etapa 2. Propagación}

Procedentes de plántulas desarrolladas de semillas germinadas. En los cultivos de segmentos nodales procedentes de plántulas desarrolladas de semillas germinadas (Figura 1C), los valores medios más elevados de longitud de microtallos desarrollados, 8.6; 8.4 y 8.2 $\mathrm{cm}$., así como de yemas neoformadas, 4.3, 4.5 y 3.9, se cuantificaron en segmentos nodales cultivados en MS con 0.1 , o con $0.05 \mathrm{mg} \cdot \mathrm{L}^{-}$ 1 de AIB y en MS sin reguladores de crecimiento, respectivamente (Tabla 2, Figura 1D). Estos resultados contrastan con los obtenidos por Torres y otros [10], quienes cuantificaron un mayor número de yemas axilares desarrolladas utilizando MS suplementado con 5 $m g \cdot L^{-1}$ de $B A$ y con los obtenidos por Chaves y otros [5] utilizando MS con $0.3 \mathrm{mg} \cdot \mathrm{L}^{-1}$ de $B A$. 
Respecto al desarrollo de yemas apicales y axilares, en este trabajo se observó que las yemas apicales se desarrollan en un periodo de tiempo más corto que las yemas axilares. En MS suplementado con $0.1 \mathrm{mg} \cdot \mathrm{L}^{-1}$ de BA más $0.05 \mathrm{mg} \cdot \mathrm{L}^{-1}$ de AIB (T5, Tabla 2), la tasa de multiplicación fue 3.7 con longitud media de microtallos de $2.7 \mathrm{~cm}$, observándose que en presencia de estos reguladores cada microtallo produjo mayor cantidad de yemas neoformadas debido a que los entrenudos fueron más cortos. Datos similares, mayor número de yemas en menor longitud de los microtallos, fueron reportados por Chaves y otros [5], quienes verificaron que para Physalis peruviana concentraciones elevadas de BA aumentan la tasa de proliferación y promueven el acortamiento de los entrenudos, en MS con $0.3 \mathrm{mg} \cdot \mathrm{L}^{-}$ 1 de BA obtuvieron 7.69 yemas, en brotes de $1.73 \mathrm{~cm}$ de longitud; mientras que en MS sin reguladores de crecimiento obtuvieron 5.42 yemas, en brotes de $6.06 \mathrm{~cm}$ de longitud. Estas observaciones confirman lo reportado por Chaves y otros [5], en cuanto a que altas concentraciones de citoquininas, en este caso el BA, inhiben la elongación de los brotes.

A.

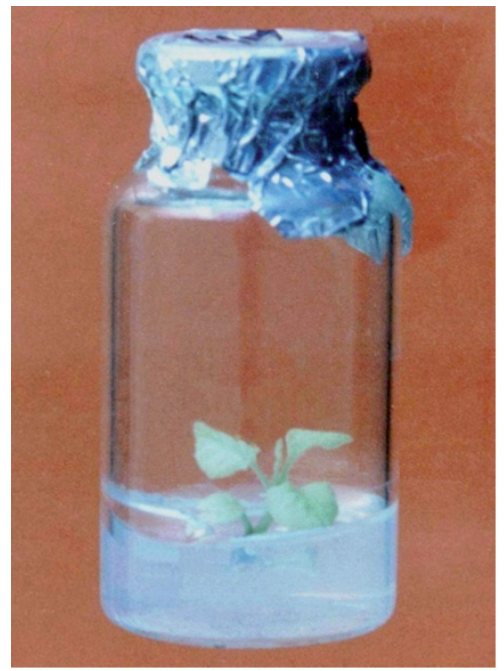

B.

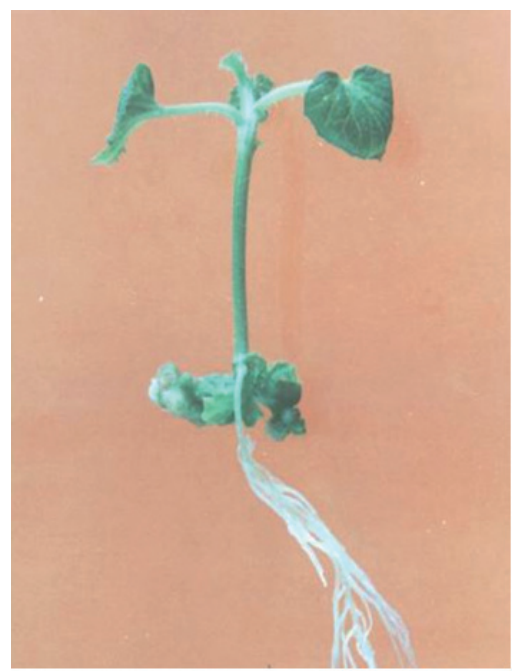


El análisis de varianza realizado para los datos de yemas neoformadas y longitud de microtallos desarrollados con respecto al regulador utilizado en el medio de cultivo, mostró diferencias estadísticamente significativas. La prueba de rango múltiple para la variable yemas neoformadas, corroboró la existencia de diferencias estadísticamente significativas entre los tratamientos, y mostró que al cultivar segmentos nodales en medio suplementado con $0.05 \mathrm{mg} \cdot \mathrm{L}^{-}$ 1 de AIB (T4) y $0.1 \mathrm{mg} \cdot \mathrm{L}^{-1}$ de AIB (T3, Tabla 2 ), se obtiene la mayor cantidad de yemas neoformadas. Además, para la variable longitud de microtallos desarrollados, demostró que el tratamiento T3 (0.1 $\mathrm{mg} \cdot \mathrm{L}^{-1}$ de AIB) y el T6 (sin reguladores), son los que más facilitan el crecimiento y desarrollo de los microtallos. Rache y Pacheco [27] indicaron que una apropiada combinación de auxina con citoquinina favorece una adecuada elongación y un aumento del número de brotes desarrollados en E. muiska; a su vez, Sotolongo y otros [28] sugieren la utilización de auxinas con el fin de superar y reducir los efectos residuales de las citoquininas favoreciendo la elongación de los brotes.

Tabla 2. Efecto de BA y AIB sobre la proliferación in vitro de uchuva a través de segmentos nodales procedentes de microtallos desarrollados a partir de plántulas obtenidas de semillas germinadas.

\begin{tabular}{cccccc}
\hline \hline Tto & $\begin{array}{c}\text { Reguladores } \\
\text { de } \\
\text { crecimiento }\end{array}$ & $\begin{array}{c}\text { Concentración } \\
\left(\mathrm{mg} \cdot \mathrm{L}^{-1}\right)\end{array}$ & $\begin{array}{c}\text { Long. } \overline{\mathrm{X}} \mathrm{cm} \\
\text { microtallos }\end{array}$ & \multicolumn{2}{c}{$\begin{array}{c}\text { Yemas axilares } \\
\text { neoformadas }\end{array}$} \\
\hline T1 & BA & 0.2 & $2.4 \pm 0.5 \mathrm{a}$ & 58 & $2.4 \pm 1.3^{\mathrm{a}}$ \\
T2 & BA & 0.1 & $2.7 \pm 1.7 \mathrm{a}$ & 70 & $2.9 \pm 1.3 \mathrm{ab}$ \\
T3 & AIB & 0.1 & $8.6 \pm 0.7 \mathrm{~b}$ & 103 & $4.3 \pm 0.8 \mathrm{c}$ \\
T4 & AlB & 0.05 & $8.4 \pm 2.0 \mathrm{~b}$ & 109 & $4.5 \pm 1.2 \mathrm{c}$ \\
T5 & BA + AIB & $0.1+0.05$ & $2.7 \pm 1.4 \mathrm{a}$ & 88 & $3.7 \pm 1.0 \mathrm{bc}$ \\
T6 & S.R. & S.R. & $8.2 \pm 2.1 \mathrm{~b}$ & 94 & $3.9 \pm 1.1 \mathrm{c}$ \\
\hline \hline
\end{tabular}

Tto: tratamiento; S.R.: $\sin$ reguladores. Promedios con una misma letra no difieren estadísticamente, según prueba Tukey $(P=0.05)$.

Procedentes de yemas axilares adultas. Para establecer y multiplicar los segmentos nodales provenientes de meristemos, se utilizó MS con $0.1 \mathrm{mg} \cdot \mathrm{L}^{-1}$ de BA más $0.05 \mathrm{mg} \cdot \mathrm{L}^{-1}$ de AIB (T5), debido a 
que en este tratamiento los microtallos presentaron entrenudos más cortos con mayor cantidad de yemas neoformadas, características útiles para establecer ciclos de micropropagación.

La tasa de multiplicación en tres ciclos de propagación de segmentos nodales provenientes de cultivo de meristemos osciló entre 4.7 y 5.1 (Figura 2), observándose un aumento progresivo de la tasa a medida que transcurrieron los ciclos de proliferación.

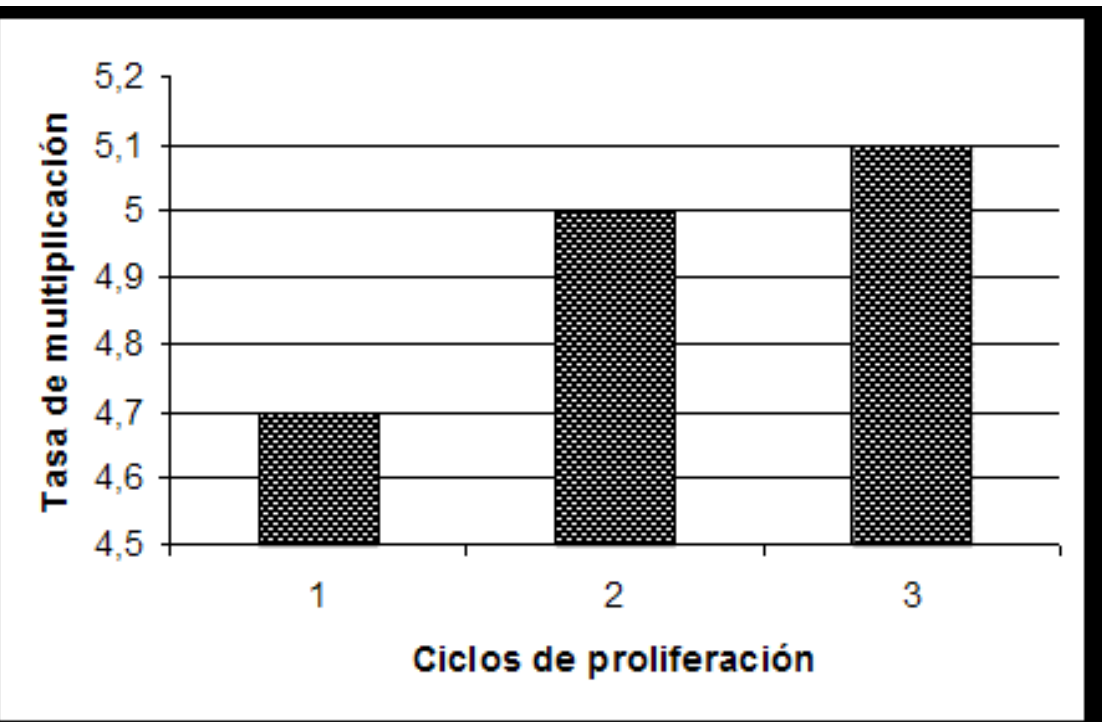

Figura 2. Tasa de multiplicación de microtallos provenientes de meristemos tomados de yemas axilares de plantas adultas. Datos obtenidos durante tres ciclos consecutivos de proliferación.

\section{Etapa 3. Enraizamiento}

En los cultivos de microtallos en MS sin reguladores de crecimiento y en MS con las concentraciones más bajas de AIB $\left(0.05\right.$ y $0.1 \mathrm{mg} \cdot \mathrm{L}^{-}$ 1), se cuantificó $100 \%$ de enraizamiento; mientras que al aumentar la concentración de AIB a $2.5 \mathrm{mg} \cdot \mathrm{L}^{-1}$, el porcentaje de microtallos enraizados disminuyó a $82 \%$ (tabla 3, Figura 1E). Resultados similares fueron obtenidos por Contreras y Almeida [24] en ensayos de enraizamiento de microtallos de Physalis ixocarpa $L$. en medio libre de reguladores. Estos resultados indican que es posible suprimir 
el uso de auxinas para inducir rizogénesis en Physalis peruviana. Probablemente el haber utilizado AIB en el medio de cultivo durante los tres ciclos de proliferación, favoreció el enraizamiento de los microtallos en MS sin reguladores de crecimiento.

Tabla 3. Efecto del AIB sobre el enraizamiento de microtallos de uchuva

\begin{tabular}{ccc}
\hline \hline $\begin{array}{c}\text { REGULADORES DE } \\
\text { CRECIMIENTO }\end{array}$ & $\begin{array}{c}\text { CONCENTRACIÓN } \\
\left(\mathbf{m g} \cdot \mathbf{L}^{-1}\right)\end{array}$ & $\begin{array}{c}\text { ENRAIZAMIENTO } \\
(\%)\end{array}$ \\
\hline \multirow{2}{*}{ AIB } & 0.05 & 100 \\
& 0.1 & 100 \\
& 2.5 & 82 \\
CONTROL & - & 100 \\
\hline \hline
\end{tabular}

\section{Etapa 4. Endurecimiento}

En las condiciones ensayadas, se cuantificó $95 \%$ de plántulas aclimatadas que reactivaron su crecimiento después de 35 días; por tanto, es evidente que el sustrato y las demás condiciones ensayadas favorecieron el desarrollo del sistema radicular de las plántulas regeneradas in vitro así como su endurecimiento (Figura 1F). López $y$ otros [17] utilizaron sustratos compuestos por arena, arena: suelo: cascarilla de arroz, y demostraron que fueron los mejores sustratos para enraizamiento de esquejes de uchuva debido a que los suelos con texturas franco-arenosas permiten el óptimo desarrollo de este cultivo y facilitan la velocidad de crecimiento y la expansión de las raíces. Por otra parte, Díaz y otros [16] utilizaron sustrato compuesto de arena y cascarilla de arroz en proporciones 2:1. Respectivamente, y obtuvieron $92 \%$ de plántulas viables que sobrevivieron a la aclimatación.

\section{Conclusiones}

Se estableció un protocolo de micropropagación de Physalis peruviana L. a partir de yemas axilares tomadas de plantas adultas, que permite la producción masiva de plántulas con características deseables en la producción. 
El protocolo de micropropagación de Physalis peruviana L. comprende: establecimiento de cultivos en MS sin reguladores de crecimiento durante treinta días y subcultivo en MS con $0.05 \mathrm{mg} \cdot \mathrm{L}^{-1}$ de AIB más $0.1 \mathrm{mg} \cdot \mathrm{L}^{-1}$ de $B A$, durante sesenta días; multiplicación a partir de segmentos nodales cultivados en MS con $0.05 \mathrm{mg} \cdot \mathrm{L}^{-1} \mathrm{de}$ AIB más $0.1 \mathrm{mg} \cdot \mathrm{L}^{-1}$ de $B A$; enraizamiento de microtallos en $\mathrm{MS}$ sin reguladores de crecimiento y aclimatación de plántulas en condiciones controladas utilizando como sustrato tierra, arena y cascarilla de arroz en proporción 3:1:2.

\section{Agradecimientos}

Los autores de este trabajo agradecen a la Dirección de Investigaciones - DIN — de la Universidad Pedagógica y Tecnológica de Colombia, por el apoyo financiero, y a los integrantes del Grupo de Investigación BIOPLASMA-UPTC, por su continua colaboración.

\section{Referencias}

[1] M. García, Uchuva, cosecha y postcosecha, Corpoica, Litopapeles Ochoa Ltda. Mosquera, Colombia, 2003.

[2] G. Fischer, "Crecimiento y desarrollo", en Producción, poscosecha y explotación de la Uchuva (Physalis peruviana L.), V. Flórez, G. Fischer \& A. Sora, Ed. Unibiblos, Universidad Nacional de Colombia: Bogotá, 2000, pp. 9-25.

[3] C. Zárate \& R. Polanía, "Análisis fitoquímico de Physalis peruviana". Trabajo de grado, Facultad de Ciencias, Departamento de Química, Universidad Nacional de Colombia, Bogotá, 1974.

[4] S. Ahmad \& A. Malik, "Withanolides from Physalis peruviana in phytochemistry", Oxford International Centre of Chemistry Science, Research Institute of Chemistry, University Karachi-Pakistan, vol. 50, no. 4, pp. 647-651, 1999.

[5] A. Chaves, M. Schuch \& A. Erig, "Estabelecimento e multiplicação in vitro de Physalis peruviana L.", Ciênc. Agrotec., Lavras, vol. 29, No. 6, pp. $1281-1287,2005$.

[6] A. Sandhu, S. Sing, P. Minhas \& G. Grewal, "Rhizogenesis of shoot cuttings of raspberry (Physalis peruviana L.)", J. Hort., vol. 46, no. 3, pp. 376-378, 1989. 
[7] G. Fisher \& P. Almanza. "Nuevas tecnologías en el cultivo de la uchuva Physalis peruviana L.", Rev. Agrod, vol. 4, no. 1-2, pp. 294, 1993.

[8] M. Zenkteler, "In vitro formation of plants from leaves of several species of the Solanaceae family", Biochem Physiol. pp. 509-512, 1972.

[9] G. Santana \& A. Angarita, "Regeneración adventicia de somaclones de Uchuva (Physalis peruviana)", Agron. Colomb, vol. 14, no. 1, pp. 59-65, 1997.

[10] O. Torres, M. Perea, A. López, A. Salamanca \& J. Mikan, "The use of Physalis peruviana tissue culture for breeding and selection", In Solanaceae III: Taxonomy, chemistry, evolution, Hawkes, Laster, Need \& Estrada, ed., Londres, 1991.

[11] R. Raghava \& Y. Murty, "Effect of growth regulators on seed germination and seedling growth of Physalis peruviana L. Comp.", Physiol. Ecol, vol. 12, no. 1, pp. 41-48, 1987.

[12] R. Raghava \& Y. Murty, "Effects of growth substances and gamma rays on stomata and epidermal cell of Physalis L.", Geobios, vol. 16, pp. 216264, 1988.

[13] R. Raghava \& N. Raghava, "Modification of seedling growth of husk tomato by seed-applied plant growth regulators and gamma rays", Geobios, vol. 20, pp. 21-26, 1993.

[14] W. Wenzel, "A cytological study of colchiploid cape gooseberry (Physalis peruviana L.)", Agroplantae, vol. 5, pp. 79-84, 1973.

[15] N. Rodríguez. Estudio citogenético en Physalis peruviana L.: "Uchuva" (Solanaceae). Trabajo de grado, Universidad Nacional de Colombia, Facultad de Ciencias, Departamento de Biología, Bogotá, 2004.

[16] D. Díaz, D. González, L. Rache \& J. Pacheco; "Efecto citogenético de la colchicina sobre yemas vegetativas de Physalis peruviana L.", Prospec. Cient., $n^{\circ}$ 4. pp. 27-40, 2008.

[17] F. López, N. Guío, G. Fischer \& D. Mirando, "Propagación de uchuva (Physalis peruviana L.) mediante diferentes tipos de esquejes y sustratos", Rev. Fac. Nal. Agr. Medellín, vol. 61, no. 1, pp. 4347-4357, 2008.

[18] N. Moreno, J. Álvarez, H. Balaguera \& G. Fischer, "Propagación asexual de uchuva (Physalis peruviana L.) en diferentes sustratos y a distintos niveles de auxina", Agron. Colomb, vol. 27, no. 3, pp. 341-348, 2009. 
[19] D. Miranda, "Criterios para el establecimiento, los sistemas de cultivo, el tutorado y la poda de la uchuva", en Avances en cultivo, poscosecha y exportación de la uchuva (Physalis peruviana L.) en Colombia, G. Fischer, D. Miranda, W. Piedrahita \& J. Romero, Ed. Unibiblos, Universidad Nacional de Colombia: Bogotá, 2005, pp. 29-54.

[20] J. Bernal, La Uchuva (Physalis peruviana L.), historia, taxonomía y biología. Memorias Primer Curso Nacional de Uchuva, Tunja, 1986.

[21] T. Murashige \& F. Skoog, "A revised medium for rapid growth and bioassay with tobacco tissue culture", Physiol. Plant, vol. 15, pp. 473479, 1962.

[22] L. Mroginski \& W. Roca, "Capítulo 2: Establecimiento de cultivos de tejidos vegetales in vitro", en Cultivo de tejidos en la agricultura, W. Roca \& L. Mroginski, Ed. Centro Internacional de Agricultura Tropical: Cali, Colombia, 1991, pp. 969.

[23] W. Putalun, P. Prasarnsiwamai, H. Tanaka \& Y. Shoyama, "Solasodine glycoside production by hairy root cultures of Physalis minima Linn", Biotechnol Lett, vol. 26, pp. 545-548, 2004.

[24] I. Contreras \& J. Almeida, "Micropropagación del tomatillo (Physalis ixocarpa L.)", Rev. Fac. Farma., vol. 45, no. 1, pp. 61-64, 2003.

[25] A. Matilla, "Desarrollo y germinación de las semillas", en Fundamentos de fisiología vegetal, J. Azcón-Bieto \& M. Talón. Ed. McGraw-Hill Interamericana: Madrid, 2008, pp. 537-558.

[26] B. Reed \& E. Abdelnour, "The use of zeatin to initiate in vitro cultures of Vaccinium species and cultivars", Hort. Sci., vol. 26, pp. 1320-1322, 1991.

[27] L. Rache \& J. Pacheco, "Micropropagación de Espeletiopsis muiska (Cuatrecasas), frailejón del Parque Natural La Ranchería-Boyacá, Colombia”, Agron. Colomb, vol. 27, no. 3, pp. 349-358. 2009.

[28] S. Sotolongo, M. García, L. Junco, G. Geada \& E. García, "Micropropagación de Psidium salutare (Myrtaceae)", Rev. Jard. Bot. Nac., vol. 24, no. 1-2, pp. 245-250, 2003. 
बाENGIA ED

DESARBRLLL

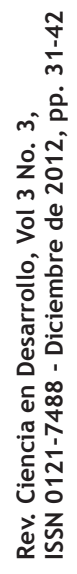

56 


\title{
EFECTO DE LAS CONDICIONES DE SÍNTESIS EN MEDIO ACUOSO PARA LA OBTENCIÓN DE ÓXIDOS POLICATIÓNICOS
}

\section{EFFECT OF THE SYNTHESIS CONDITIONS IN AQUEOUS ENVIRONMENT FOR OBTAINING POLYCATIONIC OXIDES}

\author{
J. A. Gómez-Cuaspud ${ }^{1 *}$ \\ J. S. Valencia-Ríos ${ }^{2 * *}$ \\ M. Schmal ${ }^{3 * * *}$
}

\section{Resumen}

En este trabajo se obtuvieron dos óxidos tipo perovskita basados en el sistema $\mathrm{La}_{0.75} \mathrm{Sr}_{0.25} \mathrm{Co}_{0.5} \mathrm{Fe}_{0.5} \mathrm{O}_{3}$, mediante el uso de ácido cítrico y propiónico, a fin de evaluar el potencial de cada especie para formar compuestos de coordinación y su efecto en la producción de los óxidos cerámicos finales. Los resultados del modelamiento para establecer y controlar las principales especies químicas en solución acuosa en función del pH, confirmaron que este parámetro es crucial para establecer las condiciones ideales de homogeneidad. Los análisis de difracción de rayos $X$, confirman la obtención de materiales con tamaños de cristalito diferentes, de $10.0 \mathrm{~nm}$ para el caso de la muestra conseguida con ácido cítrico y de $42.0 \mathrm{~nm}$ para

$1{ }^{*}$ Federal University of Rio de Janeiro, Chemical Engineering Program, NUCAT/PEQ/COPPE, Centro de Tecnologia, Bl. G 128, C.P. 68502, CEP 21941-914 Rio de Janeiro, Brazil. Autor de correspondecia: jagomezcua@unal.edu.co

2 ** Universidad Nacional de Colombia, Departamento de Química, Centro de Catálisis Heterogénea, Ciudad Universitaria, Bogotá, Colombia.

$3^{* * *}$ Federal University of Rio de Janeiro, Chemical Engineering Program, NUCAT/ PEQ/COPPE, Centro de Tecnologia, BI. G 128, C.P. 68502, CEP 21941-914 Rio de Janeiro, Brazil. 
la muestra con ácido propiónico. El refinamiento de los resultados de difracción y la búsqueda en las bases de datos de la ICSD, permitieron identificar la fase cristalina con un alto grado de homogeneidad y pureza en ambos casos. Los resultados de microscopía electrónica de barrido y de microanálisis por EDS, mostraron algunas similitudes a nivel superficial y textural entre los dos métodos de obtención, principalmente relacionadas con el tamaño de cristal y con el grado de densificación de los óxidos.

Palabras clave: Citrato, propionato, perovskitas

\section{Abstract}

In this work were obtained two oxides, perovskite type, based on $\mathrm{La}_{0.75} \mathrm{Sr}_{0.25} \mathrm{Co}_{0.5} \mathrm{Fe}_{0.5} \mathrm{O}_{3}$ system, through the use of citric and propionic acid, in order to assess the potential of each species to form and establish several coordination compounds and their effect in the obtention of ceramic oxides. The results of modeling to establish and control the main chemical species in aqueous solution depending on $\mathrm{pH}$, confirmed that this parameter is crucial to establish an ideal condition of homogeneity. X-ray diffraction analyses confirm the obtention of materials with different crystallite sizes of $10.0 \mathrm{~nm}$ in the case of the sample obtained by polymerization with citric acid, and $42.0 \mathrm{~nm}$ for the sample obtained with propionic acid. Refinement of X-ray results and the search in the ICSD databases allowed us the identification of the desired crystalline phase with a high degree of homogeneity and purity in both cases. The results of scanning electron microscopy (SEM) and EDS microanalysis, showed some similarities at textural and surface level between the two synthesis methods, primarily related with the crystal size and the degree of densification of the oxides.

Keywords: Citrate, propionate, perovskites. 


\section{Introducción}

Los óxidos policatiónicos tipo perovskita $\left(\mathrm{ABO}_{3}\right)$, exhiben una amplia variedad de propiedades de interés tecnológico, en la medida en que se trata de sistemas que permiten la combinación de diferentes tipos de precursores, al igual que múltiples estados de oxidación, así como técnicas de síntesis con la posibilidad de formar materiales complejos y estables, característica de relevancia en algunas aplicaciones catalíticas [1]. Si bien es cierto, hasta el momento, las principales rutas de síntesis de este tipo de materiales han sido las técnicas basadas en reacciones de estado sólido, que han permitido la obtención de fases cristalinas puras y definidas, estas suponen altos costos energéticos, toda vez que requieren altas temperaturas de síntesis, las cuales en su mayoría no son fácilmente alcanzables si se desea escalar el proceso a nivel industrial [2], [3]. Adicionalmente, las rutas de estado sólido producen claros efectos de sinterización y densificación, lo cual afecta de forma drástica algunas características superficiales como el área y la morfología específica, entre otras, que pueden reducir la aplicabilidad catalítica del material [4], [5]. En este sentido, numerosas investigaciones han evidenciado las ventajas y la flexibilidad en el uso de rutas de síntesis de química suave, que involucran la formación de compuestos de coordinación entre iones metálicos y determinados agentes complejantes, dentro de una amplia gama de ligandos $\square$, que no solo permiten conservar la mayoría de propiedades cataliticas asociadas al material, sino que incluso han facilitado disminuir los costos asociados al proceso de síntesis y diseñar una amplia serie de materiales a escala nanométrica [5-8]. De esta forma, en el presente trabajo se pretende explorar el efecto del $\mathrm{pH}$ y del tipo de ligando en la síntesis del sistema $\mathrm{La}_{0.75} \mathrm{Sr}_{0.25} \mathrm{Co}_{0.5} \mathrm{Fe}_{0.5} \mathrm{O}_{3-\delta}$ mediante un método que involucra la formación de compuestos de coordinación y posterior polimerización de los mismos con etilenglicol, para establecer su efecto en algunas propiedades estructurales y de textura del sólido obtenido.

\section{Parte experimental}

Para la síntesis del óxido policatiónico de $\mathrm{La}_{0.75} \mathrm{Sr}_{0.25} \mathrm{Co}_{0.5} \mathrm{Fe}_{0.5} \mathrm{O}_{3}$, se emplearon los correspondientes nitratos de los cationes de lantano, estroncio, cobalto y hierro en disoluciones $1.00 \mathrm{M}$ debidamente estandarizadas, con el fin de asegurar el control estequiométrico de 
las reacciones. De igual forma, se partió de disoluciones de ácido cítrico y propiónico, ajustándolas a una concentración final $2.00 \mathrm{M}$, según lo establecido por Gómez-Cuaspud [9].

Las diferentes soluciones precursoras de los iones metálicos se dosificaron en un reactor de vidrio, con agitación magnética constante a $150 \mathrm{rpm}$ y se permitió un reflujo a $80^{\circ} \mathrm{C}$, durante ocho horas. El orden de adición de los precursores, se estableció por sus constantes de hidrólisis así: Sr, La, Fe y Co; de esta forma, la cantidad total de iones en disolución fue 0.01 moles, a partir de las cuales se realizaron los diferentes ajustes para las posteriores adiciones de ácido carboxílico y etilenglicol. Después de diez minutos de agitación de la mezcla de iones, se procedió a adicionar las disoluciones de ácido en cada caso, en una proporción 2:1, con respecto a la cantidad total de cationes y se permitió la continuación del reflujo por treinta minutos más; posteriormente se agregó etilenglicol en una proporción 4:1, con respecto a la cantidad de ácido carboxílico añadido en cada caso. Luego se ajustó el pH con una disolución concentrada de amoníaco (25 $\%)$, para favorecer un medio homogéneo de reacción. En todos los casos, el reflujo se mantuvo por un periodo de ocho horas, después del cual, las mezclas fueron sometidas a un tratamiento térmico a $120^{\circ} \mathrm{C}$ por 24 horas, para obtener los correspondientes precursores metalorgánicos, los cuales se recogieron y se molturaron, para su posterior calcinación [10].

La calcinación de los sólidos se hizo en crisoles de platino a 800 ${ }^{\circ} \mathrm{C}$, empleando una rampa de $10^{\circ} \mathrm{C} / \mathrm{min}$. Una vez alcanzada la temperatura final, se permitió el tratamiento térmico por dos horas para obtener los correspondientes agregados cerámicos, que se molturaron nuevamente y tamizaron a malla 200 US, para realizar los correspondientes análisis de caracterización fisicoquímica.

\section{Resultados}

El proceso de síntesis de los precursores carboxílicos de $\mathrm{La}_{0.75} \mathrm{Sr}_{0.25} \mathrm{Fe}_{0.5} \mathrm{Co}_{0.5} \mathrm{O}_{3}$ con ácido cítrico y propiónico, mostró que la homogeneidad de los sistemas en medio acuoso es fuertemente dependiente del $\mathrm{pH}$, como lo indican los diagramas de distribución de especies de la Figura 1 y los resultados experimentales obtenidos en el caso de la muestra obtenida con ácido propiónico. 

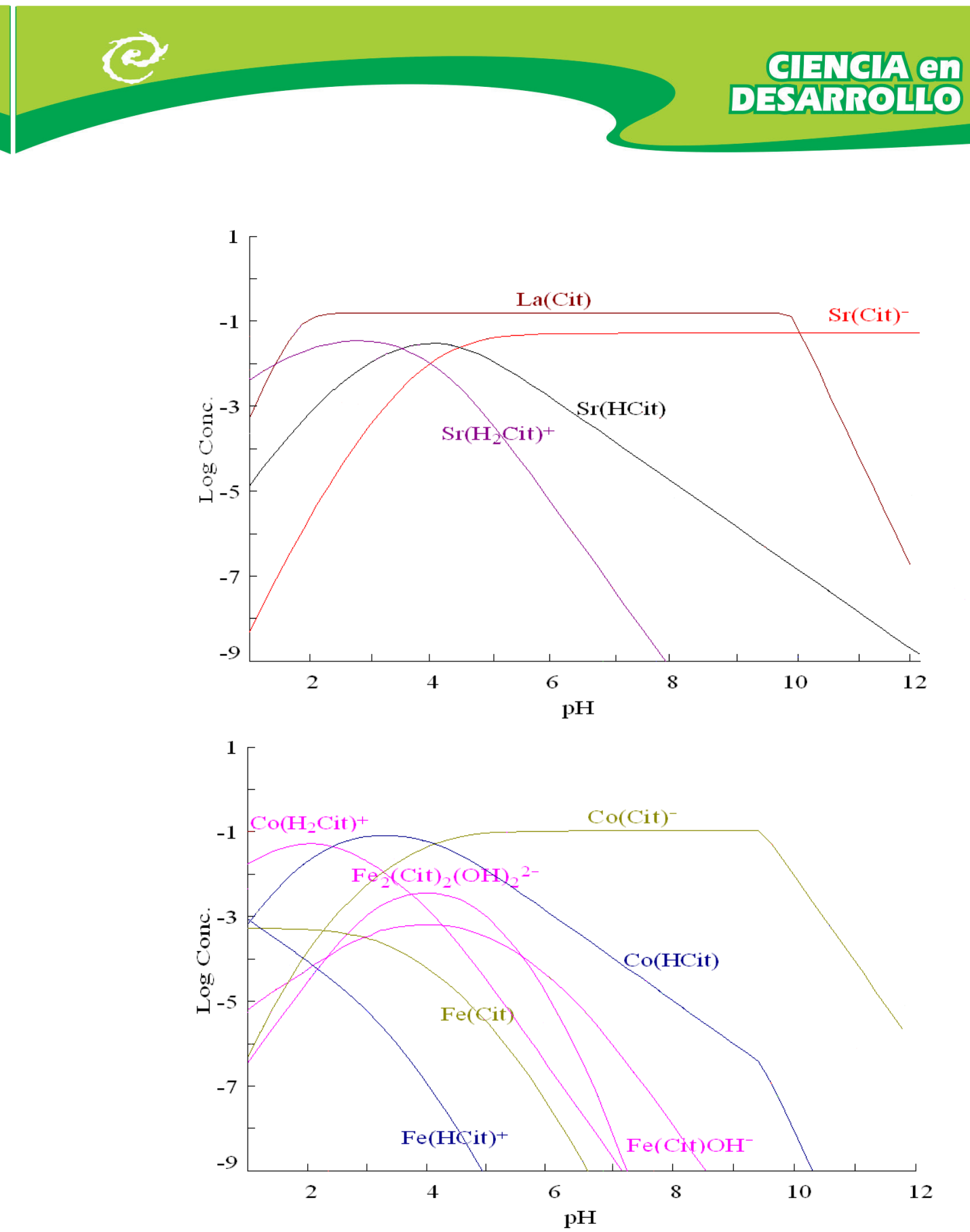

Figura 1. Modelamiento de distribución de las principales especies químicas a. lantano-estroncio y b. hierro-cobalto, presentes en la disolución obtenida mediante polimerización con ácido cítrico en función del pH.

En el caso de la muestra obtenida con ácido cítrico, se observó que la disolución de partida señala una zona específica de pH entre 4.5 y 8.5, en la cual se forma un precipitado insoluble, el cual desaparece 
al disminuir el pH con ácido nítrico, o, como en el presente caso, al incrementar la alcalinidad del medio por encima de 8.5 mediante las sucesivas adiciones de amoníaco acuoso. Por el contrario, la muestra trabajada con ácido propiónico indica la aparición de un precipitado insoluble después de sobrepasar un pH de 3.5, el cual se estabiliza incluso a niveles de alcalinidad de 13.0. Dichos resultados, tan solo permitieron analizar el efecto del ácido cítrico y propiónico a $\mathrm{pH}$ comprendidos entre 1.00 y 3.00, así los precursores obtenidos en cada caso fueron tratados térmicamente hasta la obtención de un precursor sólido, que sirvió de base para la caracterización mediante espectroscopía infrarroja como se muestra en la Figura 2. Así, en ambos espectros es claro que las bandas de absorción ubicadas entre 3400-3700 $\mathrm{cm}^{-1}$, están relacionadas con movimientos de tensión de los grupos $\mathrm{OH}$, asociados con moléculas de agua coordinadas sobre la superficie de los óxidos policatiónicos, como ha sido demostrado por algunos autores quienes han evidenciado el establecimiento de especies hidratadas intermedias de coordinación derivadas del proceso de secado de las disoluciones precursoras. De igual forma, las bandas localizadas entre $3400-3000 \mathrm{~cm}^{-1}$ están relacionadas con movimientos de tensión del enlace $\mathrm{O}-\mathrm{H}$, lo cual confirma la presencia de agua de hidratación en los materiales como ha sido reportado previamente [11], [12].

Las bandas localizadas entre $1800-1700 \mathrm{~cm}^{-1}$, están asociadas con movimientos de tensión y de vibraciones secundarias para los enlaces $-\mathrm{COOH}$ y $\mathrm{C}=\mathrm{O}$, lo cual evidencia la presencia de especies carboxílicas relacionadas con el establecimiento de compuestos de coordinación y con grupos remanentes de ácido carboxílico, según ha sido establecido [12]. Las bandas comprendidas entre 1580 y $1050 \mathrm{~cm}^{-1}$, han sido identificadas como bandas de tensión y deformación asimétrica para los enlaces $\mathrm{M}-\mathrm{COOH}, \mathrm{C}-\mathrm{H}$ y $\mathrm{C}-\mathrm{O}$, que están asociadas principalmente con la presencia de especies carboxílicas. Finalmente, la región comprendida entre 1180 y $470 \mathrm{~cm}$ 1, corresponde con movimientos de flexión fuera del plano para los enlaces $\mathrm{C}-\mathrm{H}$ y con señales asociadas a movimientos de tensión de los enlaces $\mathrm{M}-\mathrm{O}$, como ha sido establecido en trabajos anteriores [11]. 

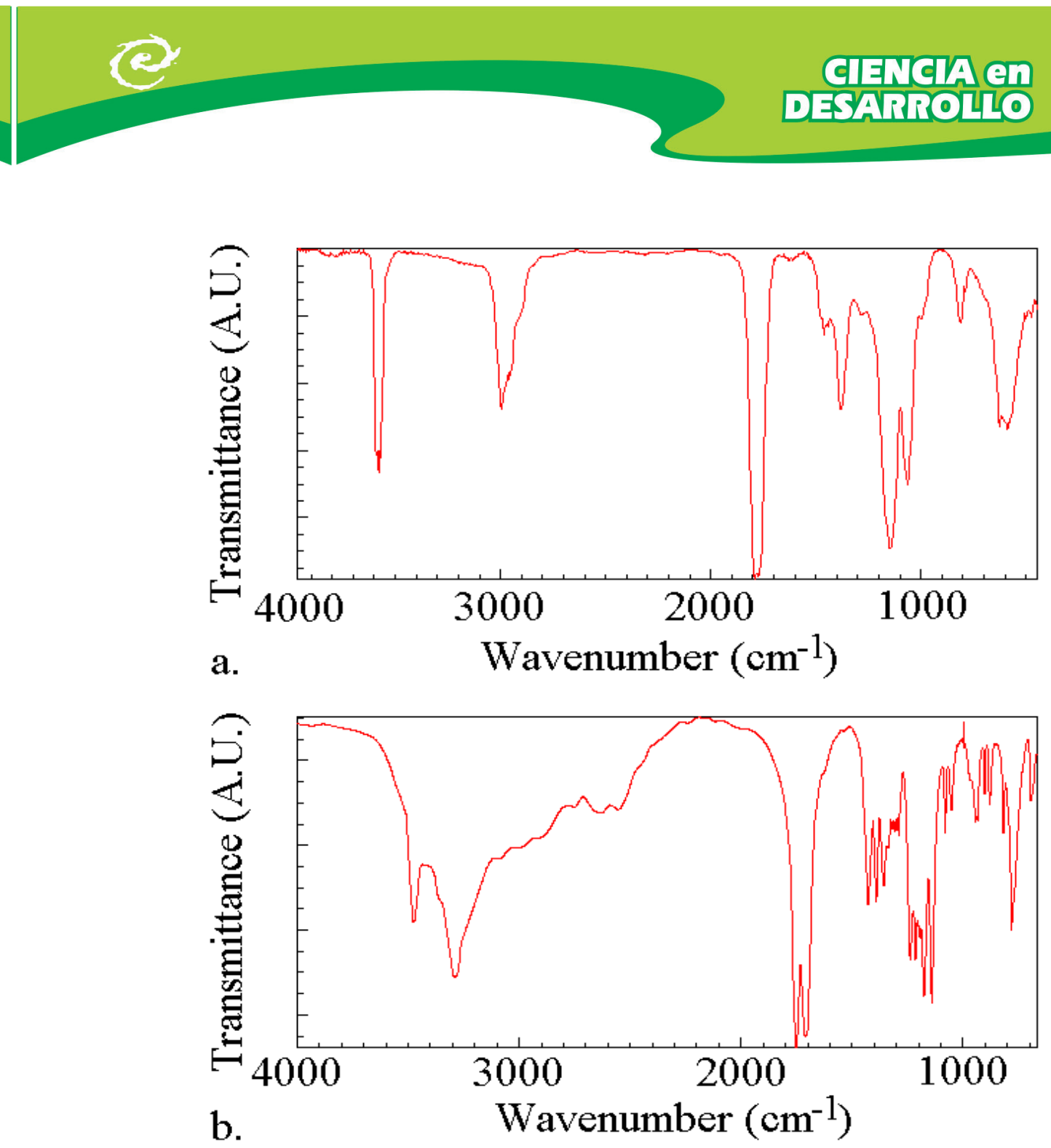

Figura 2. Espectrosinfrarrojos delosprecursoresde La ${ }_{0.75} \mathrm{Sr}_{0.25} \mathrm{Fe}_{0.5} \mathrm{Co}_{0.5} \mathrm{O}_{3}$ obtenidos con a. ácido cítrico y b. ácido propiónico.

Después del proceso de calcinación de los precursores, se obtuvieron los respectivos polvos cerámicos en cada caso. Los análisis de DRX indicaron que las muestras en general poseen una distribución y tamaño de cristal homogéneo y propio del método de síntesis utilizado, lo cual fue establecido tras realizar el respectivo proceso de refinamiento, indexación y análisis de las principales señales de difracción mediante el programa Rietveld y Cellref 3.0, como se indica en la Figura 2. 

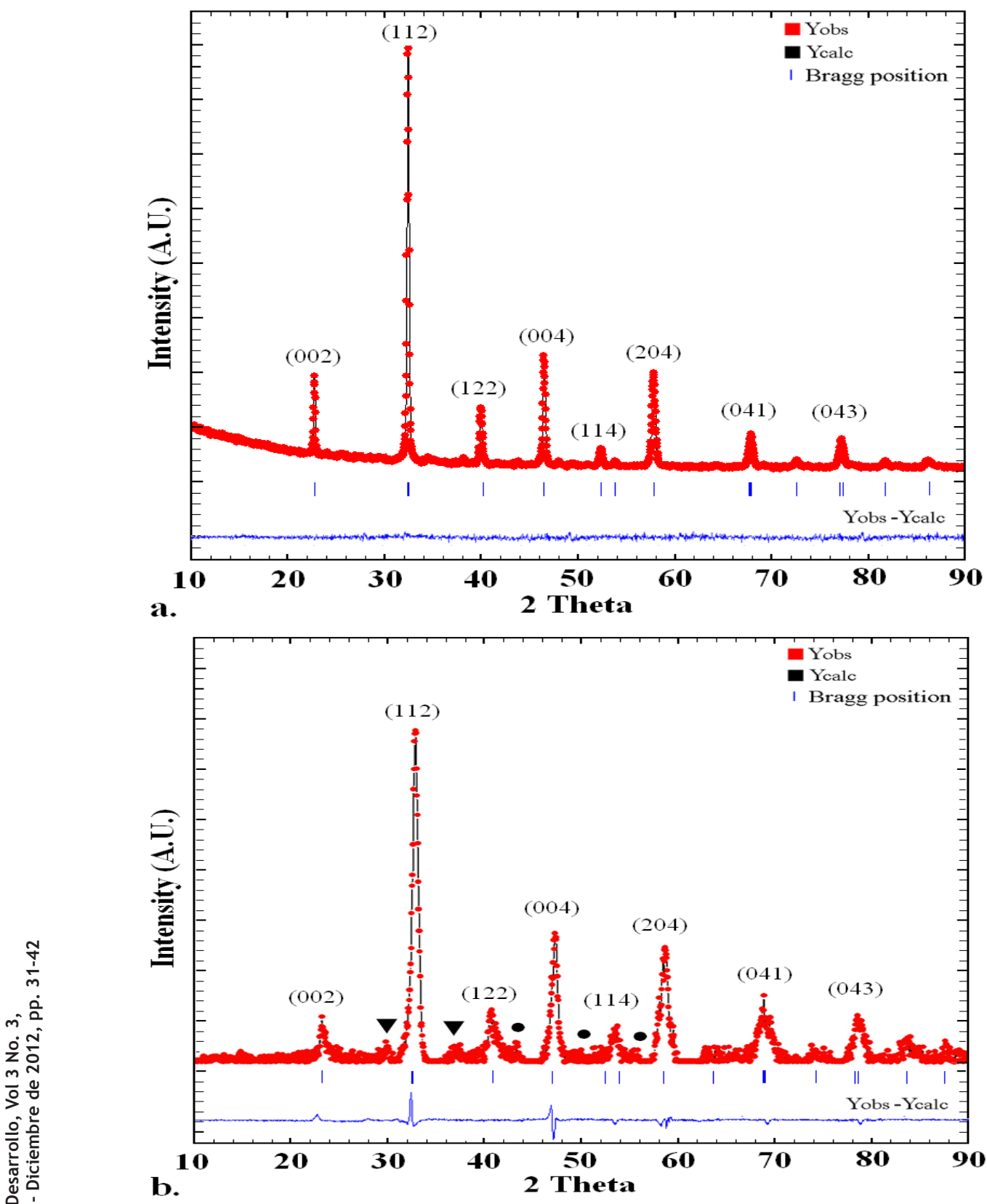

Figura 3. Espectro de difracción de rayos $X$ de la muestra de $\mathrm{La}_{0.75} \mathrm{Sr}_{0.25} \mathrm{Co}_{0.5} \mathrm{Fe}_{0.5} \mathrm{O}_{3}$, obtenida por polimerización con $\mathbf{a}$. ácido cítrico y $\mathbf{b}$. ácido propiónico con presencia de $\mathbf{\nabla} \mathrm{La}_{2} \mathrm{O}_{3} y \bullet \mathrm{SrO}$ como impurezas. 
Los posteriores análisis mediante difracción de rayos $\mathrm{X}$, indican que el sistema $\mathrm{La}_{0.75} \mathrm{Sr}_{0.25} \mathrm{Co}_{0.5} \mathrm{Fe}_{0.5} \mathrm{O}_{3}$ guarda una adecuada composición química y estructura cristalina, lo cual señala una alta correlación con respecto al sistema propuesto, con una orientación cristalina preferencial en el plano (112), como se muestra en la Figura 2. De igual forma, es claro que la muestra obtenida mediante polimerización con ácido propiónico posee un mayor grado de diferencia con respecto a la estructura cristalina de referencia usada en el refinamiento, toda vez que el ácido propiónico induce la presencia de especies oxídicas como las de $\mathrm{La}_{2} \mathrm{O}_{3}$ y $\mathrm{SrO}$ que bajo las presentes condiciones de síntesis no han podido integrarse a la estructura perovskita buscada, como se indica en la Figura 2.

La estimación del tamaño cristalino se hizo usando las señales más intensas de difracción, mediante la ecuación de Debye-Scherrer, tomando el valor de ancho medio de pico $(\beta)$, ajustado a una función Lorentziana y tomando una constante de 0.89 como referencia, resultando en un tamaño promedio de cristal de $10.0 \mathrm{~nm}$ para el caso de la muestra obtenida con ácido cítrico, y de $42.0 \mathrm{~nm}$ para la muestra obtenida con ácido propiónico. El factor de tolerancia de la composición estudiada fue determinado mediante el programa SPuDS [13], sugiriendo la estabilización de una estructura tipo perovskita con un factor de tolerancia covalente de 0.9856 calculado a una temperatura de $273 \mathrm{~K}$. $\mathrm{La}_{0.7} \mathrm{Sr}_{0.3} \mathrm{Co}_{0.5} \mathrm{Fe}_{0.5} \mathrm{O}_{3}$ correspondiente al código de colección de la ICSD número 086124, JCPDF: 00-089-1267 con grupo espacial Pbnm (62), sistema cristalino ortorrómbico con parámetros de celda $a=5.396 \AA, b=5.548 \AA$ y $c=7.719 \AA$ y volumen de celda de 227.34 $A^{3}$, dichos resultados fueron corroborados mediante el proceso de refinamiento iterado en 20 ciclos de refinamiento por comparación entre la estructura de referencia de la ICSD y el patrón experimental de difracción obtenido en cada caso.

Los resultados de microscopía electrónica obtenidas a 50 y $10 \mu \mathrm{m}$ muestran la obtención de sólidos de superficie irregular y composición homogénea como se indica en la Figura 3. Es claro que la apariencia en términos superficiales y morfológicos de las muestras guarda una estrecha relación con el desarrollo de sólidos con un reducido tamaño de partícula, lo que se manifiesta en el elevado grado de densificación de los materiales y que se relaciona con la obtención de sólidos del tipo macroporoso con baja área superficial, como ha sido establecido 
previamente [14]. El alto grado de heterogeneidad de los sólidos obtenidos está relacionado con la eliminación de sustancias volátiles como vapor de agua, $\mathrm{CO}$ y $\mathrm{CO}_{2}$, derivados del tratamiento térmico de los respectivos precursores hasta la obtención del respectivo material cerámico, como se observa en la Figura 3.
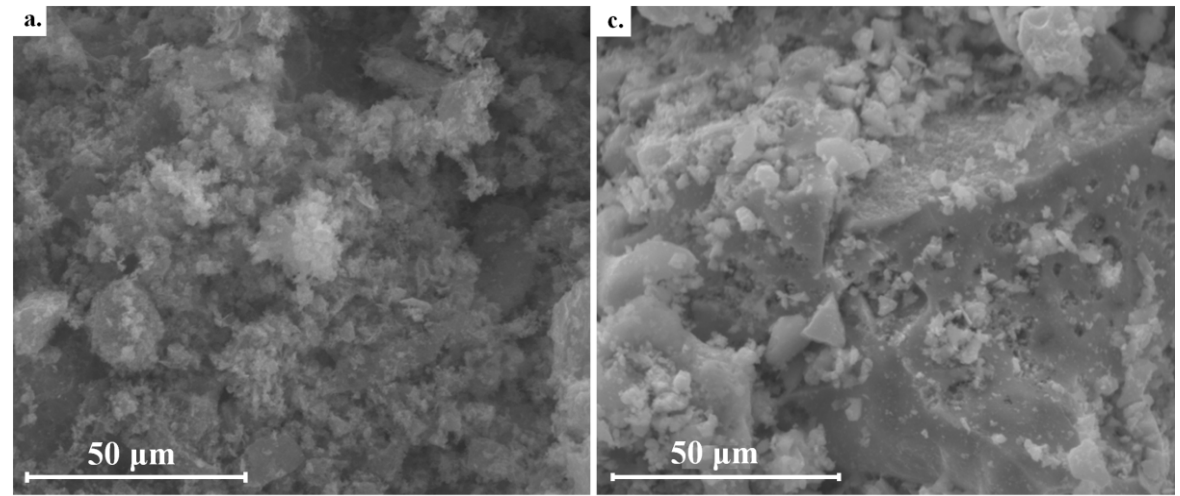

b.

$10 \mu \mathrm{m}$

Figura 4. a. y b. Micrografías electrónicas de barrido a 50 y $10 \mu \mathrm{m}$ de la muestra obtenida mediante polimerización con ácido cítrico y c. y d. con ácido propiónico.

La composición de las muestras fue verificada por microanálisis de EDS, demostrando que la composición de las muestras obtenidas guarda una estrecha relación con la composición conseguida y propuesta, como se indica en la Tabla 1. Dichos resultados eliminan la posibilidad de una eventual volatilización de especies susceptibles al tratamiento térmico, como en el caso de los óxidos de cobalto, según se indica en la Figura 4. 
Tabla 1. Composición molar porcentual de cada catión, obtenida mediante microanálisis EDS para las muestras sintetizadas con ácido cítrico y ácido propiónico.

\begin{tabular}{cccccc}
\hline \multirow{2}{*}{ Método } & \multicolumn{5}{c}{ Concentración molar \% por cada catión } \\
\cline { 2 - 6 } & $\mathbf{L a}^{3+}$ & $\mathbf{S r}^{2+}$ & $\mathbf{C o}^{3+}$ & $\mathbf{F e}^{3+}$ & $\mathbf{O}^{2-}$ \\
\hline Ácido cítrico & 0.74 & 0.26 & 0.48 & 0.51 & 2.85 \\
\hline Ácido propiónico & 0.71 & 0.27 & 0.45 & 0.46 & 2.98 \\
\hline
\end{tabular}

Los espectros de EDS para las muestras obtenidas, se muestran en la Figura 4, en los cuales es evidente la presencia de las principales señales asociadas a los cationes componentes en cada muestra. Los resultados confirman la ausencia de carbón en las muestras y permiten establecer que la temperatura de tratamiento térmico fue la más apropiada para consolidar la fase cristalina buscada. Las demás líneas son susceptibles de identificar plenamente, en la medida en que corresponden a emisiones características del lantano, estroncio, cobalto, hierro y oxígeno en cada caso.
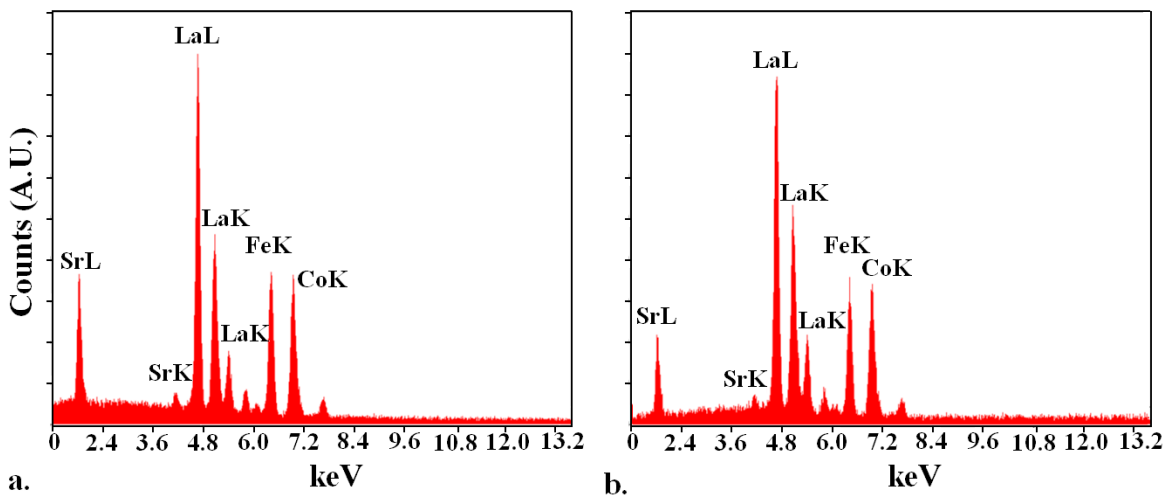

Figura 5. a. Microanálisis tipo EDS realizado en las muestras obtenidas mediante polimerización con ácido cítrico y b. con ácido propiónico.

\section{Discusión de resultados}

En la síntesis de los precursores de $\mathrm{La}_{0.75} \mathrm{Sr}_{0.25} \mathrm{Fe}_{0.5} \mathrm{Co}_{0.5} \mathrm{O}_{3}$, es claro que el efecto del ácido carboxílico utilizado tiene un efecto decisivo en el establecimiento de compuestos intermedios de coordinación que determinan las características de los materiales finales [15]. De esta forma, en el caso del método de polimerización 
con ácido cítrico, el sistema promueve la presencia en el medio de reacción de distintas especies complejas, cuya existencia predomina y evoluciona en función del $\mathrm{pH}$, de la concentración del ligando y de la fuerza iónica. Dicho resultado se modeló usando diagramas de equilibrio químico usando el programa Hydra-Medusa, según el cual, los diagramas de equilibrio para la muestra obtenida mediante polimerización con ácido cítrico muestran la prevalencia de especies solubles tipo citrato $4.5>\mathrm{pH}>8.5$, sugiriendo de esta forma que el control de este parámetro es definitivo en el establecimiento de las condiciones mínimas de reacción que permitan controlar la homogeneidad del proceso de síntesis, como se indica en la Figura 1.

Los diagramas de distribución de especies de la muestra sintetizada mediante polimerización con ácido cítrico, predicen la existencia de diferentes especies tipo citrato, hidroxilo y óxido; algunas de las cuales muestran una tendencia general a prevalecer en niveles específicos de $\mathrm{pH}$; particularmente las especies tipo citrato coexisten entre $2.00<\mathrm{pH}<5.00$. Sin embargo, es evidente que en el caso particular de los compuestos de coordinación de lantano y estroncio, dichas especies parecen ser estables a $2 \leq \mathrm{pH} \leq 9$ y 5 $\leq \mathrm{pH} \leq 12$ respectivamente; de esta forma, bajo las condiciones de síntesis planteadas en el presente trabajo $(\mathrm{pH}=2.00)$, se espera una presencia mayoritaria de especies tipo $\mathrm{La}(\mathrm{Cit})$ y $\mathrm{Sr}\left(\mathrm{H}_{2} \mathrm{Cit}\right)^{+}$; por fuera de estos niveles de $\mathrm{pH}$, se favorece la obtención de sustancias insolubles especialmente a $\mathrm{pH}$ alcalinos que podrían afectar la homogeneidad del medio de reacción.

Por el contrario, los cationes cobalto y hierro, poseen un comportamiento diferente, toda vez que la presencia de especies tipo $\mathrm{CoO}$ y $\mathrm{Fe}_{2} \mathrm{O}_{3}$ persisten en una amplia escala de $\mathrm{pH}$; a pesar de ello, el predominio de las especies citrato de cobalto tiende a ser más fuerte en determinados intervalos de $\mathrm{pH}$, de tal forma que en condiciones de $1.00 \leq \mathrm{pH} \leq 3.00$, predominan especies de tipo $\mathrm{Co}\left(\mathrm{H}_{2} \mathrm{Cit}\right)^{-}$mientras que las de tipo $\mathrm{Co}(\mathrm{HCit})$ y $\mathrm{Co}(\mathrm{Cit})^{-}$se estabilizan en condiciones de menor acidez ( $3.00 \leq \mathrm{pH} \leq 4.00$ y $5.00 \leq \mathrm{pH} \leq 9.50$ respectivamente), sugiriendo una presencia mayoritaria de $\mathrm{Co}\left(\mathrm{H}_{2} \mathrm{Cit}\right)^{-}$. Para el caso del hierro, la situación es más compleja, ya que a partir de los diagramas de la Figura 1, es predecible la formación preferente de especies tipo $\mathrm{Fe}$ (Cit), al igual que de especies minoritarias tipo $\mathrm{Fe}(\mathrm{HCit})^{+}, \mathrm{Fe}(\mathrm{Cit})$ $\mathrm{OH}-\mathrm{y} \mathrm{Fe}_{2}(\mathrm{Cit})_{2}(\mathrm{OH})_{2}{ }_{2}^{2-}$, las cuales coexisten en intervalos de $\mathrm{pH}$ muy 
reducidos que limitarían el empleo de esta catión en composiciones que requieran de su uso en intervalos de $\mathrm{pH}$ más variables [11].

En el caso de la muestra sintetizada mediante el uso de ácido propiónico, es claro que se espera la formación de diferentes especies tipo propionato en determinados valores de $\mathrm{pH}$, situación que fue comprobada modificando las condiciones de $\mathrm{pH}$. Mediante la adición controlada de amoníaco, la muestra presentó algunas características interesantes en términos de solubilidad, la cual solo se conservó en el intervalo $1.00 \leq \mathrm{pH} \leq 3.00$; por encima de $\mathrm{pH} 3.00$, la muestra se precipita y no es posible redisolverla, incluso a valores de $\mathrm{pH}=$ 13.0. Esto sugiere que bajo las condiciones de síntesis propuestas, es posible la presencia de especies solubles tipo propionato, las cuales han sido reportadas previamente [16], documentando la obtención de complejos de lantano tipo $\left[\mathrm{La}_{2}\left(\mathrm{CH}_{3} \mathrm{CH}_{2} \mathrm{COO}\right)_{6}\right.$. $\left.\left(\mathrm{H}_{2} \mathrm{O}\right)_{3}\right] \cdot 3 \cdot 5 \mathrm{H}_{2} \mathrm{O}$, los que han mostrado características de solubilidad similares a los encontrados en la presente investigación. La situación para los cationes de estroncio, hierro y cobalto es similar, toda vez que existen reportes sobre la formación de especies hidratadas de estroncio y cationes divalentes en conformaciones binarias de tipo $\left[\mathrm{Me}_{2} \mathrm{Sr}\left(\mathrm{CH}_{3} \mathrm{CH}_{2} \mathrm{COO}\right)_{6} \cdot \mathrm{n}\left(\mathrm{H}_{2} \mathrm{O}\right)_{3}\right] \cdot \mathrm{nH}_{2} \mathrm{O}$, las que han presentado solubilidades de tipo inverso, puesto que cualquier variación en factores como la temperatura o el pH se ven modificados [17].

Los análisis de difracción de rayos X (DRX) indican que los sólidos LaSCoF, obtenidos mediante polimerización con ácido cítrico y ácido propiónico, poseen una distribución y tamaño de grano, propio del método de síntesis, con orientación cristalina preferencial en el plano (112), como se muestra en la Figura 2. El refinamiento e indexado de las señales indicó que la muestra obtenida mediante polimerización con ácido propiónico induce la formación de $\mathrm{La}_{2} \mathrm{O}_{3}$ y SrO que provocan una diferencia significativa con respecto a la estructura cristalina de referencia utilizada, evidenciando la poca efectividad del grupo propionato para establecer compuestos de coordinación estables a lo largo del proceso de síntesis. Lo que conduce a la formación de gradientes de concentración por la formación de precipitados insolubles de los cationes de carácter básico que no se incorporan a la estructura perovskita, incluso después de los tratamientos térmicos, como ha sido establecido [18]. 
Con las señales de mayor intensidad y la determinación del tamaño de cristal mediante la ecuación de Scherrer-Debye, es claro que la naturaleza del catión ligante tiene un papel decisivo en el proceso de síntesis de materiales del orden nanométrico de $10.0 \mathrm{~nm}$, para el caso de la muestra obtenida mediante ácido cítrico, y de 42.0 $\mathrm{nm}$ para el caso de la muestra obtenida con ácido propiónico. Dicha diferencia puede comprenderse, pues el ácido propiónico tan solo aporta un grupo carboxilo en el establecimiento de los respectivos compuestos de coordinación, mientras que el ácido cítrico es un ligante polidentado capaz de unir los iones metálicos en disolución a través de múltiples sitios, favoreciendo un menor grado de cercanía entre cationes por impedimentos estructurales, lo que conduce a la obtención de precursores y óxidos cerámicos de tamaño nanométrico [18]. Por otro lado, factores como el $\mathrm{pH}$ son cruciales en el establecimiento de medios homogéneos de reacción que eviten la precipitación prematura de los cationes componentes menos solubles, ya que es preciso favorecer concentraciones estables de cada catión a lo largo del proceso de síntesis.

De igual forma, las micrografías electrónicas de barrido a 50 y $10 \mu \mathrm{m}$, confirmaron la obtención de un material con una textura y relieve característicos del método de síntesis empleado, mostrando un alto grado de heterogeneidad por efecto de la salida de los gases derivados del tratamiento térmico. Finalmente, el microanálisis por EDS permitió establecer un perfil de composición global de las muestras, destacándose que los sólidos no poseen impurezas detectables de carbono remanente del proceso de síntesis. Dicho resultado se justifica en virtud de la naturaleza de la fuerte reacción exotérmica que se genera entre los cationes nitrato y carboxilato de los precursores poliméricos, que promueven la consolidación de la fase cristalina buscada a temperaturas bajas y permiten la temprana eliminación de los residuos de carbono de la muestra, como se observa en la Figura 4.

\section{Conclusiones}

El proceso de síntesis de materiales cerámicos multicomponentes tipo perovskita, usando ácidos carboxílicos tipo citrato y propionato como agentes ligantes, conduce a la preparación de materiales con un tamaño de cristal del orden nanométrico y de un alto nivel 
de densificación a bajas temperaturas de reacción. De igual forma, es claro que el ácido cítrico permite la obtención de materiales con un mayor grado de pureza, toda vez que su naturaleza polidentada como ligante actúa con un mayor grado de efectividad en el proceso de formación de los respectivos compuestos de coordinación. Estos resultados confirman que el control de las condiciones iniciales de $\mathrm{pH}$, temperatura de gelificación-polimerización, naturaleza del ligante, proporción molar ligante-cationes y temperatura de calcinación en el proceso de síntesis, influyen de forma notable en la síntesis y el diseño de materiales con propiedades específicas

\section{Referencias}

[1]A. González, E. Martínez Tamayo, A. Beltrán Porter \& V. Cortés Corberán, "Synthesis of high surface area perovskite catalysts by non-conventional routes," Catal. Today, vol. 33, pp. 361-369, 1997.

[2] Z. Yang, Y. Huang, B. Dong, \& L. Hu-Lin, "Controlled synthesis of highly ordered $\mathrm{LaFeO}_{3}$ nanowires using a citrate based sol-gel route," Mater. Res. Bull, vol. 41, pp. 274-281, 2006.

[3] N. T. Hong Le, J. M. Calderón Moreno, M. Popa, D. Crespo, L. V. Hong \& N. X. Phuc, " $\mathrm{LaNiO}_{3}$ nanopowder prepared by an amorphous citrate route", J. European Ceram. Soc, vol. 26, pp. 403-407, 2006.

[4] A. Majid, J. Tunney, S. Argue, D. Wang \& M. Margeson, "Preparation of $\mathrm{SrFeO}_{2.85}$ perovskite using a citric acid assisted pechini-type method", $J$. Alloys Compounds, vol. 398, pp 48-54, 2005.

[5] L. Xue, Q. Li, Y. Zhang, R. Liu \& X. Zhen, "Synthesis, sintering and characterization of PLZST perovskite prepared by a lactate precursor route", J. European Ceram. Soc, vol. 26, pp. 323-329, 2006.

[6] M. Kakihana, M. Arima, M. Yoshimura, N. Ikeda \& Y. Sugitani, "Synthesis of high surface area $\mathrm{LaMnO}_{3}$ by a polymerizable complex method", J. Alloys Compounds, vol. 283, pp. 102-105, 1999.

[7]W. D. Yang, S. H. Huang \& Y. H. Chang, "Microstructure, magnetoresistance and electrical properties of $\mathrm{La}_{0.67} \mathrm{Sr}_{0.33} \mathrm{MnO}_{3}$ films synthesized from citric acid and ethylene glycol", Thin Solid Films, vol. 478, pp. 42-48, 2005.

[8] M. Popa, J. Frantti \& M. Kakihana, "Characterization of $\mathrm{LaMeO}_{3}$ (Me: $\mathrm{Mn}, \mathrm{Co}, \mathrm{Fe}$ ) perovskite powders obtained by polymerizable complex method", Solid State lonics, vol. 154, pp. 135-141, 2002. 
[9] J. A. Gómez-Cuaspud \& J. S. Valencia-Ríos, "Evaluación catalítica de óxidos policatiónicos tipo perovskita obtenidos por polimerización con ácido cítrico", Rev. Col. Quim, vol. 38, n² 2, pp. 303-319, 2009.

[10] J. A. Gómez-Cuaspud, J. S. Valencia-Ríos \& J. B. Carda-Castelló, "Preparation and characterization of perovskite oxides by polymerization-combustion”, J. Chil. Chem. Soc, vol. 55, pp. 283-287, 2010.

[11] J. A. Gómez-Cuaspud \& J. S. Valencia-Ríos, "Síntesis de óxidos tipo $\mathrm{LaSrCrFeO}_{3}$ mediante polimerización con ácido cítrico", Rev. Energética, vol. 42, n² 2, pp. 69-72, 2009.

[12] K. Chen-Feng \& Y. Wein-Duo, "Preparation of barium strontium titanate powder from citrate precursor", Appl. Organometal. Chem, vol. 13, pp. 383-397, 1999.

[13] M. W. Lufaso \& P. M. Woodward, "The prediction of the crystal structures of provskites using the software program SPuDS", Acta Cryst, vol. B57, pp. 725-738, 2001.

[14] L. M. Sikhwivhilu, S. K. Pillai \& T. K. Hillie, "Influence of citric acid on $\mathrm{SnO}_{2}$ nanoparticles synthesized by wet chemical processes", Journal of Nanoscience and Nanotechnology, vol. 11, n 1-7, pp. 1-7, 2010.

[15] J. D. Fernández, D. M. Araujo, L. B. Zinner, C. M. Salustiano, Z. R. Silva, J. Alves, J. A. P. da Costa \& E. Longo, "Synthesis and characterization of neodymium nickelate powder produced from polymeric precursors", J. Alloys Compounds, vol. 344, pp. 157-160, 2002.

[16] L. Ciontea, M. Nasui, T. Petrisor, R. B. Mos, M. S. Gabor, R. A. Varga \& $\mathrm{T}$. Petrisor, "Synthesis, cristal structure and thermal decomposition of $\left[\mathrm{La}_{2}\left(\mathrm{CH}_{3} \mathrm{CH}_{2} \mathrm{COO}\right)_{6}\right.$. $\left.\left(\mathrm{H}_{2} \mathrm{O}\right)_{3}\right]$. $3.5 \mathrm{H}_{2} \mathrm{O}$ precursor for high-k $\mathrm{La}_{2} \mathrm{O}_{3}$ thin films deposition", Materials Research Bulletin, vol. 45, pp. 1203-1208, 2010.

[17] K. Stadnicka, A. M. Glazer \& U. Bismayer, "The phase diagram of dicalcium/strontium/lead propionate", Phase Transitions, vol. 27, pp. 73-80, 1990.

[18] A. Zelewsky, "Stereochemistry of coordination compounds", John Wiley Ed., Chichester: Wiley, 1995, pp. 25-106. 


\title{
WELL-POSEDNESS TO THE CAUCHY PROBLEM ASSOCIATED TO THE MONLINEAR SCHRÖDINGER EQUATION
}

\section{BUEN PLANTEAMIENTO DEL PROBLEMA DE CAUCHY ASOCIADO A LA EDUACIÓN NO LINEAL DE SCHRÖDINGER}

Richard Alexander de la Cruz Guerrero *

Recepción 05/08/2011

Evaluación 12/09/2011

Aprobado 12/10/2011

\begin{abstract}
In this paper we prove that the Cauchy problem associated to nonlinear Schrödinger equation is well-posed in Sobolev spaces $H^{s}(\mathbb{R})$ using Parabolic regularization, Bona-Smith approximation and the methods proposed by lorio in [7],[8],[9].
\end{abstract}

\section{Keywords}

NLS equation, well-posedness, parabolic regularization, Bona-Smith approximation.

AMS subject classifications. 35Q55, 35G25

\section{Resumen}

En este artículo se muestra el buen planteamiento del problema de Cauchy asociado a la ecuación no lineal de Schrödinger en espacios de Sobolev $H^{s}(\mathbb{R})$ usando el método de regularización parabólica, estimativas de Bona-Smith y los métodos propuestos por lorio en [7],[8],[9].

\section{Palabras clave}

Ecuación NLS, buen planteamiento, regularización parabólica, estimativas de Bona-Smith.

*Full professor Escuela de Matemáticas y Estadística, Universidad Pedagógica y Tecnológica de Colombia Uptc, Tunja. e-mail: richard.delacruz@uptc.edu.co 


\section{Introduction}

The linear Schrödinger equation was formulated by Erwin Schrödinger in 1925 and published in 1926. It describes how the quantum state of some physical system changes with time. The nonlinear Schrödinger equations are the main object of study of many physical problems.

In this work we will study the local well-posedness to the Cauchy problem associated to nonlinear Schrödinger equation (NLS):

$$
\left\{\begin{array}{l}
i v_{t}+\Delta v+|v|^{2 \sigma} v=0, \quad x \in \mathbb{R}, t \geq 0, \\
v(0)=\phi .
\end{array}\right.
$$

If $\sigma=1$, the equation describes the propagation of a laser beam in a nonlinear optical medium whose index of refraction is proportional to the wave intensity. Also, the NLS equation successfully models other wave phenomena, such as water waves at the free surface of an ideal fluid as well as plasma waves.

Cao, Musslimani and Titi show the well-posedness of the following regularization to problem (1):

$$
\left\{\begin{array}{l}
i v_{t}+\Delta v+u|v|^{\sigma-1} v=0, \quad x \in \mathbb{R}, t \geq 0, \\
u-\alpha^{2} \Delta u=|v|^{\sigma+1} \\
v(0)=\phi
\end{array}\right.
$$

where $\alpha>0$ and $\sigma \geq 1$.

This is called the Helmholtz-Schrödinger equation and was study in [3]. Note that when $\alpha=0$, we get the NLS.

Unlike the work of Cao, Musslimani and Titi, here we used Parabolic regularization method, Bona-Smith approximation and the methods proposed by lorio [7], [9] to shows wellposedness of problem (1). The Parabolic regularization method consists of regularizing the equation (1) using the viscous term $-i \mu \mathcal{H} \Delta v$, constructing the solution to the Cauchy problem for nonlinear parabolic equation and taking the limit as the viscosity tends to zero, i.e., $\mu \rightarrow 0+$. The Bona-Smith approximation were proposed in [2]. In this paper, the estimates are used to approximate the initial data using smooth functions and obtaining uniform bounds for the solutions. These techniques were also used in [1], [5]. 


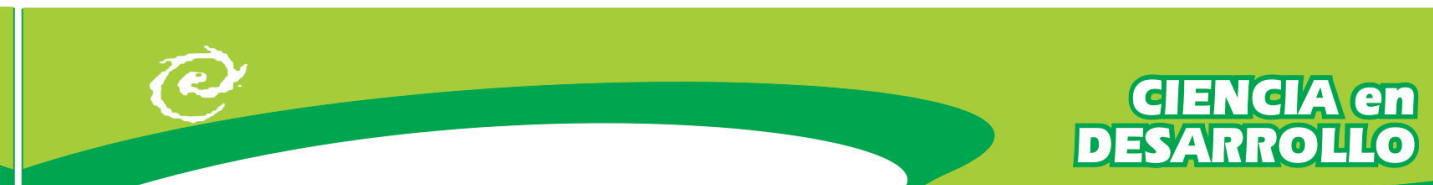

We will use the following notation:

- $\mathbb{R}$ for the real numbers.

- $\widehat{\phi}$ for the Fourier transform of $\phi$.

- If $s \in \mathbb{R}, H^{s}(\mathbb{R})$ is the Sobolev space with norm \|\|$_{s}$ and $(,)_{s}$ for its inner product.

- $\boldsymbol{B}(X, Y)$ for the space of all continuous linear operator from $X$ to $Y$, and $\boldsymbol{B}(X)$ if $X=Y$.

- $C(I ; X)$ for the space of all continuous functions on an interval $I$ into Banach space $X$.

- $C^{k}(I ; X)$ for the space of $k$ times continuously differentiable functions on an interval $I$ into Banach space $X$.

- $C_{w}(I ; X)$ for the space of all weakly continuous functions on an interval $I$ into Banach space $X$.

\section{The Regularized Problem}

We begin the analysis of the regularized problem

$$
\left\{\begin{array}{l}
i v_{t}+\Delta v+|v|^{2 \sigma} v=-i \mu \mathcal{H} \Delta v, \quad x \in \mathbb{R}, t \geq 0, \\
v(0)=\phi
\end{array}\right.
$$

where $\mathcal{H}$ denotes the Hilbert transform

$$
\mathcal{H} f(x)=\frac{1}{\pi} v p \int_{\mathbb{R}} \frac{f(y)}{x-y} d y .
$$

Regularize the NLS equation using a viscous term $-i \mu \mathcal{H} \Delta v$ where $\mu>0$.

We solved the regularized problem and then take the limit as viscosity tends to zero, i.e., $\mu \rightarrow 0+$. This procedure is known as Parabolic regularization or the Method of vanishing viscosity.

\section{The Linear Equation}

We consider the Cauchy problem associated to the linear part of equation (3)

$$
\left\{\begin{array}{l}
i v_{t}+\Delta v=-i \mu \mathcal{H} \Delta v \\
v(0)=\phi
\end{array}\right.
$$

Taking the Fourier transform in (5) we conclude that

$$
v(x, t)=\left(e^{-i \xi^{2}(1+\mu \operatorname{sgn}(\xi)) t} \hat{\phi}\right)^{\vee}
$$

For $t \geq 0$ define the linear operator

$$
\mathbb{V}_{\mu}(t) \phi=\left(e^{-i \xi^{2}(1+\mu \operatorname{sgn}(\xi)) t} \hat{\phi}\right)^{`}=e^{(i \Delta-\mu \mathcal{H} \Delta) t} \phi
$$


Theorem 1. Let $\mu \geq 0$ be fixed. Then $\mathbb{V}_{\mu}:[0, \infty) \rightarrow \boldsymbol{B}\left(H^{s}(\mathbb{R})\right)$ is a strongly continuous one-parameter unitary group in $H^{s}(\mathbb{R})$ for all $s \in \mathbb{R}$.

Theorem 2. For all $\phi \in H^{s}(\mathbb{R})$, the function $v:[0, \infty) \rightarrow H^{s}(\mathbb{R})$ defined by $v(t)=\mathbb{V}_{\mu}(t) \phi$, for all $t \in \mathbb{R}$, is continuous with the time derivative computed in $(0, \infty)$ continuous. Moreover, $v$ is the unique function in $C\left([0, \infty) ; H^{s}(\mathbb{R})\right) \cap C^{1}\left((0, \infty) ; H^{s}(\mathbb{R})\right)$ solution of problem (5).

Note that, $v \in C\left((0, \infty) ; H^{\infty}(\mathbb{R})\right) \cap C^{\infty}\left((0, \infty) ; H^{s}(\mathbb{R})\right)$.

\section{Local Theory in $H^{s}(\mathbb{R}), s>1 / 2, \mu>0$}

We use Banach's fixed theorem in a suitable function space, to find a local solution to the following integral equation associated to (3):

$$
v(t)=\mathbb{V}_{\mu}(t) \phi+i \int_{0}^{t} \mathbb{V}_{\mu}(t-\tau)|v|^{2 \sigma} v d \tau .
$$

Theorem 3. Suppose $s>\frac{1}{2}$. If $v \in C\left([0, T] ; H^{s}(\mathbb{R})\right) \cap C^{1}\left((0, T] ; H^{s-2}(\mathbb{R})\right)$ is a solution of (3) then $v$ is solution of the integral equation (7). Conversely, if $v \in C\left([0, T] ; H^{s}(\mathbb{R})\right)$ is a solution of (7) then $v \in C^{1}\left((0, T] ; H^{s-2}(\mathbb{R})\right)$ and satisfies (3).

Proposition 1. Let $F(v)=|v|^{2 \sigma} v$ and $s>\frac{1}{2}$. Then

$$
\|F(v)-F(w)\|_{s} \leq L\left(\|v\|_{s},\|w\|_{s}\right)\|v-w\|_{s}
$$

where $L(\cdot, \cdot)$ is a continuous function, nondecreasing with respect to each of its arguments. In particular,

$$
\|F(v)\|_{s} \leq L\left(\|v\|_{s}, 0\right)\|v\|_{s} .
$$

Proposition 2. Let $\phi, \varphi \in H^{s}(\mathbb{R})$ and $v, w \in C\left([0, T] ; H^{s}(\mathbb{R})\right)$ be two solutions of problem (3) satisfying $v(0)=\phi$ and $w(0)=\varphi$. If $s>\frac{1}{2}$ then

$$
\left\|v_{\mu}(t)-w_{\mu}(t)\right\|_{s} \leq\|\phi-\varphi\|_{s} \exp \left(L\left(M_{s}, M_{s}\right) t\right)
$$

for all $t \in[0, T]$ and $M_{s}$ is given by $M_{s}=\max \left\{\sup _{[0, T]}\|v(t)\|_{s}, \sup _{[0, T]}\|w(t)\|_{s}\right\}$.

In particular (3) has at most one solution.

Proof. Equation (7) implies

$$
v(t)-w(t)=\mathbb{V}_{\mu}(t)(\phi-\varphi)+i \int_{0}^{t} \mathbb{V}_{\mu}(t-\tau)\left[|v(\tau)|^{2 \sigma} v(\tau)-|w(\tau)|^{2 \sigma} w(\tau)\right] d \tau
$$

and since $\mathbb{V}_{\mu}(t)$ is unitary in $H^{s}(\mathbb{R})$ it follows that

$$
\begin{aligned}
\|v(t)-w(t)\|_{s} & \leq\|\phi-\varphi\|_{s}+\int_{0}^{t}\left\||v(\tau)|^{2 \sigma} v(\tau)-|w(\tau)|^{2 \sigma} w(\tau)\right\|_{s} d \tau \\
& \leq\|\phi-\varphi\|_{s}+\int_{0}^{t} L\left(\|v(\tau)\|_{s},\|w(\tau)\|_{s}\right)\|v(\tau)-w(\tau)\|_{s} d \tau \\
& \leq\|\phi-\varphi\|_{s}+L\left(M_{s}, M_{s}\right) \int_{0}^{t}\|v(\tau)-w(\tau)\|_{s} d \tau
\end{aligned}
$$




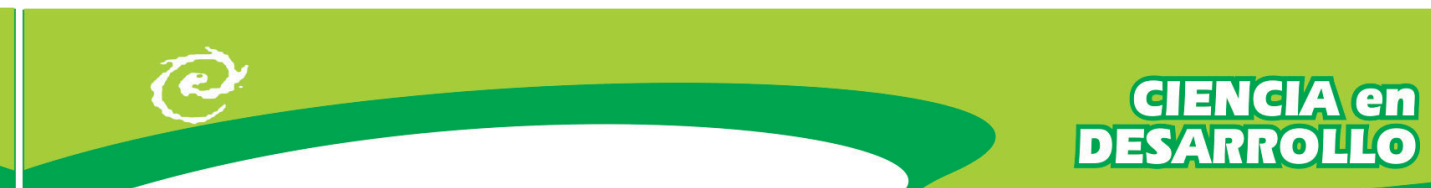

and Gronwall's inequality implies the result.

Theorem 4. Let $s>\frac{1}{2}$ and $\phi \in H^{s}(\mathbb{R})$. Then there exist a $T=T\left(\|\phi\|_{s}, M\right)>0$ and a unique $v \in C\left([0, T] ; H^{s}(\mathbb{R})\right)$ solution of problem (3).

Proof. Let $M, T>0 . T$ will be conveniently chosen later. Consider

$$
(\mathcal{A} v)(t)=\mathbb{V}_{\mu}(t) \phi+\int_{0}^{t} \mathbb{V}_{\mu}(t-\tau)|v|^{2 \sigma} v(\tau) d \tau, \quad v \in \mathcal{X}(M, T, \phi)
$$

defined on the complete metric space

$$
\mathcal{X}(M, T, \phi)=\left\{v \in C\left([0, T] ; H^{s}(\mathbb{R})\right):\left\|v(t)-\mathbb{V}_{\mu}(t) \phi\right\|_{s} \leq M\right\}
$$

provided with the distance $d(u, v)=\sup _{t \in[0, T]}\|u(t)-v(t)\|_{s^{*}}$.

Is easy to show that the map $\mathcal{A}$ has a unique fixed point in the complete metric space $(\mathcal{X}(M, T, \phi), d)$.

Theorem 5. The map $\phi \mapsto v$ defined by (3) is continuous. More precisely: let $\phi^{(n)} \in$ $H^{s}(\mathbb{R}), n=1,2,3, \ldots, \infty$ be such that $\phi^{(n)} \rightarrow \phi^{(\infty)}$ in $H^{s}(\mathbb{R})$ when $n \rightarrow \infty$. Let $v^{(n)} \in C\left(\left[0, T_{n}\right] ; H^{s}(\mathbb{R})\right) \cap C^{1}\left(\left(0, T_{n}\right] ; H^{s-2}(\mathbb{R})\right)$, where $T_{n}=T\left(M,\left\|\phi^{(n)}\right\|_{s}\right)$, be the solutions of (3) with $v^{(n)}(0)=\phi^{(n)}, n=1,2,3, \ldots, \infty$. Let $T \in\left(0, T_{\infty}\right)$. Then the solutions $v^{(n)}$ are defined in $[0, T]$ for all $n$ sufficiently large and

$$
\lim _{n \rightarrow \infty} \sup _{[0, T]}\left\|v^{(n)}-v^{(\infty)}\right\|_{s}=0 .
$$

Theorem 6. Problem (3) is locally well-posed in the sense of Hadamard.

\section{Local Well-Posedness. Case $\mu=0$}

Proposition 3. Let $\phi \in H^{s}(\mathbb{R}), s>\frac{1}{2}$. Then there exist a $T\left(\|\phi\|_{s}\right)>0$ and a function $\rho \in C([0, T] ;[0, \infty))$, both independent of $\mu$, such that $T \leq T^{*}(\mu, \phi)$ (the time of maximal interval of existence $v_{\mu}$ in $H^{s}$ ) for all $\mu>0$ and

$$
\left\|v_{\mu}(t)\right\|_{s} \leq \rho(t) \quad \text { for all } t \in[0, T] .
$$

Proof.

$$
\begin{aligned}
\frac{1}{2} \partial_{t}\left\|v_{\mu}(t)\right\|_{s}^{2} & =(v, i \Delta v)_{s}+\left(v, i|v|^{2 \sigma} v\right)_{s}-\mu(v, H \Delta v)_{s} \\
& \leq\left\|v_{\mu}(t)\right\|_{s}^{2(\sigma+1)}
\end{aligned}
$$

Let $\rho \in C\left(\left[0, T^{*}\right) ;[0, \infty)\right)$ be the maximally extended solution of

$$
\left\{\begin{array}{l}
\frac{\rho(t)}{d t}=2 C_{s}[\rho(t)]^{\sigma+1} \\
\rho(0)=\|\phi\|_{s}^{2} .
\end{array}\right.
$$


For comparision theorem of the theory of ODEs, we must have

$$
\left\|v_{\mu}(t)\right\|_{s}^{2} \leq \rho(t) .
$$

Since $\rho(t)$ and $T^{*}$ do not depend on $\mu$, the usual extension method shows that we must have $0<T\left(\|\phi\|_{s}\right) \leq T^{*}$ for all $\mu>0$. This finishes the proof.

Theorem 7. Let $s>\frac{1}{2}$ be fixed. Then, for every $\phi \in H^{s}(\mathbb{R})$, there exist a $T=T\left(\|\phi\|_{s}\right)>0$ and a function $v_{0} \in C_{w}\left([0, T] ; H^{s}(\mathbb{R})\right) \cap C_{w}^{1}\left([0, T] ; H^{s-2}(\mathbb{R})\right)$ such that $v_{0}(0)=\phi$ and $v_{0}$ is a solution of equation (3) in the weak sense, that is,

$$
\partial_{t}\left(v_{0}(t), \varphi\right)_{s-2}=\left(i \Delta v_{0}(t)+i\left|v_{0}(t)\right|^{2 \sigma} v_{0}(t)-\mathcal{H} \Delta v_{0}(t), \varphi\right)_{s-2}
$$

for all $\varphi \in H^{s-2}(\mathbb{R})$ and $t \in[0, T]$.

Moreover $\left\|v_{0}(t)\right\|_{s} \leq \rho(t)$ for all $t \in[0, T]$ where $\rho$ is as in Proposition 3 .

Proof. Let $T\left(\|\phi\|_{s}\right)$ be as in Proposition 3. We will show that $v_{\mu}$ converges to a function $v_{0} \in C\left(\left[0, T\left(\|\phi\|_{s}\right)\right] ; L^{2}(\mathbb{R})\right)$ in the $L^{2}$-norm uniformly over $\left[0, T\left(\|\phi\|_{s}\right)\right]$. Let $v_{\mu_{1}}$, $v_{\mu_{2}}$ be solutions of (3) with $v_{\mu_{1}}(0)=\phi=v_{\mu_{2}}(0)$, then

$$
\begin{aligned}
\frac{1}{2} \partial_{t}\left\|v_{\mu_{1}}-v_{\mu_{2}}\right\|_{0}^{2} & \leq-\left(\mu_{1}-\mu_{2}\right) \int_{\mathbb{R}}\left(v_{\mu_{1}}-v_{\mu_{2}}\right) \mathcal{H} \Delta v_{\mu_{2}} d x \\
& +i \int_{\mathbb{R}}\left(v_{\mu_{1}}-v_{\mu_{2}}\right)\left(\left|v_{\mu_{1}}\right|^{2 \sigma} v_{\mu_{1}}-\left|v_{\mu_{2}}\right|^{2 \sigma} v_{\mu_{2}}\right) d x
\end{aligned}
$$

Therefore,

$$
\left|v_{\mu_{1}}\right|^{2}-\left|v_{\mu_{2}}\right|^{2}=v_{\mu_{1}}\left(\bar{v}_{\mu_{1}}-\bar{v}_{\mu_{2}}\right) Q\left(\left|v_{\mu_{1}}\right|,\left|v_{\mu_{2}}\right|\right)+\bar{v}_{\mu_{2}}\left(v_{\mu_{1}}-v_{\mu_{2}}\right) Q\left(\left|v_{\mu_{1}}\right|,\left|v_{\mu_{2}}\right|\right)
$$

where

$$
Q(x, y)=x^{2(\sigma-1)}+x^{2(\sigma-2)} y^{2}+\cdots+x^{2} y^{2(\sigma-2)}+y^{2(\sigma-1)} .
$$

Let $M=\sup _{t \in\left[0, T\left(\|\phi\|_{s}\right)\right]} \sqrt{\rho(t)}$ where $\rho$ is the function defined in the proof of Proposition 3. Then

$$
\begin{aligned}
\frac{1}{2} \partial_{t}\left\|v_{\mu_{1}}-v_{\mu_{2}}\right\|_{0}^{2} & \leq\left|\mu_{1}-\mu_{2}\right|\left\|\partial_{x}\left(v_{\mu_{1}}-v_{\mu_{2}}\right)\right\|_{0}\left\|\partial_{x} u_{\mu_{2}}\right\|_{0} \\
& +\left\|v_{\mu_{1}}-v_{\mu_{2}}\right\|_{0}^{2}\left\|\left|v_{\mu_{1}}\right|^{2 \sigma}+\left(\left|v_{\mu_{1}}\right|\left|v_{\mu_{2}}\right|+\left|v_{\mu_{2}}\right|^{2}\right) Q\left(\left|v_{\mu_{1}}\right|,\left|v_{\mu_{2}}\right|\right)\right\|_{L^{\infty}} \\
& \leq M^{2}\left|\mu_{1}-\mu_{2}\right|+C M^{\sigma}\left\|v_{\mu_{1}}-v_{\mu_{2}}\right\|_{0}^{2}
\end{aligned}
$$

The Gronwall's inequality shows that exists a constant $\widetilde{C}>0$

$$
\left\|v_{\mu_{1}}-v_{\mu_{2}}\right\|_{0}^{2} \leq \widetilde{C}\left|\mu_{1}-\mu_{2}\right| \text { for all } t \in\left[0, T\left(\|\phi\|_{s}\right)\right] .
$$

Since $L^{2}$ is complete, then there exists $v_{0} \in C\left([0, T] ; L^{2}\right)$ such that

$$
\lim _{\mu \rightarrow 0} \sup _{t \in\left[0, T\left(\|\phi\|_{s}\right)\right]}\left\|v_{\mu}(t)-v_{0}(t)\right\|_{0}=0 .
$$




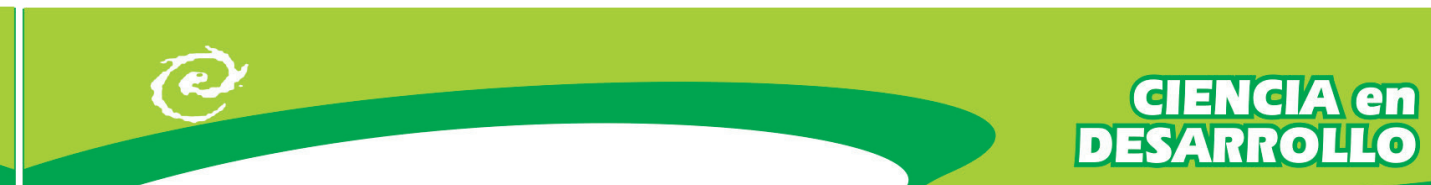

It follows that $v_{\mu}$ converges weakly to $v_{0}$ in $H^{s}(\mathbb{R})$ uniformly over $\left[0, T\left(\|\phi\|_{s}\right)\right]$. In particular $v_{0}(t)$ is weakly continuous and uniformly bounded by the function $\sqrt{\rho(t)}$.

Since $v_{\mu} \rightarrow v_{0}$ in $H^{s}(\mathbb{R})$ it follows that

$$
\begin{array}{r}
\Delta v_{\mu} \rightarrow \Delta v_{0} \text { in } H^{s-2}(\mathbb{R}) \\
\mathcal{H} \Delta v_{\mu} \rightarrow \mathcal{H} \Delta v_{0} \text { in } H^{s-2}(\mathbb{R}) \\
\left|v_{\mu}\right|^{2 \sigma} v_{\mu} \rightarrow\left|v_{0}\right|^{2 \sigma} v_{0} \text { in } H^{s}(\mathbb{R})
\end{array}
$$

uniformly over $\left[0, T\left(\|\phi\|_{s}\right)\right]$, where $\rightarrow$ stands for weak convergence.

Taking the limit as $\mu \rightarrow 0+$ we obtain

$$
\partial_{t}\left(v_{0}(t), \varphi\right)_{s-2}=\left(i \Delta v_{0}(t)+i\left|v_{0}(t)\right|^{2 \sigma} v_{0}(t)-\mathcal{H} \Delta v_{0}(t), \varphi\right)_{s-2}
$$

for all $t \in\left[0, T\left(\|\phi\|_{s}\right)\right]$.

Corollary 1. Let $v_{0}$ be as in preceding Theorem. Then $v_{0} \in A C\left([0, T] ; H^{s-2}\right)$.

$A C(I ; X)$ denotes the collection of all absolutely continuous functions from the interval $I$ into the Banach space $X$, that is, the set of all functions $F: I \rightarrow X$ of the form

$$
F(x)=F(a)+\int_{a}^{x} G(t) d t
$$

where $G: I \rightarrow X$ is Bochner integrable.

Proposition 4. Let $T>0$ be fixed, $\phi_{j} \in H^{s}(\mathbb{R}), j=1,2$, and let $v_{j}:[0, T] \rightarrow H^{s}(\mathbb{R})$ be bounded functions such that $v_{j}(0)=\phi_{j}$ and

$$
v_{j} \in C\left([0, T] ; L^{2}(\mathbb{R})\right) \cap C_{w}\left([0, T] ; H^{s}(\mathbb{R})\right) \cap A C\left([0, T] ; H^{s-2}(\mathbb{R})\right)
$$

Then

$$
\left\|v_{1}(t)-v_{2}(t)\right\|_{0} \leq\left\|\phi_{1}-\phi_{2}\right\|_{0} e^{\widetilde{G}(M, M) t}
$$

where $M=\max \left\{\sup _{[0, T]}\left\|v_{1}(t)\right\|_{s}, \sup _{[0, T]}\left\|v_{2}(t)\right\|_{s}\right\}$.

Theorem 8. Let $v_{0}$ be as in Theorem 7. Then $v_{0} \in C\left([0, T] ; H^{s}(\mathbb{R})\right) \cap C^{1}\left([0, T] ; H^{s-2}(\mathbb{R})\right)$ and is unique solution of NLS.

Proof. The uniqueness follows from Proposition 4. Since $\left\|v_{0}(t)\right\|_{s} \leq \sqrt{\rho(t)}$ it follows at once that

$$
\liminf _{t \rightarrow 0+}\left\|v_{0}(t)\right\|_{s}=\limsup _{t \rightarrow 0+}\left\|v_{0}(t)\right\|_{s}=\|\phi\|_{s},
$$

so that the limit of $\left\|v_{0}(t)\right\|_{s}$ exists as $t \rightarrow 0+$ and

$$
\lim _{t \rightarrow 0+}\left\|v_{0}(t)\right\|_{s}=\|\phi\|_{s} .
$$


Left continuity follows from the invariance of equation in (3) under the transformation

$$
(x, t) \mapsto\left(-x, t^{\prime}-t\right) .
$$

Lemma 1 (Bona-Smith approximation). Let $\phi \in H^{s}(\mathbb{R}), s>\frac{1}{2}, \tau \geq 0$ and introduce

$$
\phi^{\tau}=\exp \left(-\tau\left(1-\partial_{x}^{2}\right)^{\frac{s}{2}}\right) \phi=\left(\widehat{\phi} \exp \left(-\tau\left(1+|\cdot|^{2}\right)^{\frac{s}{2}}\right)\right)^{\prec}
$$

Then

$$
\lim _{\tau \rightarrow 0+}\left\|\phi^{\tau}-\phi\right\|_{s}=0
$$

and, there exist a constant $C=C(s)$ such that

$$
\left\|\phi^{\tau}\right\|_{s+1} \leq C\left[1+\left(\frac{1}{s \tau}\right)^{\frac{2}{s}}\right]^{\frac{1}{2}}\|\phi\|_{s}
$$

and

$$
\left\|\phi^{\tau}-\phi^{\theta}\right\|_{0} \leq C|\tau-\theta|\|\phi\|_{s} .
$$

Proposition 5. Let $s>\frac{1}{2}, \phi \in H^{s}(\mathbb{R}), \phi^{\tau}$ be as in preceding Lemma. If $v_{0}^{\tau}$ is solution of NLS with $v_{0}^{\tau}=\phi^{\tau}$ for all $\tau>0$, then there are constants $C=C\left(s,\|\phi\|_{s}, T\right)>0$ and $\eta=\eta(s) \in(0,1)$ such that

$$
\left\|v_{0}^{\tau}-v_{0}^{\theta}\right\|_{s}^{2} \leq C\left(\left\|\phi^{\tau}-\phi^{\theta}\right\|_{s}^{2}+\tau^{1-\eta}\right)
$$

for $\tau$ sufficiently small and $0 \leq \theta \leq \tau$.

Proposition 6. The map $\phi \mapsto v_{0}$ defined of $H^{s}$ to $C\left([0, T] ; H^{s}\right)$ is continuous.

\section{Global theory in $H^{s}(\mathbb{R})$}

For Global existence we study the Hamiltonian structure with small initial data. The global well-posedness of the Cauchy problem associated to

$$
\left\{\begin{array}{l}
i v_{t}+\Delta v+u|v|^{\sigma-1} v=0, \quad x \in \mathbb{R}, t \geq 0, \\
u-\alpha^{2} \Delta u=|v|^{\sigma+1}, \\
v(0)=\phi
\end{array}\right.
$$

with $\alpha>0$ was study in [3]: 
Theorem 9. Let $\phi \in H^{1}(\mathbb{R})$. If $1 \leq \sigma<3$ then there esists a unique solution $v \in$ $C\left([0, \infty) ; H^{1}(\mathbb{R})\right)$.

Furthermore, the charge

$$
Q(v)=\int_{\mathbb{R}}|v(x, t)|^{2} d x=\|v\|_{0}^{2}
$$

and Hamiltonian

$$
H(v)=\int_{\mathbb{R}}\left(|\nabla v(x, t)|^{2}-\frac{u(x, t)|v(x, t)|^{\sigma+1}}{\sigma+1}\right) d x
$$

are conserved in time.

The following result requires no smallness condition for initial data.

Theorem 10. If $1 \leq \sigma<2$ then the Cauchy problem associated to NLS with initial date $\phi \in H^{1}(\mathbb{R})$ is global well-posed in $H^{1}(\mathbb{R})$.

We used that the charge

$$
Q(v)=\int_{\mathbb{R}}|v(x, t)|^{2} d x=\|v\|_{0}^{2}
$$

and Hamiltonian

$$
H(v)=\int_{\mathbb{R}}\left(|\nabla v(x, t)|^{2}-\frac{|v(x, t)|^{2 \sigma+2}}{2 \sigma+2}\right) d x
$$

are conserved in time for show global well-posedness [9].

\section{References}

[1] B. Alvarez, "On the cauchy problem for a nonlocal perturbation of the KdV equation," Ph.D. dissertation, IMPA, 2002.

[2] J. Bona \& R. Smith, "The initial value problem for the Korteweg-De Vries equation," Phil. Trans. Roy. Soc. London, Ser. A, n. 278, pp. 555-604, 1975.

[3] Y. Cao, Z. Musslimani \& E. Titi, "Nonlinear Schrödinger-Helmholtz equation as numerical regularization of the nonlinear Schrödinger equation," Nonlinearity, vol. 21, 2008.

[4] R. De la cruz, "Buen planteamiento local para una modificación de la ecuación Korteweg-De Vries," Revista Sigma, vol. IX, n. 2, pp. 12-16, 2009.

[5] R. De la cruz, "Buen planteamiento para un par de ecuaciones regularizadas asociadas a la ecuación Benjamín-Ono," Master's thesis, Universidad Nacional de Colombia, 2009.

[6] R. De la cruz, "Parabolic regularization and nonlinear Schrödinger equation," in ICAMI 2010: A commemorative synopsis. ICAMI 2010: International Conference on Applied Mathematics and Informatics, 2010. 
[7] R. Iorio, "KdV, BO and Friends in weighted Sobolev spaces," in Function Analytic Methods for Partial Equations. New York: Springer - Verlag, vol. 1450, 1990, pp. 105 121.

[8] R. lorio, Introdução as equações de evolução não lineares. Rio de Janeiro: IMPA, 1991.

[9] R. Iorio, Fourier Analysis and Partial Differential Equations, ser. Cambridge studies in advanced mathematics. Cambridge University Press, 2001, vol. 70.

[10] R. Miura, "Korteweg-De Vries equation and generalizations i: A remarkable explicit nonlinear transformation," Journal of Mathematical Physics, vol. 9, pp. $1202-1204$, 1968.

[11] G. Scoufis, "An application of the inverse scattering transform to some nonlinear singular integro-differential equations," Ph.D. dissertation, University of Sydney, 1999. 


\title{
CARACTERIZACIÓN FÚNGICA EN EL ARCHIVO HISTÓRICO DE LA UNIVERSIDAD PEDAGÓGICA Y TECNOLÓGICA DE COLOMBIA
}

\section{FUNGAL CHARACTERIZATION IN THE HISTORICAL ARCHIVE OF UNIVERSIDAD PEDAGÓGICA Y TECNOLÓGICA DE COLOMBIA, SEAT TUNJA}

\author{
David Hernández-Velandia ${ }^{1 *}$ \\ Esteban López-Valiente ${ }^{2 * *}$ \\ Luz Marina Lizarazo-Forero ${ }^{3 * * *}$
}

\section{Resumen}

Las esporas fúngicas se consideran componentes ambientales de espacios cerrados y muchas de ellas son responsables de causar biodeterioro de libros y material audiovisual. Para la Universidad Pedagógica y Tecnológica de Colombia (UPTC) es muy importante la conservación de los bienes culturales del archivo histórico, por tal razón, en este trabajo identificamos hasta géneros comunidades de hongos presentes en el medio ambiente y en los documentos. La metodología utilizada para detectar las esporas, fue la sedimentación en placa con Agar papa dextrosa, a fin de obtener una estimación cualitativa de la presencia de

1 * Semillero de investigación Biofilia, grupo de investigación Biología Ambiental, Universidad Pedagógica y Tecnológica de Colombia. Correo electrónico: davidhvel@gmail.com

2 ** Semillero de investigación Biofilia, grupo de investigación Biología Ambiental, Universidad Pedagógica y Tecnológica de Colombia. Correo electrónico: estebanl88@hotmail.com

$3^{* * *} \mathrm{Ph}$ D. Profesora asociada, coordinadora grupo de investigación Biología Ambiental, Universidad Pedagógica y Tecnológica de Colombia. Correo electrónico: luz.lizarazo@uptc.edu.co 
hongos en los ambientes. Además se realizó el raspado de los libros afectados. La temperatura y humedad relativa se determinaron durante cada muestreo. El hongo Penicillium sp. (46,1\%) fue el género más frecuentemente aislado de los sitios de muestreo marcados $A$ y $B$, y de los libros de la muestra. Otros géneros aislados fueron Mucor sp., (16,9\%), Aspergillus sp., (10,8 \%) y Chaetomiun sp. (7,7\%).

Palabras claves: Biodeterioro, mohos, levaduras, archivo histórico.

\section{Abstract}

Fungal spores are considered environmental components of closed spaces and many of them are responsible of biodeterioration of books and audiovisual material. For Universidad Pedagógica y Tecnológica de Colombia (UPTC) is very important the conservation of its cultural assets of the historical archive. For this reason, in this work we identified even genres communities of fungi present in the environment and in documents. The methodology that we used to detect spores was the sedimentation in plaque with potato dextrose Agar, in order to obtain a qualitative estimation of the presence of fungi in environments. We also made the scraping of the affected books. Temperature and relative humidity were determined for each sample. The fungus Penicillium sp. (46.1\%) was the most frequently isolated genus of sampling sites marked as $A$ and $B$, and of the sampled books. Other isolated genera were Mucor sp. (16.9\%), Aspergillus sp. (10.8\%) and Chaetomiun sp. (7.7\%).

Keywords: Biodeterioration, molds, yeasts, historical archive.

\section{Introducción}

En el aire existe una enorme cantidad de partículas fúngicas de dimensiones relativamente grandes, que constituyen el grupo de los hongos anemófilos que, al ser inhalados, provocan cuadros respiratorios más o menos severos en individuos susceptibles y que se traducen en una serie de patologías $[1,2,3]$. 
Varias investigaciones se ha documentado la implicación de los hongos sobre el biodeterioro de libros, objetos de arte, material audiovisual, pintura, papel tapiz, madera, murales, pieles y otros, citando como los géneros más frecuentes a Chaetomium, Penicillium, Aspergillus, Stachybotrys, Paecilomyces, Cladosporium, Alternaria $[4,5,6]$.

Las condiciones que favorecen la contaminación microbiológica del aire en ambientes internos, son la humedad elevada y la temperatura [7], íntimamente relacionadas, por lo que es difícil separar los efectos que producen ambas, aunque siempre es necesario un sustrato que proporcione al hongo sus nutrientes, como la madera, la celulosa, las cortinas o las alfombras [8, 9, 10].

Ciertos hongos son alérgenos y algunos son patógenos de plantas o de humanos y producen micotoxinas. Estos hongos podrían suponer un riesgo potencial para la salud de los ocupantes de espacios cerrados, como edificios de oficinas $[11,12,13,14,15$, $16,17]$. Aproximadamente el $20 \%$ de la población humana sufre de procesos alérgicos que pueden ser provocados por la inhalación o la infestación de hongos [18,19].

El Archivo Histórico de la Universidad Pedagógica y Tecnológica de Colombia (UPTC) alberga documentos tales como resoluciones, certificados, entre otros documentos, desde el año 1953 hasta 1980. Con este trabajo, se buscó aislar las diferentes colonias fúngicas presentes en el Archivo Histórico, que pueden ser causantes del deterioro de los documentos y que podrían originar reacciones alérgicas en el personal, así como relacionar su crecimiento con la temperatura y humedad relativa del ambiente. Hay que anotar que este es el primer estudio aerobiológico realizado en el Archivo Histórico de la UPTC.

\section{Materiales y métodos}

El presente estudio se hizo en el Archivo Histórico, ubicado dentro del campus de la UPTC, durante los meses de agosto y septiembre. En dicho lugar se encuentra además un taller de scream y la oficina de especialización en archivística. 


\section{Recolección de muestras ambientales}

El muestreo ambiental se efectuó por medio del método gravimétrico de sedimentación en placa, descrito por Omeliansky $[20,21]$. Las muestras fueron tomadas semanalmente, realizándose cuatro muestreos en total, cada uno de estos hacia las 10:00 horas. Se expusieron al ambiente durante treinta minutos cajas de Petri que contenían Agar PDA (Agar Papa Dextrosa-Scharlau)®.

Para el muestreo, se dividió el área en dos zonas identificadas como A y B. En el lugar denominado A, existen 23 estantes, de los cuales se tomó el $10 \%$ usando la metodología planteada por Gómez et al. [22]. Se ubicaron de manera aleatoria cajas de Petri en la parte superior (a una altura aproximada de $230 \mathrm{~cm}$ ), parte media $(\mathrm{a} 155 \mathrm{~cm}$ ) y parte baja (a 25 $\mathrm{cm}$ ), con respecto al nivel del suelo, en los tres estantes seleccionados. El segundo lugar, denominado $B$, corresponde a un pequeño cuarto donde se almacenan libros y revistas, que no están debidamente ordenados en estantes. La toma de muestras se hizo de forma similar al sitio A, dejando cajas de Petri a una altura de $15 \mathrm{~cm}$ en promedio. Así mismo, se tomaron muestras en documentos afectados por hongos, haciendo un raspado con espátula micológica en la superficie de estos; después se procedió a sembrar la muestras en cajas de Petri que contenían Agar PDA (Agar Papa Dextrosa-Scharlau) ${ }^{\circledR}$.

\section{Análisis de muestras ambientales}

Las placas de Petri se incubaron a $28^{\circ} \mathrm{C}$, durante una semana o hasta observar desarrollo de colonias fúngicas. Las colonias fúngicas se identificaron hasta género, según morfología macroscópica y microscópica, por lo cual se hicieron montajes con azul de lactofenol, empleando la técnica de la impronta [23], por medio de cinta adhesiva transparente y montajes entre lámina y laminillas. Los montajes fueron observados en microscopio óptico de luz, con objetivos de 10x y 40x. Así mismo, se emplearon las claves de identificación taxonómica de hongos $[24,25,26,27]$.

\section{Temperatura y humedad relativa}

Simultáneamente a la toma de muestras ambientales, se reportaron datos de temperatura y humedad relativa del ambiente, 


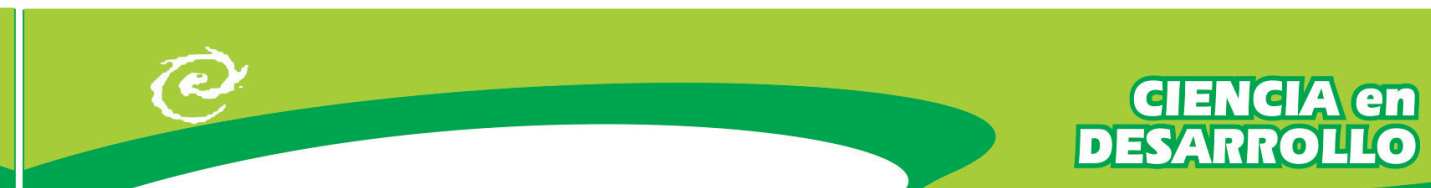

empleándose un medidor atmosférico (Davis)®, cada diez minutos, durante el tiempo de exposición de las cajas de Petri.

\section{Resultados}

\section{Análisis fúngico del archivo}

En el sitio A se registró un total de 29 colonias fúngicas pertenecientes a diez géneros entre hongos filamentosos y levaduras. Los hongos filamentosos aislados fueron Mucor, Penicillium, Geotrichum, Cladosporium, Alternaria, Aspergillus, Chaetomium, Helminthosporium, Rhizopus y un hongo levaduriforme perteneciente al género Rhodotorula. El género Mucor representó el $33.3 \%$ del total de las colonias fúngicas aisladas, seguido por Penicillium (22.2 $\%)$, Geotrichum (14.8\%), Cladosporium (11.1\%) y Alternaria (7.4\%). Los géneros Aspergillus, Helminthosporium, Chaetomium, Rhizopus y Rhodotorula representaron cada uno el $3.7 \%$ (Figura 1).

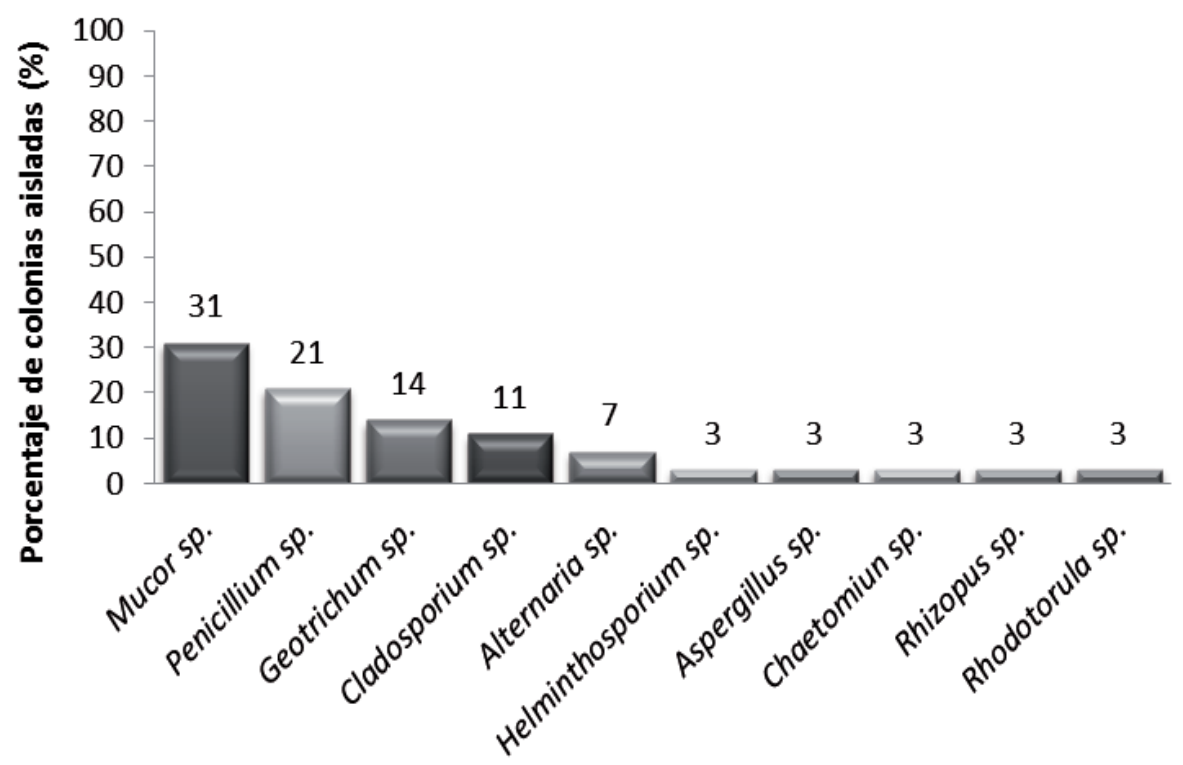

Géneros fúngicos reportados

Figura 1. Porcentaje promedio de colonias aisladas en el sitio $A$.

En el lugar B se aisló un total de 22 colonias pertenecientes a cinco géneros: Penicillium, Aspergillus, Chaetomium, Fusarium y Mucor. De estos 
géneros, Penicillium (54.4\%), fue el hongo más representativo de este lugar, seguido por Aspergillus con un $27.2 \%$, sobre el total de las colonias. Por su parte, los géneros Chaetomium, Fusarium y Mucor representaron cada uno el $9.1 \%$ (Figura 2).

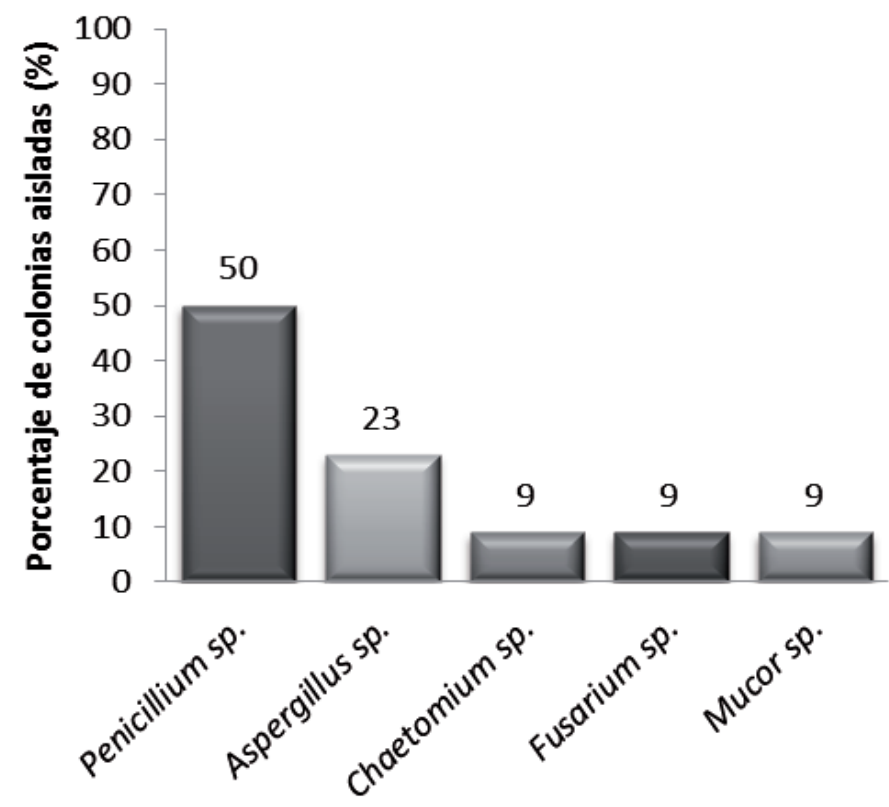

Géneros fúngicos reportados

Figura 2. Porcentaje promedio de colonias aisladas en el sitio B

En total se aislaron 65 colonias pertenecientes a once géneros fungicos: Mucor, Penicillium, Geotrichum, Cladosporium, Alternaria, Aspergillus, Chaetomium, Helminthosporium, Rhizopus, Fusarium y Rhodotorula.

De estos, Penicillium, Mucor, Aspergillus y Chaetomium se registraron en los dos lugares de muestreo (Figuras 3, 4, 5, 6). En general, en el lugar A se encontró un número mayor de colonias y géneros, en comparación con el lugar B. Penicillium (46.1\%) fue el género con mayor número de colonias en los dos lugares y en los libros muestreados, seguido por Mucor (16.9\%), Aspergillus (10.8 $\%)$, y Chaetomium $(7.7 \%)$ (Tabla 1$)$. 


\section{बाझत्तिबत DESABROLRO}

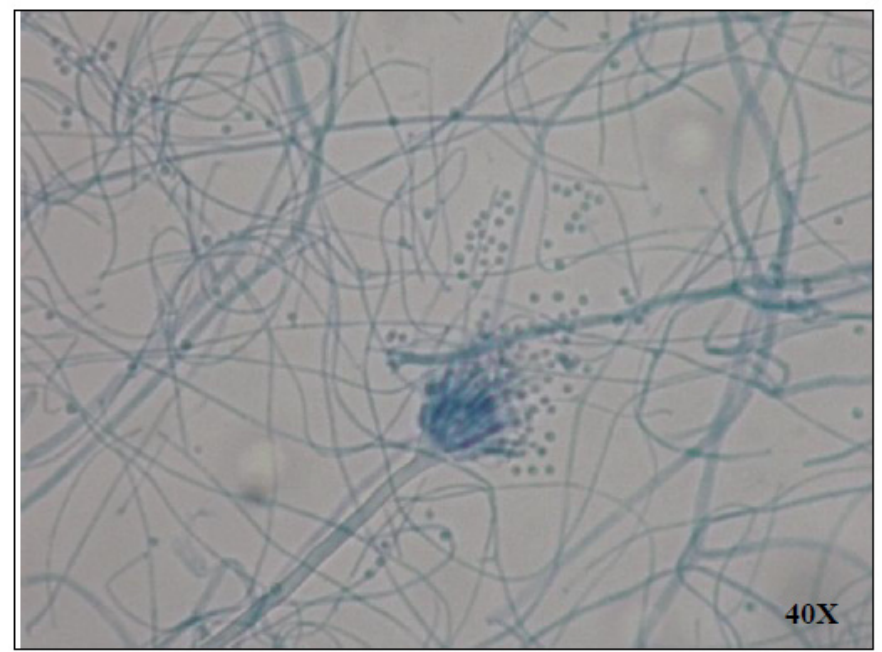

Figura 5. Género Aspergillus (fuente los autores)

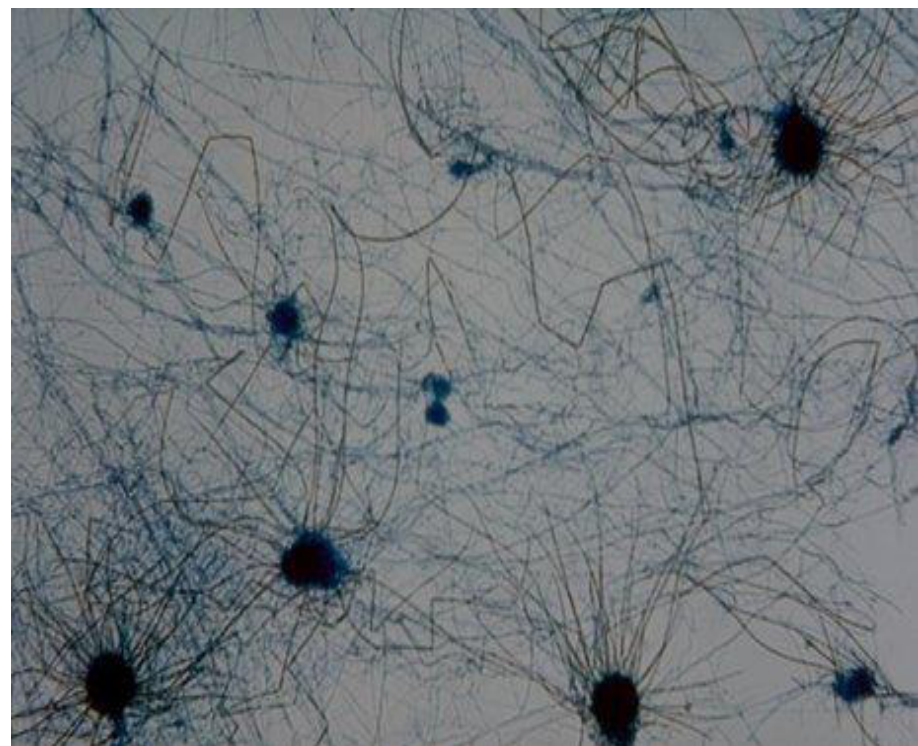

Figura 6. Género Chaetomium (fuente los autores)

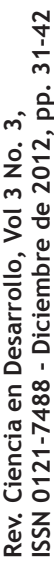




\section{Variables ambientales}

En el sitio A se registró una temperatura promedio de $19^{\circ} \mathrm{C}( \pm$ $0.95)$ y una humedad relativa promedio de $59.5 \%( \pm 1.9)$. En el sitio $B$ se presentó una temperatura y una humedad relativa promedio de $20{ }^{\circ} \mathrm{C}( \pm 4.1)$ y $56.7 \%( \pm 4.8)$, respectivamente.

\section{Discusión}

En los sitios A y B se registró la presencia de Penicillium, siendo el género que se aisló con mayor frecuencia. Las esporas de este género de hongos son un componente habitual de la aeromicoflora de interiores y exteriores [28, 29, 30, 31, 32, 33, 34, 35, 36]. Sus conidios, como los de Aspergillus, están en todas partes, en el aire y en el suelo. Algunas especies de Penicillium pueden comportarse como patógenos y causar enfermedades como alergias, asma y alveolitis alérgica [9, 30]. A su vez, según De la Rosa et. al. [37], este género está implicado en casos de hipersensibilidad. También se ha reportado la especie Penicillium frequentans, como causante de suberosis [38].

Mucor, representado por un $17 \%$, es un género saprófito y aerobio, presente en el polvo [33]. Según Gallo [4], es uno de los responsables de causar el biodeterioro de libros y madera. Mucor, junto con otros hongos como Cladosporium, son frecuentemente causantes de enfermedades como rinitis, asma y neumonías [38].

El género Aspergillus es muy común en ambientes internos y cerrados $[30,31,32,33,34,35,36,39]$. Este fue el tercer género con mayor número de colonias. Sus esporas se dispersan fácilmente en el aire, debido a un mayor tamaño aerodinámico, y producen enzimas que les permite habitar en cualquier sustrato con humedad óptima para su crecimiento. Algunas especies producen micotoxinas, mientras que otras son patógenas para el hombre, ocasionando manifestaciones clínicas como asma bronquial, aspergilosis alérgica broncopulmonar, alveolitis alérgica extrínseca, aspergioma y aspergilosis invasiva [30, 40, 41].

Chaetomiun es un genero fúngico que se puede encontrar sobre papel húmedo. Sus hifas atacan la pared secundaria de las traqueidas y de las fibras leñosas. Algunas especies producen micotoxinas. Un 
antibiótico "chaetomina", se ha aislado de Ch. cochlioides [9, 30]. Hidalgo y Borrego [42] encontraron que este género es moderamente degradativo de la celulosa del papel.

La humedad relativa de los sitios $\mathrm{A}$ y $\mathrm{B}$, es menor a lo reportado por Lidwell en 1990 [43], quien menciona que el $65 \%$ de la humedad relativa, es el valor mínimo para el crecimiento de hongos. Los niveles elevados de hongos que muestran grados variables de xerofilia, al tener una necesidad menor de agua, pueden indicar la existencia de sitios de cultivo que son menos húmedos, pero, aun así, importantes para el crecimiento [44, 45]. Varían desde especies de Cladosporium ligeramente xerófilas (capaces de soportar condiciones de sequedad) a especies moderadamente xerófilas, como Aspergillus versicolor y algunas del género Penicillium, y las extremadamente xerófilas como Aspergillus penicillioides, Eurotium y Wallemia [13, 46].

\section{Conclusiones}

Del ambiente se aislaron hongos de los géneros Penicillium, Mucor, Aspergillius, Cladosporium, Alternaria, reconocidos como agentes patógenos oportunistas de alergias, rinitis, asma, conjuntivitis. Además han sido implicados en el síndrome del edificio enfermo.

En los documentos analizados se aislaron los géneros Penicillium y Chaetomium, hongos de los que se ha confirmado que poseen actividad fúngica en papel, por la formación de compuestos metabólicos volátiles

\section{Agradecimientos}

Los autores del trabajo expresan un agradecimiento muy especial a la bióloga Deisy Lisseth Toloza Moreno, por su apoyo y colaboración, al fitopatólogo Jorge Orlando Blanco, por su colaboración en la confirmación de los géneros fúngicos, ya la Dirección de Investigaciones (DIN) de la UPTC, por la financiación del proyecto.

\section{Referencias}

[1] J. Salvaggio \& L. Aukurst, "Mould induced asthma", J. Allergy Clin. Immunol., vol. 68, pp. 327-346, 1981. 
[2] J. Portnoy, C. S. Barnes \& K. Kennedy, "Sampling for indoor fungi, current reviews of allergy and clinical immunology", The Journal of Allergy and Clinical Immunology, vol. 13, pp. 189-198, 2005.

[3] P. Salo, S. Arbes, M. Sever, R. Jaramillo, R. Cohn \& S. London, "Exposure to Alternaria alternate in US homes is associated with asthma symptoms", The Journal of Allergy and Clinical Immunology, vol. 118, $n^{\circ}$ 4, pp. 892-898, 2006.

[4] F. Gallo, "Aerobiological research and problems in libraries", Aerobiologia, vol. 9, pp. 117-130. 1993.

[5]A. Singh, M. Ganguli, A. B. Singh, "Fungal spores are an important component of library air", Aerobiologia vol. 11, n 4, pp. 231-37, 1995.

[6] M. Nugari, M. Realini \& A. Roccardi, "Contamination of mural paintings by indoor airborne fungal spores", Aerobiologia, vol. 9, n²-3, pp. 31-39, 1993.

[7] J. Karbowska-Berent, R. Górny, A. Strzelczyk \& A. Wlazlo, "Airborne and dust borne microorganisms in selected Polish libraries and archives", Building and Environment, vol. 46, pp. 1872-1879, 2011.

[8] B.G. Shelton, K.H. Kirkland, W.D. Flanders \& G.K. Morris, "Profiles of airborne fungi in buildings and outdoor environments in the United States", Appl. Environ. Microbiol., vol. 68, pp. 1743-1753, 2002.

[9] L. C. Sáenz \& B. M. Gutiérrez, "Esporas atmosféricas en la comunidad de Madrid", en Documentos técnicos de salud pública. Comunidad de Madrid. Madrid: Consejería de Sanidad, 2003.

[10]P. Chandra-Mouli, S. Venkata-Mohan \& S. Jayarama-Reddy, "Assessment of microbial (bacteria) concentrations of ambient air al semi-arid urban region: influence of meteorological factors", Applied Ecology and Environmental Research, vol. 3, $n^{\circ}$ 2, pp. 139-149, 2005.

[11] D. J. Bueno, J. O. Silva \& G. Oliver, "Hongos ambientales: un año de estudio", Anales de Documentación, vol. 6, pp. 27-34, 2003.

[12] T. A. Guerrero, D. Sánchez-Ruiz, J. F. Martínez-Chacón, Y. Yánez-García, R. Chacón-Álvarez, \& M. Chio-Wong, "Aislamiento de hongos en instalaciones deportivas de la UNAM", Rev Fac Med UNAM, vol. 46, n 3, pp. 93-96, 2003.

[13] B. Flannigan, "Calidad del aire interior: contaminación biológica. Riesgos ambientales", Enciclopedia de Salud y Seguridad en el Trabajo, 2007.

[14] T. I. Rojas, E. Martínez, M. J. Aira \& M. Almaguer, "Aeromicota de ambientes internos: comparación de métodos de muestreo", Boletín Micológico, vol. 23, pp. 67-73, 2008.

[15] J.D. Miller, "Fungi as contaminants in indoor air", Atmospheric Environment, vol. 26A, pp. 2163-2172, 1992.

[16] S. N. Labarrere, F. A. Gómez, R. I. Ávila, A. M. E. Guevara \& L. B. Fernández, "Riesgos biológicos en ambientes confinados", Revista Cubana de Salud y Trabajo, vol. 4, n 1-2, pp. 4-7, 2003.

[17] M. Zuraimi \& K. Tham, "Indoor air quality and its determinants in tropical child care centers", Atmospheric Environment, vol. 42, pp. 2225-2239, 2008. 
[18] D. W. Li \& B. Kendrick, "A year-round comparison of fungal spores in indoor and outdoor air", Mycologia, vol. 87, pp. 190-195, 1995a.

[19] D. W. Li \& B. Kendrick, "A year round out door aeromycological studying Waterloo, Ontario, Canada", Grana, vol. 34, pp. 199-207, 1995b.

[20] E. Bogomolova \& I. Kirtsideli, "Airborne fungi in four stations of the St. Petersburg underground railway system", International Biodeterioration and Biodegradation, vol. 63, pp. 156-160, 2009.

[21] S. Borrego, V. Pons \& I. Perdomo, "La contaminación microbiana del aire en dos depósitos del Archivo Nacional de la República de Cuba”, Revista CENIC Ciencias Biológicas (Cuba), vol. 39, n 1, pp. 63-69, 2008.

[22] A. Gómez, I. Garante, J. C. Martínez, M. A. Valdivieso, L. L. Rubio, G. P. Tarazona \& M.S. Medina, "Evaluación de alergenos presentes en polvo y ambiente de algunas bibliotecas de Bogotá, D.C.", Universitas Médica, vol. 46, $n^{\circ}$ 1, pp. 13-20, 2005.

[23] M. Schaechter, F. Neidhardt \& J. Ingraham, "Microbe", Ed. American Society for Microbiology (Estados Unidos), pp. 610, 2006.

[24] H. Barnett, Illustrated Genera of Imperfect Fungi, 2nd ed. Estados Unidos: Burgess Publishing Company, 1960.

[25] H. Barnett \& B. Hunter, "Illustrated Genera of Imperfect Fungi", $3^{\text {th }}$ ed. Estados Unidos: Burgess Publishing Company, 1972.

[26] K. Domsh, W. Gams \& T. Anderson, Compendium of Soil Fungi, vol. 1, 1 $1^{\text {st }}$ part, Estados Unidos: Academic Press, 1980a.

[27] K. Domsh, W. Gams \& T. Anderson, Compendium of Soil Fungi, vol. 1, $2^{\text {nd }}$ Part, Estados Unidos: Academic Press, 1980b.

[28] S. Shadzi, M.H. Zahraee \& M. Chadegani. "Incidence of airborne fungi in Isfahan, Iran", Mycoses, vol. 36, pp. 69-73, 1993.

[29] V. Ibáñez, L. Thompson \& J. Mañalich, "Fluctuación estacional de hongos anemófilos en Santiago -norte- Chile”, Boletín Micológico, vol. 13, pp. 4756, 1998.

[30] C. Calizaya, G. Salazar \& J. Silva, "Evaluación de hongos ambientales en mercados de abastos de la ciudad de Tacna, Perú", Revista Mexicana de Micología, vol. 31, pp. 65-67, 2010.

[31] S. Docampo, M. M. Trigo, M. Recio, M. Melgar, J. García-Sánchez, M. C. Calderón-Ezquerro \& B. Cabezudo, "High incidence of Aspergillus and Penicillium sporesin the atmosphere of the cave of Nerja (Malaga, southern Spain)", Aerobiologia, vol. 26, pp. 89-98, 2010.

[32] D. W. Li \& J. Lamondia, "Airborne fungi associated with ornamental plant propagation in greenhouses", Aerobiologia, vol. 26, pp. 15-28, 2010.

[33] S. Borrego \& I. Perdomo, "Aerobiological investigations inside repositories of the National Archive of the Republic of Cuba", Aerobiologia, vol. 28, $n^{\circ} 3$, pp. 303-316. September 2012. 
[34] T. S. Nayar \& P. S. Jothish, "An assessment of the air quality in indoor and outdoor air with reference to fungal spores and pollen grains in four working environments in Kerala, India", Aerobiologia, vol 29, n 1, pp. 131152. March 2013.

[35] R. Balasubramanian, P. Nainar \& A. Rajasekar, "Airborne bacteria, fungi, and endotoxin levels in residential microenvironments: a case study", Aerobiologia, vol. 28, $n^{\circ}$ 3, pp. 375-390. September 2012.

[36] P. Reanprayoon \& W. Yoonaiwong, "Airborne concentrations of bacteria and fungi in Thailand border market", Aerobiologia, vol 28, $n^{\circ} 1, p p .49-60$. March 2012.

[37] M.C. De La Rosa, M.A. Mosso \& C. Ullán, "El aire: hábitat y medio de transmisión de microorganismos", Revista UCM, vol. 5, pp. 375-402, 2002.

[38] A. Villar, A. X. Muñoz, M. J. Cruz, \& F. Morell, "Neumonitis por hipersensibilidad a Mucor sp. en un trabajador en la industria del corcho", Archives Bronconeumology, vol. 45, nº 8, pp. 405-407, 2009.

[39] I. Pyrri \& E. Kapsanaki-Gotsi, "Diversity and annual fluctuations of culturable airborne fungi in Athens, Greece: a 4-year study", Aerobiologia, vol 28, $n^{\circ} 2$, pp. 249-262. June 2012.

[40] R.L. Quiroga de Pascual \& R. Nobile, "Incidencia de hongos ambientales durante un año en la ciudad de Córdoba”, Revista Argentina de Micología, vol. 8, pp.16-22, 1985.

[41] Z.G. Nunes, A.S. Martins, A.L. Altoe, M.M. Nishikawa, M.O. Leite, P.F. Aguiar, \& S.E. Fracalanzza, "Indoor air microbiological evaluation of offices, hospitals, industries, and shopping centers", Instituto Oswaldo Cruz, vol. 100, pp. 321-330, 2005.

[42] Y. Hidalgo \& S. Borrego, "Aislamiento y caracterización de hongos en documentos de la Biblioteca Nacional José Martí", Anales de investigación, vol. 2, pp. 95-101, 2006.

[43] Lidwell, O.M., Principles of bacteriology, virology and immunity. Ed. Edward Arnold, London, 1990.

[44] L. Medina, A. Tuozzo, J. Herrera, Y. Perozo \& L. González, "Estudio de hongos en bibliotecas de la Universidad de Carabobo-Valencia", Revista Universidad, vol. 3, $n^{\circ}$, pp. 5-20, 1999.

[45] N. Valentín, "Microbial contamination in archives and museums: health hazards and preventive strategies using air ventilation systems", The Getty Conservation Institute, 2007.

Retrieved from: http://www.getty.edu/conservation/science/climate/paper valentin.pdf.

[46] A. M. Jones \& R.M. Harrison, "The effects of meteorological factors on atmospheric bioaerosol concentrations-a review", Science of the Total Environment, vol. 326, n 1-3, pp. 151-180, 2003. 


\title{
SÍNTESIS DE COLOIDES DE Au, \\ Ir E Ir-Au Y SU ESTUDIO EN LA HIDROGENACIÓN DE ACROLEÍNA EN FASE GAS
}

\section{COLLOID SYNTHESIS OF Au, Ir AND Ir-Au AND ITS STUDY ON HYDROGENATION OF ACROLEIN IN GAS PHASE}

\author{
Hugo A. Rojas Sarmiento ${ }^{1 *}$ \\ Sonia Mancipe Estévez ${ }^{2 * *}$ \\ José J. Martínez Zambrano ${ }^{3 * * *}$ \\ Patricio Reyes ${ }^{\square *}$ \\ Maria H. Brijaldo ${ }^{\square * * * * *}$
}

\section{Resumen}

Estudiamos la síntesis de catalizadores coloidales de Au, Ir e IrAu, soportados en $\mathrm{TiO}_{2}$. Los sólidos obtenidos fueron caracterizados por difracción de rayos $X(X R D)$, reducción a temperatura programada (TPR), fisisorción de nitrógeno, quimisorción de hidrógeno y microscopia electrónica de transmisión (TEM). La actividad catalítica se evaluó en la hidrogenación selectiva de acroleína en fase gas. Los resultados de caracterización indicaron que las partículas metálicas no estaban completamente reducidas, por lo que fue necesario un posterior tratamiento térmico de reducción a $773 \mathrm{~K}$; tratamiento que no afectó el tamaño de partícula obtenido por microscopia electrónica de transmisión. La adición de iridio a oro incrementó la capacidad de disociación de hidrógeno con respecto al catalizador de oro

\footnotetext{
1 * Grupo de Catálisis, Universidad Pedagógica y Tecnológica de Colombia -UPTC-, Tunja, Colombia. Autor de correspondencia: hurojas@udec.cl

$2{ }^{* * * *}$ Grupo de Catálisis, Universidad de Concepción, Concepción, Chile.

$3^{* * * * * *}$ Instituto de Química, Campus do Valonguinho, Universidade Federal Fluminense, Niterói-RJ-Brasil.
} 
monometálico y mejoró su actividad catalítica en la hidrogenación selectiva del grupo $\mathrm{C}=\mathrm{O}$ de la acroleína.

Palabras claves: Hidrogenación, acroleína, coloides, oro, iridio,
$\mathrm{TiO}_{2}$.

\section{Abstract}

We studied the synthesis of colloidal catalysts of $\mathrm{Au}$, Ir and AuIr, supported on $\mathrm{TiO}_{2}$. The solids obtained were characterized by $X$ ray diffraction (XRD), temperature programmed reduction (TPR), nitrogen physisorption, chemisorption of hydrogen and transmission electronic microscopy (TEM). The catalytic activity was evaluated in the selective hydrogenation of acrolein in gas phase. The results of characterization indicated that the metal particles were not completely reduced, so it was necessary a subsequent heat treatment of reduce at $773 \mathrm{~K}$. This treatment did not affect the particle size obtained by transmission electron microscopy. The addition of iridium to gold increased the dissociation capacity of hydrogen with respect to the monometallic gold catalyst and improved catalytic activity in the selective hydrogenation of $\mathrm{C}=\mathrm{O}$ group of acrolein.

Keywords: Hydrogenation, acrolein, colloids, gold, iridium, $\mathrm{TiO}_{2}$.

\section{Introducción}

Dentro de las reducciones quimioselectivas de aldehídos $\alpha, \beta-$ insaturados, se convierte en un gran reto científico la hidrogenación del enlace $\mathrm{C}=\mathrm{O}$ en la molécula de acroleína. La ausencia de sustituyentes en el enlace $\mathrm{C}=\mathrm{C}$, desfavorece la adsorción preferencial del grupo $\mathrm{C}=\mathrm{O}$, la reducción de acroleína produce una baja selectividad en comparación con las moléculas de crotonaldehído, citral y cinamaldehído [1]. Un enfoque útil es el uso de catalizadores de oro soportado, que han mostrado favorecer la conversión hacia los alcoholes insaturados en las hidrogenaciones selectivas $[1,2,3$, $4,5,6,7,8]$. Sin embargo, la capacidad de disociación de hidrógeno en los catalizadores de oro es menor comparada con los metales del grupo 8-10 [9,6]. Por tanto, la modificación de partículas de oro por un segundo metal que favorezca la velocidad de disociación de 
hidrógeno molecular y además incremente la actividad catalítica del oro, es un aspecto interesante en catálisis heterogénea, por esto ha sido de provecho el estudio de partículas bimetálicas de Ir-Au soportadas [10,11].

Por otra parte, el control en la formación de clusters de $A u^{0}$, permite investigar la dependencia del tamaño de partícula en el comportamiento catalítico, generalmente los catalizadores de oro soportado son sintetizados por impregnación incipiente [12], deposición-precipitación [13] o coprecipitación [5], mostrándose en estos métodos que el soporte influye drásticamente en la formación de los clusters de oro [7]. Una metodología interesante es la síntesis de coloides metálicos [14, 15, 16], que por reducción química de sus sales precursoras, presentan tamaños de partícula independientes del soporte. Para prevenir la agregación de las nanopartículas metálicas, son empleados agentes estabilizantes, pero muchas veces estos interfieren en la selectividad obtenida [17]. En este sentido, debe recurrirse a métodos donde se use el soporte como agente estabilizante. Recientemente, Reyes et al., [18] informaron que es posible obtener coloides de $\mathrm{Pt}$ con un pequeño tamaño de partícula, usando el soporte como agente estabilizante y reduciendo el metal a altas presiones de hidrógeno en medio básico. La solubilidad del metal en la solución se incrementa y a su vez se desplaza el equilibrio de óxido-reducción a la formación del metal reducido y soportado.

En este trabajo se buscó la optimización de coloides metálicos de oro, respecto al tamaño y composición. La síntesis de coloides condujo a excepcionales selectividades hacia la reducción preferencial del grupo carbonilo en la acroleína, además fue posible la obtención de sistemas bimetálicos que incrementaron la capacidad hidrogenante del oro.

\section{Parte experimental}

Las muestras coloidales de Au (1\%), Ir (1\%) y Au-Ir (0.5-0.5\%), se prepararon en suspensión del soporte por el método de alta presión de $\mathrm{H}_{2}$ en medio básico, método reportado por Reyes et al., [18], para lo cual $3 \mathrm{~g}$ de soporte ( $\mathrm{TiO}_{2}$ Degussa P-25), una solución estequiométrica de $\mathrm{NaOH}$ y el precursor metálico se sometieron a una presión de $\mathrm{H}_{2}$ de 4,13 MPa en un autoclave recubierto de teflón durante $24 \mathrm{~h}$, 
con agitación a $1000 \mathrm{rpm}$, posterior filtración y secado bajo vacío a temperatura ambiente. Los precursores usados fueron $\mathrm{H}_{2} \mathrm{IrCl}_{6}$ (Aldrich) y $\mathrm{HAuCl}_{4}$ (Aldrich).

El área superficial de los sólidos fue evaluada por el método del punto B en un equipo Micromeritics Autochem 2920. Los análisis de difracción de rayos $X(X R D)$ se realizaron en un equipo X'Pert + PRO system PANalytical (configuración: Bragg-Brentano). Los estudios de reducción a temperatura programada (TPR) se evaluaron en un equipo Micromeritics Autochem 2920, asistido por espectrometría de masas, utilizando una mezcla de $10 \% \mathrm{H}_{2} / \mathrm{Ar}(30 \mathrm{~mL} / \mathrm{min})$. Para determinar la dispersión metálica, se hicieron estudios de quimiadsorción de $\mathrm{H}_{2}$, bajo la metodología de titulación oxigeno-hidrógeno a $308 \mathrm{~K}$, en un equipo Micromeritics ASAP 2020. Los análisis de microscopía electrónica de transmisión (TEM) para los catalizadores reducidos, se realizaron en un equipo Jeol JEM-1200 EXII. El tamaño de partícula no se vio afectado por el tratamiento térmico a $773 \mathrm{~K}$.

La reacción de hidrogenación de acroleína se hizo en fase gas a $313 \mathrm{~K}$, utilizando $0.2 \mathrm{~g}$ de catalizador y una cantidad de acroleína puesta en un saturador, por el cual se hizo pasar un flujo de hidrogeno (50 $\mathrm{ml} / \mathrm{min}$ ), mientras la acroleína se encontraba a baja presión de vapor a condiciones estándar. El tiempo de reacción fue de $2 \mathrm{~h}$. Previo a la reacción, los catalizadores fueron activados in-situ a $773 \mathrm{~K}$, así de esta manera se pudo asegurar la reducción completa de los sólidos sintetizados por coloides de alta presión de hidrogeno y el efecto SMSI de los catalizadores, con lo que se favoreció la hidrogenación de acroleína. Los productos de reacción fueron analizados en un cromatógrafo de gases Varian 3400 , con el uso de una columna capilar HP Wax.

\section{Resultados y discusión}

En la Figura1 se pueden observar los perfiles de difracción de rayos $X$ de los coloides sin reducir. La línea de difracción más intensa de oro aparece a $38^{\circ}$ con plano (111), que coincide con una de las señales de $\mathrm{TiO}_{2}$. Puede indicarse la probable presencia de especies cristalinas de partículas metálicas de Au. Una situación similar se presenta en los perfiles de difracción de los catalizadores de $\mathrm{Ir} / \mathrm{TiO}_{2}$ e Ir-Au/ $\mathrm{TiO}_{2}$, los cuales muestran un pico a $41^{\circ}$ correspondiente al soporte, y cercano a una de las líneas de difracción de Ir. 


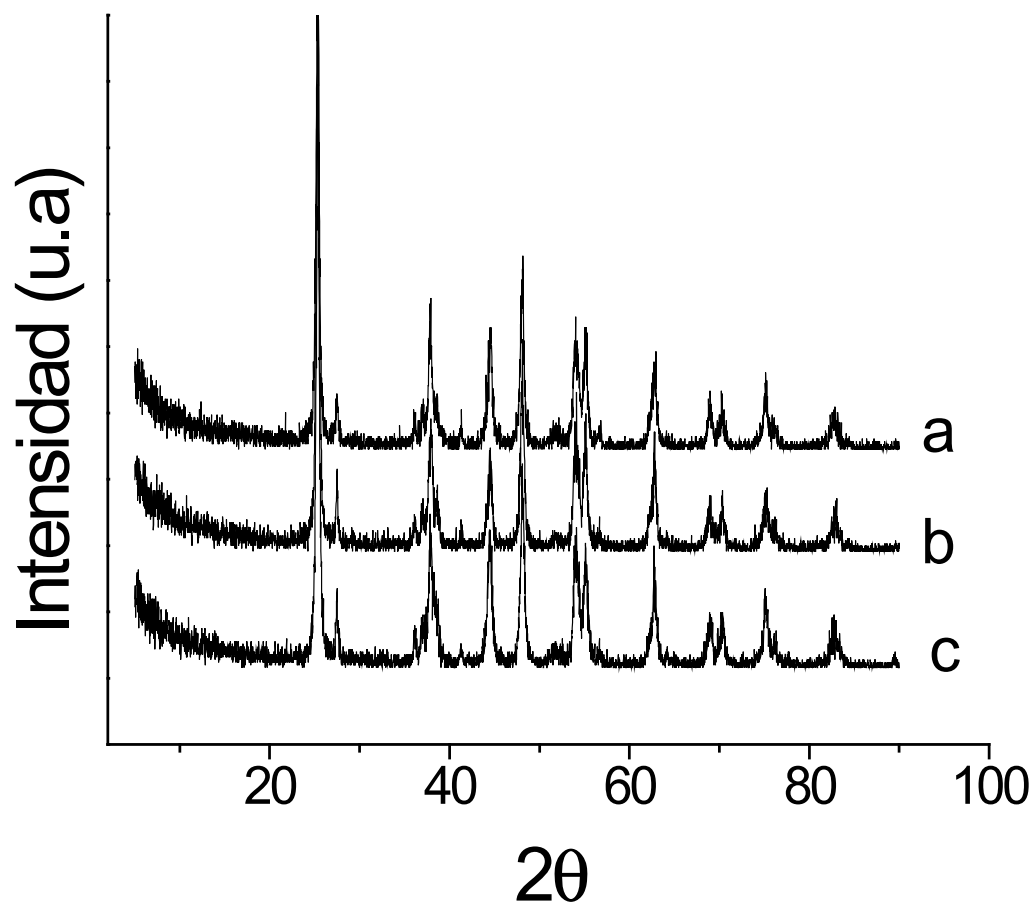

Figura 1. Perfiles de difracción de rayos $X$ de los catalizadores de (a) Ir/ $\mathrm{TiO}_{2}$, (b) Ir-Au/TiO, (c) $\mathrm{Au} / \mathrm{TiO}_{2}$.

En la Tabla 1 se evidencia que no existe una variación significativa de los valores de área superficial en el catalizador monometálico de Ir, mientras que para el sólido bimetálico de Au-Ir y el monometálico de $A u$, se observó un aumento en el área superficial del soporte después de la adición de las partículas metálicas. Lo que era de esperarse, considerando que el $\mathrm{Au}$ puede rodear a la titania, o estas partículas metálicas se pueden situar dentro de la estructura del soporte, provocando un aumento en el área superficial en estos catalizadores. La dispersión metálica que se obtuvo para los coloides por titulación $\mathrm{O}_{2}-\mathrm{H}_{2}$ a $308 \mathrm{~K}$, indicó que comparando el catalizador monometálico de Ir con el catalizador bimetálico de Ir-Au, estos presentaron una relación $\mathrm{H} / \mathrm{Me}$ (Me: metal) similar, $\mathrm{y}$, además se observó que los tamaños de partícula medidos por quimisorción de 
hidrógeno y microscopia electrónica de transmisión, muestran una buena correlación, debido a que se obtuvieron tamaños promedio de partícula análogos por las dos técnicas de caracterización.

Tabla 1. Resultados de caracterización de fisisorción de $\mathrm{N}_{2}$, dispersión metálica $(\mathrm{H} / \mathrm{Me})$ y tamaño de partícula $(\mathrm{Tp})$ obtenidos por titulación $\mathrm{O}_{2}-\mathrm{H}_{2}$ a $308 \mathrm{~K}$ y TEM

\begin{tabular}{|c|c|c|c|c|}
\hline Catalizador & $\mathrm{S}_{\mathrm{BET}} \mathrm{m}^{2} / \mathrm{g}$ & $\begin{array}{c}\mathrm{H} / \\
\mathrm{Me}\end{array}$ & $\begin{array}{c}\mathrm{Tp}, \mathrm{nm} \\
\text { quimisorción }\end{array}$ & $\begin{array}{c}\mathrm{Tp}, \mathrm{nm} \\
\mathrm{TEM}\end{array}$ \\
\hline $\mathrm{TiO}_{2}$ & 58 & - & - & - \\
$\mathrm{Ir}$ & 57 & 0,7 & 1,43 & $1,3 \pm 0,3$ \\
$\mathrm{Ir}-\mathrm{Au}$ & 68 & 0,8 & 1,34 & $1,6 \pm 0,9$ \\
$\mathrm{Au}$ & 65 & - & - & $4,6 \pm 0,9$ \\
\hline
\end{tabular}

La Figura 2 muestra los perfiles de reducción a temperatura programada (TPR) de los coloides sin reducir. Se pudo observar que el catalizador $\mathrm{Ir} / \mathrm{TiO}_{2}$ presentó cuatro picos, a $373 \mathrm{~K}, 480 \mathrm{~K}$ con un pequeño hombro a $520 \mathrm{~K}$ y a $570 \mathrm{~K}$. El pico a $373 \mathrm{~K}$ puede ser asignado a la reducción de especies de $\mathrm{IrO}_{2}$ mientras los tres picos restantes pueden ser debidos a la reducción de especies $\mathrm{IrO}_{\mathrm{x}} \mathrm{Cl}_{\mathrm{y}}$ a especies $\mathrm{Ir}^{0}$, en forma similar a lo que se observa en catalizadores de $\mathrm{Pt} / \mathrm{TiO}_{2}$ [19]. Un perfil ligeramente diferente se observó para el catalizador bimetálico de $\mathrm{Ir}-\mathrm{Au} / \mathrm{TiO}_{2}$, que pudo deberse a un decrecimiento en el pico a $480 \mathrm{~K}$, que se explica por la posible formación de complejos metálicos de Ir-Au, y debido a que el catalizador bimetálico contiene el $0.5 \%$ de carga metálica con respecto a los coloides monometálicos de Ir y Au al $1 \%$. Además se debe mencionar que distintos tipos de especies de IrOxCly pueden formarse, sin embargo los complejos Ir-Au inhiben la formación de algún tipo de especies, es por esto que para el caso del catalizador bimetálico se observa la ausencia del pico a $520 \mathrm{~K}$, presente en el catalizador monometálico de Ir. Para $\mathrm{Au} / \mathrm{TiO}_{2}$, solo dos señales son detectadas correspondientes a la reducción a oro metálico $(460 \mathrm{~K})$ y la reducción de especies $\left[\mathrm{AuCl}(\mathrm{OH})_{x}\right]^{-}$a $570 \mathrm{~K}$. 


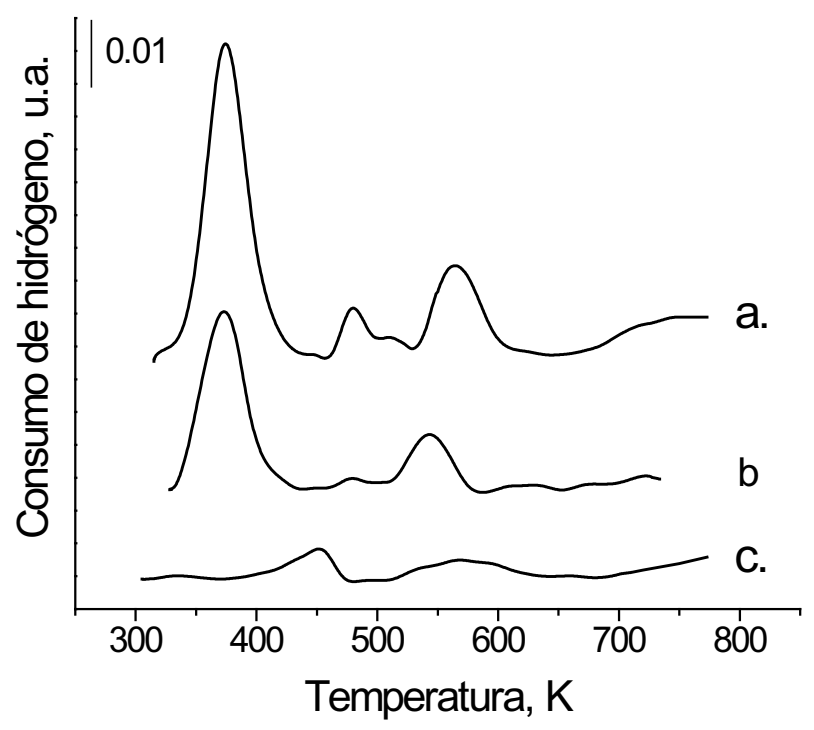

Figura 2. Perfiles de reducción de los catalizadores de (a). $\mathrm{Ir} / \mathrm{TiO}_{2}$, (b) Ir-Au/TiO${ }_{2}$, (c) $\mathrm{Au} / \mathrm{TiO}_{2}$.

Además, los resultados obtenidos por reducción a temperatura programada sugieren un mecanismo distinto de deposición de los coloides. Zhao Propone una secuencia de reacciones a partir de $\left[\mathrm{IrCl}_{6}\right]^{2-}$ que son hidrolizados a $\left[\mathrm{Ir}(\mathrm{OH})_{6}\right]^{2-}$ por calentamiento en presencia de $\mathrm{NaOH}[20]$, los monómeros de $\left[\operatorname{lr}(\mathrm{OH})_{6}\right]^{2-}$, en una concentración suficientemente alta se polimerizan parcialmente para formar $\mathrm{IrO}_{x} \cdot \mathrm{nH}_{2} \mathrm{O}$, que se estabilizan por grupos $\mathrm{OH}^{-}$. Sin embargo, es posible la formación de complejos de iridio $\left[\mathrm{IrCl}(\mathrm{OH})_{x}\right]^{-}$en menor proporción (picos a partir de $480 \mathrm{~K}$ ), debido a que no es posible eliminar por completo los residuos clorados. Para catalizadores de oro, el mecanismo de deposición de coloides puede ser similar al descrito para el método de deposición-precipitación con $\mathrm{NaOH}$ (DP$\mathrm{NaOH}$ ). La deposición podría ocurrir a través de una reacción de los iones complejos de oro $\left[\mathrm{AuCl}(\mathrm{OH})^{3}\right]^{-}$con los grupos hidroxilo de la superficie de soporte [21]. Entonces, se pudo afirmar que el proceso de obtención de coloides metálicos en medio básico y presencia de hidrógeno a altas presiones no aseguró la reducción completa del metal, por lo cual, y de acuerdo con los resultados de TPR, se 
procedió a reducir a $773 \mathrm{~K}$ en atmósfera de hidrógeno a $30 \mathrm{~mL} / \mathrm{min}$. Los sólidos obtenidos a esta temperatura permiten que especies de $\mathrm{TiO}_{2-x}$ migren sobre la superficie metálica favoreciendo la actividad catalítica de los catalizadores, como previamente ha sido demostrado por varios autores [22, 23,24].

Al comparar los resultados de distribución de tamaño de partícula obtenidos por quimisorción de hidrógeno (Tabla 1) de los coloides sin reducir y de los coloides después de reducidos, teniendo en cuenta que la reducción a $773 \mathrm{~K}$ no altera los valores de tamaño de partícula medido por microscopía electrónica de transmisión (Figura 3 ), se observa que el catalizador de Ir presentó un tamaño promedio de partícula similar al bimetálico de Ir-Au. Esto es debido a que es posible obtener estructuras auto-organizadas de $\mathrm{Au}$ e $\mathrm{IrO}_{2}$, en las cuales las partículas de Au se sitúan en pilares de $\mathrm{IrO}_{2}$ formados en substratos como $\mathrm{TiO}_{2}$ [25]. La interfase activa de $\mathrm{Au} / \mathrm{IrO}_{2}$ incrementa la resistencia a la coalescencia de las nanopartículas de Au [26] un hecho indispensable para la obtención de nanopartículas de Au de tamaño de partícula menores a $5 \mathrm{~nm}$. Aunque para $\mathrm{Au} / \mathrm{TiO}_{2}$ se alcanza el mayor tamaño de partícula, la baja actividad de este catalizador se puede explicar debido a la posible sinterización de las partículas de oro por la presencia de especies de cloro provenientes del precursor metálico [27].
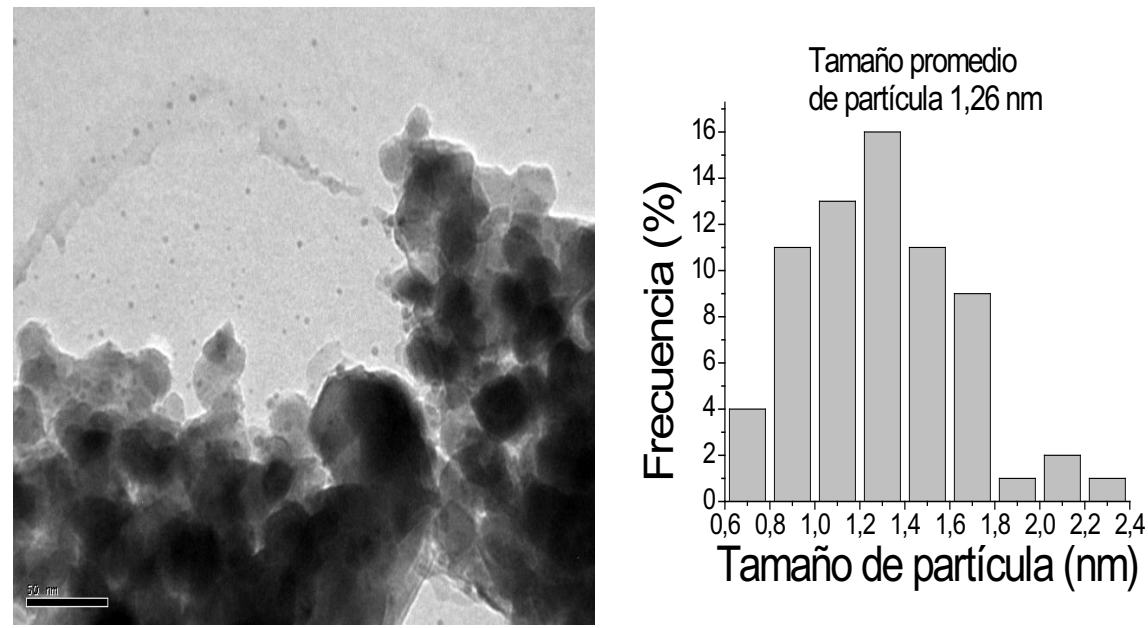

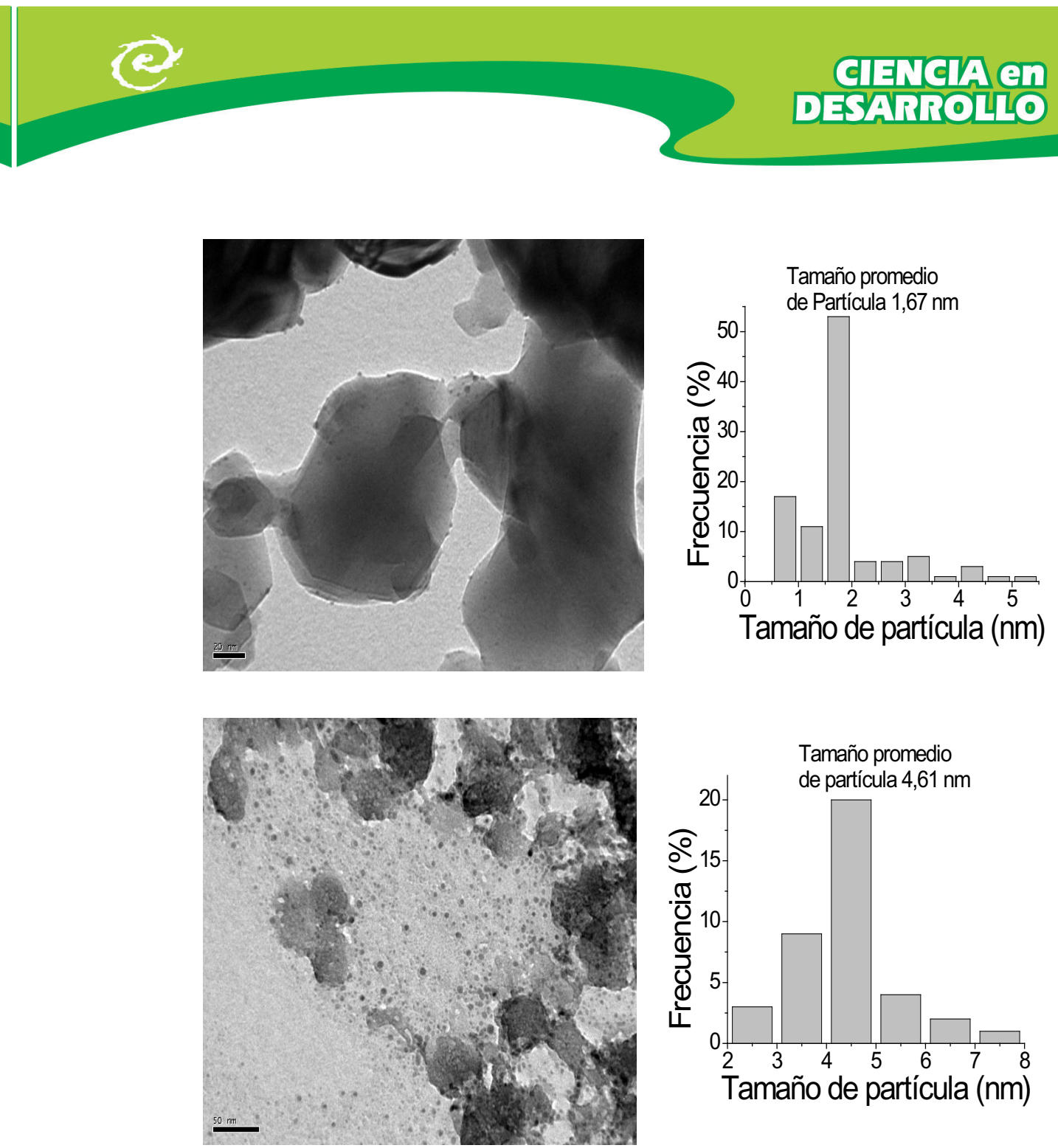

Figura 3. Imágenes obtenidas por MET y su correspondiente distribución de tamaño de partícula: (a). Ir/TiO ${ }_{2}$, (b) Ir-Au/TiO, (c) $\mathrm{Au} / \mathrm{TiO}_{2}$.

Los resultados de la evaluación catalítica en fase gas de acroleína se resumen en la Tabla 2. La conversión a $2 \mathrm{~h}$ fue expresada como el porcentaje de las moles transformadas con respecto al total de moles alimentadas. La energía de activación se obtuvo siguiendo una ecuación de velocidad de primer orden. La conversión se expresó a $313 \mathrm{~K}$, debido a la desactivación de los catalizadores a mayores temperaturas. Se puedo observar que el sólido de $\mathrm{Au} / \mathrm{TiO}_{2}$ presentó una menor conversión y una mayor energía de activación con respecto 
a los demás catalizadores, sin embargo la adición de iridio a oro incrementa substancialmente la actividad catalítica; de hecho, las energías de activación son similares para el catalizador monometálico de Ir y el bimetálico de Ir-Au, lo que puede deberse a los tamaños de partícula similares que se obtuvieron en estos dos catalizadores.

Con respecto a la selectividad en la hidrogenación de acroleína, se presenta una baja selectividad en los catalizadores monometálicos de Ir y de Au soportados con respecto al catalizador bimetálico de Ir-Au, lo cual está de acuerdo con los resultados mostrados previamente. En el catalizador bimetálico Ir-Au, el alcohol alílico es el principal producto obtenido en la hidrogenación de acroleína. Así, se sugiere que es posible incrementar la actividad catalítica del oro y favorecer la selectividad en la hidrogenación al grupo carbonilo con este tipo de sistemas bimetálicos. Resultados similares se han mostrado recientemente en reacciones de hidrogenación de moléculas más grandes, como es el caso de la molécula de cinamaldehído [28]. Además se observó que por microscopia, el catalizador bimetálico tiene un tamaño promedio de partícula pequeño, lo que favorece la conversión y selectividad hacia el alcohol insaturado, mientras que el catalizador monometálico de Au tiene un tamaño de partícula superior que no favorece la actividad catalítica de este sólido. Se destacó también el hecho de que los catalizadores al ser reducidos a $773 \mathrm{~K}$, presentaron el efecto SMSI, en donde las partículas $\mathrm{TiO}_{2-x} \mathrm{mi}-$ gran hacia la superficie del catalizador favoreciendo de esta manera la orientación de la molécula de acroleína para la ruptura preferencial del enlace $\mathrm{C}=\mathrm{O}$, mientras se mantiene el enlace olefínico, y así poder obtener el alcohol insaturado (alcohol alílico).

Tabla 2. Resultados de actividad catalítica de los catalizadores estudiados

\begin{tabular}{|c|c|c|c|}
\hline Catalizador & Conv, $\%$ & $\mathrm{E}_{\text {act }} \cdot \mathrm{KJ} / \mathrm{mol}$ & $\mathrm{S}_{\mathrm{C}=0}, \%$ \\
\hline $\mathrm{Ir} / \mathrm{TiO}_{2}$ & 32 & 46 & 9 \\
\hline $\mathrm{Ir}-\mathrm{Au} / \mathrm{TiO}_{2}$ & 26 & 54 & 38 \\
\hline $\mathrm{Au} / \mathrm{TiO}_{2}$ & 7 & 83 & 26 \\
\hline
\end{tabular}




\section{Conclusiones}

Coloides de Ir-Au pueden ser obtenidos con pequeños tamaños de partícula. La deposición de los metales involucra la formación de iones complejos en los que reacciona el $\mathrm{NaOH}$ con el precursor metálico, por lo que es necesario reducir posteriormente los catalizadores para obtener el metal reducido, sin que esto afecte el tamaño de partícula obtenido.

Los catalizadores de Ir-Au empleados en la hidrogenación de acroleína, mostraron un incremento en la reducción preferencial del grupo carbonilo, y, por tanto, mejor selectividad hacia el alcohol insaturado respecto de las catalizadores monometálicos de $\mathrm{Au} / \mathrm{TiO}_{2}$ e $\mathrm{Ir} / \mathrm{TiO}_{2}$, debido a la obtención de pequeños tamaños de partícula y porque se trata de un sistema bimetálico en donde Ir mantiene la conversión y Au aumenta la selectividad hacia el alcohol alílico.

\section{Agradecimientos}

Agradecemos el apoyo financiero otorgado por COLCIENCIASUPTC-SENA, al proyecto $\mathrm{N}^{\circ} 110948925094$.

\section{Referencias}

[1] P. Claus, H. Hofmeister \& C. Mohr, "Identification of active sites and influence of real structure of gold catalysts in the selective hydrogenation of acrolein to allyl alcohol", Gold Bulletin, vol. 37, n 3-4, pp. 181-186, 2004.

[2] P. Claus, "Heterogeneously catalysed hydrogenation using gold catalysts", Applied Catalysis A: General, vol. 291, nº 1-2, pp. 222-229, 2005.

[3] P. Claus, A. Bruckner, C. Mohr \& H. Hofmeister, "Supported gold nanoparticles from quantum dot to mesoscopic size scale: Effect of electronic and structural properties on catalytic hydrogenation of conjugated functional groups", Journal of the American Chemical Society, vol. 122, n 46, pp. 11430-11439, 2000.

[4] C. Milone, R. Ingoglia \& S. Galvagno, Gold supported on iron oxyhydroxides: a versatile tool for the synthesis of fine chemicals, Gold Bulletin, vol. 39, n² 2, pp. 54-65, 2006. 
[5] C. Milone, M. L. Tropeano, G. Gulino, G. Neri, R. Ingoglia \& S. Galvagno, "Selective liquid phase hydrogenation of citral on $\mathrm{Au} / \mathrm{Fe}_{2} \mathrm{O}_{3}$ catalysts", Chemical Communications, nº 8, pp. 868-869, 2002.

[6] R. Zanella, C. Louis, S. Giorgio \& R. Touroude, "Crotonaldehyde hydrogenation by gold supported on $\mathrm{TiO}_{2}$ : Structure sensitivity and mechanism", Journal of Catalysis, vol. 223, n² 2, pp. 328-339, 2004.

[7] P.G.N. Mertens, H. Poelman, X. Ye, I.F.J. Vankelecom, P. A. Jabobs \& D.E. De Vos, "Au0 nanocolloids as recyclable quasihomogeneous metal catalysts in the chemoselective hydrogenation of $\alpha, \beta$-unsaturated aldehydes and ketones to allylic alcohols", Catalysis Today, vol. 122, n 3-4, pp. 352-360, 2007.

[8] L.N. Protasova, E.V. Rebrov, T.S. Glazneva, A. Berenguer-Murcia, Z.R. Ismagilov \& J. C. Schouten, "Control of the thickness of mesoporous titania films for application in multiphase catalytic microreactors", Journal of Catalysis, vol. 271, n² 2, pp. 161-169, 2010.

[9] M. Okumura. T. Akita \& M. Haruta, "Hydrogenation of 1,3-butadiene and of crotonaldehyde over highly dispersed Au catalysts", Catalysis Today, vol. 74, n³-4, pp. 265-269, 2002.

[10] A. Gómez-Cortés, G. Díaz, R. Zanella, H. Ramírez, P. Santiago \& J.M. Saniger,

"Au-Ir/TiO 2 prepared by deposition precipitation with urea: improved activity and stability in CO oxidation", Journal of Physical Chemistry C, vol. 113, $n^{\circ} 22$, pp. 9710-9720, 2009.

[11] X. Bokhimi, R. Zanella \& C. Ángeles-Chávez, "Rutile-supported Ir, Au, and Ir-Au catalysts for CO oxidation", Journal of Physical Chemistry C, vol. 114, n³3, pp. 14101-14109, 2010.

[12] M. Bowker, A. Nuhu \& J. Soares, "High activity supported gold catalysts by incipient wetness impregnation", Catalysis Today, vol. 122, n 3-4, pp. 245-247, 2007.

[13] M. Haruta \& M. Daté, "Advances in the catalysis of Au nanoparticles", Applied Catalysis A: General, vol. 222, n 1-2, pp. 427-437, 2001.

[14] V.I. Pârvulescu, V. Pârvulescu, U. Endruschat, G. Filoti, F.E. Wagner, C. Kübel \& R. Richards, "Characterization and Catalytic-Hydrogenation Behavior of $\mathrm{SiO}_{2}$-Embedded Nanoscopic $\mathrm{Pd}, \mathrm{Au}$, and $\mathrm{Pd}-\mathrm{Au}$ Alloy Colloids", Chemistry - A European Journal, vol. 12, nº 8, pp. 2343-2357, 2006.

[15] S. Domínguez-Domínguez, A. Berenguer-Murcia, D. Cazorla-Amorós 


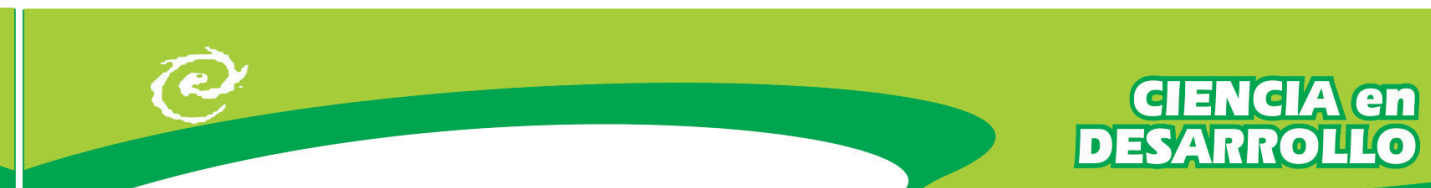

\& A. Linares-Solano, "Semihydrogenation of phenylacetylene catalyzed by metallic nanoparticles containing noble metals", Journal of Catalysis, vol. 243, n 1, pp. 74-81, 2006.

[16] J.A. López-Sánchez, N. Dimitratos, C. Hammond, G.L. Brett, L. Kesavan, S. White, P. Medziak, R. Tiruvalam, R.L. Jenkins, A.F. Carley, D. Knight, C.J. Kiely \& G.J. Hutchings, "Facile removal of stabilizer-ligands from supported gold nanoparticles", Nat Chem, vol. 3, n 7, pp. 551-556, 2011.

[17] H. Shi, N. Xu, D. Zhao \& B.Q. Xu, "Immobilized PVA-stabilized gold nanoparticles on silica show an unusual selectivity in the hydrogenation of cinnamaldehyde", Catalysis Communications, vol. 9, n 10, pp. 19491954, 2008.

[18] C. Campos, M. Oportus, C. Urbina, G. Torres, J.L.G. Fierro, \& P. Reyes, "Modificación superficial de $\mathrm{SiO}_{2}$ con cinconidina en la preparación de catalizadores de $\mathrm{Pt}$ usados en la reacción de hidrogenación ennatioselctiva de 1 fenil 1,2-propanodiona", Simposio Iberoamericano de Catálisis, Chile, 2010. 
बाइसबाAल

DESARBOLLO

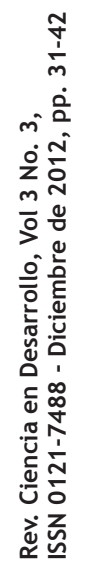

110 


\title{
EFECTO DE LA TEMPERATURA $Y$ PH EN LA VELOCIDAD DE PRECIPITACIÓN Y EXTRACCION DE ALMIDÓN DE PAPA CRIOLLA (Solanum phureja)
}

\section{EFFECT OF TEMPERATURE AND PH ON THE RATE OF PRECIPITATION AND EXTRACTION OF STARCH FROM NATIVE POTATO (Solanum phureja)}

\author{
Lucio González Montiel ${ }^{1 *}$ \\ Ricardo Adolfo Parra Huertas ${ }^{\square * *}$ \\ Diana Jaqueline Pimentel Gonzales ${ }^{\square * * *}$
}

Recepción 05/08/2011

Evaluación 12/09/2011

Aprobado 12/10/2011

\section{Resumen}

Químicamente, el almidón es una mezcla de polisacáridos que contienen regiones cristalinas y no cristalinas en capas alternadas, constituidos por glucosa como monómero estructural. En este trabajo se evaluó el efecto de la temperatura $\left(4^{\circ} \mathrm{C}, 15^{\circ} \mathrm{C}\right.$ y $\left.40^{\circ} \mathrm{C}\right)$ y del pH (ácido, neutro y básico) sobre las velocidades de precipitación y los porcentajes de almidón de papa criolla (Solanum phureja). Los resultados mostraron que las diferentes temperaturas y $\mathrm{pHs}$ afectan la velocidad de precipitación y el rendimiento de almidón. El mayor rendimiento de extracción de almidón (15,63\%), se logró a condiciones ambientales y no se afectó por causa del $\mathrm{pH}$. A una temperatura de 40 ${ }^{\circ} \mathrm{C}$ y $\mathrm{pH}$ ácido, el rendimiento se modificó drásticamente alcanzando

1 * Maestría, docente investigador Universidad de la Cañada, Teotitlán de Flores Magón, Oaxaca, México. 
solo un $11,06 \%$. El tratamiento que presentó mejores rendimientos y velocidad de precipitación, fue una temperatura de $15{ }^{\circ} \mathrm{C}$ y un $\mathrm{pH}$ ácido.

Palabras clave: Almidón, rendimiento, $p H$, temperatura, precipitación.

\section{Abstract}

The starch is chemically a mixture of polysaccharides containing crystalline and non-crystalline regions in alternating layers, consisting of glucose as structural monomer. This study evaluated the effect of temperature $\left(4^{\circ} \mathrm{C}, 15^{\circ} \mathrm{C}\right.$ and $40^{\circ} \mathrm{C}$ ) and $\mathrm{pH}$ (acidic, neutral and basic) on precipitation rates and percentages of native potato starch (Solanum phureja). The results showed that the different temperatures and $\mathrm{pHs}$ affect the precipitation rate and yield of starch. The higher yield of starch extraction (15.63\%), was achieved at ambient conditions and was not affected by $\mathrm{pH}$. At a temperature of $40{ }^{\circ} \mathrm{C}$ and acid $\mathrm{pH}$, the performance was drastically modified reaching only $11.06 \%$. The treatment that presented better yields and precipitation rate, was a temperature of $15^{\circ} \mathrm{C}$ and an acid $\mathrm{pH}$.

Keywords: Starch, yield, $\mathrm{pH}$, temperature, precipitation.

\section{Introducción}

En los últimos años, uno de los temas de investigación en el área de los materiales ha sido la evaluación del uso de materias primas obtenidas a partir de recursos naturales, para ser empleadas como excipientes en productos farmacéuticos. Dentro de este contexto se encuentra el almidón, materia prima de origen natural más utilizada debido al amplio rango de beneficios físicos, químicos y organolépticos que ofrece a diferentes clases de productos [1].

\section{Almidón}

El almidón es la fuente más importante de energía en la dieta humana. En la industria de alimentos, el almidón mejora 
las propiedades funcionales en productos alimenticios, como la gelificación, la estabilidad, la emulsión y la adhesión [2,3,4]. Existen actualmente en el mercado diferentes fuentes comerciales de almidón, destacándose el maíz, el trigo, el arroz, el sorgo, la yuca y la papa $[1,3,4]$

\section{Papa criolla}

La papa es un tubérculo de reconocida importancia en el mundo. Ocupa el cuarto lugar — después del arroz, el trigo y el maíz-, dentro de los productos alimenticios agrícolas. En Colombia, la papa es importante como alimento básico de la población, con una producción de 170.000 hectáreas por año. Colombia es el primer país productor de papa criolla (Solanum Phureja) en Latinoamérica, con un mercado interno bueno en los departamentos de Antioquia, Valle del Cauca, Boyacá, Nariño y Cundinamarca. En la actualidad, la industria de procesamiento del tubérculo está en crecimiento; así, en los mercados europeos se encuentran presentaciones de papa criolla frita y conservas enlatadas y en vidrio. Las principales bondades de la papa criolla son su alto valor nutricional, buen sabor, ciclo de vida corto, costos de producción inferiores y un alto potencial de exportación como producto exótico procesado. Los problemas del producto tienen que ver con el alto grado de mezcla de tubérculos de las variedades nativas, la heterogeneidad en tamaño del mismo y, además, es altamente perecible, entre otros [2,5].

El objetivo de este trabajo fue determinar el efecto de la temperatura y del $\mathrm{pH}$ sobre el rendimiento y velocidad de precipitación del almidón de papa criolla.

\section{Métodos}

Este trabajo se llevó a cabo en los laboratorios de alimentos del programa de Química de Alimentos de la Universidad Pedagógica y Tecnológica de Colombia, sede Tunja. El experimento consistió en determinar el efecto en la velocidad de precipitación de almidón y el rendimiento, al modificar la temperatura y el $\mathrm{pH}$. Para ello se manejaron tres niveles en los tratamientos: temperaturas, $4^{\circ} \mathrm{C}, 15^{\circ} \mathrm{C}$ y $40{ }^{\circ} \mathrm{C}$ y pHs: ácido, neutro y básico. 


\section{Materiales}

Se seleccionaron muestras de papa criolla (Solanum phureja) del mercado local, teniendo en cuenta que estuviera libre de daños físicos o fitosanitarios. Las muestras se trasladaron a los laboratorios de la universidad en cajas de cartón evitando lesiones en los tubérculos.

\section{Extracción del almidón de papa criolla}

Tabla 1. Diseño experimental

\begin{tabular}{|c|c|c|c|}
\hline $\begin{array}{l}\text { Tratamiento } \\
\text { Temperatura }\end{array}$ & \multicolumn{3}{|c|}{$\begin{array}{l}\text { Niveles } \\
\mathrm{pH}\end{array}$} \\
\hline Refrigeración $\left(4^{\circ} \mathrm{C}\right)$ & $\begin{array}{l}\text { Ácido } \\
\text { Neutro } \\
\text { Básico }\end{array}$ & $\begin{array}{l}3.0 \\
6.8 \\
12.0\end{array}$ & $\begin{array}{l}\text { ácido cítrico } 0.05 \mathrm{M} \\
* \\
\text { hidróxido de sodio } 0.05 \mathrm{M}\end{array}$ \\
\hline Ambiente $\left(15^{\circ} \mathrm{C}\right)$ & $\begin{array}{l}\text { Ácido } \\
\text { Neutro } \\
\text { Básico }\end{array}$ & $\begin{array}{l}3.0 \\
6.8 \\
12.0\end{array}$ & $\begin{array}{l}\text { ácido cítrico } 0.05 \mathrm{M} \\
\text { h } \\
\text { hidróxido de sodio } 0.05 \mathrm{M}\end{array}$ \\
\hline $\begin{array}{c}\text { Temperaturas altas } \\
\left(40^{\circ} \mathrm{C}\right)\end{array}$ & $\begin{array}{l}\text { Ácido } \\
\text { Neutro } \\
\text { Básico }\end{array}$ & $\begin{array}{r}3.0 \\
6.8 \\
12.0\end{array}$ & $\begin{array}{c}\underset{*}{\text { ácido cítrico }} \underset{*}{0.05 \mathrm{M}} \\
\text { hidróxido de sodio } 0.05 \mathrm{M}\end{array}$ \\
\hline
\end{tabular}

* No se añadieron reactivos ni sustancias para modificar el pH

La extracción del almidón de papa criolla (Solanum phureja) se hizo mediante una modificación al método propuesto por Guizar [6]. El tubérculo de papa criolla fue lavado, descascarado y rebanado en cubos de $1 \mathrm{~cm}$ aproximadamente, mezclados con tres volúmenes de agua destilada y licuados por cinco minutos a velocidad máxima. Después, la suspensión obtenida fue centrifugada a $1500 \mathrm{rpm} / 5$ min, la muestra se decantó y el sobrenadante (pulpa) fue licuado nuevamente y dejado en reposo durante 60 minutos. Posteriormente, la muestra fue dividida en tres partes para llevar a cabo los tres tratamientos que se muestran en el cuadro 1. Luego, las muestras fueron filtradas a través de gasa. Los sólidos remanentes fueron eliminados y el filtrado fue lavado hasta que el agua de lavado quedo translúcida, lo que indicaría la finalización del proceso de extracción 
del almidón. Posteriormente, las fracciones que contenían el almidón se dejaron en refrigeración $\left(4^{\circ} \mathrm{C}\right)$, a temperatura ambiente $\left(15^{\circ} \mathrm{C}\right)$ y en estufa $\left(40^{\circ} \mathrm{C}\right)$ a diferentes valores de $\mathrm{pH}$, según cada tratamiento. El porcentaje se determinó por gravimetría, secando la muestra a 40 ${ }^{\circ} \mathrm{C}$ y monitoreando el peso cada treinta minutos durante cinco horas, hasta alcanzar peso constante en cada una de las muestras.

\section{Determinación del pH}

Se determinó según el método 981.12 de la AOAC [7], utilizando un potenciómetro marca Hanna.

\section{Resultados y discusión}

La Figura 1 permite apreciar que a una temperatura de $15^{\circ} \mathrm{C}$ y pHs ácidos, hubo el mayor rendimiento de extracción de almidón y la mayor velocidad de precipitación, en comparación con las muestras tratadas a pHs básicos, donde disminuyó tanto el rendimiento como la velocidad de precipitación del almidón; sin embargo, los tres tratamientos a las cinco horas mostraron el mismo rendimiento de extracción de almidón del $15,63 \%$, en condiciones de temperatura ambiente.

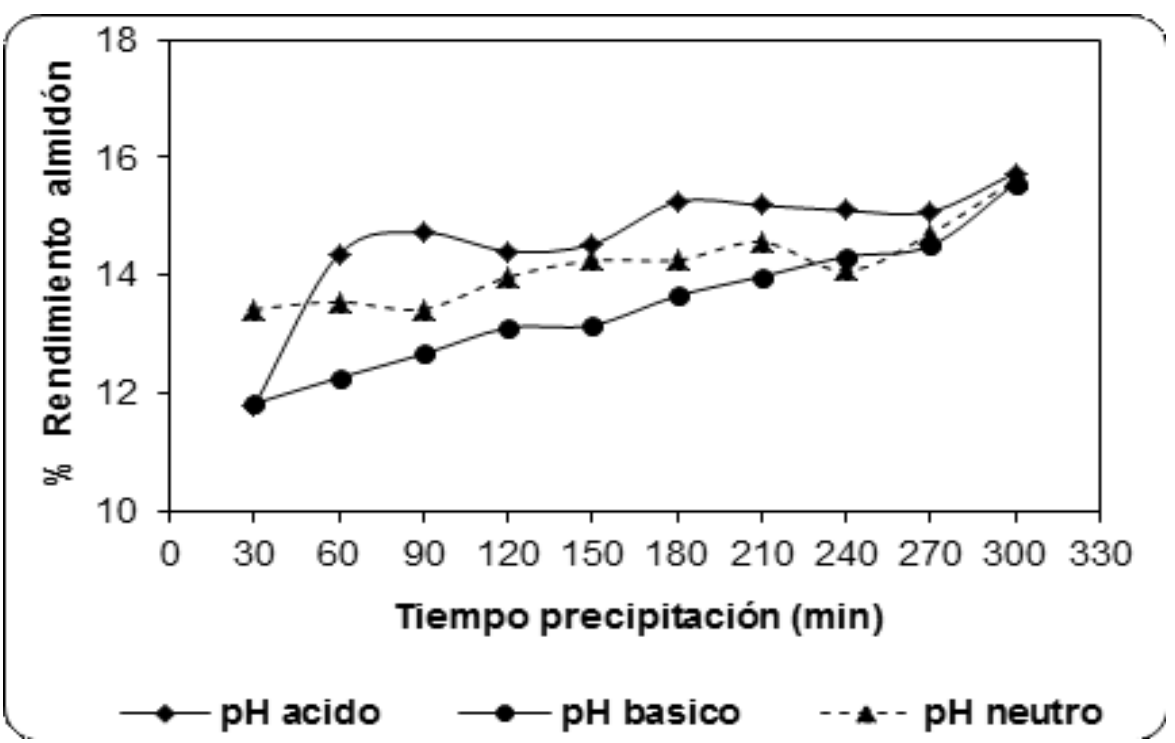

Figura 1. Rendimiento y velocidad de precipitación en la extracción de almidón a $15^{\circ} \mathrm{C}$ y diferentes valores de $\mathrm{pH}$. 


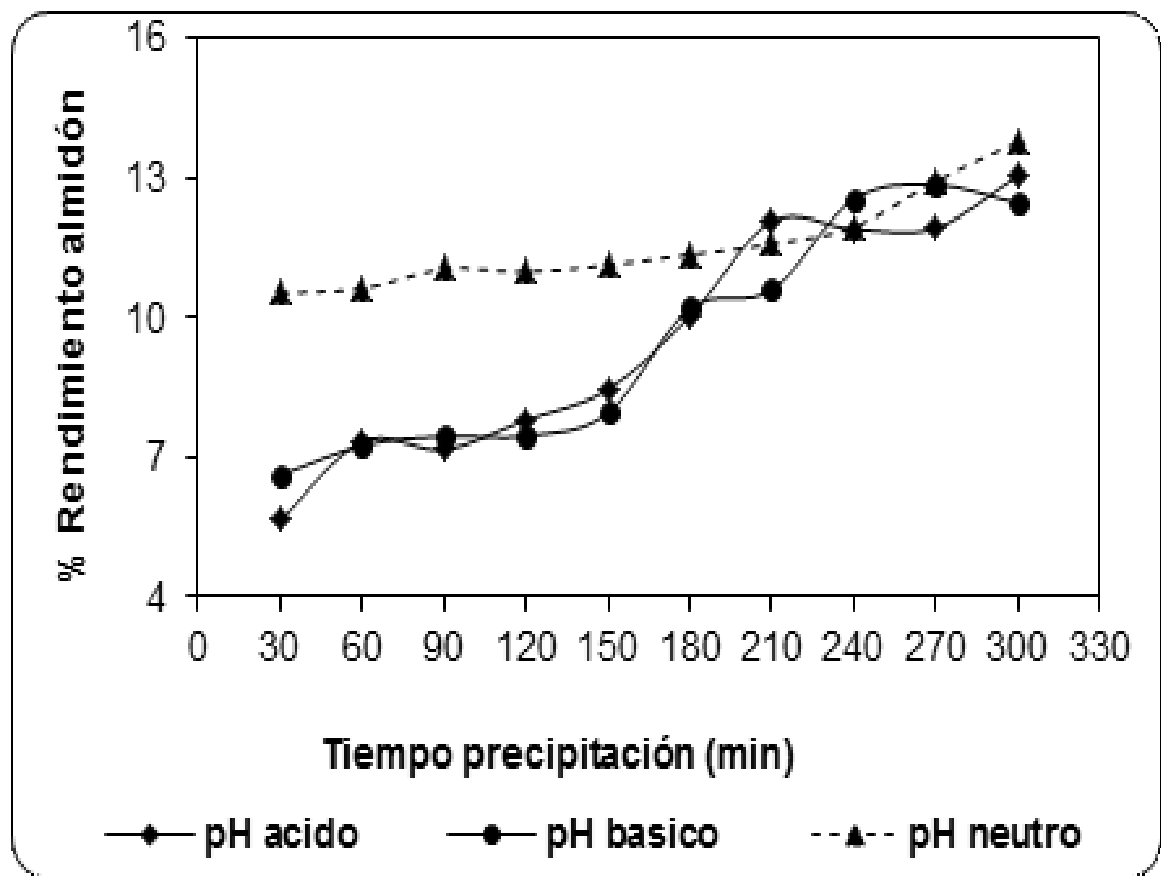

Figura 2. Rendimiento y velocidad de precipitación en la extracción de almidón a $4{ }^{\circ} \mathrm{C}$ y diferentes valores de $\mathrm{pH}$.

En la Figura 2 se observa que los mayores porcentajes de almidón se presentaron a pHs neutros en los primeros minutos de precipitación, mientras que a pHs básico y ácido, el comportamiento fue similar entre sí.

Las temperaturas de refrigeración afectaron drásticamente los rendimientos de almidón desde los primeros minutos hasta las tres horas, en las muestras cuyo $\mathrm{pH}$ era básico o ácido. Adicionalmente se observó que las muestras de $\mathrm{pH}$ neutro no fueron afectadas por la temperatura de refrigeración. El rendimiento de almidón promedio para los tres tratamientos fue aproximadamente del 13,75\%. La velocidad de precipitación fue mayor para el tratamiento que tenía $\mathrm{pH}$ neutro, en comparación con los tratamientos de $\mathrm{pH}$ ácido y básico. 


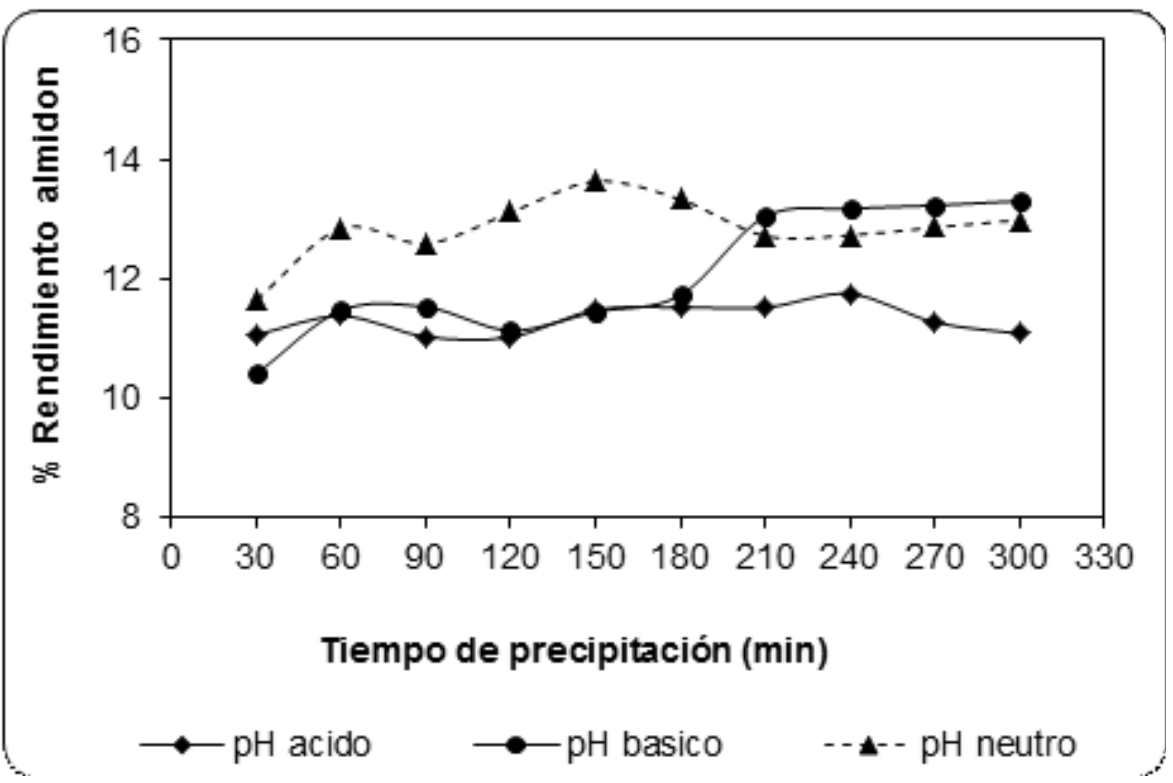

Figura 3. Efecto de la temperatura $40^{\circ} \mathrm{C}$ y diferentes $\mathrm{pH}$ en la velocidad de precipitación y rendimiento de almidón.

El rendimiento de extracción de almidón a temperatura de $40^{\circ} \mathrm{C}$ (Figura 3) para los diferentes pHs, presentó un comportamiento similar; sin embargo, el rendimiento para las muestras de $\mathrm{pH}$ básico fue más alto, mientras que a pH ácido, el rendimiento mostró ser inferior.

Comparando las figuras 1,2 y 3 , se aprecia que a temperatura ambiente, el rendimiento de extracción de almidón para los diferentes tratamientos de $\mathrm{pH}$, fue mayor al $12 \%$, mientras que a temperaturas de refrigeración, los rendimientos se encontraron en un intervalo del 12 al $13 \%$; y para los tratamientos a $40{ }^{\circ} \mathrm{C}$, el rendimiento osciló entre 11 y $12 \%$.

Al comparar los valores obtenidos para los diferentes tratamientos, se determinó el rendimiento de una muestra de papa criolla (Solanum phureja) usando un tiempo de precipitación de 24 horas. El rendimiento alcanzado fue del 17,86 \%. Lo anterior indica que aunque el tiempo de precipitación empleado para los diferentes tratamientos de $\mathrm{pH}$ y temperatura, fue corto (cinco horas), los rendimientos son cercanos al valor de $17,86 \%$. 
De otro lado, Loyola y otros [8] encontraron en el almidón de papa (Solanum tuberosum) valores de rendimiento en el rango de 12.78-15.89 \%, en un tiempo de precipitación de 24 horas; valores inferiores a los desarrollados por la papa criolla.

En términos generales, la precipitación del almidón es más rápida a altas temperaturas, debido a que la viscosidad del agua aumenta con el descenso de la temperatura. También los rendimientos se pueden ver afectados por el $\mathrm{pH}$, por cambios en la estructura del almidón; de hecho, en soluciones ácidas, el almidón puede hidrolizarse en un porcentaje bajo (la hidrólisis completa requiere de tiempos mayores a seis horas y temperaturas cercanas a las de ebullición), mientras que en soluciones básicas, el almidón se puede gelatinizar a temperatura ambiente.

\section{Análisis estadístico}

El análisis de los datos obtenidos de los diferentes tratamientos de $\mathrm{pH}$ y temperatura para el almidón de papa criolla (Solanum phureja), fueron trabajados estadísticamente aplicando ANOVA y utilizando Excel. (Tabla 2).

Tabla 2. Análisis estadístico

\begin{tabular}{|l|c|c|c|c|c|}
\hline $\begin{array}{c}\text { Fuente de } \\
\text { variación }\end{array}$ & $\begin{array}{c}\text { Grados de } \\
\text { libertad }\end{array}$ & $\begin{array}{c}\text { Suma de } \\
\text { cuadrados }\end{array}$ & $\begin{array}{c}\text { Cuadrado } \\
\text { medio }\end{array}$ & $\mathbf{F}_{\text {cal }}$ & $\mathbf{F}_{\text {tabulado }}$ \\
\hline Total & 8 & 26.8 & 3.35 & & \\
Tratamientos & 2 & 22.65 & 11.32 & 23.58 & 6.94 \\
Interacción & 2 & 2.20 & 1.1 & 2.29 & 6.94 \\
Error & 4 & 1.95 & 0.48 & & \\
\hline
\end{tabular}

Estadísticamente, los resultados mostraron que las temperaturas entre sí afectan significativamente el rendimiento de almidón a diferentes pHsM; lo contrario ocurrió con la interacción de las distintas temperaturas, pues no afectaron significativamente el rendimiento de extracción del almidón. 


\section{Conclusiones}

La utilización de las temperaturas de $4{ }^{\circ} \mathrm{C}, 15^{\circ} \mathrm{C}$ y $40^{\circ} \mathrm{C}$ y los diferentes rangos de $\mathrm{pH}$, afectaron el rendimiento de extracción del almidón de papa criolla. La temperatura de $40{ }^{\circ} \mathrm{C}$ favoreció la velocidad de precipitación del almidón, mientras que las temperaturas de refrigeración presentaron los mayores rendimientos de extracción de almidón.

\section{Agradecimientos}

Los autores agradecen a la Universidad Pedagógica y Tecnológica de Colombia, por la colaboración en el desarrollo del proyecto.

\section{Referencias}

[1] D. Rodríguez, M. Espitia, Y. Caicedo, Y. Córdoba, Y. Baena \& C. Mora, "Caracterización de algunas propiedades físico-químicas y farmacotécnicas del almidón de arracacha (Arracacia xanthorriza)", Revista Colombiana de Ciencias Químicas Farmacéuticas, vol. 34, $\mathrm{n}^{\circ}$ 2, pp. 140-146, 2005.

[2] R. Soares, A. Lima, R. Oliveira, A, Pires \& V. Soldi, "Thermal degradation of biodegradable edible films based on xanthan and starches from different sources", Polymer Degradation and Stability, vol. 90, pp. 449454, 2005.

[3] M. Hansena, A. Blennowb, S. Pedersenc, L. Norgaarda \& S. Engelsen, "Gel texture and chain structure of amylomaltase-modified starches compared to gelatin", Food Hydrocolloids, vol. 22, pp. 1551-1566, 2008.

[4] L. Zadui, H. Yamauchi, C. Matsuura, S. Takigawa \& T. Noda, "Thermal analysis of mixtures of wheat flour and potato starches", Food Hydrocolloids, vol. 22, pp. 499-504, 2008.

[5] G. Ligarreto \& M. Suarez, "Evaluación del potencial de los recursos genéticos de papa criolla (Solanum phureja) por calidad industrial", Agronomía Colombiana, vol. 21, nº 1-2, pp. 83-94, 2003.

[6] M. Guizar, S. Montañez \& I. García, "Caracterización parcial de nuevos almidones obtenidos del tubérculo de camote del cerro (Dioscorea Spp)", Revista Iberoamericana de Tecnología Postcosecha, vol. 9, $\mathrm{n}^{\circ}$ 1, pp. 81-88, 2008. 
[7] Association of Official Analytical Chemists - AOAC_, Official Methods of Analysis. Virginia, p.1000-1050, 1990.

[8] N. Loyola, E. Oyarce \& C. Acuña, "Evaluación del contenido de almidón en papas (Solanum tuberosum, sp. tuberosum cv. desirée), producidas en forma orgánica y convencional en la provincia de Curicó, región del Maule", Revista IDESIA, vol. 28, n², pp. 41-52, 2010. 


\title{
MICROWAVE AND ULTRASOUND ACTIVATION EFFECT ON CATIONIZATION OF CORN AND POTATO STARCHES
}

\section{EFECTO DE LA IRRADIACIÓN ASISTIDA POR MICROONDAS Y ULTRASONIDO SOBRE LA CATIONIZACIÓN DE LOS ALMIDONES DE MAÍZ Y PAPA}

\author{
Efrén Muñoz-Prieto ${ }^{1 *}$ \\ Joaquín Palacios-Alquisira ${ }^{2 * *}$ \\ Carlos Rius-Alonso ${ }^{3 * * *}$ \\ Jesús Arenas-Alatorre ${ }^{4 * * * * *}$
}

Recepción 05/08/2011 Evaluación 12/09/2011 Aprobado 12/10/2011

\section{Abstract}

The aim of this study was to identify and compare the effect of ultrasound (US) and microwave (MW) irradiation on the assisted synthesis reaction to obtain cationic corn and potato starch derivatives, with cationizing agent (3-chloro-2-hydroxypropyl)-trimethylammonium chloride in solution and in limited solvent conditions, known as a paste

1 * Universidad Pedagógica y Tecnológica de Colombia, School of Chemical Sciences, Tunja, Colombia. E-mail: efren17@gmail.com

2 ** American Chemical Society, Universidad Nacional Autonóma de México, Laboratorio de Fisicoquímica Macromolecular, Facultad de Química, Ciudad Universitaria México D.F. E-mail: polylab1@servidor.unam.mx

$3{ }^{* * * *}$ Mexican Chemical Society, Universidad Nacional Autónoma de México, Laboratorio 204 de Química Orgánica, Facultad de Química, Ciudad Universitaria México D.F. E-mail: riusal@hotmail.com

$4^{* * * *}$ Universidad Nacional Autónoma de México, Instituto de Física, Departamento de Materia Condensada, México. E-mail: jarenas@fisica.unam.mex 
process. The starch derivatives were characterized by techniques, such as Fourier Transformed Infrared Spectroscopy, Thermo Gravimetric Analysis, Differential Scanning Calorimetry, Scanning Electron Microscopy and Atomic Force Microscopy. The application of both (MW) and (US) irradiation as energy sources permitted the shortening of the etherification time to minutes from the previously reported 18 hours of traditional heating. The results show the high potential of alternative energy sources to innovate and increase the efficiency of a technological starch derivatization process.

Keywords: Cationic starch, characterization, microwave, synthesis, ultrasound.

\section{Resumen}

El objetivo de este estudio fue identificar y comparar el efecto de la irradiación asistida por microondas y ultrasonido en la reacción de sintesis, para obtener derivados catiónicos a partir de los almidones de maíz y papa, con el agente cationizante cloruro de (3-cloro-2hidroxipropil) trimetilamonio en solución y en condiciones limitadas de disolvente, conocido como un proceso en pasta. Los derivados de almidón se caracterizaron por técnicas, tales como: Espectroscopia Infrarroja de Transformadas de Fourier, Análisis Termogravimétrico, Calorimetría Diferencial de Barrido, Microscopía Electrónica de Barrido y Microscopía de Fuerza Atómica. La aplicación de irradiación por microondas y ultrasonido, como fuentes de energía, permite la disminución del tiempo de eterificación a minutos, comparado con reportes anteriores, de 18 horas de calefacción tradicional. Los resultados muestran el alto potencial de fuentes de energía alternativas para innovar y aumentar la eficiencia de un proceso tecnológico de derivatización del almidón.

Palabras clave: Almidón catiónico, caracterización, microondas, síntesis, ultrasonido. 


\section{Introduction}

It has been extensively reported, that microwave (MW) heating makes reactions take place faster than under conventional thermal conditions and limit the occurrence of slower side reactions [1, 2], thus, greater yields are usually obtained. The results of the study conducted by Jyothi et al. [3, 4] indicate that succinylation of starch can be achieved in shorter reaction times, that microwave activation developed newer and versatile uses for cassava starch. Via microwave heating described a rapid method in the acetylation of cassava starch and the physicochemical properties of the obtained product [5]. Cassava starch acetylation changed starch molecular motion, resulting in a decrease in the glass transition temperature.

As published recently, zincatated potato starch was prepared in a solid-state, microwave-assisted reaction [6]. Reactions were faster than the ones proceeding on convectional heating. A series of cationic starch derivatives were synthesized by grafting a cationic moiety such as glycidyl octyl dimethylammonium chloride (GODAC), glycidyl dodecyl dimethylammonium chloride (GDDAC), and glycidyl tetradecyl dimethylammonium chloride (GTDAC), on the starch backbone, using $\mathrm{NaOH}$ as a catalyst [7]. During the last two decades, ultrasound microwave irradiation, became important as non-conventional forms of energy in physical and chemical processing [8], applicable as well in carbohydrate chemistry. It has been reported [9-11] that microwave and ultrasound can accelerate specific organic reactions and offer better yields.

Microwave heating involves the direct absorption of energy by functional groups that bear ionic conductivity or a dipole rotational effect, and this energy is then released into the surrounding solution [12]. This absorption of energy causes the functional groups involved to have higher reactivity to other surrounding reactants, than when simply incubated with the reactants at the same temperature. In other words, the enhanced rate of the reaction is due to the reactant being stirred by the molecular dipole rotation and the molecules themselves acting as a stirring bars. In contrast to conventional heating $(\mathrm{CH})$, the salient feature of "dipole rotation" constitutes one efficient form of "molecular agitation" or 
"molecular stirring," many aspects of which can be explored in chemical reactions [12]. The changes in chemical structure of ultrasound-treated cornstarch (UTCS) granules are presented and discussed in Huang, Q., et al. work [11]. After microwave assisted acetylation of starch took place, a reduction in the $\mathrm{Tg}$, strong hydrophobicity, and important exocorrosion affecting the granules were noticed. These changes were due to chemical modifications [13].

Ultrasound was used as an efficient method for microporous starch production $[14,15]$ and as a method of extraction. Ultrasonic irradiation offers an important potential for the conversion of biomass raw materials, such as polymeric carbohydrates, to useful lower weight molecules [8].

The use of microwave and ultrasound heating, is the focal point of this work, dedicated more specifically to the preparation of the cationic starch derivatives and simultaneously compared between the preparation in solution versus paste or cake state, with variable concentration of cationized agent and temperature. It was found that etherification could be completed during a very short reaction time under milder conditions with both types of irradiation. The obtained starch derivatives were characterized by FT-IR, TGA, DSC, SEM and AFM Materials and Methods

\section{Materials}

Corn and potato starches, analytical grade sodium hydroxide and hydrochloric acid were purchased from Merck-Mexico, SA, Mexico. N-(3-Chloro-2-hydroxypropyl) trimethylammonium chloride (CHPTAC) was procured from Sigma-Aldrich Co, Mexico. Quimicam S.A. of Central Valle of Mexico, supplied analytical grade isopropanol.

\section{Microwave cationization of corn and potato starches}

\section{Different (CHPTAC) concentrations in solution}

Starch was cationized by reacting samples with the cationic monomer CHPTAC, as follows: samples of $0.25 \mathrm{~g}$ of corn starch were 
dissolved in $25 \mathrm{ml}$ of distilled water at $80{ }^{\circ} \mathrm{C}$ for one hour and mixed with $0.360 ; 0.486 ; 0.678 ; 0.778 \mathrm{~g}$ of CHPTAC ; additionally, $2.5 \mathrm{~mL}$ of 1 molar solution of sodium hydroxide was added to each solution [16]. Starch reactions in solution were allowed to proceed in a Discover SP CEM Microwave Synthesis System equipped with The Synergy ${ }^{\mathrm{TM}}$ software and volume independent infrared temperature sensor, which provides the simplest means to measure the reaction temperature in a non-invasive manner, for example at $50^{\circ} \mathrm{C}$ for 30 minutes. After that, diluted hydrochloric acid was added to lower the $\mathrm{pH}$ below 7 to fully stop the cationization process [17]. The reaction solutions were thereafter cooled to room temperature, and the polymer was precipitated by adding an excess of isopropanol solvent. Similar experiments were carried out under microwave assisted conditions, $0.25 \mathrm{~g}$ of corn starch in $25 \mathrm{~mL}$ of deionized water with $0.778 \mathrm{~g}$ of CHPTAC and 2.5 $\mathrm{mL}$ of $\mathrm{NaOH} 0.1 \mathrm{~N}$ at temperatures of $40,50,60,70,80^{\circ} \mathrm{C}$.

\section{Microwave cationization starch in cake or paste state at different temperatures}

In the laboratory, native corn and potato starch samples were cationized by microwave-assisted radiation in the paste state. For this condition, $4.5 \mathrm{~g}$ of starch was mixed with $1.218 \mathrm{~g}$ of CHPTAC and $4.5 \mathrm{~mL}$ of $\mathrm{NaOH} 10 \mathrm{~N}$ added to the mixture. The mixture was divided into six parts; each sample reacted by microwave heating at different temperatures. The duration of the heat treatments ranged from 5 to 40 minutes. The solution was subsequently cooled to room temperature and the polymer was precipitated by adding isopropanol. It was then dried in a vacuum oven at $40^{\circ} \mathrm{C}$ for $4 \mathrm{~h}$.

\section{Ultrasound cationization of starch in solution}

$2.5 \mathrm{~g}$ of starch in $25 \mathrm{~mL}$ of water were pre-heated at $50{ }^{\circ} \mathrm{C}$ for 2 minutes using a horn-type Ultrasonic Processor Model: GEX 130 System, $20 \mathrm{kHz}$ ) at $70 \%$ sonic power, $130 \mathrm{~W}$. Next, $0.778 \mathrm{~g}$ of CHPTAC and $2.5 \mathrm{~mL}$ of $\mathrm{NAOH} 0.1 \mathrm{~N}$ were added to obtained gel like solutions and the reaction was followed. Thus, sonication was applied for $5,10,15,20,25,30$ and 40 minutes, with occasional stirring, a sample was taken each time. Water cooling bath was used to maintain 
the temperature near $50 \pm 2^{\circ} \mathrm{C}$. The products were precipitated with isopropanol and further dried at $40^{\circ} \mathrm{C}$ (Fig. 2a).

$0.25 \mathrm{~g}$ of dry basis native corn starch samples were suspended in $25 \mathrm{~mL}$ of water, $2.5 \mathrm{~mL} \mathrm{NaOH} 1 \mathrm{~N}$ and mixed with $0.778 \mathrm{~g}$ of CHPTAC. The reaction was carried out at $40,50,60,70{ }^{\circ} \mathrm{C}$ using a horn-type Ultrasonic Processor Model: GEX 130 System, $20 \mathrm{kHz}$ ) at $70 \%$ sonic power $130 \mathrm{~W}$. After that, dilute hydrochloric acid was added to each sample to lower the $\mathrm{pH}$ below 7 to stop the cationization process [17]. The solutions were thereafter cooled to room temperature and the polymers were precipitated adding an excess of isopropanol solvent. They were then dried in a vacuum oven at $40{ }^{\circ} \mathrm{C}$ for 6 hours.

\section{Characterization of cationic starches}

\section{Infrared Measurements}

FTIR spectra of native and cationic starches were recorded on an IR Spectrum 400 Perkin Elmer FTIR Spectrometer, using the Spectroscopy Attenuated Total Reflectance (FTIR/ ATR) technique. The spectra were obtained with a resolution of $4 \mathrm{~cm}^{-1}$ between a wave number range of 400 and $4000 \mathrm{~cm}^{-1}$. For each spectrum, 32 scans were co-added.

\section{Thermal Analysis}

Thermogravimetric Analysis (TGA). The thermal stability of the native and etherified hemicelluloses was performed using Thermogravimetric Analysis (TGA), TGA/SDTA 851e Mettler Toledo. The scans were run from $20{ }^{\circ} \mathrm{C}$ to $340{ }^{\circ} \mathrm{C}$ at a rate of $10{ }^{\circ} \mathrm{C}$ per minute under nitrogen flow.

Differential scanning calorimetry (DSC). The thermal properties of selected samples were determined using a DSC 82 Mettler Toledo differential scanning calorimeter. A sample of $5 \mathrm{mg}$ was weighed in a pre-weighed aluminum pan. The pan was sealed hermetically and transferred to the heating chamber of the calorimeter. An empty pan was used as a reference, and the sample was heated from -40 to $240^{\circ} \mathrm{C}$ at a rate of $10{ }^{\circ} \mathrm{C} \mathrm{min}-1$, and then cooled back to $20^{\circ} \mathrm{C}$ at the same rate. 
The temperatures corresponding to the onset of gelatinization (To), peak $(T p)$, endset $(\mathrm{Te})$, and also the heat of gelatinization $(\Delta \mathrm{H})$ were recorded.

\section{Scanning Electron Microscopy (SEM)}

The morphology of the samples of native corn and potato starches, as well as those of the modified starches, were investigated using a LV-SEM, JSM-5600LV equipped with secondary and retro dispersive electron detectors. The instrument was set to a difference in accelerating voltage of $15 \mathrm{kV}$, operated at $12 \mathrm{~Pa}$ of pressure in the specimen chamber. The magnification range was changed from $100 \mathrm{x}$ to 1500x. SEM images were obtained with secondary electrons. For the SEM analysis, samples were fixed onto an aluminum specimen holder with carbon tape. The sample was covered with a thin layer of $500 \mathrm{~nm}$ of carbon, especially if the sample was a poor conductor, to prevent electric charge on the surface of the sample.

\section{Atomic Force Microscopy (AFM)}

AFM imaging was carried out using a MAF JSPM-4210 Scanning Probe Microscopy Instrument (JEOL) in air at ambient temperature and humidity controlled. Starch and cationic derivatives samples were spread directly on an AFM sample holder. The images of native and cationized starches were recorded in the tapping mode. The topographic and amplitude images were taken simultaneously. Silicon probes were used with a nominal spring constant of $20-100 \mathrm{~N} / \mathrm{m}$ and a scan frequency of $0.5 \mathrm{~Hz}$. Scan areas were of $2 \times 2 \mu \mathrm{m}, 3 \times 3 \mu \mathrm{m}, 4 \times 4 \mu \mathrm{m}$.

\section{Results and Discussion}

\section{Microwave and Ultrasound}

Table-1 shows the effect of temperature and time on conversion, for a constant amount of starch sample of $28 \times 10^{-3} \mathrm{~mol}$ or $28 \mathrm{mmol}$ and $46 \mathrm{mmol}$ of CHPTAC with $45 \mathrm{mmol} \mathrm{NaOH}$. The results show reactions assisted by $\mathrm{MW}$, experiments done in paste state, time and temperature increases the conversion percentage. Corn samples at $60^{\circ} \mathrm{C}$ and $10 \mathrm{~min}$ the conversion was reduced. At $70^{\circ} \mathrm{C}$ and 5 min the conversion is maximal. 
Table 1. Synthetic details of corn and potato cationic starch derivatives, by microwave irradiation $(p$

\begin{tabular}{ccccccc}
\hline Sample & $\begin{array}{c}\text { Corn starch } \\
\text { Temperature } \\
{ }^{\circ} \mathrm{C}\end{array}$ & $\begin{array}{c}\text { Corn starch } \\
\text { Time } \\
\text { (minutes) }\end{array}$ & $\begin{array}{c}\text { Corn } \\
\text { starch } \\
\text { Conversion } \\
\%\end{array}$ & $\begin{array}{c}\text { Potato starch } \\
\text { Temperature } \\
{ }^{\circ} \mathrm{C}\end{array}$ & $\begin{array}{c}\text { Potato Starch } \\
\text { Time } \\
\text { (minutes) }\end{array}$ & $\begin{array}{c}\text { Potato } \\
\text { starch } \\
\text { Conversion } \\
\%\end{array}$ \\
\hline 1 & 50 & 5 & 42 & 60 & & 70 \\
2 & 55 & 5 & 62 & 65 & 5 & 82 \\
3 & 55 & 10 & 88 & 70 & 5 & 84 \\
4 & 60 & 5 & 91 & 60 & 10 & 91 \\
5 & 60 & 10 & 77 & 65 & 10 & 92 \\
6 & 70 & 5 & 97 & 70 & 10 & 96 \\
\hline
\end{tabular}

Figure (1) shows the percentage conversion versus the CHPTAC molar concentration data for corn and potato starch samples. Both reactions were activated by microwave at a constant temperature of $50{ }^{\circ} \mathrm{C}$ in solution. Figure (1) shows that, as expected, increasing CHPTAC monomer concentration, the conversion percentage of polymer modification increased for both samples corn and potato in solution reaction assisted by microwave irradiation, and better yields were observed for corn samples.

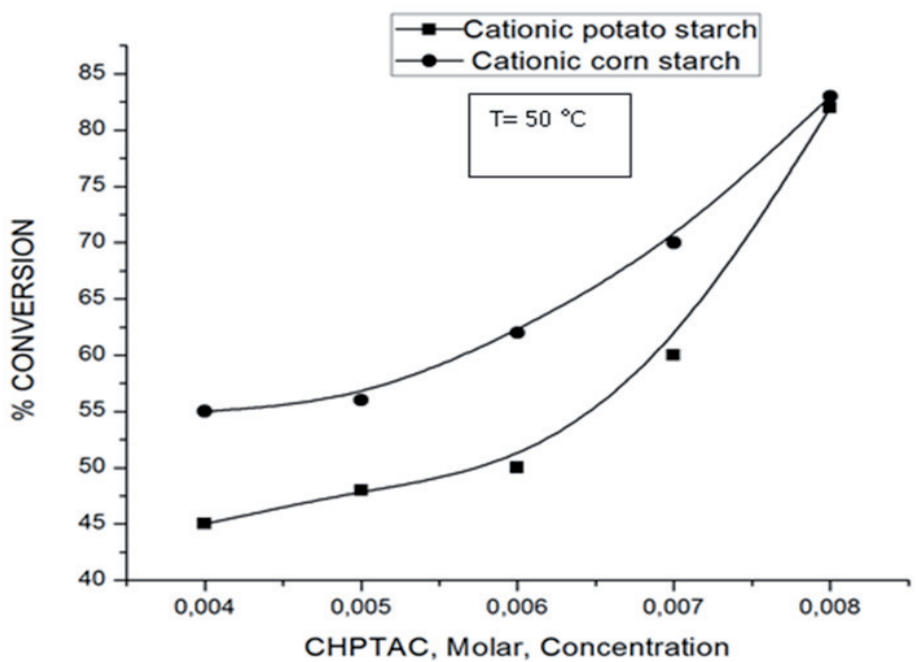

Figure 1. Concentration of CHPTAC, versus percentage conversion of Cationic Starches by MW irradiation 
The application of ultrasound irradiation as an energy source, shortened the etherification time to several minutes and increased the efficiency of starch cationization. From Figure 2a, a better conversion was observed for ten to twenty minutes at the same temperature.

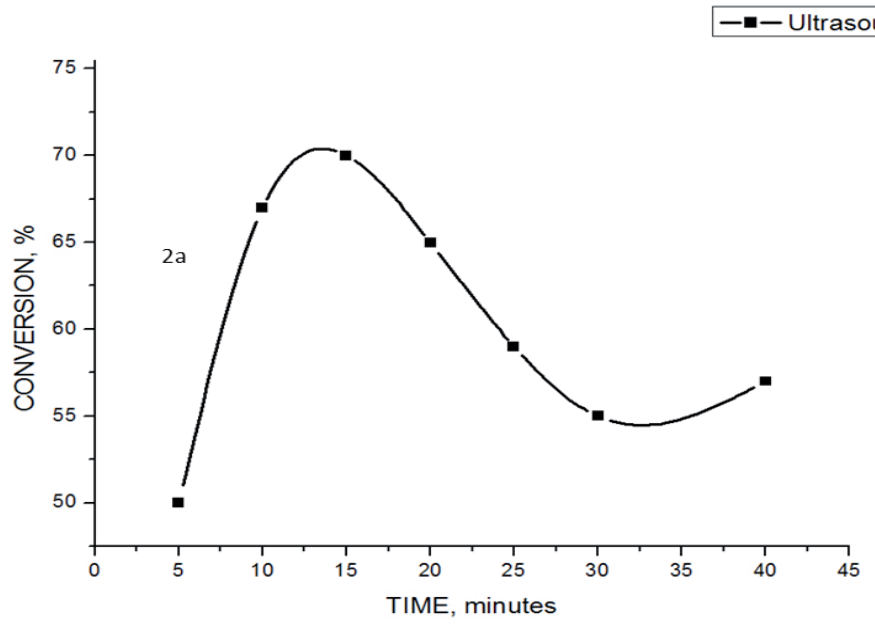

Figure 2a. Conversion of cationic corn starch in solution by ultrasound.

Figure $2 \mathrm{~b}$ shows experimental conditions and results for two cationic starches. The first reaction for corn starch sample was assisted by microwave irradiation; the second reaction for potato starch was activated by ultrasound. The samples assisted by ultrasound activation reached a maximum of percentage conversion at $50{ }^{\circ} \mathrm{C}$. The other sample obtained by $\mathrm{MW}$ irradiation attained a maximum percentage conversion at $70^{\circ} \mathrm{C}$. As it can be perceived, the ultrasound activated reaction proceeded well at low temperatures, which is a promising so the technique can be applied successfully with significant energy savings. Figure $2 b$ shows a coincidental time conversion, while at higher temperatures there is a decrease in polymer modification. 


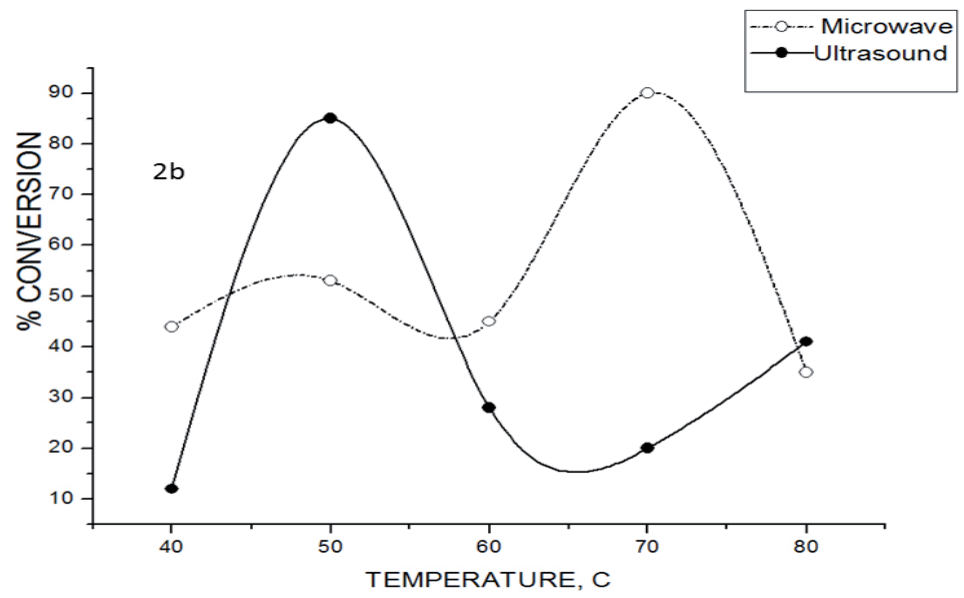

Figure $\mathbf{2 b}$. Conversion of cationic corn starch by microwave and cationic potato starch in solution by ultrasound.

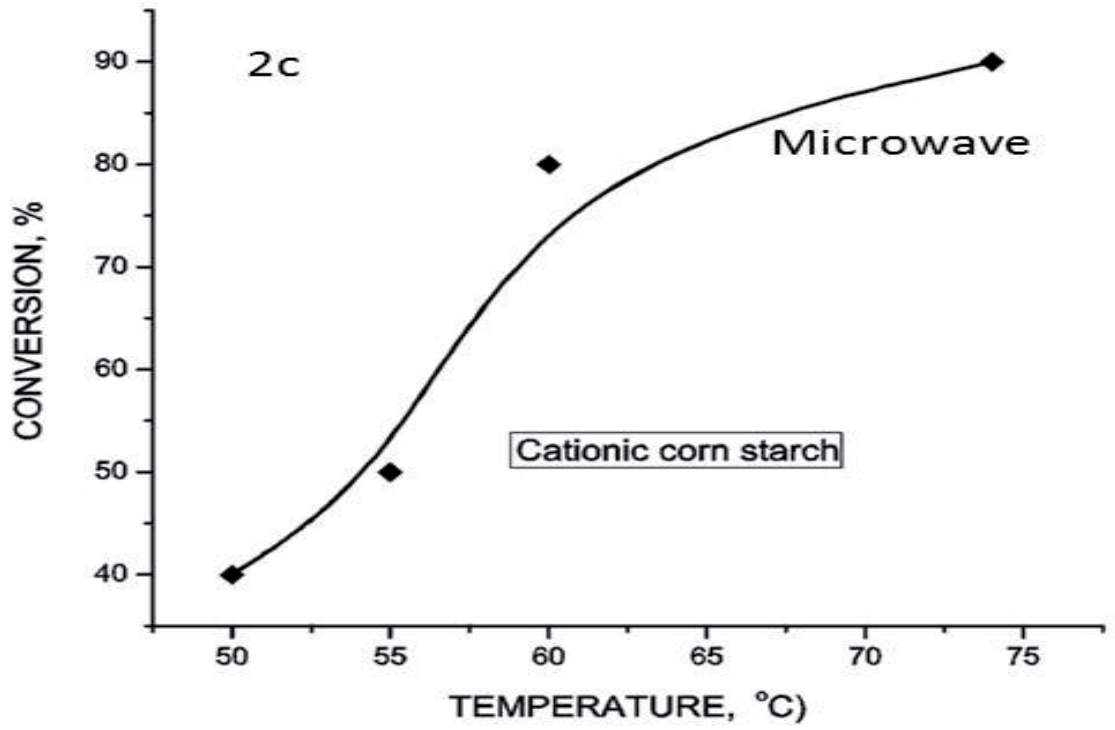

Figure 2c. Conversion of cationic corn starch by microwave related to temperature. 
Ultrasound activation is a unique phenomenon of cavitation, generates high-energy and/or excited state species, thereby inducing a cascade of radical and electron transfer (ET) processes with subsequent bond breaking of compounds present in the solution. The extreme local conditions provided by the cavitational collapse, occur during extremely short times, a few microseconds, which ensures an almost adiabatic process [18]. In our case, the dispersive effect is important because starch particles disperse out and react quickly and effectively with the CHPTA agent at higher temperatures.

Figure 2c shows the percentage conversion of corn starch at different temperatures. For example, 0.0040 molar of starch reacted with a controlled amount of cationizing agent 0.0080 molar of under identical conditions as previously described synthesis under microwave irradiation. This synthetic pathway is more efficient at higher temperatures in a temperature range studied of 60 to $70{ }^{\circ} \mathrm{C}$. The MW and US irradiation led to shorter reaction times and was dependent upon the dipole strength of reactants, its mobility and mass and the matrix state of the dipole [19].

The experiments showed the influence on the cationic efficiency of various factors. For the same concentration of cationic agent and raw starch, the effects of reaction time, temperature, and phase state of the medium were investigated. The products exhibited the better percentage yield in a temperature range of $60-70{ }^{\circ} \mathrm{C}$ with ten minutes reaction time and were consistent with previous studies [20-22].

Figure $2 \mathrm{~d}$ indicates the influence of temperature and time on the process of cationization of potato starch in a paste state. It can be seen that time extended to 10 minutes favors the cationization process in the range of temperatures studied. If the microwave irradiation is maintained for five minutes, the best temperature for high conversion is $65^{\circ} \mathrm{C}$. 


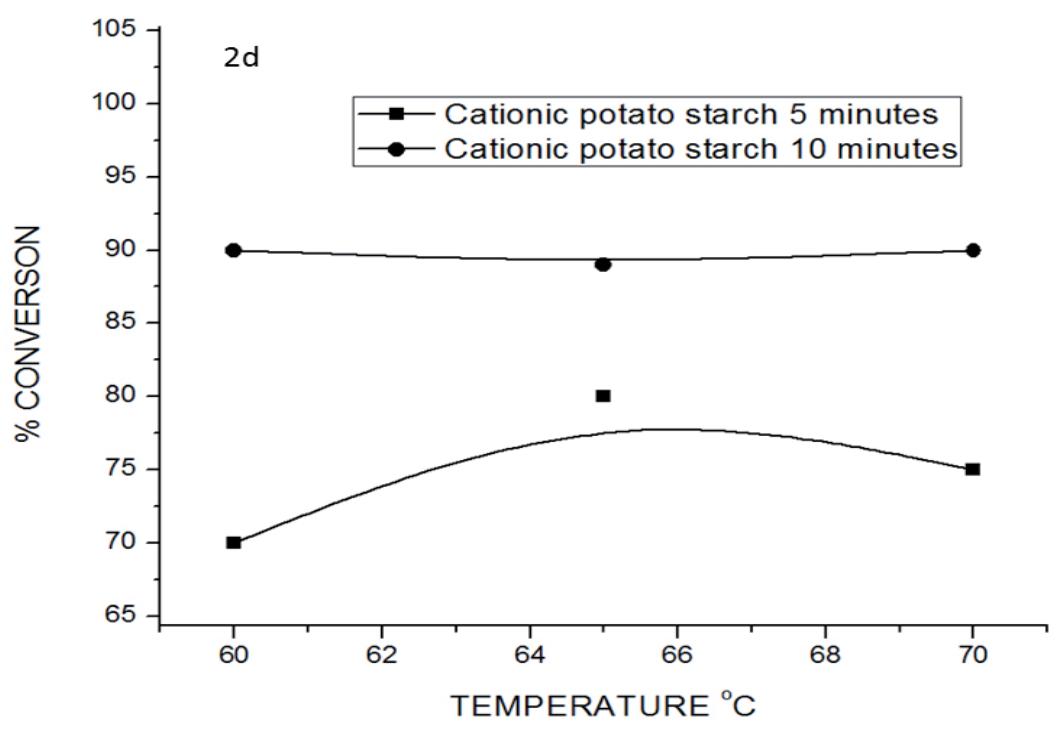

Figure 2d. Conversion of cationic potato starches by microwave irradiation.

The cationic potato starch derivative will have the highest yield of the reaction at a temperature of $60^{\circ} \mathrm{C}$, if microwave irradiation is hold up for ten minutes. Not important difference in percentage conversion was observed, when this reaction was run at temperatures higher than $60^{\circ} \mathrm{C}$, even if it reaches $70^{\circ} \mathrm{C}$. Effective starch modification can be achieved when microwave irradiation supports the activity of the cationizing agent added to the reaction mixture.

\section{Infrared Spectra}

The FTIR spectra of potato starch and the cationic potato starch derivative are shown in Figure 3. For the potato starch, in (Figure ----3), the broad peak at $3351.34 \mathrm{~cm}^{-1}$ is due to the $\mathrm{H}_{2} \mathrm{O}$ stretching vibration. The two bands at, $2924.43 \mathrm{~cm}^{-1}$ are due to antisymmetric and symmetric stretch respectively, and $1151 \mathrm{~cm}^{-1}$ are due to the $\mathrm{C}-\mathrm{O}$ stretching vibration. The peak at $1639.87, \mathrm{~cm}^{-1}$ is due to the first overtone of $\mathrm{O}-\mathrm{H}$ bending or $\mathrm{H}_{2} \mathrm{O}$ deformation. Two bands at 1077 and $1022 \mathrm{~cm}^{-1}$ are for the $\mathrm{CH}_{2}-\mathrm{O}-\mathrm{CH}_{2}$ stretching vibration. 


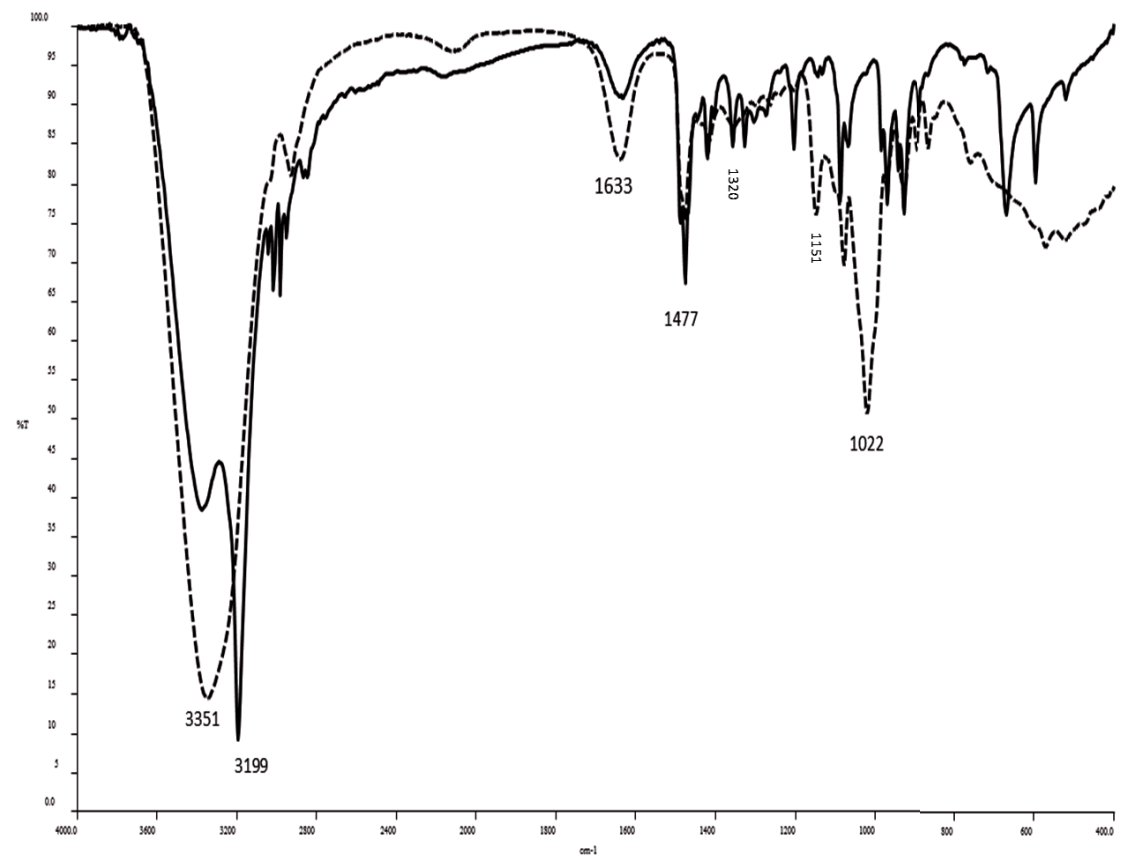

Figure 3. FTIR Spectra: ---- Infrared Spectrum of potato starch. Infrared Spectrum of cationic potato starch, microwave assisted.

For the cationic potato starch, (Figure 3), the broad peak at 3320 $\mathrm{cm}^{-1}$ is due to the $\mathrm{H}_{2} \mathrm{O}$ stretching vibration. The two bands at, 2924.43 $\mathrm{cm}^{-1}$ are due to antisymmetric and symmetric stretch respectively, and $1149.5 \mathrm{~cm}^{-1}$ are due to the $\mathrm{C}-\mathrm{O}$ stretching vibration. The peak at 1644 $\mathrm{cm}^{-1}$ is due to the first overtone of $\mathrm{O}-\mathrm{H}$ bending or $\mathrm{H}_{2} \mathrm{O}$ deformation. The band at $1320 \mathrm{~cm}^{-1}$ is due to $\mathrm{CH}_{2}, \mathrm{CH}$ deformation. The bands at $1000 \mathrm{~cm}-1$ are due $\mathrm{C}-\mathrm{OH}$ stretch vibration, and the band at $840 \mathrm{~cm}^{-1}$ $\mathrm{CH}_{2}-\mathrm{O}-\mathrm{CH}_{2}$ correspond at ring mode stretching vibration [23].

The presence of an additional band at $1405 \mathrm{~cm}^{-1}$ assignable to the $\mathrm{C}-\mathrm{N}$ stretching vibration, which is not present in raw starches, is clear proof of the incorporation of a cationic moiety onto the backbone of the starch. It should be mentioned that such a band was absent in starch. It is worth mentioning, the band corresponding to $\mathrm{C}-\mathrm{Cl}$ at 671 $\mathrm{cm}^{-1}$ was absent in the cationic product. According to the literature and to the reference spectra, the fundamental stretching and deformation 
vibrations of the $\mathrm{CH} 3$ groups in trimethylammonium $\left(\mathrm{CH}_{3}\right)_{3} \mathrm{~N}_{1}$ are expected at approximately $3100-3020 \mathrm{~cm}^{-1}$ and $1477 \mathrm{~cm}^{-1}$ [23] .

\section{Thermogravimetric Analysis (TGA)}

Figures 4.1 and 4.2 show the mass loss of four starch samples recorded by (TGA) analysis and the correspondent DTG curves. Figure 4.1 cationic corn sample prepared by microwave activation in paste state. The TG and DTG curves, and thermo-grams of native and cationic starches: cationic corn in paste by microwave (mw) irradiation (Fig. 4.1.1); cationic potato in paste (mw) (Fig. 4, 1, 2); cationic corn (mw) in solution (Fig. 4.1.3); and cationic potato (mw) in solution (Fig. 4.1.4). These samples are compared with a raw starch (Fig. 4.1.5). From the TG curves displayed in Fig. 4.1 we observe that on further increase in temperature there was a sharp mass loss at $313{ }^{\circ} \mathrm{C}$ for native cornstarch (Fig. 4.1.5), at $242{ }^{\circ} \mathrm{C}$ for cationic corn (mw) in solution (Fig. 4.1.3), and at $259{ }^{\circ} \mathrm{C}$ for cationic cornstarch microwave in paste (Fig. 4.1.1). All mass losses resulted from the partial decomposition of cationized starch. From Fig. 4.1 we can identify differences between the samples, and the thermal stability and degradability of starch derivatives can be noted as well. Thermograms for cationic corn and potato starches, microwave assisted in solution; degrade in a similar manner (Fig. 4.1.3 and Fig. 4.1.4).

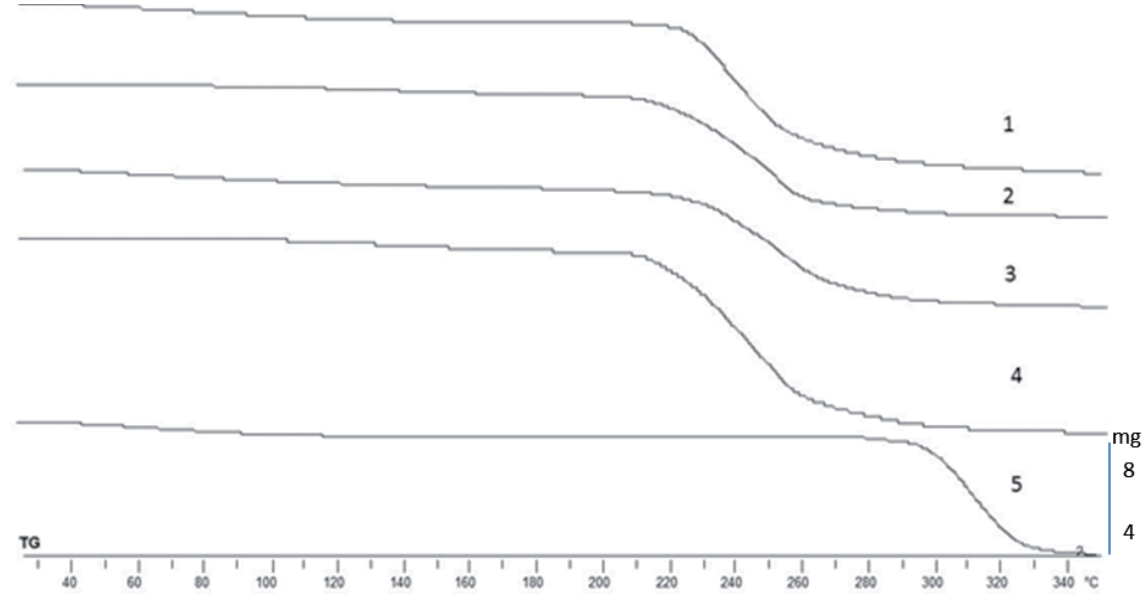

Figure 4.1. TGs: Cationic starch samples prepared by microwave activation: 1.Corn paste. 2. Potato paste 3. Corn in solution. 4. Potato in solution. 5. Raw starch. 
Cationic corn and potato derivatives obtained by microwave in a paste state behave different in Figures 4.1.1 and 4.1.2. The first degradation stage occurs for both within the interval of $128-140{ }^{\circ} \mathrm{C}$ and the second strong weight loss within the interval of $230-248{ }^{\circ} \mathrm{C}$, showing the increase of thermal stability of the starches prepared in a paste state over those obtained in solution and completely microwave assisted. The chemically modified starch samples lose mass earlier than the original corn sample.

The DTG curve obtained for cationic corn starch microwave (mw) in paste, is illustrated in Fig. 4.2a, cationic potato $(\mathrm{mw})$ in solution in Fig. 4.2b, native cornstarch in Fig. 4.2c, and cationic corn (mw) in solution in Fig. 4.2d. From the graphs in Fig. 4.2c, we can see that they are samples in which there was a mass loss of $9 \%$ around the gelification point temperature of $67-68{ }^{\circ} \mathrm{C}$ for cornstarch, and the correspondent cationized Fig 4.2a does not present mass loss. From the DTG plot Fig. 4.2c, it can be observed that the thermal degradation of native starch commenced at $288^{\circ} \mathrm{C}$ following a significant mass loss with an increase in the temperature to $318^{\circ} \mathrm{C}$. However, the cationic starch was thermally decomposed at a temperature of $233^{\circ} \mathrm{C}$, and

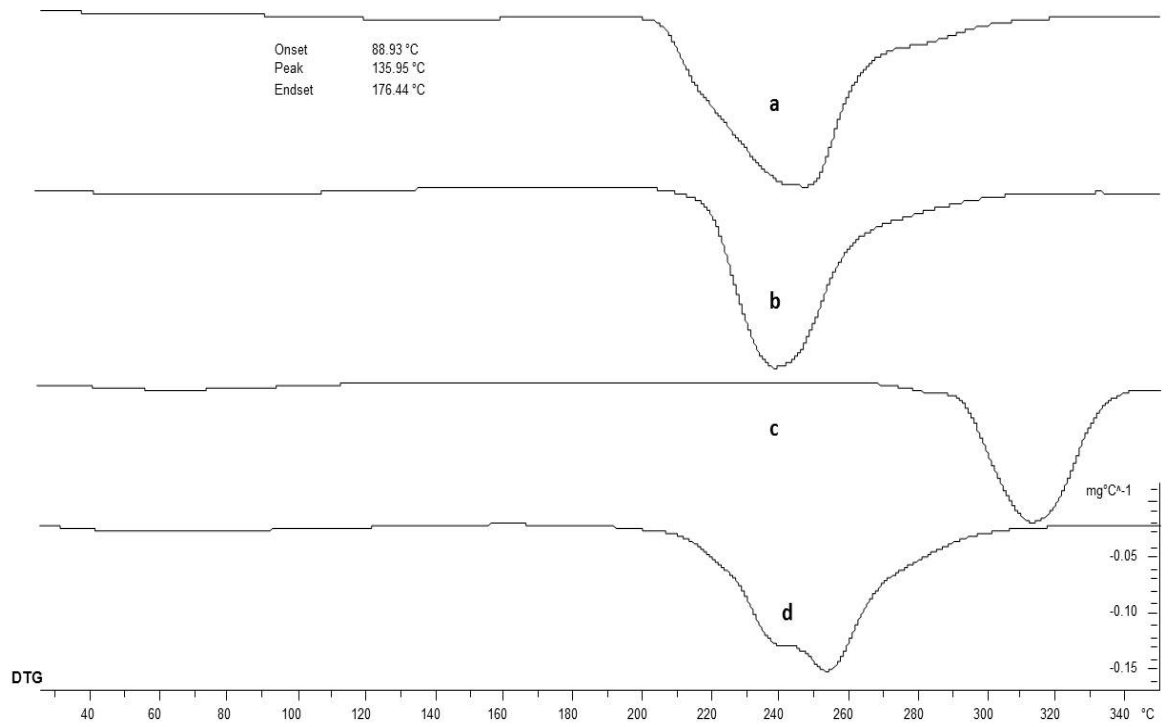

Figure 4.2. DTGs: (a) Cationic corn ( $m w$ ) paste. (b) Cationic potato ( $m w)$ in solution. (c) Corn starch. (d) Cationic corn ( $m w)$ in solution. 
the rate of mass loss was rapid between 240 and $265^{\circ} \mathrm{C}$, which were low temperatures in comparison to the native starch. Clearly, the cationically modified starches undergo thermal degradation at a lower temperature than in the case of native starch. This indicates that the thermal stability of cationic starch decreased due to the cationization. This result was similar to those described by [24] and [25], who examined the effect of chemical modification on starch by using the thermal analysis method.

Cationic potato obtained by microwave in solution degrades in two stages. The first stage begins at about $82.6^{\circ} \mathrm{C}$ for all the material with a weight loss of $6.3 \%$ this is due to loss of residual water. The second stage exhibited a rapid weight loss at $220{ }^{\circ} \mathrm{C}$ reaching its maximum at $240{ }^{\circ} \mathrm{C}$ as shown in Fig. 4.2b. Cationic corn obtained in solution by MW activation its first weight loss of $8.54 \%$. at $58.99{ }^{\circ} \mathrm{C}$. The second peak reached its maximum at $257^{\circ} \mathrm{C}$.

\section{Differential Scanning Calorimetry (DSC)}

Differential Scanning Calorimetry (DSC) has become widely accepted as the most suitable method for the evaluation of different carbohydrate gelatinization, starch gelatinization as a multistage process [26], and other thermal behavior [27-30]. DSC thermograms facilitate the analysis of starch transition temperatures (i.e. onset, $\mathrm{T}_{\mathrm{o}}$; peak, $\mathrm{T}_{\mathrm{p}}$; and conclusion, $\mathrm{T}_{\mathrm{c}}$ ) [31]. The thermal behaviors of our samples are shown in Fig. 5: cornstarch Fig. 5a, cationic corn microwave $(\mathrm{mw})$ in solution Fig. $5 \mathrm{~b}$, cationic potato starch in paste Fig. $5 \mathrm{c}$, cationic corn starch (mw) paste Fig. $5 \mathrm{~d}$, and cationic potato starch (mw) in solution Fig. 5e. DSC of native corn Fig. 5a gelatinizes in a temperature range between 78 and $94{ }^{\circ} \mathrm{C}$ before retro-gradation sets in. Modified starches extending the retro-degradation temperature heavily show a decrease in the stability of the cationic product [32, 33]. The calorimetric data in Fig. 5 clearly shows the difference among the starch derivatives. For example, corn starch containing water (Fig. 5a) was submitted to thermal processing with temperatures above $100{ }^{\circ} \mathrm{C}$. This activity shows the gelatinization process of the starch in such a way that it melts and presents only a one phase transition attributed to water vaporization $[3$ 


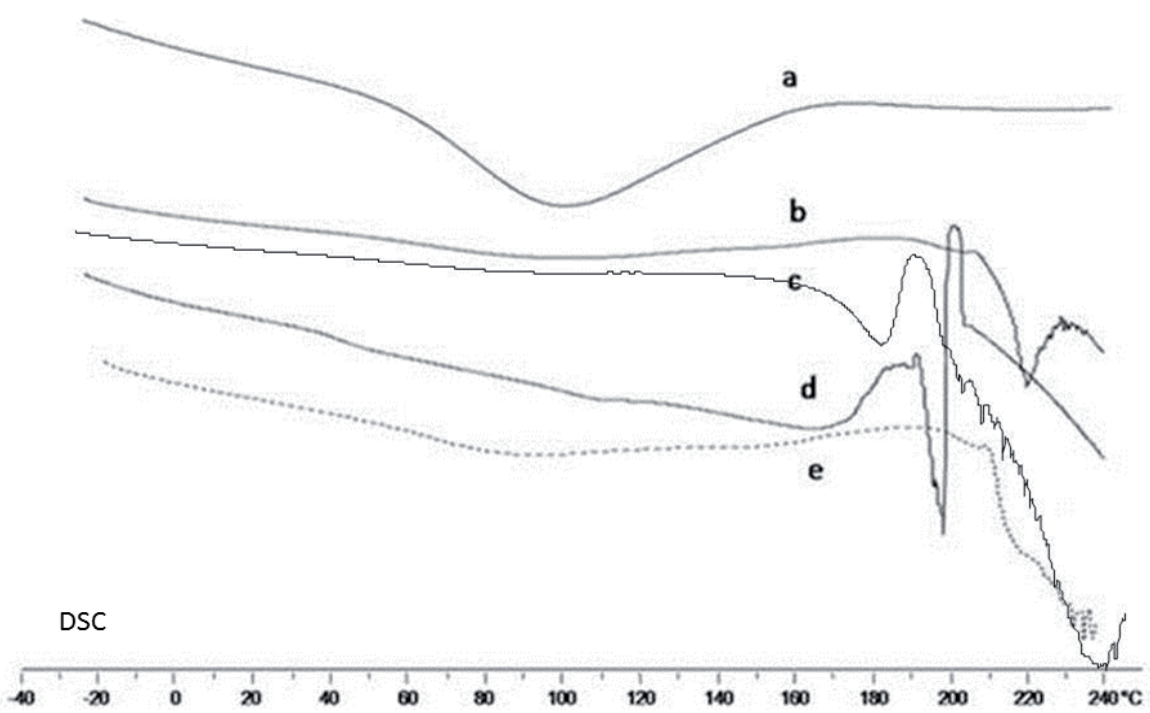

Figure 5. DSCs behavior of raw starch and its corresponding cationic derivatives: (a) Corn starch. (b) Cationic corn ( $\mathrm{mw}$ ) in solution. (c) Cationic potato starch (mw) in paste. (d) Cationic cornstarch ( $m w)$ in paste. (e) Cationic potato starch ( $\mathrm{mw}$ ) in solution.

The single narrow endotherm for cationic corn microwave in solution Fig. 5b, and cationic potato starch microwave irradiated in solution Fig. 5e, related to the water-mediated melting of starch crystallites, were initiated by the stripping of starch chains in the swollen amorphous regions [35]. For cationic potato starch microwave in a paste state (Fig. 5c) and for cationic corn starch in the paste state Fig.5d, the endothermic heat flow that was found in the DSC tests was low. This finding was probably due to overall gelatinization during the reaction condition and the drying process before the DSC test.

A close analysis of the DSC endotherms shows important differences in the thermal behavior of these samples. There is some similitude between starches and corresponding derivatives in solution as deduced from the curves shown in Fig. 5. For example: for corn starch (Fig. 5a), To 22, 49; Tp corresponded to $94.01^{\circ} \mathrm{C}$ and $\mathrm{Te}$ equaled $167.62{ }^{\circ} \mathrm{C}$ for cationic corn microwave in solution (Fig. $5 b$ ), $\mathrm{Tp} 74,40$ and $\mathrm{Te} 181,62{ }^{\circ} \mathrm{C}$; for cationic potato $(\mathrm{mw})$ in solution, $\mathrm{Tp}$ is $87.38^{\circ} \mathrm{C}$. There is a peak displacement for cationic derivatives in a paste state as we can see from the same graph example: To 
4.33; Tp equal $163.98{ }^{\circ} \mathrm{C}$ and $\mathrm{Te} 185.95{ }^{\circ} \mathrm{C}$ for cationic corn (mw) in paste (Fig. $5 \mathrm{~d}$ ) or similar in cationic potato starch $(\mathrm{mw})$ paste Fig. $5 \mathrm{c}$, where Tp is $182.35^{\circ} \mathrm{C}$. Analysis of DSC endotherm has established the water dependency of starch gelatinization. Tp becomes higher for microwave irradiated starches in paste and indicated a stronger or irregular arrangement of molecules after cationization. The decrease of water content in cationic starch derivatives produced structure changes and led to the increase of the glass transition temperature, which could indicate better molecular order within the granule after substitution. Several researchers revealed that chemical substitution served to facilitate the melting of amylopectin crystallites [29, 36].

\section{Scanning Electron Microscopy (SEM)}

The images obtained by SEM of potato and corn starches and the respective modified starches by cationization are shown in Figs. 6.1 and 6.2: SEM images of native corn starch Fig. $6.1 \mathrm{a}$, native potato starch Fig.6.1b, and their corresponding cationized derivatives Fig. 6.1c, and Fig.6.1d. Samples of the cationic starch derivatives correspond to cationic potato and corn starches obtained by microwave radiation in paste at 60 or $70{ }^{\circ} \mathrm{C}$ for 10 minutes.

The changes in the structure of ultrasound-treated corn starch granules are presented and discussed. We found that the Scanning Electron Microscopy (SEM) of the crystalline structure of treated granules did not change, but the amorphous area was slightly destroyed [11].

Figure 6.1 shows the scanning electron micrographs of the native and cationic starches. Native cornstarch Fig. 6.1a presents granules with irregular shapes and various sizes. The surface morphology of potato starch, Fig $6.1 \mathrm{~b}$, is more regular; the granules are generally large, voluminous, and oval-shaped with an eccentric hilum. When viewed under polarized light, the granules are birefringent, indicating a high degree of molecular order within the granule. Modified starches (Fig. 6.1c and Fig. 6.1d) are not similar to native cornstarch, as more evident planar configuration was observed on some granular surface. Some inward concaves were also found in the granules of Fig. 6.1c, along with partially disintegrated granules and small fragments. SEM photos showed that the paste process deformed the starch granules. 
Fig. 6.2 shows SEM images of potato cationized starch derivative Fig. 6.2a, Fig. 6.2b, Fig. 6.2c, and Fig.6.2d sequentially with their deformation influenced by exposure to electrons. The granules of Fig. 6.2 displayed the highest extent of fragmentation. Some large granules have especially deep holes that form pores at their surface Fig. 6.2.d. The inward concaves on the surface of the starch was also reported in reference [35] on starch citrates. The cause of the inward concaves might be a result of the swelling of starch granules during the cationization process, followed by a collapse during cooling after the termination of the reaction. The collapsed region is believed to be less organized than the rest of the granule and is the region where cationization mainly occurred. The increased superficial porosity might facilitate the diffusion of the cationizing agent into the inner region and contribute to the alteration of granular morphology. Fig. 6.2a shows a clear appreciation of rapid sequential deformation just during the photography. Through Fig.6.2.d it is evident that the sample's exposure to the electrons' beam energy during the test is an aspect that requires further studies.
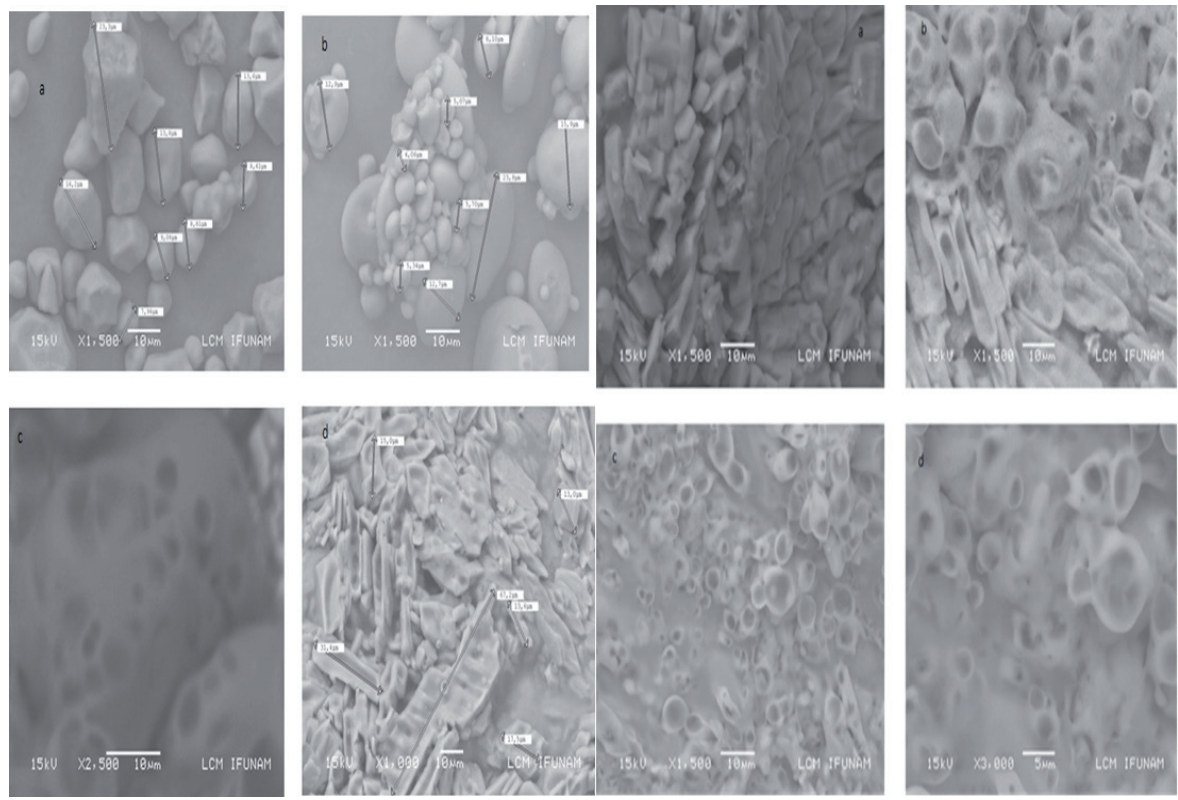

Figure 6. Fig. 6.1 SEM images of native corn (a), potato (b) starch granules and their corresponding cationized derivatives (c) and (d). Fig.6.2 SEM sequentially images of cationic potato starch derivative (a), (b), (c), (d) and their deformation influenced by exposition to electrons. 


\section{Atomic Force Microscopy (AFM)}

Fig.7.1 shows changes of corn starch (Fig. 7.1a), potato starches (Fig. 7.1b), and their respective cationic corn (Fig, 7.1c) and cationic potato (Fig. $7.1 \mathrm{~d}$ ), with rough surfaces qualitatively characterized by AFM. This investigation showed that native potato and cornstarch granules, similar to cationic derivatives, have very complex surfaces consisting of numerous fine particles with diameters of $20-40 \mathrm{~nm}$. In general, starch cationized derivatives have a large-scale coarse surface with a ridge-and-valley structure with many depressions. $\alpha$-amylase action caused the shortening of carbohydrate chains and the extension of surface roughness Fig. 7.1 [37].

Corn

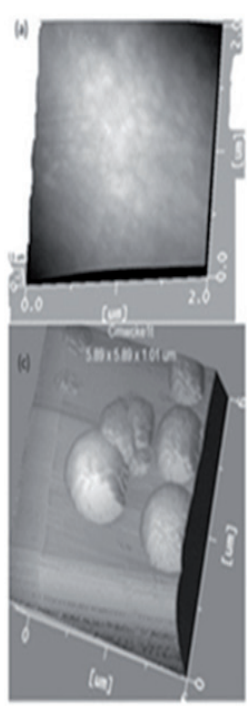

7.1
Potato

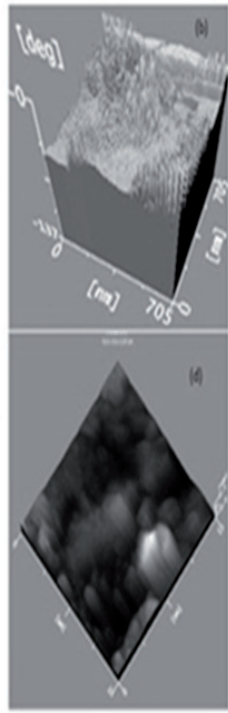

Corn

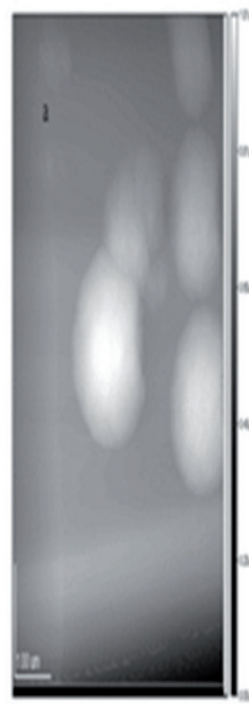

7.2

Potato

Native

Modified

Figure 7.1. Changes of corn (a) and potato (b) starches and their respective cationized (c), (d) roughness surface qualitatively characterized by AFM. Fig.7.2 AFM images taken in tapping mode of derivative surfaces

of cornstarch in solution and cationic potato derivative in paste stage, assisted microwave irradiation. The image surface area is $1 \mu \mathrm{m} \times 1 \mu \mathrm{m}$ (a) and $1 \mu \mathrm{m} \times 1.3 \mu \mathrm{m}(b)$ 
In the following Fig.7.2, we can see AFM images taken in tapping mode of derivative surfaces of cationic cornstarch in solution (Fig. 7.2a) and cationic potato derivative in paste (Fig. 7.2b), assisted by microwave irradiation. The image surface area is $1 \mu \mathrm{m} \times 1 \mu \mathrm{m}(\mathrm{a})$ and $1 \mu \mathrm{m} \times 1.3 \mu \mathrm{m}$ (b). The layered structure of the cationic corn and potato starch granules in paste and the surface revealed by AFM offers the advantage of highly localized $(\sim \mathrm{nm})$ topographic imaging, into granular structure. Fig. 7.2a and Fig. 7.2b show the 3D topographical view of corn and potato starch in paste state. The raw starch exhibits a smooth topography, it clearly shows that the surface of the starch is composed of larger blocklets of size ranging from 100 to $200 \mathrm{~nm}$ separated by gaps. Each blocklet is further composed of smaller blocklets $20-30 \mathrm{~nm}$ in size separated by much shallower depressions and a potato modified rough surface starch due to the presence of modified components present in the polymer.

\section{Conclusions}

The results unequivocally confirmed the highly positive effect of ultrasound and microwave irradiation-assisted reactions of starch cationization with CHPTAC, as comparable percentage conversions, were achieved within five to ten minutes under related reaction conditions, for incorporating a cationic moiety onto the backbone of polysaccharide. For corn and potato starches in a paste state, by microwave and ultrasound irradiation, might produce cationized derivatives with higher levels of substitution. In the solution for corn derivatives, modification occurs during very short reaction times, and DSC offers evidence for better transformations in cationic cornstarch in solution and paste. TGA results show that cationic starches lose thermal stability with regard to raw material. These results also confirm the presence of the modified material distinct from the native one due to the occurrence of the double peaks in the cake state process for both corn and potato derivatives. SEM and AFM observations confirm findings for the surface structure. Pronounced modification of granular potato starch morphology was obtained after the cationization process. 


\section{Acknowledgements}

The authors are grateful to the laboratories at the Universidad Nacional Autónoma de México (UNAM) and the Universidad Pedagógica y Tecnológica de Colombia (UPTC) for their support.

Correspondence and requests for materials should be addressed to: Efrén Muñoz Prieto, School of Chemical Sciences, Universidad Pedagógica y Tecnológica de Colombia, Tunja, Colombia, efren17@ gmail.com Tel : +5787422174/76, Cel.: +57313 3667195 .

\section{References}

[1] A. Čížová, I. Sroková, V. Sasinková, A. Malovíková \& A. Ebringerová, "Carboxymethyl Starch Octenylsuccinate: Microwave- and Ultrasoundassisted Synthesis and Properties", Starch-Stärke, vol. 60, pp. 389-397, 2008.

[2] G. X. Xing, S. F. Zhang, B. Z. Ju \& J. Z. Yang, "Microwave-assisted Synthesis of Starch Maleate by Dry Method", Starch-Stärke, vol. 58, pp. 464-467, 2006.

[3] A. N. Jyothi, S. N. Moorthy, J. N. Sreekumar \& K. N. Rajasekharan, "Studies on the properties of citrate derivatives of cassava (Manihot esculenta Crantz) starch synthesized by microwave technique", Journal of the Science of Food and Agriculture, vol. 87, pp. 871-879, 2007.

[4] A. N. Jyothi, K. N. Rajasekharan, S. N. Moorthy \& J. Sreekumar, "Microwave-Assisted Synthesis and Characterization of Succinate Derivatives of Cassava (Manihot esculenta Crantz) Starch", StarchStärke, vol. 57, pp. 556-563, 2005.

[5] A. C. Kumoro, D. S. Retnowati \& C. S. Budiyati, "Microwave assisted synthesis and characterization of acetate derivative cassava starch", American Journal of Food Technology, vol. 5, pp. 100-110, 2010.

[6] H. Staroszczyk \& P. Janas, "Microwave-assisted synthesis of zinc derivatives of potato starch", Carbohydrate Polymers, vol. 80, pp. 962969, 2010.

[7] Y. Wei, F. Cheng \& H. Zheng, "Synthesis and flocculating properties of cationic starch derivatives", Carbohydrate Polymers, vol. 74, pp. 673679, 2008.

[8] N. Kardos \& J.L. Luche, "Sonochemistry of carbohydrate compounds", Carbohydrate Research, vol. 332, pp. 115-131, 2001.

[9] L. Contat-Rodrigo, N. Haider, A. Ribes-Greus \& S. Karlsson, "Ultrasonication and microwave assisted extraction of degradation products from degradable polyolefin blends aged in soil", Journal of Applied Polymer Science, vol. 79, pp. 1101-1112, 2001.

[10] Y. C. Fu, L. Dai \& B. B. Yang, "Microwave finish drying of (tapioca) starch 
pearls", International Journal of Food Science \& Technology, vol. 40, pp. 119-132, 2005.

[11] Q. Huang, L. Li \& X. Fu, "Ultrasound Effects on the Structure and Chemical Reactivity of Cornstarch Granules", Starch-Stärke, vol. 59, pp. 371-378, 2007.

[12] S. T. Chen, P. H. Tseng, H. M. Yu, C. Y. Wu, K. F. Hsiao, S. H. Wu \& K. T. Wang, "The Studies of Microwave Effects on the Chemical Reactions", Journal of the Chinese Chemical Society, vol. 44, pp. 169-182, 1997.

[13] C. I. K. Diop, H. L. Li, B. J. Xie \& J. Shi, "Combinatorial effects of mechanical activation and chemical stimulation on the microwave assisted acetylation of corn (Zea mays) starch", Starch-Stärke, vol. 63, pp. 96-105, 2011.

[14] Y. Wu, X. Du, H. Ge \& Z. Lv, "Preparation of microporous starch by glucoamylase and ultrasound", Starch-Stärke, vol. 63, pp. 217-225, 2011.

[15] Z. Zhang, Y. Niu, S. R. Eckhoff \& H. Feng, "Sonication Enhanced Cornstarch Separation”, Starch-Stärke, vol. 57, pp. 240-245, 2005.

[16] S. Pal, D. Mal \& R. P. Singh, "Characterization of cationic starch: An efficient flocculating agent", Journal of Applied Polymer Science, vol. 108, pp. 2674-2681, 2008.

[17] A. Larsson \& S. Wall, "Flocculation of cationic amylopectin starch and colloidal silicic acid. The effect of various kinds of salt", Colloids and Surfaces A: Physicochemical and Engineering Aspects, vol. 139, pp. 259-270, 1998.

[18] P. Cintas and J. L. Luche, "Green chemistry. The sonochemical approach", Green Chemistry, vol. 1, pp. 115-125, 1999.

[19] A. C. M. Metaxas, R. J., Industrial Microwave Heating: The Institution of Engineering and Technology, 1988.

[20] B. Kaur, F. Ariffin, R. Bhat \& A. A. Karim, "Progress in starch modification in the last decade", Food Hydrocolloids, vol. In Press, Corrected Proof.

[21] A. Loupy, "Solvent-free microwave organic synthesis as an efficient procedure for green chemistry", Comptes Rendus Chimie, vol. 7, pp. 103-112, 2004.

[22] J. P. Rao \& K. E. Geckeler, "Polymer nanoparticles: Preparation techniques and size-control parameters", Progress in Polymer Science, vol. 36, pp. 887-913, 2011.

[23] S. Pal, D. Mal \& R. P. Singh, "Cationic starch: an effective flocculating agent”, Carbohydrate Polymers, vol. 59, pp. 417-423, 3/15/ 2005.

[24] P. Aggarwal \& D. Dollimore, "The effect of chemical modification on starch studied using thermal analysis", Thermochimica Acta, vol. 324, pp. 1-8, 1998.

[25] Y. Wang \& W. Xie, "Synthesis of cationic starch with a high degree of substitution in an ionic liquid", Carbohydrate Polymers, vol. 80, pp. 11721177, 2010.

[26] J. Ahmed, H. S. Ramaswamy, A. Ayad \& I. Alli, "Thermal and dynamic rheology of insoluble starch from basmati rice", Food Hydrocolloids, vol. 22, pp. 278-287, 2008. 
[27] V. Balsamo, F. López-Carrasquero, E. Laredo, K. Conto, J. Contreras \& J. L. Feijoo, "Preparation and thermal stability of carboxymethyl starch/ quaternary ammonium salts complexes", Carbohydrate Polymers, vol. 83, pp. 1680-1689, 2011.

[28] Y. Huang, J. Lu \& C. Xiao, "Thermal and mechanical properties of cationic guar gum/poly(acrylic acid) hydrogel membranes", Polymer Degradation and Stability, vol. 92, pp. 1072-1081, 2007.

[29] H. Liu, F. Xie, L. Yu, L. Chen \& L. Li, "Thermal processing of starchbased polymers", Progress in Polymer Science, vol. 34, pp. 1348-1368, 2009.

[30] J. L. Ren, R. C. Sun, C. F. Liu, L. Lin \& B. H. He, "Synthesis and characterization of novel cationic SCB hemicelluloses with a low degree of substitution", Carbohydrate Polymers, vol. 67, pp. 347-357, 2007.

[31] L. Yu \& G. Christie, "Measurement of starch thermal transitions using differential scanning calorimetry", Carbohydrate Polymers, vol. 46, pp. 179-184, 2001.

[32] F. Xie, W. C. Liu, P. Liu, J. Wang, P. J. Halley \& L. Yu, "Starch thermal transitions comparatively studied by DSC and MTDSC", Starch-Stärke, vol. 62, pp. 350-357, 2010.

[33] A. Ayoub, F. Berzin, L. Tighzert \& C. Bliard, "Study of the Thermoplastic Wheat Starch Cationisation Reaction under Molten Condition", S[34] S. A. da Silva, M. M. da Conceição, A. G. de Souza \& R. O. Macêdo, "Calorimetric and kinetic parameters of manioc derivatives", Thermochimica Acta, vol. 328, pp. 177-181, 1999.

[35] W. Y. Kuo \& H.-M. Lai, "Changes of property and morphology of cationic corn starches", Carbohydrate Polymers, vol. 69, pp. 544-553, 2007.

[36] H. Liu, L. Ramsden \& H. Corke, "Physical properties and enzymatic digestibility of hydroxypropylated ae, wx, and normal maize starch", Carbohydrate Polymers, vol. 40, pp. 175-182, 1999.

[37] L. Peng, L. Zhongdong \& J. F. Kennedy, "The study of starch nano-unit chains in the gelatinization process", Carbohydrate Polymers, vol. 68, pp. 360-366, 2007. 


\title{
MATHEMATHICAL MODEL FOR ESTIMATING THE RADIATION FIELD IN PHOTOCATALYTIC REACTORS
}

\section{MODELO MATEMÁTICO PARA LA ESTIMACIÓN DEL CAMPO RADIANTE EN REACTORES FOTOCATÁLICOS}

\author{
Miguel Ángel Mueses* \\ Fiderman Machuca-Martínez*
}

Recepción 05/08/2011

Evaluación 12/09/2011

Aprobado 12/10/2011

\section{Abstract}

This paper proposes a new approach for estimating the radiant field in photocatalytic heterogeneous reactors. The effective radiation field model was developed from the constitutive equations for emission and absorption of energy. The new model considers five components for the radiation energy balance: i)The net energy flux in the volume $u$, through a surface in the system. ii) The total energy is absorbed by catalyst particles. iii) The loss of energy is by scattering. iv) The gain in energy is by scattering (a phase function of the scattered energy is required) and the net energy flux in the volume is through the reactor surface. The model is an integro-differential unidimensional function in terms of an arbitrary nondimensional variable $X$, where $\alpha(X)$ is the surface area of the reactor, $\kappa_{u}, \sigma_{u}$ are the average coefficients of volumetric absorption and scattering, respectively. The model was used for the radiation field simulation with Six Flux Model (for CPC reactor and $\left.\mathrm{TiO}_{2}-\mathrm{P} 25\right)$. The model allows obtaining good results and is faster than the rigorous solution of radiation field.

Keywords: Absorption model, emission model, modeling, photocatalysis, volumetric rate of absorption of energy. 


\section{Resumen}

En este trabajo se propone un nuevo enfoque para la estimación del campo radiante en reactores fotocatalíticos heterogéneos. El modelo de campo de radiación efectiva se desarrolló a partir de las ecuaciones constitutivas para la emisión y absorción de energía. El nuevo modelo contempla cinco componentes para el balance de energía de radiación: i) El flujo neto de energía en el volumen $u$ a través de la superficie $\alpha$ en el sistema. ii) La energía total es absorbida por las partículas del catalizador. iii) La pérdida de energía es por dispersión. iv) La ganancia de energía es por dispersión (se necesita una función de fase de la energía dispersada) y el flujo neto de energía en el volumen se da a través de la superficie del reactor. El modelo es una función unidimensional integro-diferencial en términos de una variable arbitraria $X$ adimensional, donde $\alpha(X)$ es el área de superficie del reactor, $k_{u}, \sigma_{u}$ son los coeficientes medios de absorción volumétrica y la dispersión, respectivamente. El modelo fue utilizado para la simulación del campo de radiación, con el modelo Six Flux (para un reactor $\mathrm{CPC}$ y $\mathrm{TiO}_{2}-\mathrm{P} 25$ ). Permite obtener buenos resultados y es más rápido que la solución rigurosa de la ecuación de campo radiante.

Palabras clave: Fotocatálisis, modelamiento, modelo de absorción, modelo de emisión, velocidad volumétrica de absorción de energía.

\section{Introduction}

The design of solar photocatalytic reactors for water detoxification requires a proper understanding of the dynamics of molecular processes at the semiconductor/solution interface. The main limitation is the formulation of the detailed mechanisms of the photocatalytic processes involving complex substances or mixtures [1, 2].

The heterogeneous photocatalytic processes are strongly influenced by four key components: system reactive (substrate), catalyst (semiconductor), geometry reactor (reactor type) and radiation field (luminous flux) [3 - 5]. The geometry and radiation field introduce 
a non-intrinsic nature to this type of process (reflected in kinetic of reaction rate). These characteristics are the major differences with the conventional chemical processes.

The performance on photocatalysis depends critically on the amount of incident radiation that can be used to activate the catalyst particles and therefore it requires a correct quantification of volumetric rate of energy absorption (VREA). This, in turn, will allow an adequate description of the kinetic parameters such as quantum yields $[6,7]$.

Generally, the most appropriate models for the description of radiation fields are based on analysis of fundamental principles of radiant energy balances and transport theory of photons, which give rise to an equation called generalized radiative transfer equation, RTE $[3,4,8]$. Currently, the most researched mathematical approaches focus on the solution of RTE.

Cassano et al. [3, 4] have made great efforts for a proper description of VREA through rigorous solution of the RTE using a complex method known as discrete ordinate (DOM), proposed in 1979 by Duderstadt and Martin [6]. This method allows describing the volumetric rates of photon absorption with minimal discrepancies, however, it requires high computational time and complex numerical methods for their solution.

Li Puma et al. [9-10] have implemented a model called "multiflux" which has two approaches: the two flux model (TFM) that allows introducing the scattering of energy in two directions (Cartesian coordinates) and the six flux model (SFM) which associate the photons transport paths in six directions in Cartesian coordinates. This model is semi-empirical because it uses experimental solar radiation data and parameter adjustment for stochastic methods.

The standard definition of quantum yield for heterogeneous systems is given as the quotient of the reaction rate at a particular location in the reactor and the local volumetric rate of photon absorption (LVRPA) [11, 12]. In the models that explicitly take 
quantum yields into account, the quantum yields are calculated by adjusting parameters of the overall reaction rate that are assumed constants in the specific system, independent of operating conditions (except the luminous flux). However, recent research has shown that the process conditions (initial concentration of catalyst and reacting species, $\mathrm{pH}$, wavelength, photon flux), the type of reactor and its geometry, the scale of operation and the type of catalyst affect the overall performance of the process [13].

This paper proposes a new approach to the description of radiation fields, based on a modification of the radioactive transfer equation assuming isotropy field.

\section{Development of mathematical model}

For the formulation of model, we use the next definition or postulate [6]:

Definition 1: the energy radiation field can be calculated by applying the following: "it is possible to redistribute the total energy $\zeta(\underline{x}, \lambda)$ of an incident photon flux on an energy absorber surface, in a constant energy field $\left\langle\xi_{N}^{*}\right\rangle$ which surrounds isotropicly the element of absorption, regardless of the direction and spreading frequency".

Definition 2: the radiant field inside the reactor remains isotropic nature and is spread evenly throughout the system volume.

So, the Eq (1) is obtained on the definition of radiation specific intensity $I_{\lambda}(\underline{x}, \underline{\Omega}, t)[3,4]$, this concept is associated with the energy of beam of radiation per unit time $(t)$, per unit solid angle $(\Omega)$ from the direction of propagation, per unit surface area $(A)$ as the projected direction $\theta$ and per unit wavelength interval $(d \lambda)$ (see Figure 1a). 


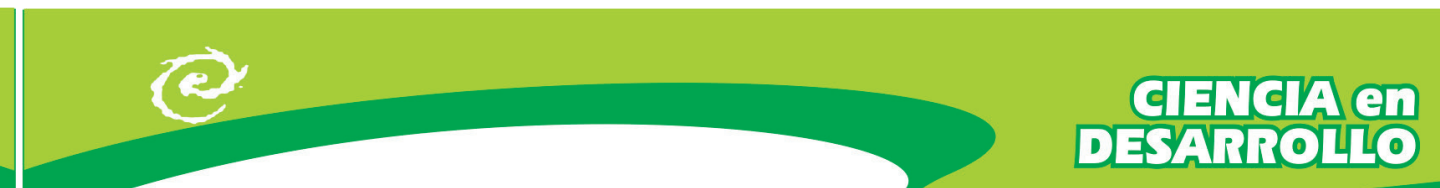

$$
I_{\lambda}(\vec{x}, \vec{\Omega}, t)=\lim _{d A, d \Omega, d \lambda \rightarrow 0}\left\{\frac{d E^{*}}{d A \cos (\theta) d \Omega d \lambda}\right\}
$$

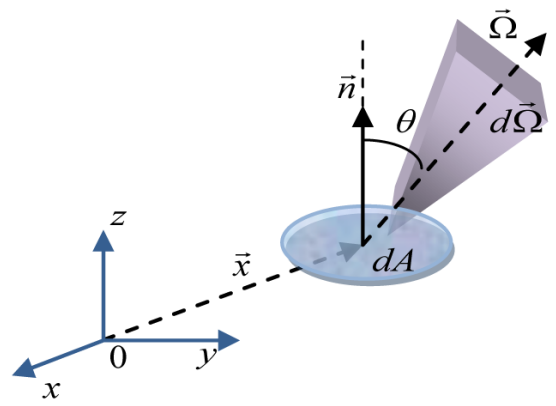

a)

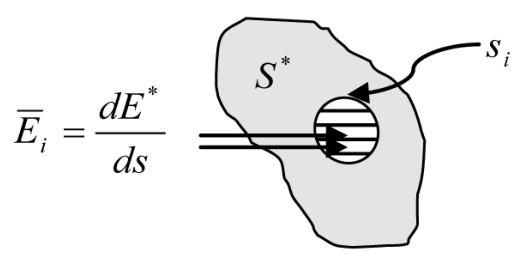

b)

Figure 1. (a) Definition of radiation specific intensity, b) incident specific energy

If $d E^{*}$ is the photon flux incident, and maintaining the condition of limit to zero, so:

$$
d E^{*}=I_{\lambda}(\vec{x}, \vec{\Omega}, t) d A \cos (\theta) d \Omega d \lambda
$$

Now, $d s$ is a differential surface with limit to zero:

$$
d s=d A \cos (\theta)
$$

If the $\bar{E}_{i}$ is defined as the specific energy per unit differential surface:

$$
\bar{E}_{i}=\frac{d E^{*}}{d s}=I_{\lambda}(\vec{x}, \vec{\Omega}, t) d \Omega d \lambda
$$


From Figure 1.b, $\varphi_{s, i}^{*}$ is the fraction of surface area as the relationship differential surface area $s_{i}$ and total surface area $S[4]^{*}$ :

$$
\varphi_{s, i}^{*} \equiv \frac{S_{i}}{S^{*}}
$$

The global net energy $\left\langle E_{N}^{*}>\right.$ of the surface $S^{*}$ is defined as the contribution of all energy, $\bar{E}_{i}$ of Ns elements [8]:

$$
\left\langle E_{N}^{*}\right\rangle=\lim _{N s \rightarrow \infty} \sum_{i=1}^{N s} \varphi_{s, i}^{*} \bar{E}_{i}=\lim _{N s \rightarrow \infty} \sum_{i=1}^{N s} \varphi_{s, i}^{*} I_{\lambda}(\vec{x}, \vec{\Omega}, t) d \Omega d \lambda
$$

Now, using the conventional definition of spectral incident radiation $G_{\lambda}(\underline{x}, t)(E q .7)[2,3]$, and the fundamental theorem of calculus, we can show that:

$$
\begin{gathered}
G_{\lambda}(\vec{x}, t)=\int_{\Omega} I_{\lambda}(\vec{x}, \vec{\Omega}, t) d \Omega \\
\frac{d G_{\lambda}(\vec{x}, t)}{d \Omega}=\frac{1}{d \Omega} \int_{\Omega} I_{\lambda}(\vec{x}, \vec{\Omega}, t) d \Omega=I_{\lambda}(\vec{x}, \vec{\Omega}, t)
\end{gathered}
$$

Reorganizing the $\mathrm{Eq}(8)$, with the $\mathrm{Eq}(6)$ and using the definition to $\zeta_{i}(\underline{x}, \lambda) \equiv d G_{\lambda}(\underline{x}, t) d \lambda$ and the transformation: $\lim _{\rightarrow \infty}(\Sigma)=\int$, so:

$$
\left\langle E_{N}^{*}\right\rangle=S^{*}\left\langle\bar{E}_{N}^{*}\right\rangle=\lim _{N s \rightarrow \infty} \sum_{i=1}^{N s} \varphi_{s, i}^{*} \zeta_{i}(\vec{x}, \lambda)=\int_{S} \zeta(\vec{x}, \lambda) d S
$$

Where $\left\langle\bar{E}^{*}\right\rangle$ is the effective net global energy. This model describes an isotropic radiation field.

\section{Emission model}

Using the previous conditions, $\zeta$ is only a function of wavelength, therefore:

$$
\left\langle\bar{E}_{N}^{*}\right\rangle=\frac{1}{S^{*}} \int_{S} \zeta(\lambda) d S
$$

The function $\zeta(\lambda)$ is calculated from the photochemical power source $\Gamma^{*}(\lambda)$ over reactor area $S$ : 


$$
\zeta(\lambda)=\frac{\int_{\lambda} \overline{\mathrm{Y}}_{T R} \Gamma^{*}(\lambda) d \lambda}{\int_{\lambda} d \lambda}=\frac{\overline{\mathrm{Y}}_{T R}}{\left(\lambda^{2}-\lambda\right)} \int_{\lambda} \Gamma^{*}(\lambda) d \lambda
$$

The parameter $\tilde{Y}_{T R}$ is the reactor wall average transmittance coefficient:

$$
\overline{\mathrm{Y}}_{T R}=\frac{1}{4 \pi} \int_{\Omega} \mathrm{Y}_{T R}(\Omega) d \Omega
$$

Finally, the mathematical expression to estimate the energy of isotropic radiation field $\left(\left\langle E_{N}^{*}\right\rangle\right)$ incident on the surface area $\left(S^{*}\right)$ for photocatalytic heterogeneous reactors is:

$$
\left\langle\bar{E}_{N}^{*}\right\rangle=\left(\frac{1}{S^{*}}\right) \frac{\bar{Y}_{T R}}{(\lambda-\lambda)} \int_{S} \int_{\lambda} \Gamma^{*}(\lambda) d \lambda d S
$$

Where $\tilde{Y}_{T R}$ is average transmittance coefficient (dimensionless), $\Gamma^{*}(\lambda)$ is a power function from radiation source $\left(W / m^{2}\right), S^{*}$ is total area of wall reactor absorption $\left(\mathrm{m}^{2}\right),\left(\lambda^{\prime}-\lambda\right)$ is wavelength interval $(\mathrm{nm})$ and $d S, d \lambda$ are integration functions.

\section{Absorption model}

The Eq. (9) is a function of the absorption total surface. Now considering the relationship of total particles surface $\left(S^{*}\right)$ and volume reactor $\left(v_{\mathrm{R}}\right)$ :

$$
\frac{S^{*}}{v_{R}}=C_{C a t} S_{g}
$$

where $C_{\text {Cat }}$ is to catalyst concentration $(g / L)$ and $S_{g}$ is the specific surface area of the catalyst $\left(\mathrm{m}^{2} / \mathrm{g}\right)$. If now we use the elementary theorem calculus and Eq. (14), this equation can be transformed to volume function:

$$
\left\langle\hat{E}_{N}^{v}\right\rangle=\frac{1}{v_{R}^{*}} \int_{v_{R}} \varsigma^{*}(v) d v
$$

(10)

$\left\langle\hat{E}_{N}^{v}>\right.$ is the overall volumetric rate of energy absorption (OVREA), $S^{*}(v)$ is the local volumetric rate of energy absorption (LVREA) [6], $V^{*}{ }{ }^{\prime}$ $v_{R}$ and $v$ are total reactor volume, integration volume and integration function of the volume, respectively. This parameter depends on the 
reactor volume, besides it is an isotropic function independent of wavelength $(\lambda)$ and propagation angle $(\Omega)$.

The LVREA can be calculated using the next expression in terms of reactor volume:

$$
\varsigma^{*}(v)=\kappa_{v} \varsigma(v)
$$

Where $s(v)$ is net effective energy per catalyst surface area unit $\left(E / m^{2}\right)$ and $k_{v}$ is a volumetric absorption coefficient $\left(\mathrm{m}^{-1}\right)$.

According to the consideration of postulate 1 , the net effective energy in each point of the reactor is estimated through the solution of the radiative transfer equation modified (RTEM). This equation arises from a balance of overall net radiant energy in a volume of differential control (see Figure 2-a).

a)

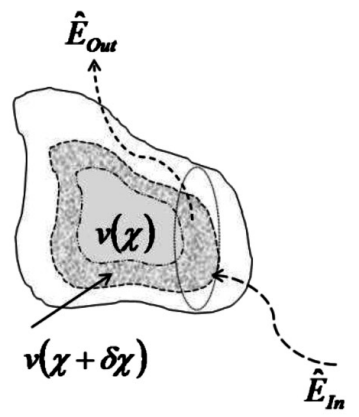

Figure 2. a) Volume of differential control, b) Differential balance element

The Figure 2-b shows the five components for the radiation energy balance: i) $E_{\text {in }}$ is net energy flux entering the volume $u$ across the surface $\alpha$ ii) $E_{a b s}$ is total energy absorbed to catalyst particles iii) $E_{\text {out,scatt }}$ is lost energy by scattering iv) $E_{i n, \text { scatt }}$ is the gained energy by scattering (it needs a phase function from to energy dispersed) $v$ ) $E_{\text {out }}$ is net energy flux leaving the volume $v$ across the surface $\alpha$.

In mathematical terms for a reactor volume $\mathrm{v}(\mathrm{X})$, the net effective energy balance is given by the expression: 


$$
\begin{aligned}
& -\frac{1}{\alpha(\chi)} \frac{d}{d \chi}[\alpha(\chi) \cdot \varsigma(\chi)]+ \\
& \left(\bar{\kappa}_{v}+\bar{\sigma}_{v}\right) \varsigma(\chi)=\bar{\sigma}_{v} \xi_{N}^{*}(\varsigma)
\end{aligned}
$$

This expression is an integro-differential unidimensional function in terms of an arbitrary dimensionless variable $X$, where $\alpha(X)$ is surface area of the reactor, $\kappa_{u}, \sigma_{u}$ are the average coefficients of volumetric absorption and scattering, respectively, $\xi_{N}^{*}(\varsigma)$ is a scattering function.

So, the Eq. (9), Eq. (13) and Eq. (17) show the new concept proposed for estimating the radiation fields in heterogeneous photocatalytic reactors.

\section{Model validation for solar radiation on CPC reactor}

The emission model (Eq. 13) was applied using a similar method reported in [9] for total solar radiation at Cali, Colombia $\left(3^{\circ}\right.$ 30 ' North Latitude) for determination of $\left(\left\langle E^{*}{ }_{N}\right\rangle\right)$ incident on the wall photocatalytic heterogeneous solar reactor.

The absorption model, Eq. (17), was applied at CPC solarscale reactor. This was solved using a numerical coupled for Ray Tracing Technique [9, 10], conventional Runge-Kutta and modified Netwon-Raphson Method [14, 15]. The CPC was simulated with similar operating condition used for Colina-Márquez et al., [9, 10]. We consider $30 \mathrm{~W} / \mathrm{m}^{2}$ for total incident radiation on the solar reactor on clear sunny day. The Figure 3 shows the results for the simulation of radiation field.

These values and performance are similar to values reported previously $[9,10]$, which were evaluated at different catalyst concentration. For this simulation we used $0.35 \mathrm{~g} / \mathrm{L}$ of catalyst. However, the description of the radiation field is very satisfactory and is in accordance to the typical distribution light inside of heterogeneous photocatalytic solar reactors. For the solar radiation conditions, on a clear and sunny day with $10=30 \mathrm{~W} \cdot \mathrm{h} / \mathrm{m}^{2}$ as the standard solar irradiance, the performances of the VREA profiles in the CPC reactor 
is shown in Figure 3. The new model is faster in the time computing and only two the parameters.

The performance of the VREA shows that there is high photon absorption at the reactor boundary layer near the wall or interphase. For the CPC, values of the optical thickness $\delta$ close to zero show a profile of high energy. However, for high values of $\delta$, the energy available for activation is negligible.

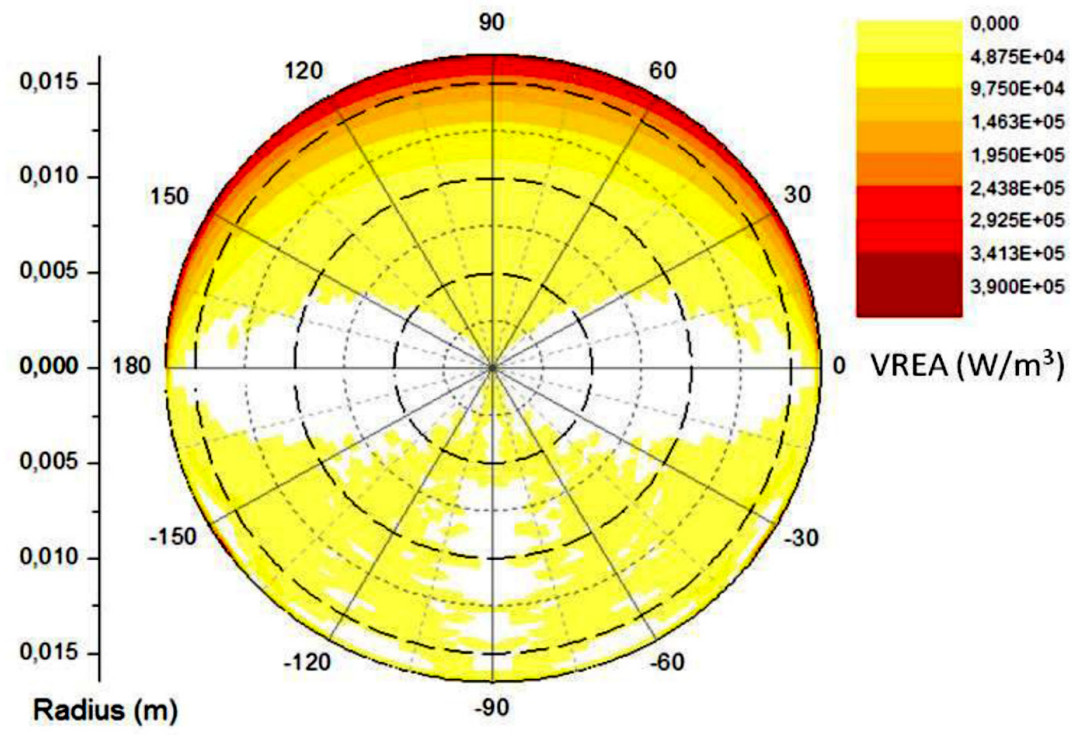

Figure 3. Radiation field simulation with proposed model for CPC reactor on sunny day at $C_{C a t}=0.3 \mathrm{~g} / \mathrm{L}$

\section{Conclusions}

A new mathematical approach was proposed for description of radiation fields in heterogeneous photocatalytic reactors, based on isotropic radiation flux.

The model for the estimating radiation in photoreactors was developed for TiO2-P25 and solar irradiation is applicable to any other photocatalytic conditions and it is independent of the operating conditions, the geometry and the scale of the reactor. 
The advantage of the new model is that it is easy to apply. The number of setting variables is less than rigorous models and these correspond to the system (reactor and catalyst).

According to the consideration of postulate 1 , the net effective energy in each point of the reactor is estimated through the solution of the radiative transfer equation modified (RTEM).

The new model is an integro-differential unidimensional function in terms of an arbitrary dimensionless variable $X$, where $\alpha(X)$ is surface area of the reactor, $k_{u}, \sigma_{u}$ are the average coefficients of volumetric absorption and scattering, respectively, $\xi_{N}^{*}(\varsigma)$ is a scattering function.

\section{Acknowledgements}

The authors thank to the Vice-Head of the Research Office of Universidad del Valle for supporting this study (Grant 2520). M. A. Mueses thanks to Universidad de Cartagena for financial support during doctoral internship. The authors thank also to COLCIENCIAS for the financial support during their Ph.D. studies.

\section{References}

[1] N. Serpone \& A. Emeline, Semiconductor Photocatalysis: past, present and future outlook, J. Phys. Chem. Lett. vol. 3, pp. 673-677, 2012.

[2] D. Friedmann, C. Mendive \& D. Bahnemann, $\mathrm{TiO}_{2}$ for water treatment: parameters affecting the kinetics and mechanism of photocatalysis , Appl. Catal., vol. 99, pp. 398-406, 2010.

[3] A. Cassano, C. Martin, R. Brandi \& O. Alfano, "Photoreactor Analysis and Design: Fundamentals and Applications", Ind. Eng. Chem. Res., vol. 34, pp. 2155 - 2201, 1995.

[4] A. Cassano \& O. Alfano, "Reaction Engineering of Suspended Solid Heterogeneous Photocatalytic Reactors", Catal. Today, vol. 58, $n^{\circ}$ 2-3, pp. 167-197, 2000.

[5] T. Van Gerven, G. Mul, J. Moulijn \& A. Stankiewicz, A review of intensification of photocatalytic processes, Chem. Eng. Proc., vol. 46, $n^{\circ}$ 9, pp. 781-789, 2007.

[4] F. Machuca, J. Colina-Márquez \& M. Mueses, "Determination of Quantum Yield in a Heterogeneous Photocatalytic System Using a FittingParameters Model", J. Adv. Oxid. Technol., vol. 11, n 1, pp. 42-48, 2008. 
[5] M. Mueses, J. Colina \& F. Machuca, Degradación fotocatalítica de ácido dicloroacético al aplicar un campo de radiación de baja energía, Ingeniería y Desarrollo, vol. 24, pp. 33-47, 2008.

[6] J. Duderstadt \& R. Martin, Transport Theory, New York : Wiley, pp. 21-422, 1979.

[7] G. L. Puma, Dimensionless analysis of photocatalytic reactors using suspended solid photocatalysts, Chem. Eng. Res. Desing, vol. 83 A7, pp. 820-826, 2005.

[8] G. L. Puma \& A. Brucato, Dimensionless analysis of slurry photocatalytic reactors using a two-flux and six-flux radiation absorption-scattering models , Catal. Today, vol. 122, pp. 78-90, 2007.

[9] J. Colina-Márquez, F. Machuca-Martínez \& G. L. Puma, Photocatalytic mineralization of commercial herbicides in a pilot-scale solar CPC reactor: Photoreactor modeling and reaction kinetics constants independent of radiation field, Env. Sci. Technol., vol. 43, n 23, pp. 8953-8960, 2009.

[10] J. Colina-Márquez, F. Machuca-Martínez \& G. L. Puma, Radiation absorption and optimization of solar photocatalytic reactors for environmental applications , Env. Sci. Technol., vol. 44, no 13 , pp. 51125120, 2010.

[11] J. Marugan, R. van Grieken, A. Cassano \& O. Alfano, Quantum efficiency of cyanide photooxidation with $\mathrm{TiO} 2 / \mathrm{SiO} 2$ catalysts: Multivariate analysis by experimental design, Catal. Today, vol. 129, pp. 143-151, 2007.

[12] N. Serpone, Relative photonic efficiencies and quantum yields in heterogeneous photocatalysis , J. Photochem. Photobiol., A, vol. 104, pp. 1-12, 1997.

[13] S. Ahmed, M. Rasul, R. Brown \& M. Hashib, Influence of parameters of the heterogeneous photocatalytic degradation of pesticides and phenolic contaminants in wastewater: a short review , J. Environ. Manage., vol. 92, pp. 311-330, 2011.

[14] M. A. Mueses, F. MAchuca-Martínez, Modelo matemático para estimación de eficiencias fotónicas no-intrínsecas en reacciones fotocatalíticas heterogéneas , Información Tecnológica, vol. 23, n 3 , pp. 43-50, 2012.

[15] M.A. Mueses, Modelo de rendimiento cuántico para sistemas simples y mezclas multicomponentes aplicado en escalamiento y simulación de reactores fotocatalíticos heterogéneos, tesis doctoral, Escuela de Ingeniería Química, Universidad del Valle, Cali, Colombia, 2012. 


\title{
SÍNTESIS SOL-GEL DE DIÓXIDO DE TITANIO PARA EL PROCESO DE FOTODEGRADACIÓN
}

\section{SOL-GEL SYNTHESIS OF TITANIUM DIOXIDE FOR THE PHOTODEGRADATION PROCESS}

\author{
Sandra Cipagauta Díaz ${ }^{1 \bullet}$ \\ José Ricardo Gómez Romero ${ }^{2 *}$ \\ Francisco Javier Tzompantzi Morales ${ }^{30 .}$ \\ Agileo Hernández Gordillo4.... \\ Hugo Alfonso Rojas Sarmiento ${ }^{50 . . .}$
}

Recepción 05/08/2011 Evaluación 12/09/2011 Aprobado $12 / 10 / 2011$

\section{Resumen}

Para este trabajo se sintetizaron materiales nanoestructurados de dióxido de titanio por el método Sol-Gel, a baja temperatura. El pH de gelación se fijó en $3\left(\mathrm{TiO}_{2}-\mathrm{a}\right)$ y $9\left(\mathrm{TiO}_{2}-b\right)$, se calcinaron a $500^{\circ} \mathrm{C}$, con el fin de estudiar la influencia del $\mathrm{pH}$ en las propiedades electrónicas, ópticas y estructurales en el proceso de fotodegradación.

1 - Magíster en Ingeniería Ambiental, estudiante Doctorado en Ciencias Químicas, Universidad Autónoma Metropolitana-Iztapalapa, Departamento de Química, Área de Catálisis, Grupo Ecocatal, México D.F. Correo electrónico: angala9804@hotmail.com

2 - Doctor. de Specialité Cinetique Chimie, Doctor. Sciences Physiques. Licenciado en Química, docente Universidad Autónoma Metropolitana-Iztapalapa, Departamento de Química, Área de Catálisis, Grupo Ecocatal, México D.F.

3 -.. Doctor en Ciencias, licenciado en Química, docente Universidad Autónoma Metropolitana-Iztapalapa, Departamento de Química, Área de Catálisis, Grupo Ecocatal, México D.F. Correo electrónico: fitz@xanum.uam.mx

4 … Doctor en Ciencias, licenciado en Química, maestro en Ciencias e Ingeniería de Materiales, Universidad Autónoma Metropolitana-Iztapalapa, Departamento de Química, Área de Catálisis, Grupo Ecocata, México D.F. Correo electrónico: agileo12@hotmail.com

5 …. Doctor en Ciencias Químicas, magíster en Química, licenciado en Química y Biología, docente Escuela de Ciencias Químicas, Facultad de Ciencias, Universidad Pedagógica y Tecnológica de Colombia. Grupo de Catálisis (GC-UPTC). Correo electronic: hugo.rojas@uptc.edu.co 
Los resultados indican que los semiconductores poseen tamaños de partículas entre 7 y $10 \mathrm{~nm}$. Las áreas superficiales específicas de los materiales, determinadas por el método BET, son: $80 \mathrm{~m}^{2} / \mathrm{g}$ $\mathrm{TiO}_{2}$-a y $61 \mathrm{~m}^{2} / \mathrm{g} \mathrm{TiO}{ }_{2}-b$, muy superiores a la obtenida con la titania Degussa P25 (50 $\left.\mathrm{m}^{2} / \mathrm{g}\right)$. La espectroscopia UV-vis de reflectancia difusa se utilizó para determinar la distancia energética entre bandas $\left(E_{g p}\right)$ de los materiales, teniendo el siguiente orden: $E_{g p}\left(\mathrm{TiO}_{2}-\mathrm{a}\right)<E_{g p}$ $\left(\mathrm{TiO}_{2}-b\right)<E_{g p}$ (Degusa P25). Los DRX sugieren que los materiales son principalmente fase anatasa. La imagen de TEM muestra que el $\mathrm{TiO}_{2}$-a presenta un menor tamaño de partículas $(5 \mathrm{~nm})$ en comparación con el otro semiconductor.

La actividad fotocatalítica se probó en la degradación de 4-nitrofenol (4-NP). La mineralización del contaminante hasta el 98 $\%$ (TOC), se obtuvo con la muestra de $\mathrm{TiO}_{2}-a$, exhibiendo la más alta fotoactividad.

Palabras clave: Dióxido de titanio, fotocatálisis, 4-nitrofenol, mineralización, síntesis Sol-Gel.

\section{Abstract}

For this study were synthesized nanostructured materials of titanium dioxide by sol-gel method, at low temperature. The $\mathrm{pH}$ of gelation was set at 3 (TiO2-a), and 9 (TiO2-b), calcined at $500^{\circ} \mathrm{C}$ , to study the influence of $\mathrm{pH}$, in the electronic, optical, structural properties in the process of photodegradation.

The results indicate that the semiconductors have particle sizes between $7 \mathrm{~nm}$ and $10 \mathrm{~nm}$. The BET specific surface areas of the samples are among $\mathrm{TiO}_{2}-b 61 \mathrm{~m}^{2} / \mathrm{g}$ and $\mathrm{TiO}_{2}$-a $83 \mathrm{~m}^{2} / \mathrm{g}$ higher than that of Degussa P25 titania (50 $\mathrm{m}^{2} / \mathrm{g}$ ). The UV-vis spectroscopy of diffuse reflectance was used to determine the $\left(E_{b p}\right)$ band gap energy of the samples, where the values have the following order $E_{b g}\left(\mathrm{TiO}_{2}-\mathrm{a}\right)<$ $E_{b g}\left(\mathrm{TiO}_{2}-b\right)<E_{b g}$ (Degussa P25). The DRX indicate that the materials consist mainly of anatase phase. The TEM image shows that the TiO2-a presents smaller particle sizes $(5 \mathrm{~nm})$ compared to the other semiconductor. 
The photocatalytic activity for the prepared samples was tested in the 4- nitrophenol (4-NP) degradation. The mineralization of the contaminant up to $98 \%$ (TOC) was obtained with TiO2-a sample, exhibiting the highest photoactivity.

Keywords: Titanium dioxide, photocatalysis, mineralization, SolGel synthesis.

\section{Introducción}

El agua es un compuesto esencial para el ser humano. Sin embargo, factores como los procesos industriales, las actividades rurales y urbanas son fuentes continuas de contaminación del recurso hídrico, haciendo que se supere la capacidad de autolimpieza, y, como consecuencia, disminuye su calidad y altera los ecosistemas [1].

En Colombia existe un desarrollo importante en técnicas que permiten el tratamiento de agua residual, capaz de cumplir con la legislación actual sobre calidad del agua, no obstante, las tecnologías convencionales no son capaces de eliminar eficientemente un grupo de contaminantes, denominados contaminantes orgánicos emergentes, que se consideran de importancia por su carácter tóxico, carcinogénico, mutagénico, y su escasa o nula biodegradabilidad [2].

Dentro de las alternativas actualmente exploradas para remediación de aguas contaminadas, se encuentran los Procesos Avanzados de Oxidación (POAs). Los POAs hacen parte de una familia de tecnologías que utilizan la elevada capacidad oxidante del radical hidroxilo $\left({ }^{*} \mathrm{OH}\right)$, para la eliminación de contaminantes. Las más estudiadas utilizan combinaciones de ozono, peróxido de hidrógeno, radiación ultravioleta y fotocatálisis heterogénea [3].

La fotocatálisis heterogénea es una disciplina que ha despertado un creciente interés en los últimos años, ya que su campo de aplicación incluye una extensa variedad de reacciones, entre las 
que se encuentran: oxidaciones suaves o totales, deshidrogenación, transferencia de hidrógeno, intercambio isotópico de oxígeno $\left(\operatorname{con}^{18} \mathrm{O}\right)$ e hidrógeno (con deuterio), depósito de metales, descontaminación de agua, remoción de contaminantes gaseosos, acción bactericida, entre otras. [4]. En la fotocatálisis heterogénea, el fotocatalizador, habitualmente, es un semiconductor de banda ancha, que absorbe energía radiante (visible o UV). El proceso general se ilustra en la Figura 1 [5].

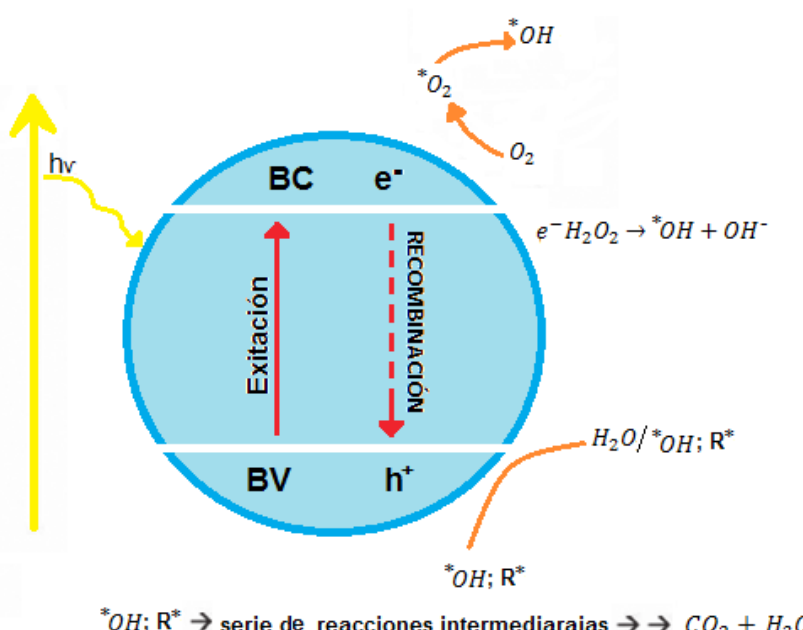

Figura 1. Esquema del proceso de fotocatálisis heterogénea [4].

Uno de los óxidos metálicos semiconductores de banda ancha más investigado, es el $\mathrm{TiO}_{2}$. Según pruebas comparativas efectuadas, se ha demostrado que es el semiconductor más resistente a la corrosión química y a la fotocorrosión. Así mismo es un material económico, muy estable químicamente y trabaja en un rango amplio de $\mathrm{pH}$. Es capaz de producir transiciones electrónicas por absorción de luz en el ultravioleta cercano (UV-A) $(<387 \mathrm{~nm})$ [6-8].

Actualmente, la síntesis vía Sol-Gel del $\mathrm{TiO}_{2}$ ha demostrado ser una herramienta útil, ya que permite que sus propiedades estructurales, texturales, electrónicas y morfológicas puedan ser modificadas durante el paso de "sol" a "gel", y, por tanto, que los 
materiales puedan fotoinducir reacciones moleculares en su superficie [9-11].

El proceso Sol-Gel permite obtener, a bajas temperaturas, materiales con un alto grado de pureza y en los que se puede ejercer un mejor control sobre las propiedades resultantes [12-13].

Aparentemente, la eficiencia de las reacciones fotocatalíticas del $\mathrm{TiO}_{2}$, son inducidas por una deseable área específica, por su fase anatasa estabilizada, por la conveniente transferencia de masa que se da dentro de los mesoporos y por la disminución en la energía entre bandas [14]. Sin embargo, estos materiales son comúnmente preparados mediante el uso de surfactantes tipo plantilla (compuestos orgánicos de cadenas largas), los cuales, al eliminarse por tratamiento térmico, causan el colapso de la estructura porosa en la mayoría de los casos [15].

Por esta razón, en este trabajo se sintetizaron materiales de $\mathrm{TiO}_{2}$ utilizando el método Sol-Gel, modificando el pH de gelificación hasta $\mathrm{pH} 3$ y $\mathrm{pH}$ 9. Los catalizadores de hidrolisis fueron ácido acético e hidróxido de amonio, los cuales también cumplen la función de "platilla" modificadora de cadena corta, con el fin de aumentar el área específica, extender el rango de foto-respuesta y mejorar la actividad fotocatalítica. Así mismo se pretende observar el efecto en el tamaño de partícula y las fases cristalinas. La actividad fotocatalítica del $\mathrm{TiO}_{2}$ modificado se evaluó en la degradación de 4-clorofenol, elegido como molécula modelo por ser un contaminante altamente expandido en los ecosistemas acuáticos.

\section{Metodología}

\section{Síntesis de óxidos de titanio}

Las muestras de $\mathrm{TiO}_{2}$ fueron sintetizadas por el método Sol-Gel. Se mezclaron cantidades estequiometrias de n-butóxido de titanio IV $\left(\mathrm{Ti}\left(\mathrm{OC}_{4} \mathrm{H}_{9}\right)_{4}\right.$, Aldrich $\left.+99 \%\right)$ en butanol $\left(\mathrm{H}_{3} \mathrm{C}-\left(\mathrm{CH}_{2}\right)_{3}-\mathrm{OH}\right.$, Aldrich 99.4 $\%$ ) en una relación molar 1:25. Se ajustaron los valores de $\mathrm{pH}$ a 3 con ácido acético $\left(\mathrm{CH}_{3}-\mathrm{COOH}\left(\mathrm{C}_{2} \mathrm{H}_{4} \mathrm{O}_{2}\right)\right.$, J.T.Baker $\left.99 \%\right)$ y $\mathrm{pH}$ 
9 con hidróxido de amonio $\left(\mathrm{NH}_{4} \mathrm{OH}\right.$, Merck $\left.25 \%\right)$ mediante goteo lento y agitación vigorosa, hasta alcanzar una temperatura de $70{ }^{\circ} \mathrm{C}$. La hidrólisis del alcóxido fue llevada a cabo al adicionar mediante goteo lento, agua destilada previamente enfriada a $4{ }^{\circ} \mathrm{C}$ para evitar la drástica hidrólisis en relación molar con el alcóxido 12:1. Posterior a la ruptura del gel, se ajusta el pH nuevamente a pH 3 con $\mathrm{CH}_{3}-\mathrm{COOH}$ $\left(\mathrm{C}_{2} \mathrm{H}_{4} \mathrm{O}_{2}\right)$ y pH 9 con $\mathrm{NH}_{4} \mathrm{OH}$. Después se añeja la solución durante 24 horas. La calcinación de los materiales se realizó en aire a $500{ }^{\circ} \mathrm{C}$ durante 5 horas, a una velocidad de $2{ }^{\circ} \mathrm{C}$ por minuto. Los materiales son denotados $\mathrm{TiO}_{2}$-a (óxido de titanio $\mathrm{pH} 3$ ), $\mathrm{TiO}_{2}-\mathrm{b}$ (oxido de titanio $\mathrm{pH}$, y como referencia se utilizó una muestra comercial de dióxido de titanio Degussa P25.

\section{Caracterización de los catalizadores}

La fisisorción de nitrógeno para determinar el área específica de los materiales, se efectuó a la temperatura del nitrógeno líquido -196 ${ }^{\circ} \mathrm{C}\left(77^{\circ} \mathrm{K}\right)$, en un equipo marca Quantachrome modelo Autosorb 3B. Previo al análisis, las muestras se desgasificaron a $250{ }^{\circ} \mathrm{C}$ durante $12 \mathrm{~h}$. Los patrones de difracción de rayos $\mathrm{X}$ se obtuvieron en un difractómetro D 5000 marca Siemens, el cual utiliza radiación Cu Ko $(\lambda=1.5406 \AA \hat{)})$ y un monocromador de grafito en el rayo difractado, con un paso de $0.03^{\circ}, 2 \theta=10^{\circ}-70^{\circ} \mathrm{yt}=0.3 \mathrm{~s}$. Los espectros de reflectancia difusa U.V.-visible se obtuvieron mediante un espectrofotómetro Shimadzu UV-2401, utilizando $\mathrm{BaSO}_{4}$ como muestra de referencia y realizando el análisis de las muestras en el intervalo de 200-800 $\mathrm{nm}$. Las micrografías se obtuvieron en un microscopio electrónico de transmisión marca Jeol 2100F, operado a 200 KV.

\section{Actividad fotocatalítica}

La actividad fotocatalítica se evaluó en la degradación de 4-nitrofenol $\left[\left(\mathrm{C}_{6} \mathrm{H}_{5} \mathrm{NO}_{3}\right)\right.$ Aldrich grado analítico], concentración inicial en $30 \mathrm{mg} / \mathrm{L}$. La reacción se llevó a cabo en un reactor de vidrio anular con recirculación, situando en el centro del mismo, una lámpara tubular de mercurio de alta presión (lámpara UV marca Pen-Ray UVP, emisión a $254 \mathrm{~nm}, 216$ watts, $18 \mathrm{~mA}$, intensidad $2.5 \mathrm{~mW} / \mathrm{cm}^{2}$ ), utilizada como fuente de radiación ultravioleta (Figura 2). El fotocatalizador 
(0.2g) se suspendió mediante agitación magnética en $200 \mathrm{~mL}$ de la solución problema. Previamente, la solución del contaminante es burbujeada por un periodo mínimo de tres horas, para alcanzar una concentración de oxígeno disuelto aproximada a $5 \mathrm{mg} / \mathrm{L}$. Durante la reacción, la suspensión es alimentada con flujo de aire a $2 \mathrm{mg} / \mathrm{s}$. La concentración del contaminante en función del tiempo de reacción se analizó en un espectrofotómetro marca Varian modelo Cary 100.

\section{Resultados y discusión}

\section{Caracterización de los semiconductores}

La Figura 3 muestra los patrones de difracción de rayos $X$ del óxido de titanio comercial (Degussa P-25) y los óxidos de titanio sintetizados a los dos $\mathrm{pH}$. El material $\mathrm{TiO}_{2}-\mathrm{a}$

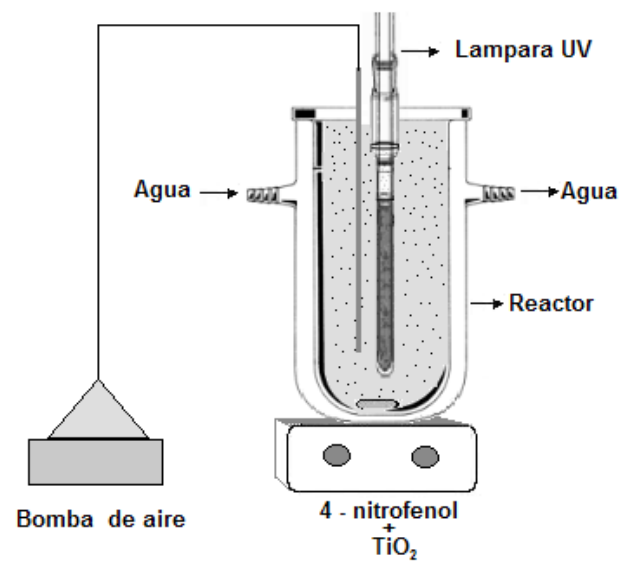

Figura 2. Esquema del equipo experimental utilizado en la degradación del 4-nitrofenol con lámpara UV.

exhibió líneas de difracción en $2 \theta=25^{\circ}, 37^{\circ}, 48^{\circ}, 54^{\circ}, 55^{\circ}, 62^{\circ}$ y $71^{\circ}$, que corresponden a los planos cristalográficos (101), (004), (200), (105), (211), (204), y (116), característico de la fase anatasa (tetragonal) del óxido de titanio [14]. De igual forma, el TiO2-b sintetizado a $\mathrm{pH} 9$ exhibe los picos típicos de anatasa tetragonal, pero adicionalmente se observa la presencia de rutilo en $2 \theta=27^{\circ}$. Los 
tamaños de cristal para estos materiales se calcularon empleando el método descrito en la literatura [16], los tamaños obtenidos son de $10 \mathrm{~nm}$ para $\mathrm{pH} 3$ y $14 \mathrm{~nm}$ para $\mathrm{pH}$ 9, respectivamente. A diferencia de los materiales sintetizados, el óxido de titanio comercial presenta una mezcla bien definida de dos fases cristalinas, la más baja perteneciente a la fase rutilo $2 \theta=27^{\circ}, 36^{\circ}, 41^{\circ}, 44^{\circ}$ y $57^{\circ}$ y la más alta perteneciente a la fase anatasa (tetragonal), con un tamaño de cristal de 40nm [15-16]. El efecto del pH se ve reflejado en el tamaño de cristal, pues a medida que aumenta el pH de gelificación, el tamaño de cristal también lo hace, tal como ha sido reportado por otros autores [17-18]. Los resultados obtenidos sugieren que es posible sintetizar dióxido de titanio fase anatasa a voluntad, mediante el ajuste del $\mathrm{pH}$ de gelificación.

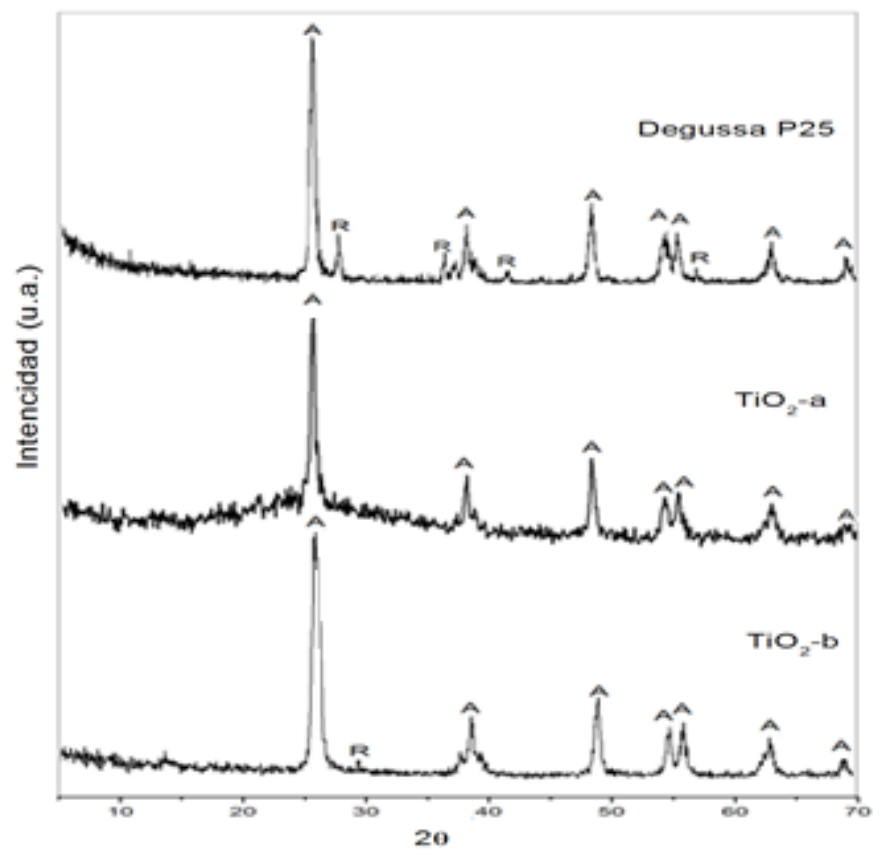

Figura 3. Patrones de difracción de rayos $X$ a) $\mathrm{TiO}_{2}$ Degussa $P 25$ b) $\left.\mathrm{TiO}_{2}-\mathrm{a} \quad c\right) \mathrm{TiO}_{2}-b$

La Tabla 1 resume los resultados de $\mathrm{pH}$ de síntesis, área superficial, volumen y tamaño de poro de los fotocatalizadores. Se observa que los materiales sintetizados poseen un área específica 
de $60 \mathrm{~m}^{2} / \mathrm{g}$ y $80 \mathrm{~m}^{2} / \mathrm{g}$, valores que superan el área específica del material de referencia Degussa P-25 en casi un $50 \%$, lo que puede ser atribuido al uso de plantillas [15] y al proceso de síntesis por SolGel [13].

La Figura 4 muestra las isotermas que se originan de los análisis de fisisorción con nitrógeno. Las isotermas de adsorción son del tipo IV, de acuerdo con la clasificación BDDT (Brunauer, Deming, Deming y Teller) característico de materiales mesoporosos, con histéresis tipo H1, según la IUPAC. La distribución de tamaño de poro en estos meso-poros es mono-modal, característica de óxido de titanio. [19]

Tabla 1. Propiedades texturales de los óxidos de titanio

\begin{tabular}{cccccc}
\hline Material & $\begin{array}{c}\mathbf{p H} \text { de } \\
\text { síntesis }\end{array}$ & $\mathbf{S}_{\mathrm{BET}}\left(\mathbf{m}^{2} / \mathbf{g}\right)$ & $\begin{array}{c}\text { Diámetro } \\
\text { de poro } \\
\left(\mathbf{c m}^{3} / \mathbf{g}\right)\end{array}$ & $\begin{array}{c}\text { Volumen } \\
\text { de poro } \\
(\AA \mathbf{A})\end{array}$ & $\begin{array}{c}\text { Tamaño } \\
\text { de } \\
\text { partícula }\end{array}$ \\
\hline $\mathrm{TiO}_{2}$ & 3 & 80 & 62 & 0.15 & 5 \\
\hline $\mathrm{TiO}_{2}$ & 9 & 63 & 71 & 0.12 & 10 \\
\hline $\begin{array}{c}\text { Degussa } \\
\mathrm{P} 25\end{array}$ & -- & 50 & 160 & 0.24 & 23 \\
\hline
\end{tabular}

Las micrografías electrónicas de transmisión (MET) de los tres fotocatalizadores se presentan en la Figura 5. Como se observa, el fotocatalizador de $\mathrm{TiO}_{2}$-a (Fig. 4-a), posee tamaño de partícula más pequeño que el $\mathrm{TiO}_{2}$ de referencia, con granos bien definidos. Por el contrario, la muestra de $\mathrm{TiO}_{2}$-b (Fig. 4-b), presenta aglomerados de partículas ligeramente más grandes que el material sintetizado a $\mathrm{pH}$ 3 , pero más pequeña si se compara con la referencia. El tamaño de partícula está influenciado por el $\mathrm{pH}$, ya que a $\mathrm{pH}$ bajo, las partículas se agregan para formar estructuras poliméricas, mientras que a $\mathrm{pH}$ alto, las partículas aumentan de tamaño; este efecto se debe a la variación de la solubilidad con la curvatura de la superficie y con el pH [20]. El tamaño de partícula se presenta en la Tabla 1, como se ve, se han sintetizado materiales con tamaño de partícula inferior a $10 \mathrm{~nm}$. 


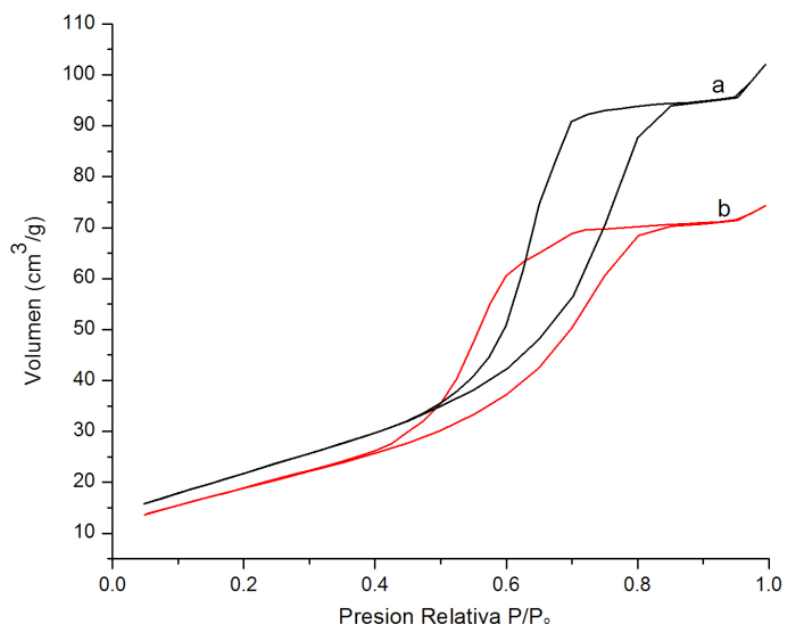

Figura 4. Isoterma de adsorción-desorción de los materiales:

a) $\mathrm{TiO}_{2}-\mathrm{a}$ b) $\mathrm{TiO}_{2}-b$
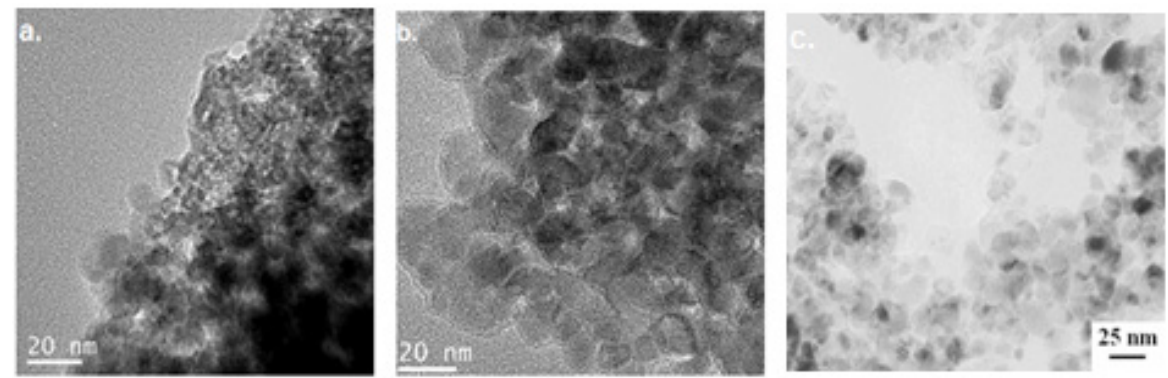

Figura 5. Fotografías MET de las muestras en estudio a) TiO2-a b) $\mathrm{TiO}_{2}-b$ c) $\mathrm{TiO}_{2}$-Degussa P25 [18]

La Figura 6 presenta los espectros de reflectancia difusa UV-Vis del óxido de titanio comercial y los óxidos de titanio sintetizados. Se observa que todos los materiales presentan una fuerte absorción alrededor de los $400 \mathrm{~nm}$, la cual es atribuida a las transiciones de los electrones de la banda de valencia a la banda de conducción pertenecientes al $\mathrm{TiO}_{2}$. Sin embargo, se observan ligeras diferencias atribuidas a los catalizadores de hidrólisis. La mayor absorbancia la posee el óxido de titanio Degussa P25, seguida por el material $\mathrm{TiO}_{2}-\mathrm{b}$ y finalmente $\mathrm{TiO}_{2}-\mathrm{a}$. 

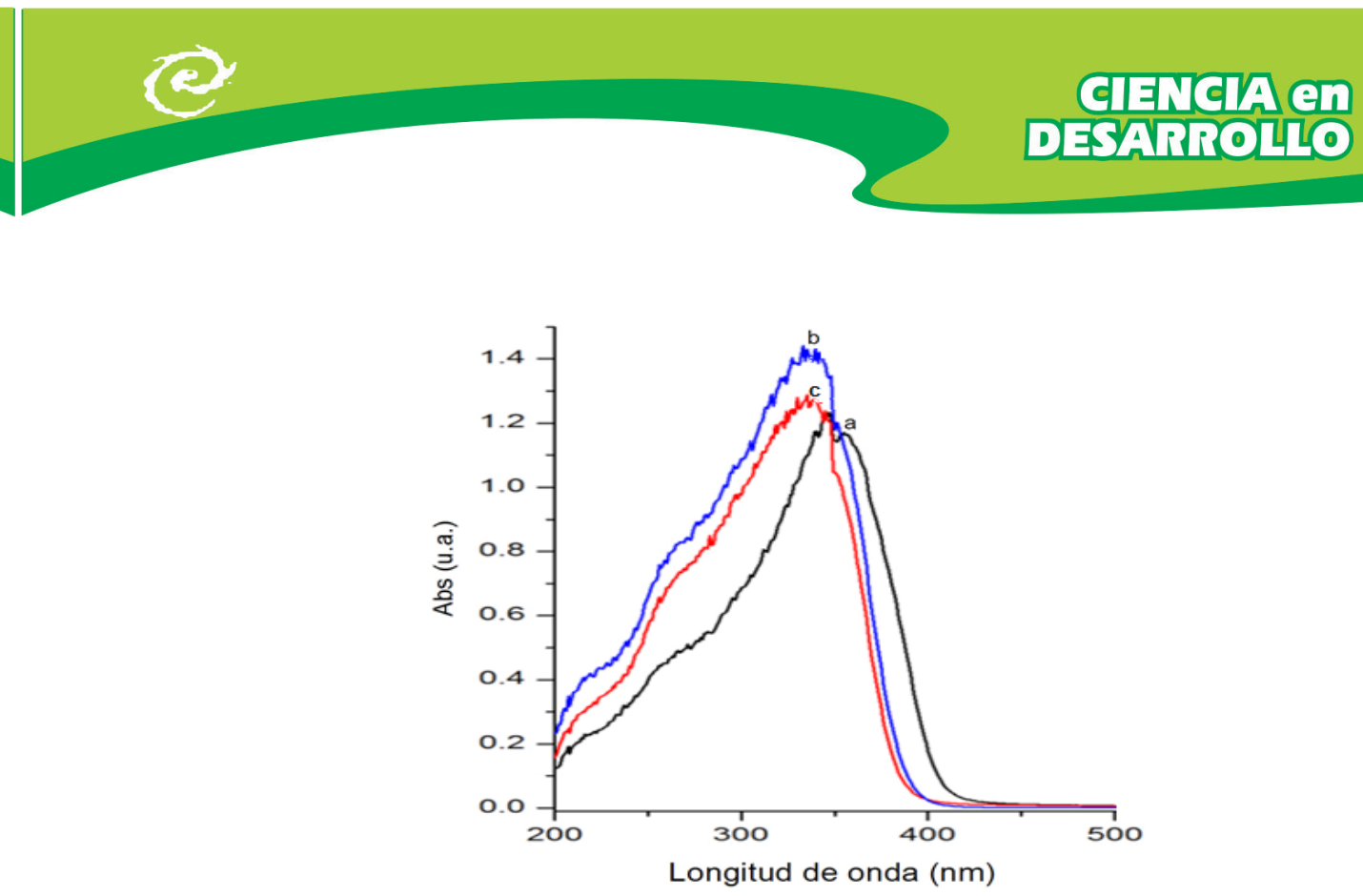

Figura 6. Espectro UV-vis de óxido de titanio, a) $\mathrm{TiO}_{2}-\mathrm{a}$, b) $\mathrm{TiO}_{2}-$ b, c) Degusa P25

Los valores de la distancia energética entre bandas fueron calculados mediante la Ec (1) [19].

$$
\propto(\boldsymbol{h} v)=\boldsymbol{A}\left(\boldsymbol{h} v-\boldsymbol{E}_{g}\right)^{m / 2}
$$

Donde a es el coeficiente absorbancia, hv la energía del fotón, A una constante y $m=1$ para transposición directa entre bandas. La distancia energética entre bandas $\left(\mathrm{E}_{\mathrm{gp}}\right)$, se determinó utilizando los espectros de reflectancia difusa U.V.-visible de la Figura 6 [21], mediante la extrapolación de una línea recta a partir de la curva de absorción hacia el eje de la abscisa. Cuando $\alpha$ es igual a cero, entonces la Ec. (1) se reduce a la expresión (2):

$$
E_{g}=h v=\frac{h c}{\lambda}
$$

Donde longitud de onda $(\lambda)$, expresada en nanómetros, corresponde a la extrapolación, se convierte a unidades de energía en electrón volts (eV) [21]. La Tabla 2 muestra los resultados del cálculo de la distancia energética entre bandas para los materiales 
sintetizados, los cuales exhiben el siguiente orden: $\mathrm{E}_{\mathrm{gp}}\left(\mathrm{TiO}_{2}-\mathrm{a}\right)<\mathrm{E}_{\mathrm{gp}}$ $\left(\mathrm{TiO}_{2}-\mathrm{b}\right)<\mathrm{E}_{\mathrm{gp}}$ (Degusa P25). Este orden mantiene una relación con la actividad de fotodegradación de las muestras.

Tabla 2. Distancia energética entre banda y tamaño de cristalito de los óxidos de titanio

\begin{tabular}{ccc}
\hline Catalizador & $\begin{array}{c}\text { Tamaño de cristalito } \\
(\mathbf{n m})\end{array}$ & $\mathbf{E}_{\mathbf{g p}}(\mathbf{e V})$ \\
\hline Degussa P25 & 40 & 3.2 \\
\hline $\mathrm{TiO}_{2}-\mathrm{a}$ & 10 & 3.0 \\
\hline $\mathrm{TiO}_{2}-\mathrm{b}$ & 14 & 3.1 \\
\hline
\end{tabular}

\section{Actividad fotocatalítica}

La actividad fotocatalitica se ha evaluado en la degradación de 4-Nitrofenol (4-NP) utilizando radiación UV. En la Figura 7 se observa el porcentaje de degradación de 4-nitrofenol, en función del tiempo de irradiación, utilizando los fotocatalizadores sintetizados y el material de referencia Degussa P25. Como se verifica en la gráfica, todos los materiales tienden a la degradación total del 4-NP, sin embargo el que presenta un mejor porcentaje de degradación es el TiO2-a con un $97 \%$, seguido de TiO2-b con un $92 \%$ y finalmente Degussa P25, con un $86 \%$. La fotodegradación del contaminante orgánico sigue una cinética de pseudo-primer orden, concordando con lo reportado en la literatura [22-23]. La constante de velocidad es calculada a partir de la línea recta de la Figura 8 [23], así mismo el tiempo de vida media se calcula haciendo uso de la EC 3 :

$$
t_{1 / 2}=\frac{\ln 2}{k} \quad t_{1 / 2}=\frac{\ln 2}{k}
$$

En donde $\mathrm{K}$ es la constante de velocidad. Los resultados son reportados en la Tabla 4. 


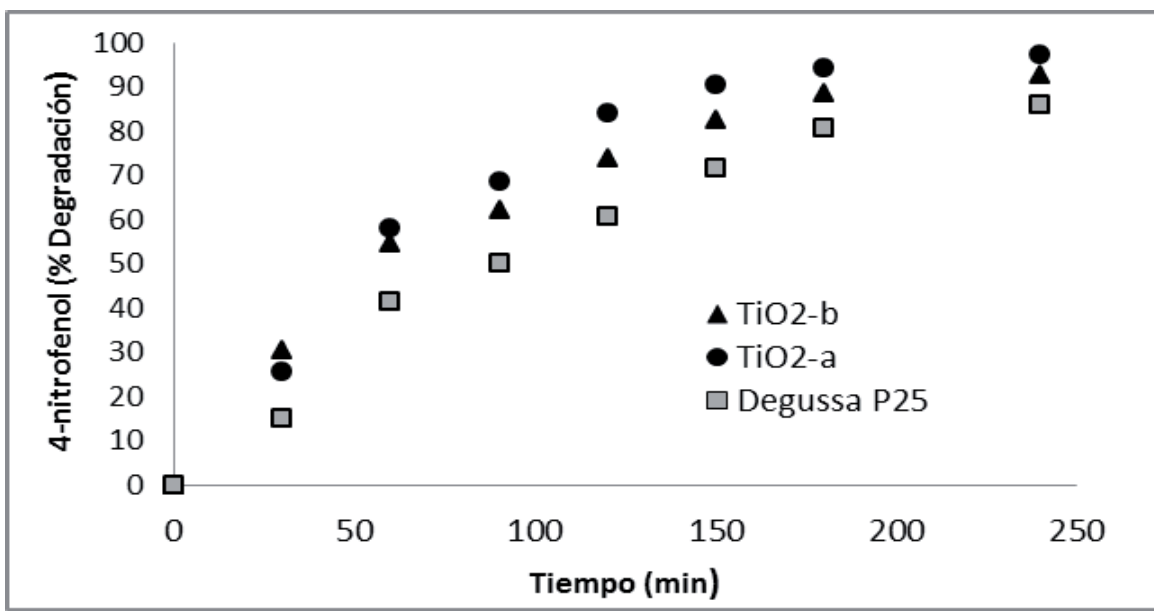

Figura 7. Porcentaje de degradación de 4-Nitrofenol de óxido de titanio Degusa P25, $\mathrm{TiO}_{2}-\mathrm{a}, \mathrm{TiO}_{2}-b$.

La constante de velocidad de reacción del óxido de titanio comercial Degussa P25, es inferior a las constantes de velocidad de los óxidos de titanio sintetizado, corroborándose con el perfil de actividad fotocatalíca mostrado en la Figura 9 y con la diferencia en tiempos de degradación total.

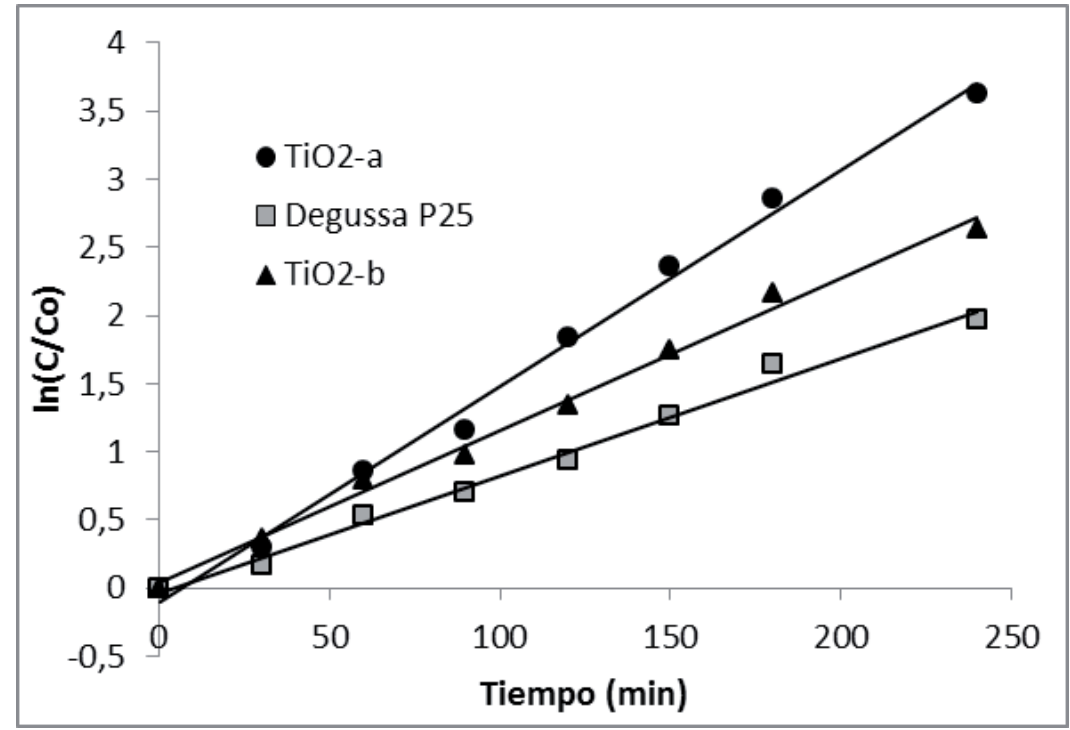

Figura 8. Cinética de pseudo-primer orden para pruebas de degradación de 4-nitrofenol 
El análisis cinético confirma que el semiconductor $\mathrm{TiO}_{2}$-a es el que presenta una mayor constante de velocidad, así como un tiempo de vida media de 44 minutos. Como se observa en la Tabla 3, la diferencia entre el sólido más activo y el sólido menos eficiente, es de $11 \%$ a 240 minutos, logrando mineralizar el 4-NP hasta dejar un remanente de $3,1 \mathrm{mg} / \mathrm{L}$, con un porcentaje de mineralización del $89 \%$. La menor mineralización se presenta con el óxido de titanio comercial Degussa P25.

Tabla 3. Resultados de cinética y carbono orgánico total (COT) de la fotodescomposición de 4-NP con los semiconductores de $\mathrm{TiO}_{2}$.

\begin{tabular}{cccccc}
\hline $\begin{array}{c}\text { Semicon- } \\
\text { ductor }\end{array}$ & $\begin{array}{c}\mathrm{K}^{\mathrm{a}} \\
\left(\mathbf{m i n}^{-1}\right)\end{array}$ & $\begin{array}{c}\mathbf{t}_{1 / 2} \\
\left(\mathbf{m i n}^{-1}\right)\end{array}$ & $\begin{array}{c}\text { Degra- } \\
\text { dación } \\
\text { 4-NP (\%) }\end{array}$ & $\begin{array}{c}\text { COT } \\
\text { remanente } \\
(\mathbf{m g} / \mathrm{L})\end{array}$ & $\begin{array}{c}\text { Mineralización } \\
\text { COT (\%) }\end{array}$ \\
\hline $\mathrm{TiO}_{2}-\mathrm{a}$ & $15.8 \mathrm{E}^{-3}$ & 43.87 & 97 & 3.1 & 89 \\
\hline $\mathrm{TiO}_{2}-\mathrm{b}$ & $11.2 \mathrm{E}^{-3}$ & 61.88 & 92 & 4.3 & 84 \\
\hline Degussa P25 & $8.6 \mathrm{E}^{-3}$ & 80.59 & 86 & 5.6 & 79 \\
\hline
\end{tabular}

De acuerdo con la difracción de rayos $\mathrm{x}$, el semiconductor $\mathrm{TiO}_{2}$-a se encuentra en fase anatasa, además es el que posee una menor $\mathrm{E}_{\text {gap }}$ (3.05), lo que le confiere una mayor eficiencia en la degradación del contaminante [17]. Además se ha demostrado que el tamaño de poro es importante en la actividad fotocatalítica. Tamaños de poro cercanos a los $4 \mathrm{~nm}$ son los más adecuados, porque permiten atrapar las moléculas que se van a descomponer, y además originan los volúmenes de poro y superficies expuestas más altas [24]. 


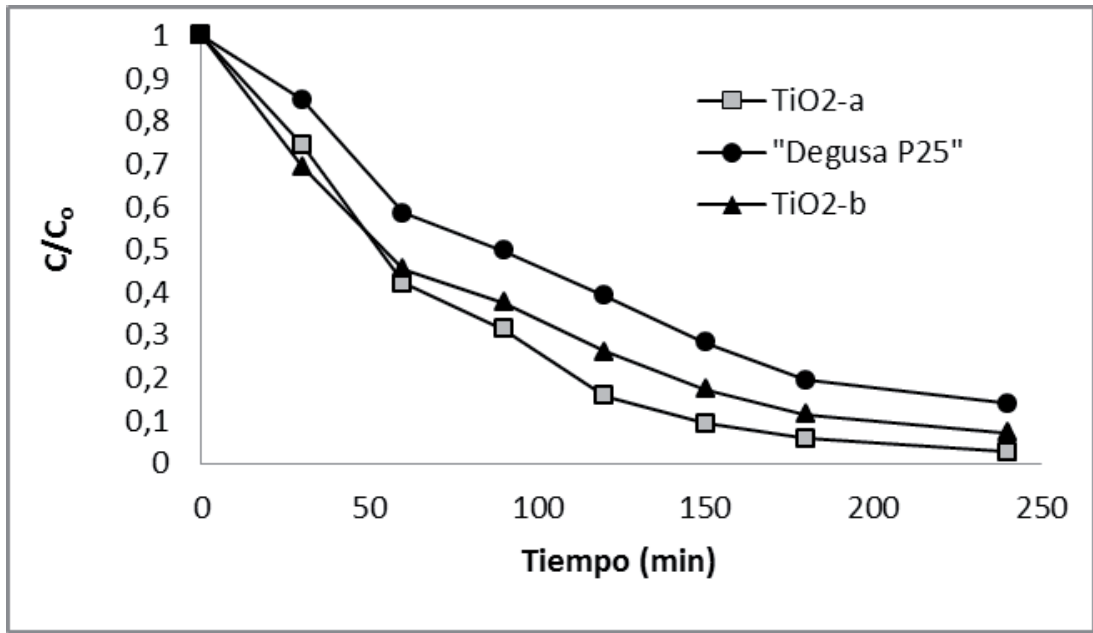

Figura 9. Perfil de actividad fotocatalítica desarrollado durante la degradación de 4-NP

\section{Conclusiones}

La técnica Sol-Gel permitió sintetizar materiales nanoparticulados de dióxido de titanio, con tamaños de partícula inferiores a $10 \mathrm{~nm}$. Se logró obtener dióxido de titanio puro en fase anatasa, por ajuste de la gelificación a un valor de $\mathrm{pH} 3$. La modificación del pH también conduce a obtener un área superficial específica de $80 \mathrm{~m}^{2} / \mathrm{g}$, un $50 \%$ mayor que la muestra comercial.

La prueba para la actividad fotocatalítica demostró que los materiales sintetizados tienen mejor actividad que el material de referencia empleado. Lo que se atribuye al proceso de síntesis y a la utilización de moléculas como plantillas, ya que permitieron obtener materiales con tamaño de poro pequeños, áreas específicas grandes, menor distancia entre bandas, que el óxido de titanio Degussa P25. 


\section{Referencias}

[1] E. Gil Pavas, "Fotocatálisis: una alternativa viable para la eliminación de contaminantes", Redalyc., vol. 127, pp. 59-64, sep. 2002.

[2] Uso del Dióxido de Titanio como Semiconductor. Grupo tar org. Sevilla, España, 2012.

[3] L.F. Garcés Giraldo, "Fotodegradación de aguas residual coloreadas analizadas mediante las superficies de respuesta, $P+L$, vol. 6, pp. 5059, jun. 2011.

[4] J. M. Herrmann, "Destrucción de contaminantes orgánicos por fotocatálisis heterogénea”, Solar Safe Water, pp. 153-170, nov. 2006.

[5] L. F. Garcés Giraldo. E. A. Mejía Franco \& J. J. Santamaría Arango, "La fotocatálisis como alternativa para el tratamiento de aguas residuales", Lasallista, vol. 1, pp. 83-91, 2005.

[6] C. A. Jaramillo Páez \& G. Taborda Ocampo," La fotocatálisis: aspectos fundamentales para la remoción de contaminantes", R.U.C, pp. 71-88, dic. 2006.

[7] R. López, R. Gómez \& S. Oros-Ruiz, "Photophysical and photocatalytic properties of $\mathrm{TiO}_{2}-\mathrm{Cr}$ sol-gel prepared semiconductors", Catal today, feb. 2011.

[8] M. Papamija \& V. Sarria, "Degradación fotocatalítica de ibuprofeno empleando dióxido de titanio”, Revista de ing. U. Pp. 47-53, jun. 2010.

[9] A. M. Reyes Rodríguez, M. P. Estebanez \& J. Isasi Marín, "Efecto que ejerce la temperatura y el $\mathrm{pH}$ en la síntesis sol-gel de ortofosfato de litio", RE, vol. 4, pp. 1-16, 2012.

[10] M. T. Ramírez Alba et al., "Estado del arte del proceso sol-gel en México", redalyc, vol. 17, pp. 183-188, oct. 2010.

[11] X. Chen \& S. S. Mao, "Titanium dioxide nanomaterials: Syntesis, propierties, Modifications, and Applications”, Chem.Rev, vol. 107, pp. 2891-2959, Mar. 2006.

[12] R. López \& R. Gómez, "Photocatalytic Degradation of 4-Nitrophenol on Well Characterized Sol-Gel Molybdenum Doped Titania Semiconductors, Top Catal, pp. 504-511, ene. 2011. 
[13] C. Su, B. Y. Hong \& C. M. Tseng, "Sol-gel preparation and photocatalysis of titanium dioxide”, Catal Today, vol. 96, pp.119-126, jun. 2004.

[14] J. M. Hernández, R. Enríquez, R. García Alamilla, L. A. García Serrano \& A. Cueto Hernández, "Síntesis, caracterización y actividad fotocatalítica de óxido de titanio modificado con nitrógeno", Cerámica y vidrio, vol. 50, pp. 245-252, oct. 2011.

[15] J. García Martínez, "Sólidos ordenados desde la nano a la macroestructura", U. A., pp. 1-19, 2006.

[16] G. Monrós, M. C. Martí, J. Carda, M. Tena, P. Escribano \& M. Anglada, J. mater sci., vol. 28, 1993.

[17] M. A. Santana-Aranda*, M. Morán-Pineda, J. Hernández, S. Castillo \& R. Gómez, "Physical properties of $\mathrm{TiO}_{2}$ prepared by sol-gel under different pH conditions for photocatalysis", Smctsm, vol. 18, pp. 46-49, mar. 2005.

[18] D. H. Aguilar, L. C. Torres-González, L. M. Torres-Martínez \& T. López, "A Study of the Crystallization of $\mathrm{ZrO}_{2}$ in the Sol-Gel System: $\mathrm{ZrO}_{2}+\mathrm{SiO}_{2}$ Lasallista de Investigación.

[19] B.T. Xiong, B. X. Zhou, L-H Li, J. Cai, Y-B Liu \& W-M Cai, "Preparation of nanocrystalline anatase $\mathrm{TiO}_{2}$ using basic sol-gel method", VERSITA, vol. 62, pp. 382-387, 2008.

[20] Laboratorio de nanotecnología [online], México UAl, disponible en: http://www.labnano.org.mx/esp\%20proceso\%20sol-gel.htm

[21] Roto Himeno Fumitaka Ohashi, Tetsuji Kume, Erika Asai, Takayuki Ban, Takatoshi Suzuki, Tamio lida, Hitoe Habuchi, Yasuo Tsutsumi, Hironori Natsuhara \& Shuichi Nonomura, "Optical band gap of semiconductive type II Si clathrate purified by centrifugation", J. Non Crystal. Solids, pp 1-3, dic. 2012.

[22] B. Neppolian, S. Sakthivel, B. Arabondoo, M. Palanichamy \& V. Murugesan, "Kinetics of photocatalytic degradation of reactive yellow 17 dye in aqueous solution using UV irradiation", J. Environ. Sci Health A, vol. 36, pp. 203, 2001.

[23] C. S. Turchi, D. F. Ollis, "Kinetics of dye decolorization in an air-solid system", Appl Catal, pp. 315-325, J. catal, vol. 122, pp. 315-325, 1990.

[24] N. Arconada \& A. Castro Durán, "Recubrimientos meso-estructurados de $\mathrm{TiO}_{2}$-anatasa obtenidos por el método EISA con actividad fotocatalítica", Bol. Soc. Esp. Ceram., vol. 49, pp. 405-412, 2005. 
बाENGIA ER

DESARBOLLO

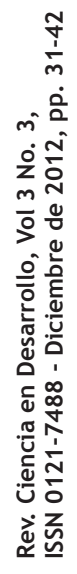

174 


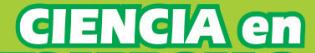 \\ DEsAnROLE}

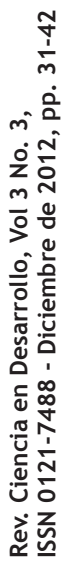


बाENGIA ED

DESARBOLLO

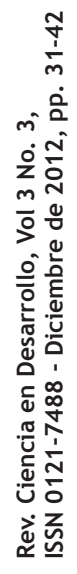

176 